\title{
WestVirginiaUniversity
}

THE RESEARCH REPOSITORY @ WVU

Graduate Theses, Dissertations, and Problem Reports

2002

\section{Development of lightweight FRP bridge deck designs and evaluations}

Isaac Lem Howard

West Virginia University

Follow this and additional works at: https://researchrepository.wvu.edu/etd

\section{Recommended Citation}

Howard, Isaac Lem, "Development of lightweight FRP bridge deck designs and evaluations" (2002). Graduate Theses, Dissertations, and Problem Reports. 1280.

https://researchrepository.wvu.edu/etd/1280

This Thesis is protected by copyright and/or related rights. It has been brought to you by the The Research Repository @ WVU with permission from the rights-holder(s). You are free to use this Thesis in any way that is permitted by the copyright and related rights legislation that applies to your use. For other uses you must obtain permission from the rights-holder(s) directly, unless additional rights are indicated by a Creative Commons license in the record and/ or on the work itself. This Thesis has been accepted for inclusion in WVU Graduate Theses, Dissertations, and Problem Reports collection by an authorized administrator of The Research Repository @ WVU. For more information, please contact researchrepository@mail.wvu.edu. 


\title{
DEVELOPMENT OF LIGHTWEIGHT FRP BRIDGE DECK DESIGNS AND EVALUATIONS
}

\author{
Isaac Howard \\ Thesis submitted to the College of \\ Engineering and Mineral Resources at \\ West Virginia University in partial \\ fulfillment of the requirements for the \\ degree of
}

Master of Science

In

Civil Engineering

\author{
Hota GangaRao, Ph.D., Chair \\ Udaya Halabe, Ph.D. \\ Vimala Shekar
}

Morgantown, West Virginia

2002

Keywords: Bridge Deck, Lightweight, Pultrusion, FRP 


\section{ABSTRACT \\ Development of Lightweight FRP Bridge Deck Designs and Evaluations}

\section{Isaac Howard}

The focus of this study was to develop and analyze lightweight FRP bridge decks and determine their adequacy under AASHTO's HS25 loading case with minimum stringer spacings of five feet. Two different multicellular decks were designed and tested during this study. Both decks had fiber volume fractions of approximately $54 \%$ and weighed $14-15 \mathrm{lb} / \mathrm{ft}^{2}$ of deck area. Testing was performed to determine both the elastic and failure response at the component level and the elastic response at the system level. Theoretical correlation of stiffness was made via approximate classical lamination theory, and maximum transverse load distribution factors were predicted. In addition, several failure modes were identified and theoretically correlated to obtain applicable limit states based on the strain to failure approach. The study found that local resistance and force transfer across the joints were the areas of potential improvement. The remainder of the study showed adequate performance of the decks. 
Dedicated to My Wife Natalie for Her

Support, Patience, and Encouragement 


\section{ACKNOWLEDGEMENTS}

First and foremost, the author would like to express his gratitude to God for providing the opportunity to pursue higher education.

A special thanks is due to Dr. Hota V. S. GangaRao who was both the author's advisor and committee chairman. He provided valuable insight into all areas of the project from conducting the experiments, to analyzing the test data, to philosophical viewpoints about the work. These indispensable contributions will never be forgotten.

Special thanks are also owed to the remainder of the advisory committee. Vimala Shekar served as both an advisory committee member and as an engineering scientist. Her contributions to the work are too numerous to mention, but much of the success of the work is due to her efforts. Dr. Udaya Halabe contributed a great deal to the work through his classroom teaching and insightful thoughts on the work itself.

The author is indebted to David Turner, Dana Humberson, and Bill Comstock for their help in maintaining computer resources and/or preparation of the test specimens.

Many additional students and faculty were very helpful during the course of this work, and their assistance was greatly appreciated. Among them were Donald Tusing, Krit Laosirphong, Ricardo Basto, Srinivas Aluri, Rex Cyphers, Venket Natarajan, Lynne Jacobs, and Sherry Uphold.

The Federal Highway Administration, US Department of Transportation, provided the funding for the project. Bedford Reinforced Plastics, Inc. manufactured and donated the samples that were tested. A very special thank you is due these two organizations since this research could not have been conducted without adequate funding and test samples.

Finally, the author would like to express a special thank you to his family who were so supportive during the work. Without their support, the work would not have been a success. 


\section{TABLE OF CONTENTS}

TITLE PAGE

$\begin{array}{ll}\text { ABSTRACT } & \text { ii }\end{array}$

ACKNOWLEDGEMENTS iv

TABLE OF CONTENTS $\quad$ V

LIST OF FIGURES C xiii

LIST OF TABLES Xvi

\section{CHAPTER 1}

\section{INTRODUCTION}

1.1 General and Background Information 1

1.2 Objectives 2

1.3 Scope 3

\section{CHAPTER 2}

\section{LITERATURE REVIEW}

2.1 Introduction $\quad 5$

2.2 Pultrusion 5

2.3 Types of Fibers and Resins 9

2.4 Relevant Research Conducted on FRP 10

2.4.1 Static Testing at the Component Level 10 
$\begin{array}{ll}\text { 2.4.1.1 Bending } & 10\end{array}$

$\begin{array}{ll}\text { 2.4.1.2 Torsion } & 13\end{array}$

$\begin{array}{ll}\text { 2.4.1.3 Buckling } & 13\end{array}$

2.4.2 System Level Static Testing $\quad 14$

$\begin{array}{lll}2.5 & \text { FRP Deck Loads and Resistances } & 15\end{array}$

$\begin{array}{lll}2.6 & \text { Conclusions } & 17\end{array}$

\section{CHAPTER 3}

TESTING AND EVALUATION OF FRP COMPONENTS UNDER TORSION, WEB BUCKLING, AND WEB LOAD DISTRIBUTION

$\begin{array}{llr}3.1 & \text { Introduction } & 18\end{array}$

$\begin{array}{llr}3.2 & \text { Torsion } & 19\end{array}$

$\begin{array}{lll}\text { 3.2.1 Specimen Preparation } & 19\end{array}$

$\begin{array}{ll}\text { 3.2.2 Test Set-Ups and Procedures } & 19\end{array}$

3.2.2.1 Torsion 19

3.2.2.2 Torsion and Bending $\quad 20$

$\begin{array}{lll}3.2 .3 & \text { Test Results } & 23\end{array}$

$\begin{array}{ll}\text { 3.2.3.1 Torsion } & 23\end{array}$

$\begin{array}{ll}\text { 3.2.3.2 Torsion and Bending } & 27\end{array}$

3.3 Web Buckling 29

3.3.1 Test Set-Up and Procedure 29

$\begin{array}{lll}3.3 .2 & \text { Test Results } & 30\end{array}$

3.3.3 Incorporation of Results into the Euler Buckling Formula 32 
3.4 Web Load Distribution 32

3.4.1 Test Set-Up and Procedure 33

3.4.2 Test Results 34

3.5 Conclusions 34

\section{CHAPTER 4}

TESTING AND EVALUATION OF FRP COMPONENTS UNDER

\section{BENDING}

$\begin{array}{lll}4.1 & \text { Introduction } & 37\end{array}$

4.2 Component Preparation 38

$\begin{array}{lll}\text { 4.2.1 Longitudinal Components } & 38\end{array}$

4.2.2 Rehabilitated Longitudinal Component 38

$\begin{array}{lll}\text { 4.2.3 Transverse Component } & 39\end{array}$

$\begin{array}{lll}4.3 & \text { Test Set-Ups } & 40\end{array}$

4.3.1 Longitudinal Components 40

4.3.2 Rehabilitated Longitudinal Component 42

4.3.3 Transverse Component 42

$4.4 \quad$ Test Procedures 45

4.5 Test Results $\quad 45$

4.5.1 Longitudinal Components 45

4.5.1.1 Elastic Properties of Longitudinal Components 45

4.5.1.2 Failure Modes of Longitudinal Components $\quad 48$

4.5.2 Rehabilitated Longitudinal Component 51 
4.5.2.1 Elastic Properties of Rehabilitated

Longitudinal Component

4.5.2.2 Failure Mode of Rehabilitated

Longitudinal Component

4.5.3 Elastic Testing of Transverse Component

53

4.6 Comparison of Experimental Stiffness Results and Theoretical Analysis 55

$\begin{array}{lll}4.7 & \text { Conclusions } & 56\end{array}$

\section{CHAPTER 5}

\section{PHILOSOPHY OF COMPONENT LEVEL FAILURE MODES}

$\begin{array}{lll}5.1 & \text { Introduction } & 58\end{array}$

5.2 Failure due to Web Buckling 59

5.3 Failure due to Shear 62

5.3.1 Failure in the Longitudinal Direction due to

Web/Flange Separation $\quad 64$

5.3.2 Failure due to Punching Shear 67

5.3.3 Failure due to Racking Shear $\quad 70$

5.3.4 Failure due to Torsional Shear 73

$\begin{array}{lll}\text { 5.4 Failure due to Bending } & 74\end{array}$

5.4.1 Bending Failure due to Buckling of the Compression Flange 74

5.4.2 Transverse Bending Failure of Top Flange 76

$\begin{array}{lll}5.5 & \text { Joint Failure } & 78\end{array}$

5.6 Conclusions and Recommendations $\quad 82$ 
$\begin{array}{lll}\text { 5.6.1 Conclusions } & 82\end{array}$

$\begin{array}{lll}\text { 5.6.2 Recommendations } & 84\end{array}$

\section{CHAPTER 6}

\section{TESTING AND EVALUATION OF FRP DECKS STIFFENED BY STEEL STRINGERS}

$\begin{array}{lll}6.1 & \text { Introduction } & 86\end{array}$

6.2 Deck and Stringer Preparation for Testing 86

$\begin{array}{lll}\text { 6.2.1 Surface Preparation of Decks } & 87\end{array}$

6.2.1.1 Polyester Deck $\quad 87$

6.2.1.2 Vinyl Ester Deck $\quad 87$

6.2.2 Surface Preparation of Stringers 88

6.2.3 Connection of Deck to Stringers 88

$\begin{array}{llr}6.3 & \text { Test Set-Ups } & 88\end{array}$

$\begin{array}{lll}\text { 6.3.1 Support Conditions } & 88\end{array}$

$\begin{array}{ll}\text { 6.3.2 Loading Conditions } & 89\end{array}$

$\begin{array}{lll}\text { 6.3.3 Instrumentation } & 91\end{array}$

6.3.3.1 Instrumentation of Polyester Deck 91

6.3.3.2 Instrumentation of Vinyl-Ester Deck 96

$\begin{array}{lll}6.4 & \text { Test Procedures } & 98\end{array}$

$\begin{array}{lll}6.5 & \text { Test Results } & 98\end{array}$

6.5.1 Transverse Load Distribution Factor 98

$\begin{array}{lll}\text { 6.5.2 Deflection } & 100\end{array}$ 
$\begin{array}{ll}\text { 6.5.2.1 Global Deflection } & 100\end{array}$

$\begin{array}{ll}\text { 6.5.2.2 Local Deflection } & 102\end{array}$

6.5.2.3 Deck Deflection Relative to Stringers 104

6.5.3 Degree of Composite Action Between Deck and Stringers 105

6.5.4 Effects of Warping and Secondary Torsion 107

$\begin{array}{lll}\text { 6.5.5 Effective Deck Width } & 108\end{array}$

$\begin{array}{lll}\text { 6.6 Theoretical Evaluation } & 109\end{array}$

$\begin{array}{ll}\text { 6.6.1 Effective Flange Width } & 109\end{array}$

$\begin{array}{ll}\text { 6.6.2 Transverse Load Distribution Factor } & 110\end{array}$

$\begin{array}{lll}6.7 & \text { Conclusions } & 114\end{array}$

\section{CHAPTER 7}

\section{FRP DECK RESPONSE TO IN-PLANE SHEAR}

$\begin{array}{lll}7.1 & \text { Introduction } & 117\end{array}$

$\begin{array}{lll}7.2 & \text { Specimen Preparation } & 118\end{array}$

$\begin{array}{lll}7.3 & \text { Instrumentation } & 118\end{array}$

$\begin{array}{lll}7.4 & \text { Test Set-Up and Procedure } & 119\end{array}$

$\begin{array}{lll}7.5 & \text { Test Results } & 121\end{array}$

$\begin{array}{lll}7.6 & \text { Conclusions } & 124\end{array}$

\section{CHAPTER 8}

CONCLUSIONS AND RECOMMENDATIONS

8.1 Introduction 
$\begin{array}{ll}\text { 8.2 Conclusions } & 126\end{array}$

$\begin{array}{lll}8.3 & \text { Recommendations } & 132\end{array}$

$\begin{array}{ll}\text { BIBLIOGRAPHY } & 134\end{array}$

\section{APPENDIX A}

\section{COMPUTATION OF LAMINA PROPERTIES}

$\begin{array}{llr}\text { A.1 Introduction } & 139\end{array}$

$\begin{array}{lll}\text { A.2 Material Properties } & 139\end{array}$

$\begin{array}{lll}\text { A.3 Fiber Volume Fraction } & 140\end{array}$

$\begin{array}{lll}\text { A.4 Lamina Properties } & 141\end{array}$

$\begin{array}{lll}\text { A.5 Lamina Product Specifications } & 142\end{array}$

\section{APPENDIX B}

\section{COMPUTATION OF BENDING AND SHEAR STIFFNESS}

$\begin{array}{lll}\text { B.1 Introduction } & 144\end{array}$

$\begin{array}{lll}\text { B.2 Elastic Modulus } & 144\end{array}$

B.3 In-Plane and Extensional-Bending Coupling Stiffness ([A] and [B]) 144

$\begin{array}{lll}\text { B.4 Flange and Web Bending Stiffness } & 145\end{array}$

$\begin{array}{lll}\text { B.5 Global Bending Stiffness } & 146\end{array}$

B.6 Global Shear Stiffness in YZ Plane 146

B.7 Theoretical Bending and Shear Stiffness Results 147 


\section{APPENDIX C}

RAW TEST DATA

152 


\section{LIST OF FIGURES}

$\begin{array}{lll}\text { Figure 2.1 Pultrusion Schematic } & 6\end{array}$

Figure 2.2 Pultrusion Pictures from Bedford Reinforced Plastics, Inc. 8

Figure 3.1 Instrumentation of Torsion Specimen 21

$\begin{array}{lll}\text { Figure } 3.2 & \text { Torsion Test Set-Up } & 22\end{array}$

$\begin{array}{lll}\text { Figure } 3.3 & \text { Torsion and Bending Test Set-Up } & 22\end{array}$

Figure 3.4 Definition of Material Coordinate System 23

Figure 3.5 Torque v/s Average Angle of Twist (Polyester Component) 25

Figure 3.6 Load v/s Strain (Torsion and Bending)-Polyester Component 27

Figure 3.7 Test Set-Up for Web Buckling Specimens 29

Figure 3.8 Definition of Webs for Buckling Tests 30

Figure 3.9 Failure Mode of Polyester Web Buckling Specimens 31

Figure 3.10 Failure Mode of Vinyl Ester Web Buckling Specimens 31

Figure 3.11 Web Load Distribution Orientation \#1 (Polyester Component) 33

Figure 3.12 Web Load Distribution Orientation \#2 (Polyester Component) 33

Figure 4.1 Work Plan for Rehabilitated Longitudinal Component 38

Figure 4.2 Test Set-Up for Longitudinal Experiments 40

Figure 4.3 Instrumentation of Polyester Component \#1 41

Figure 4.4 Instrumentation of Polyester Component \#2 41

Figure 4.5 Instrumentation of Vinyl Ester Components \#1 and \#2 42

Figure 4.6 Test Set-Up for Rehabilitated Longitudinal Component 43

Figure 4.7 Instrumentation of Rehabilitated Longitudinal Component 43

Figure 4.8 Test Set-Up for Transverse Experiments 44

Figure 4.9 Instrumentation of Transverse Component 44

Figure 4.10 Load v/s Deflection for Longitudinal Components 45

Figure 4.11 Load v/s Maximum Strain for Longitudinal Components 46

Figure 4.12 Damage due to Punching Shear Failure Mode 50

Figure 4.13 Damage due to Web/Flange Separation Failure Mode (End View) 50

Figure 4.14 Damage due to Top Flange Buckling Failure Mode 50 
Figure 4.15 Load v/s Strain of Rehabilitated Longitudinal Component

(10”x 20" Patch Load)

Figure 4.16 Failure Mode of Rehabilitated Longitudinal Component 53

Figure 4.17 Load v/s Strain of Transverse Components 54

Figure 4.18 Transverse Test With 3/8" Wearing Surface 55

Figure 5.1 Test Set-Up for Web Buckling Specimens 60

Figure 5.2 Failure Mode of Polyester Web Buckling Specimens 62

Figure 5.3 Failure Mode of Vinyl Ester Buckling Specimens 62

Figure 5.4 Description and Orientation of Possible Shear Failure Modes 63

Figure 5.5 Representative Test Set-Up of Bending Components 64

Figure 5.6 Damage due to Web/Flange Separation Failure Mode (End View) 66

Figure 5.7 Damage due to Punching Shear Failure Mode 69

Figure 5.8 Test Set-Up and Failure Mode of 1" Wide Shear Component 70

Figure 5.9 Test Set-Up of Racking Shear Component 71

Figure 5.10 Failure Mode of Racking Shear Component 72

Figure 5.11 Damage due to Top Flange Buckling Failure Mode 75

Figure 5.12 Test Set-Up and Failure Mode of Transverse Flange Experiment 77

$\begin{array}{lll}\text { Figure 5.13 Joint Failure Schematic } & 79\end{array}$

Figure 5.14 Failure Mode of Joint Test 80

Figure 6.1 Test Set-Up for FRP Deck and Steel Stringer System 89

Figure 6.2 Phase I Loading Case-Concentric 89

$\begin{array}{lll}\text { Figure 6.3 Phase II Loading Case-Concentric } & 90\end{array}$

Figure 6.4 Phase III Loading Case-Symmetric 90

Figure 6.5a Location of Deflection Gages for Polyester Deck 92

Figure 6.5b Location of Strain Gages for Polyester Deck (Top View) 93

Figure 6.5c Location of Strain Gages for Polyester Deck

(Bottom View with Stringers) 94

Figure 6.5d Location of Strain Gages for Polyester Deck

(Bottom View without Stringers) 95

Figure 6.6a Instrumentation of Vinyl Ester Deck (Top View) 96

Figure 6.6b Instrumentation of Vinyl Ester Deck (Bottom View) 97 
Figure 6.7 Strain Distribution of Central Stringer-Stringer \#2

Figure 6.8 Effective Flange Width Dimensioning and Coordinate System Definition

Figure 6.9 Schematic of Equivalent Steel Section over EFW 112

$\begin{array}{lll}\text { Figure 7.1 Material Coordinate System } & 117\end{array}$

Figure 7.2 Instrumentation of In-Plane Shear Deck 119

$\begin{array}{lll}\text { Figure 7.3 Test Set-Up for In-Plane Shear } & 121\end{array}$

Figure B1 Local and Global Coordinate Systems 145

Figure B2 Cross-Section of Polyester Component 148

Figure B3 Cross-Section of Vinyl Ester Component 149

Figure B4 Fiber Architecture of Polyester Component 150

$\begin{array}{lll}\text { Figure B5 Fiber Architecture of Vinyl Ester Component } & 151\end{array}$ 


\section{LIST OF TABLES}

Table $2.1 \quad$ E-Glass Fibers $\quad 9$

Table 2.2 Polyester Resins 10

$\begin{array}{lll}\text { Table 2.3 Vinyl Ester Resins } & 10\end{array}$

Table 3.1 Results of Web Buckling Tests 30

Table 3.2 Maximum Deflections and Strains for Web Load Distribution 34

Table 4.1 Clear Spans and Patch Loads of Longitudinal Components 40

Table 4.2 Bending Stiffness of Longitudinal Components 48

Table 4.3 Modulus of Elasticity of Longitudinal Components 48

Table 4.4 Ultimate Load, Strain, and Failure Modes of Longitudinal Components 49

Table 4.5 Maximum Strains for Rehabilitated Longitudinal Component 52

Table 4.6 Failure Characteristics of Rehabilitated Longitudinal

Component and Polyester Component \#1 53

Table 4.7 Elastic Properties of the Transverse Component 54

Table 4.8 Stiffness Comparison of Experimental Results and Theoretical Analysis $\quad 56$

Table 5.1 Failure Behavior of Webs Exposed to Buckling Loads 61

Table 5.2 Comparison of Punching Shear Failure Results with Limit States 69

Table 5.3 Results of Transverse Bending Failure Testing of Top Flange 77

Table 6.1 Instrumentation Identification for Polyester Deck Testing 91

Table 6.2 Instrumentation Identification for Vinyl Ester Deck Testing 96

Table 6.3 Transverse Load Distribution Factors of Deck/Stringer Systems 99

Table 6.4 Maximum Global Deflections of Deck/Stringer Systems 101

Table 6.5 Maximum Local Deflections of Deck/Stringer Systems 102

Table 6.6 Maximum Relative Deflection of Deck to Stringers 104

Table 6.7 Warping and Secondary Torsion Properties 108

Table 6.8 Results of Theoretical Determination of TLDF 113

Table 7.1 Results of In-Plane Shear Testing Based on Deflection Data 124

Table A1 TVM-3408/Version 1001 Product Specifications 142 
Table A2 NEMP 120/2001 Product Specifications 143

Table A3 CDBM3415 Product Specifications 143

Table A4 CDB400 Product Specifications 143

$\begin{array}{lll}\text { Table B1 Theoretical Bending Stiffness Values } & 147\end{array}$

$\begin{array}{lll}\text { Table B2 Theoretical Shear Stiffness Values } & 147\end{array}$

$\begin{array}{lll}\text { Table C1 Torsion } & 152\end{array}$

$\begin{array}{lll}\text { Table C2 Torsion and Bending } & 154\end{array}$

Table C3 Web Load Distribution 155

Table C4 Polyester Component \#1 155

Table C5 Polyester Component \#2 156

Table C6 Vinyl Ester Component \#1 156

Table C7 Vinyl Ester Component \#2 157

Table C8 Elastic Testing of Rehabilitated Longitudinal

Component (12”x 12” Patch Load) 158

Table C9 Elastic Testing of Rehabilitated Longitudinal

Component (12”x 24” Patch Load) 159

$\begin{array}{lll}\text { Table C10 } & \text { Elastic Testing of Rehabilitated Longitudinal } \\ & \text { Component (6"x 24" Patch Load) } & 160\end{array}$

Table C11 Rehabilitated Longitudinal Component Failure Test 161

$\begin{array}{lll}\text { Table C12 Transverse Testing } & 161\end{array}$

Table C13 Polyester Deck Phase I 162

Table C14 Polyester Deck Phase II 163

$\begin{array}{lll}\text { Table C15 Polyester Deck Phase III } & 165\end{array}$

Table C16 Vinyl Ester Deck Phase III 166

$\begin{array}{lll}\text { Table C17 In-Plane Shear } & 167\end{array}$ 


\section{CHAPTER 1 \\ INTRODUCTION}

\subsection{General and Background Information}

In today's ever-changing world, people are constantly reviewing material constituents and processing to improve the quality of end products; hence enhancing the quality of life. As a result, along with other science and engineering communities, the structural engineering community is constantly searching for ways to make new and improved materials in an economical manner. This is especially true in infrastructure applications because of serious deficiencies of the existing structures. According to a Federal Highway Administration publication, 31.4\% of the nation's 581,942 bridges are either structurally deficient or functionally obsolete (Lopez-Anido et.al. 1999). This staggering deficiency is attributed primarily to corrosion caused by the natural environment and the use of de-icing chemicals. In addition, obsolete highway structures, especially bridges, are also attributed to increasing axle loads and frequencies, coupled with material aging. Due to the large amount of rehabilitation work that needs to be performed, development of new materials more equipped to handle severe traffic and environmental conditions are essential.

Currently, concrete and steel are the main structural materials used in mass quantities for buildings, bridges, and other large structural elements. These materials have been used for many years with much success, but they each have their own problems that can limit the effectiveness of a structural system. Some of their obvious shortcomings include corrosion, low strength to weight ratio, and loss of performance due to mechanical as well as thermal fatigue. Therefore, the challenge that is presented from a material development point of view is to improve some, if not all, of the above problems while not compromising the other structural properties such as strength, stability, stiffness, and durability.

Fiber Reinforced Plastics (FRP's) are one of the materials being researched and tested in an attempt to make a new structural material that is superior to concrete and steel for specific applications such as bridge decks. While an attempt to arrive at 
structural materials superior to conventional materials such as concrete and steel is a daunting task, past performances of FRP's give some hope to the material and structural engineers working in this particular area that advancement of state-of-theart materials such as composites can be successful.

FRP's are made primarily of fibers and resins combined together in such a way that their composite is stronger than the individual constituents. FRP's possess low density, better fatigue and corrosion resistance, and result in very high strength to weight properties (Shekar 2000). In an attempt to take advantage of these properties, bridge decks, restoration of conventional structures, reinforcing bars in concrete, shear transfer through dowels for concrete paving, and a variety of other applications are being tested using FRP's to determine their applicability. While all of these are very worthwhile endeavors, the only work preformed in this text deals with bridge deck research and application.

The science of using fiber reinforced plastics in infastructural applications is still in the early stages of development. However, some advances in production and construction have been made (Howdyshell et.al. 1998 and Busel 2000). Additional advances are needed in: 1) obtaining more test data on FRP's for a better definition of their performance, 2) improvements in manufacturing processes, and 3) creation of standards to allow for safe and efficient designs.

The State of West Virginia has been experimenting with FRP materials for highway bridges. GangaRao et.al (1999) gives two examples. Both the Laurel Lick Bridge in Lewis County and the Wickwire Run Bridge in Taylor County use composite decks, and the superstructure of the Laurel Lick Bridge is made out of composites as well. Both bridges were constructed in 1997 and are still performing adequately.

\subsection{Objectives}

The primary objective of this project was to develop FRP multicellular bridge deck modules to resist AASHTO's HS25 loading for a minimum girder spacing of five feet while weighing approximately fifteen pounds per square foot of deck area. The development of FRP deck modules has been divided into many subtasks. The subtasks with primary foci can be seen as follows: 
Design multicellular shape to maximize structural efficiency;

Develop fiber architecture with emphasis on continuity of fibers from web to flange;

Design to resist combined effects of shear, axial, and bending loads as well as prevent local buckling failure in the web;

Evaluate structural properties including:

Component Level

- Failure strength,

- Web buckling resistance,

- Bending stiffness,

- Torsional stiffness, and

- Failure modes through static testing.

\section{$\underline{\text { System Level }}$}

- In-plane shear stiffness,

- Local, global, and relative deck deflection,

- Effective deck width,

- Transverse load distribution factors, and

- Degree of structural compositness between FRP deck and steel stringers.

\subsection{Scope}

Chapter 2 contains a brief sampling of published literature describing the current situation of fiber reinforced plastics use in engineering, as well as the areas where performance is satisfactory and those where it is not. The study focuses on static testing at the component and system levels. Additional literature can be obtained from the Annotated Bibliography of GangaRao and Shekar (2002).

Chapter 3 deals with the determination of the torsional behavior of the 8" deep FRP components, their web buckling response, and the load distribution response of the FRP modules. Determination of torsional stiffness, bending stiffness under a variety of constant torques, ultimate web buckling loads with corresponding failure 
modes, and the best component orientation for web load distribution are presented therein.

Chapter 4 deals with the bending response of FRP bridge deck components. The components elastic properties were determined in both the longitudinal and transverse directions, and the failure modes are presented and discussed. Also, the rehabilitation of a component is presented in the fourth chapter of this text.

Chapter 5 explores the philosophy of component level failure modes observed during testing. The failure modes were quantified and limit states were established in an attempt to better understand the failure behavior of FRP composite bridge decks.

Chapter 6 discusses the response of FRP deck and steel stringer systems. The system response to deflection, transverse load distribution, degree of compositness between deck and stringers, and effective deck width has been determined and presented in this chapter. These issues are studied from both experimental and theoretical standpoints.

Chapter 7 explores the response of an FRP deck to in-plane shear. The inplane shear modulus $\left(\mathrm{G}_{\mathrm{xy}}\right)$ is approximated and discussed herein. Finally, Chapter 8 gives conclusions and recommendations learned from the previous seven chapters.

Appendix A contains both the necessary information about the lamina making up the FRP bridge decks being studied and the equations used to calculate the lamina properties. Appendix B uses the information gained from Appendix A and computes the bending and shear stiffness values of the FRP decks. The final appendix, Appendix C, contains tables of all the raw data collected during this study. 


\section{CHAPTER 2 \\ LITERATURE REVIEW}

\subsection{Introduction}

The field of composites has made great strides in the past few years due to the large amount of time and effort expended by government agencies (Howdyshell et.al. 1998), universities (Shekar 2000), and private organizations (Busel 2000). These research, development, and implementation efforts in composites are beginning to pay dividends in terms of low cost, yet durable, construction products such as bridge decks. Static testing that has been performed on both component and system level have been briefly discussed herein. Also, constituent materials used to create the composites are described along with general information about the pultrusion process.

\subsection{Pultrusion}

Pultrusion is a manufacturing process in which FRP composites can be massproduced while retaining the necessary tolerances and mechanical properties for design and implementation. Advantages include the ability to create prismatic members of high quality in any length while incorporating complex fiber architectures. Figure 2.1 shows a basic schematic of the process, and Figure 2.2 shows photographs taken at Bedford Reinforced Plastics, Inc. These pictures were taken as a part was pultruded. Note that the part itself is arbitrary and is not associated with the actual work performed in this report. Figure 2.1 and Figure 2.2 are merely pictorial representations of the process.

Summary of Pultrusion Process (Maji et.al. 1999)

1) Spools of continuous fibers are pulled through the guide into the resin bath and saturated in the liquid while maintaining proper fiber alignment.

2) The fibers then pass through forming fixtures that eliminate excess resin and air voids, while the fibers are grouped into their specified shape.

3) The fibers then enter the heating platforms where they are cured. The curing occurs at multiple temperature ranges as the part moves through the platform. 
4) The finished part then exits the heating platform where the curing took place. It then passes through the pullers that have been forcing the process. The component is then cut to a specified length.

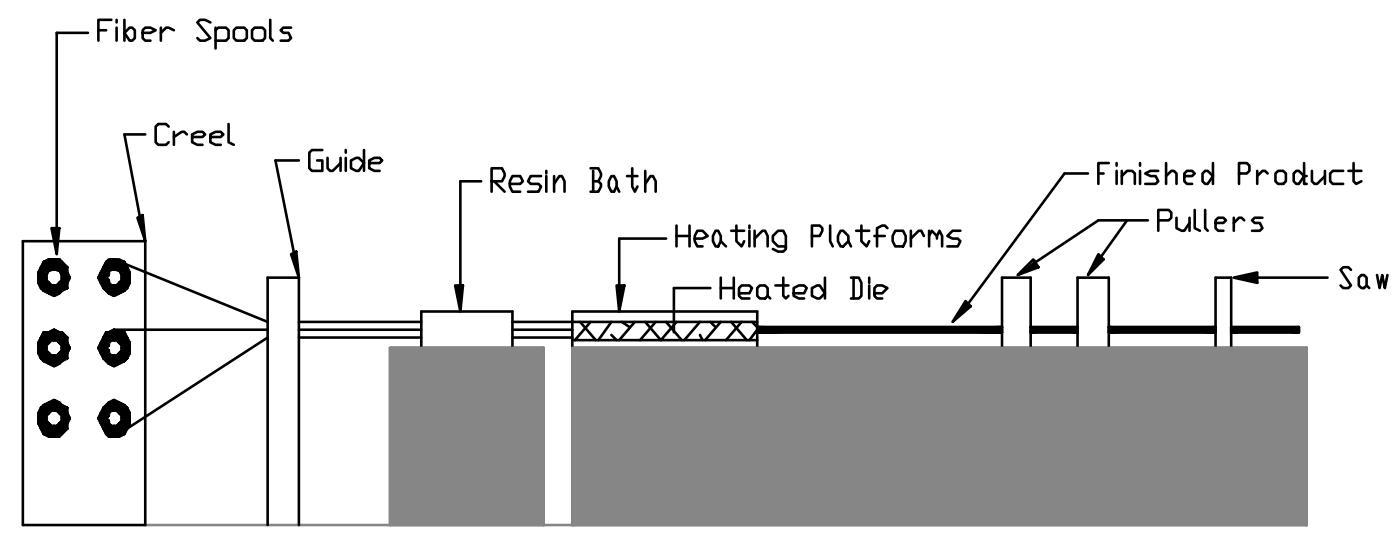

Figure 2.1-Pultrusion Schematic

Numerous factors play important roles in the making of a good part via pultrusion. Research was performed in this area by many researchers including (Maji et.al. 1999) and (Freed 2002). It was observed that the five most important factors to control in the pultrusion process were:

1) Die temperature,

2) Fiber volume fraction,

3) Pull speed,

4) Percent of voids, and

5) Misalignment of fibers and pullers.

These parameters must be optimized in order to achieve a high-quality part in a costeffective manner.

Maji et.al. (1999) determined the pull force/speed governs the operability of the process, and the alignment of pullers is also very important for successful production of a part. The tension forces transmitted to the fibers are a direct result of the pull force, and it must be maintained uniformly in all areas of the part at intensities large enough to hold the fibers in a proper alignment, yet small enough to avoid damage to the fibers. If the pull force/speed is not properly adjusted, fabrics in some layers may be tensioned higher than in other layers causing potential tensile 
damage to the high tensioned areas, leading to wrinkled fiber alignments in low tension areas. Freed (2002) recommended a pull speed of $8 \% /$ min for a complex part.

The die temperature must contain a gradient that allows proper curing of the part. The die temperature usually divides the curing into three phases:

1) Liquid phase,

2) Gel phase, and

3) Solid phase.

They occur in this order and the properties of the part change dramatically in each of the three phases. The viscosity of the resin initially decreases with the addition of temperature, but as the gel zone and solid phase approach, viscosity increases very quickly. The resin also expands during this part of the process. If the die temperature and pull speed are not properly adjusted, large shear forces between the resin and fabrics develop causing loss of mechanical properties. Freed (2002) recommended that the uncured resin remain pressurized for the longest possible time at the maximum pull speed.

The fiber volume fraction of the part being pultruded is also a critical factor to consider. Increases in the volume of fibers demand increases in pull speeds, and adjustments have to be made to the die temperatures. Fiber increases also force the alteration of the puller alignment. In addition, the production rate may have to be changed in order to achieve the desired fiber wet out characteristics necessary to arrive at the indispensable properties such as strength, stiffness, etc.

Freed (2002) also studied the void content of pultruded components. The amount of voids in a composite decreases its structural strength. A rule of thumb is a $1 \%$ increase in voids will decrease the composite strength by $10 \%$. It was discovered the void content does not significantly change with pull speed. However, the pressure and viscosity of the resin greatly affect wettability, which dictates the amount of voids. 


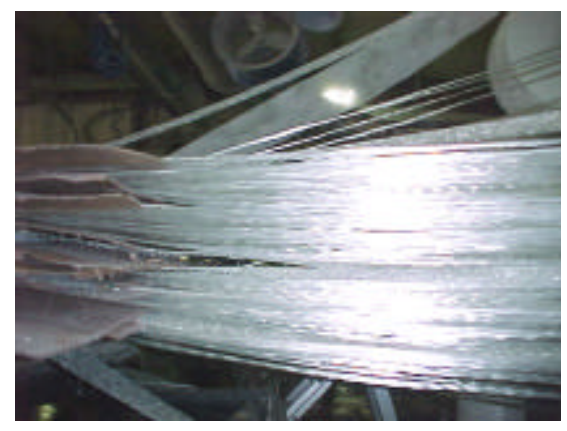

\#4

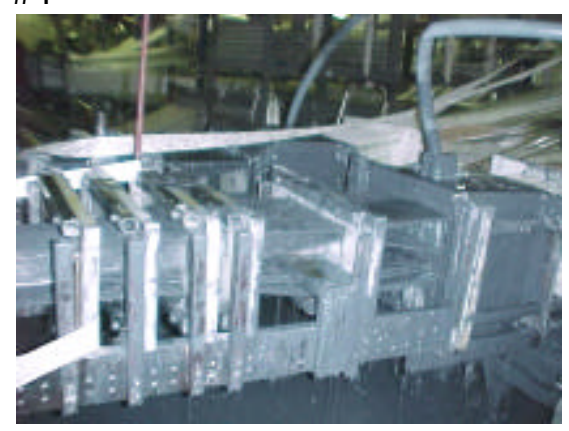

\#6

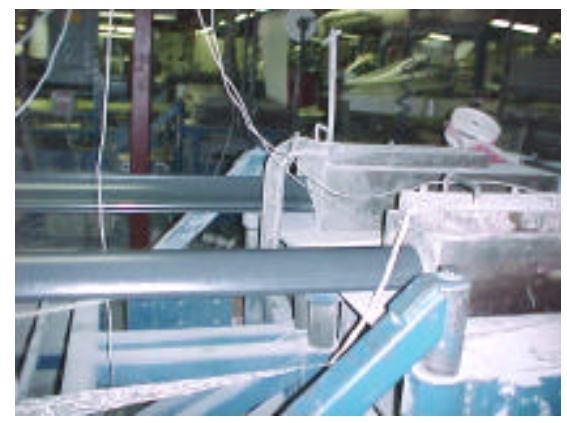

\#8

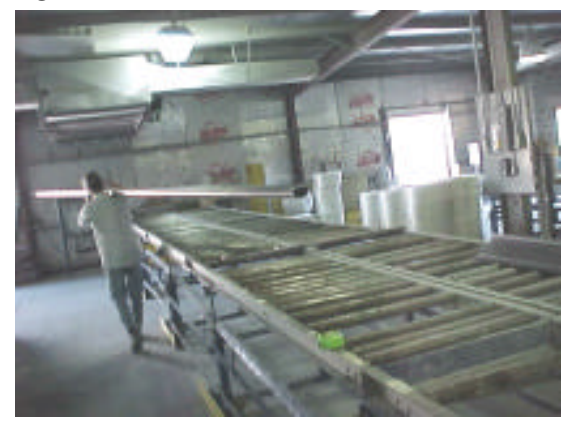

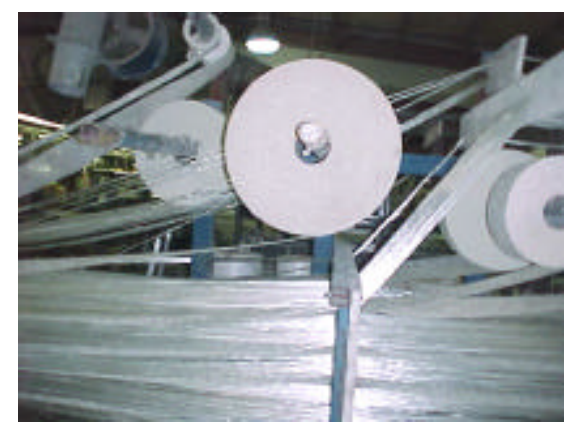

\#3

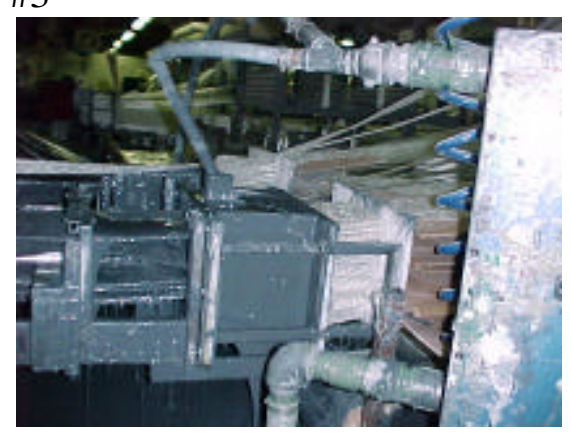

\#5

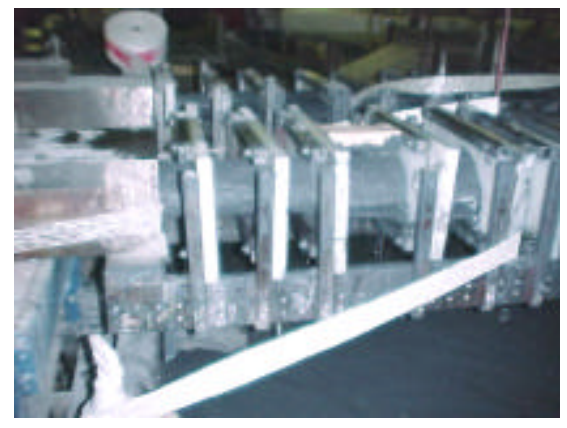

\#7

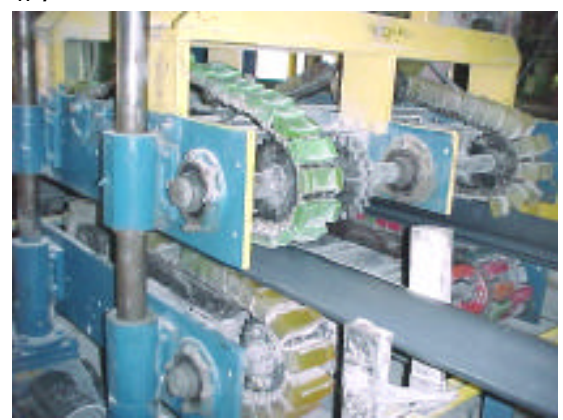

Figure 2.2-Pultrusion Pictures from Bedford Reinforced Plastics, Inc. 


\subsection{Types of Fibers and Resins}

The predominant fiber types used in composite applications are glass, carbon, and organic, while the main resin used for the pultrusion process is a thermoset matrix (Barbero 1998). Examples of thermoset matrices include polyesters, vinyl esters, epoxies, and phenolics. Although any of these materials can be used to create composite materials, the study performed in this report only deals with glass fibers (particularly E-glass fibers) combined with either polyester or vinyl ester resins. These materials will be discussed in more detail in the following paragraphs.

According to (Mallick 1993) and (Barbero 1998), E-glass fibers possess the advantages, disadvantages, and typical properties shown in Table 2.1 .

\begin{tabular}{|c|c|c|c|}
\hline \multicolumn{2}{|c|}{ Typical Properties } & Advantages & Disadvantages \\
\hline Diameter (micro-in) & 393 & Inert & Other Materials Stronger \\
\hline Specific Gravity & 2.54 & Corrosion Resistant & Affected by Fatigue \\
\hline Tensile Modulus (Msi) & 10.5 & Low Cost $(\$ 0.75 / \mathrm{lb})$ & Sensitive to Abrasion \\
\hline Tensile Strength (Ksi) & 500 & Few Surface Defects & Relatively High Specific \\
\% Strain to Failure & 4.8 & Insulative & Bravity \\
\hline Poisson's Ratio & 0.2 & Very Common & Britle \\
\hline
\end{tabular}

Table 2.1-E-Glass Fibers

Of the information listed in the above table, the low cost is the main reason that the E-glass fibers are being researched and used in bridge decks. They are currently the most economical of all commercially available fibers (Mallick 1993).

According to (Mallick 1993), (Barbero 1998), and (Altizer 1996) polyester and vinyl ester resins typically possess the advantages, disadvantages, and properties shown in Table 2.2 and Table 2.3, respectively. The use of these resins is predominantly due to cost and resistance to environmental attack. 


\begin{tabular}{|c|c|c|c|}
\hline \multicolumn{2}{|c|}{ Typical Properties } & Advantages & Disadvantages \\
\hline Tensile Modulus (Ksi) & $400-500$ & UV Resistance & \multirow{2}{*}{ Not Extremely } \\
\hline Tensile Strength (Ksi) & $3-11$ & $\$ 0.65-\$ 1.00 / \mathrm{lb}$ & \\
\hline Compressive Strength (Ksi) & $15-17$ & Corrosion Resistant & Moisture Uptake \\
\hline Shear Strength (Ksi) & 11 & Alkalinity Resistant & Salt Resistance \\
\hline Tensile \% Elongation & $1.4-3.3$ & One of the Easier & \multirow{2}{*}{ Freeze-Thaw } \\
\cline { 1 - 2 } \cline { 1 - 2 } Flexural Modulus (Ksi) & 1000 & \multirow{2}{*}{ Resins to Use in the } & Weakens Above \\
\hline Flexural Strength (Ksi) & $28-35$ & & \\
\hline Poisson's Ratio & 0.38 & & \\
\hline
\end{tabular}

Table 2.2-Polyester Resins

\begin{tabular}{|c|c|c|c|}
\hline \multicolumn{2}{|l|}{ Typical Properties } & Advantages & Disadvantages \\
\hline Tensile Modulus (Ksi) & 500 & \multirow{2}{*}{$\begin{array}{c}\text { Excellent Corrosion } \\
\text { Resistance }\end{array}$} & Up to $\$ 1.80 / \mathrm{lb}$ \\
\hline Tensile Strength (Ksi) & 12 & & \multirow{2}{*}{$\begin{array}{c}\text { Alkalinity } \\
\text { Resistance }\end{array}$} \\
\hline Compressive Strength (Ksi) & 17 & Freeze-Thaw Resistance & \\
\hline Shear Strength (Ksi) & 12 & Salt Resistance & Moisture Uptake \\
\hline Tensile \% Elongation & $5-6$ & Very Durable & \multirow{2}{*}{$\begin{array}{c}\text { Weakens Above } \\
200^{0} \mathrm{~F}\end{array}$} \\
\hline Flexural Modulus (Ksi) & 490 & Fatigue Resistant & \\
\hline Flexural Strength (Ksi) & 18 & \multirow{2}{*}{$\begin{array}{l}\text { Resistance to Multiple } \\
\text { Attacks Simultaneously }\end{array}$} & \multirow{2}{*}{$\begin{array}{l}\text { Minor Pultrusion } \\
\text { Problems }\end{array}$} \\
\hline Poisson's Ratio & 0.38 & & \\
\hline
\end{tabular}

Table 2.3-Vinyl Ester Resins

\subsection{Relevant Research Conducted on FRP}

Experiments conducted both by the author's mentioned in this chapter and the author of this text followed either GangaRao and Shekar (2002) or equivalent methods. The test methods contained therein are similar to current AASHTO standards, and are in the process of being adopted by AASHTO. These methods take into account the slight differences necessary to test a composite material relative to an isotropic material.

\subsubsection{Static Testing at the Component Level}

\subsubsection{Bending}

Nagaraj (1994) performed static tests on FRP box and wide flange shapes containing fabrics and rovings. The dimensions of the component cross-sections were 4"x 4"x 0.25 ". The testing was performed on 72" spans. Stiffness values (EI) 
for the box sections were $2.21-2.75\left(10^{7}\right) \mathrm{lb}^{*}$ in ${ }^{2}$ while the wide flange values ranged from $2.77-2.98\left(10^{7}\right) \mathrm{lb} * \mathrm{in}^{2}$. The failure mode of the box sections was due to local compression flange buckling followed by web/flange separation. Similarly, the wide flange sections experienced local compression flange buckling followed by cracks forming at the web/flange junction. The analysis was performed via approximate classical lamination theory (ACLT) and finite element analysis. Both yielded results in the vicinity of those found by testing. However, the bending specimens in this study were relatively small in terms of their thickness. As a result, the effects of shear-lag and leakage were not present to the extent they would be in members thick enough for a highly traveled bridge deck. Therefore, larger sections need to be tested for their stiffness and strength, and compared with these thinner sections.

Nagy (1996) researched the effects of static loading on "Pultruded-Core Sandwich Deck Panels". The components were made of pultruded I-beams in between hand-lay-up face plates. The depths of the components were in the neighborhood of 9", and the lengths ranged from 614'. The Fbeams were made of "EXTERN 550" materials, and quasi-isotropic E-glass (BTI QM-5602) was used for the plates. Testing in the transverse direction resulted in degrading stiffness with loading and a failure at the web/flange junction due to bending induced tensile and shear cracking. A longitudinally tested component 14' long failed at 219 kips in double bending by tension and delimitation of the bottom plate. All the composite decks evaluated in this study had stiffness values below that initially held by concrete. In order to adequately evaluate the usefulness of a design such as this, the effects of torsion on the specimen would have to be evaluated. Also, the stiffness needs improvement in order to be competitive with conventional materials.

Sonti (1997) performed static tests on a composite containing fabrics and rovings with a multicellular shape. Static tests were performed on a specimen with a fiber volume fraction in the 30-35\% range with dimensions of $72 " \mathrm{x} 24 " \mathrm{x} 5.5 "$. The experiment yielded a tensile modulus slightly under $3\left(10^{6}\right)$ psi, and a global failure at 25 kips. The loading caused the same type of failure commonly seen in FRP components under bending. The web and flange separated (delaminated) in addition 
to shear failure, to some extent, in the interior webs. Also, the finite element modeling performed in this study correlated well with experimental findings. In addition, a combination of micro and macro mechanics was implemented to predict the bending stiffness of the component and arrived at satisfactory results. This study shows that existing models can predict the behavior of FRP components under bending; however, fiber architectures with higher fiber volume fractions are needed to increase both the stiffness and ultimate load.

Vedam (1997) also conducted similar tests to that of Sonti (1997). The testing was performed on a double-trapezoid and hexagonal shape (first generation component). The outer dimensions of the component cross-section were 12"x 8", and the testing span ranged from 60-108". Also, the fiber volume fraction was in the range of $45-50 \%$, and the weight of the component was $22 \mathrm{lb} / \mathrm{ft}^{2}$ of surface area. The bending stiffness (EI) was found to be approximately $8.44\left(10^{8}\right) \mathrm{lb}^{*}$ in $^{2}$, and the failure mode was again at the junction of the web and flange. A 30 kip load was being applied at the time of failure. The method of analysis in this study was the approximate classical lamination theory (ACLT). The findings were in good correlation with experimental values. The experimental specimen had a relatively high weight compared to the resulting stiffness. This issue must be improved if FRP bridge decks are to be integrated with our country's infrastructure.

Shekar (2000) performed static testing on the second generation double trapezoid and hexagonal component. The outer dimensions and the range of fiber volume fraction were the same as Vedam (1997). The testing was performed on a 108" span, and the weight of the component was $19 \mathrm{lb} / \mathrm{ft}^{2}$ of surface area. The stiffness was found to be $8.27\left(10^{8}\right) \mathrm{lb}^{*} \mathrm{in}^{2}$, and the ultimate bending stress was found to be $30 \mathrm{ksi}$. The failure mode was separation of the web and flange. Again, the ACLT approach was adopted for analytical purposes, and it performed well. The weight to stiffness ratio improved slightly, but greater improvement is needed to make FRP bridge decks competitive with conventional materials for cost effectiveness.

The separation of the web and flange is partially due to fiber discontinuity between the web and flange. Components with fiber architectures continuing from 
the web to the flange possess more of an ability to transfer forces away from the joint where stress concentration exists. As a result, the failure load should be increased with these types of architectures.

Stone (2001) investigated a honeycomb sandwich panel design manufactured by Kansas Structural Composites, Inc. The bending component had outer dimensions of 156"x 23"x 23". The test resulted in a failure at 194 kips due to delamination between the top face and core material. Based on simple beam theory and a failure criterion of maximum fiber stress, a failure $30 \%$ lower than the actual value was predicted. The experiment also arrived at a span-to-deflection ratio of approximately 115. Fiber discontinuity between the core and faces (top and bottom) of the material is a drawback of this type of design. The stress concentration at the junction coupled with an immediate increase in shear stress is a combination that needs to be minimized.

\subsubsection{Torsion}

Sotiropoulos (1995) studied torsional effects at the component level in an attempt to arrive at the shear stiffness. The work was performed on a closed cellular specimen 10' long. The cross-section was approximately 5.25"x 6" with a wall thickness of 0.2". Both single and double cell sections were tested, and their respective stiffness values were found to be $1.67\left(10^{5}\right) \mathrm{lb}^{*}$ in ${ }^{2}$ and $4.25\left(10^{5}\right) \mathrm{lb}^{*}$ in $^{2}$. The theoretical formulations used were mostly for isotropic materials, and the theory was somewhat inconsistent with the FRP components, which are orthotropic. This study also conducted coupon level torsion tests, and those values differed by $15 \%$ from the component level testing. Reasons for such an error could be attributed to secondary torsion or warping, shear-lag, and slippage of the boundaries of the component level test. The study clearly shows that accurate shear stiffness values at the component level must be obtained with great care.

\subsubsection{Buckling}

Quio (1997) conducted buckling tests on FRP Fshaped components. Analysis was also performed using micro/macro mechanics with a combination of laminated 
composite beam and stability principles. Two I-sections were tested, and their dimensions were 6"x 6"x 0.25 " and 12"x 12"x 0.5 ". The smaller section experienced lateral-torsional buckling at a load of $30 \mathrm{kips}$, and flexural-torsional buckling at a load of 37 kips. Likewise, the larger specimen experienced lateral-torsional buckling at a load of 30 kips, and flexural-torsional buckling at a load of 38 kips. The study was very successful at both the experimental and theoretical levels. Studies of this nature need to be conducted on various shapes to establish the overall behavior of FRP structural shapes under buckling loads.

\subsubsection{System Level Static Testing}

Sotiropoulos (1995) studied the behavior of an FRP deck and steel stringer system. The deck was a multicellular shape containing a fber architecture of rovings and mats. The system was approximately 95" wide and 193" long with three stringers spaced 43" apart. The deck depth was slightly over 5".

Sotiropoulos (1995) collected deflection data for both global deflection and deck deflection relative to stringers. Maximum global deflection was found for both concentric and symmetric load cases. Concentric refers to a patch load placed at the center point of the deck while symmetric refers to two patch loads placed equidistant from the central stringer. At a load of $43 \mathrm{kips}$, the maximum global deflection for the concentric loading case was 0.31", and the maximum global deflection for the symmetric loading case was $0.30 "$. Furthermore, deck deflection relative to stringers was found with and without diagonal stiffeners. Without any diagonal stiffening, a maximum relative deflection of $0.16 "$ was observed at 32 kips. On the other hand, addition of four diagonal stiffeners caused the maximum relative deflection to drop to $0.11^{\prime \prime}$

Other parameters of interest researched by Sotiropoulos (1995) were the transverse load distribution factor (TLDF) and the degree of compositness between the deck and stringers. The maximum TLDF due to concentric loading was found to be 0.559 , while 0.439 was the maximum value due to symmetric loading. Also, the degree of compositness between the deck and stringers was found to be $39 \%$.

The deck system did not meet the global deflection requirements. Part of the reason could be attributed to the relatively low degree of compositness of the deck 
and stringers considering that mechanical fasteners were used. However, the method of analysis did correlate well with experimental results under bending loads. The analysis was performed via orthotropic plate theory in conjunction with strength of materials. Based on the results of Sotiropoulos (1995), this approach appears to have the potential to create a design methodology that is reasonable for FRP decks stiffened with steel stringers.

Fiber reinforced plastic bridge decks are currently being manufactured and can be readily purchased. One such deck is a low profile fiber-reinforced foam (FRF) core sandwich panel. The deck is manufactured by 3TEX, Inc. (Busel 2000). The deck is approximately 3.3" thick and has an ultimate strength of 80 kips at a 28" stringer spacing. The deck is designed according to AASHTO'S standard HS25 loading (AASHTO 1998). The weight of the deck is $7 \mathrm{lb} / \mathrm{ft}^{2}$ of deck area. While a good product, the stringer spacing of $28 "$ is very compact. Increasing this spacing is a key issue in the composite bridge deck industry.

Another FRP bridge deck currently available is the DuraSpan ${ }^{\mathrm{TM}}$ deck created by Martin Marietta Composites, Inc. (Busel 2000). The trapezoidal core deck tube design is slightly less than $8^{\prime \prime}$ deep and weighs $18 \mathrm{lb} / \mathrm{ft}^{2}$ of deck area. The fiber architecture consists of a balanced quasi-isotropic lay-up, and the stiffness is of the order of concrete. This deck is similar to the one being investigated in this report. The deck being researched here is a little deeper and weighs around $3-4 \mathrm{lb} / \mathrm{ft}^{2}$ less. However, the basic idea is similar.

\subsection{FRP Deck Loads and Resistances}

FRP bridge decks exhibit noteworthy behavior in a few areas related to loads and resistances not observed in decks of conventional materials. From a loading point of view, the three main areas of difference are: 1) temperature, 2) impact, and 3) shrinkage. From a resistance point of view, the lack of data, short and long term, create problems for a probabilistic determination of resistance and knockdown factors. Also, the resistance of these orthotropic decks is much different in a local

sense than for conventional materials such as concrete bridge decks. It is also noteworthy that the commonality of orthotropic bridge decks such as FRP's is lacking 
relative to concrete decks. As a result, the limit states imposed on the FRP decks are more on the conservative side.

\section{$\underline{\text { Loads }}$}

Thermal effects in FRP structures create a temperature gradient up to $100^{\circ} \mathrm{F}$ according to (GangaRao and Shekar 2002), while concrete decks only have a gradient up to $45^{\circ} \mathrm{F}$ based on (Taly 1998). The higher gradient poses potential problems especially when discussing freeze-thaw issues of FRP decks. Shrinkage, though, is not a problem in FRP decks as in conventional materials. There are no shrinkage reduction factors since FRP decks do not experience shrinkage.

Impact factors are potentially higher for FRP bridge decks than for conventional ones other than orthotropic decks. AASHTO (1996) gives standard specifications for bridges and recommends a maximum allowable impact factor of 0.3. Similarly, AASHTO (1998) reports the maximum allowable impact factor as 0.33 for LRFD methods.

Research was performed by Reiner et.al. (2002) on three different FRP decks placed on a three-lane, five-span bridge. The total span of the test bridge was approximately 700', and all decks were approximately 8" deep. Each of the three types of decks seen in the following list was placed on a different section of the bridge. The three types of decks were as follows with the maximum impact factor recorded in parenthesis:

1) Pultruded double trapezoid and hexagon shape (Superdeck $\left.{ }^{\mathrm{TM}}\right)(0.28)$,

2) Foam cell core encased with E-glass fabric faces (0.42), and

3) Corrugated core sandwiched between hand lay-up face sheets (0.27).

\section{$\underline{\text { Resistances }}$}

From a resistance point of view, FRP bridge decks are forced to take a conservative approach to resistance factors at the current time. As a result, GangaRao and Shekar (2002) reported a resistance factor in flexure as $(\phi=0.75)$, while ACI committee 318 (1999) reports the resistance factor in flexure of concrete as $(\phi=0.90)$. In addition to low material resistance factors, FRP decks are also 
currently saddled with high knockdown factors. These knockdown factors take into account freeze-thaw cycles, $\mathrm{pH}$, and sustained stresses. Maximum knockdown factors are recommended to be as high as 0.4 (GangaRao and Shekar 2002).

Local effects are also critical in FRP decks; i.e., their ability to resist service loading. Since the orthotropic FRP decks are made of relatively thin sections, local shear failures become a serious problem if the loading patch is smaller than the rib (vertical web) spacing. Chapter 5 of this report elaborates on local shear issues in greater detail. Troitsky (1987) recommended a method of analysis for decks with ribs spaced at a given distance apart and treats these ribs as simple supports. The loaded flange is then treated as a beam on the ribs acting as simple supports. The deflections computed by classical methods are then multiplied by (1/6) to account for continuity over the ribs, plate action, etc. Although there are many other limit states at the local level for orthotropic bridge decks, the local shear (punching) failure generally governs the design. In order to limit the effect of these types of failures, the flange thickness must be adequate to handle local stresses.

\subsection{Conclusions}

The work described in this chapter gives a brief overview of the types of research being conducted, their positive points, and areas of potential improvement. From these efforts, the goal of the present study has, hopefully, been better defined. For example, creating more fiber continuity between the web and flange, designing a system to allow for wider stringer spacing, and reducing the weight while not reducing the stiffness are all areas of potential improvement. Also, maintaining the levels of buckling and torsional resistance are also a critical issues. The current 8" deep lightweight decks weighing $14-15 \mathrm{lb} / \mathrm{ft}^{2}$ of surface area have been tested and evaluated. The results of the work performed are presented in the remaining chapters of this report. 


\section{CHAPTER 3}

\section{TESTING AND EVALUATION OF FRP COMPONENTS UNDER TORSION, WEB BUCKLING, AND WEB LOAD DISTRIBUTION}

\subsection{Introduction}

This chapter deals with three main topics that influence the behavior of an FRP bridge deck component. They are:

1) Behavior under torsional loads,

2) Web buckling response, and

3) Web load distribution.

The response to torsional loading was examined for two reasons. The first was to determine the out-of-plane torsional stiffness $\left(\mathrm{G}_{\mathrm{yz}}\right)$ (See Figure 3.4), and the second was to study the effects of different torsional loadings on the bending stiffness. The results of these tests can be seen in section 3.2.

Local stability of a component with respect to web buckling is a critical parameter in any design. If the web of a component buckles, local failures can possibly occur leading to costly structural repairs. As a result, the resisting load (causing such a failure) must be greater than that of the induced design load from vehicles. Also, the severity of the web buckling failure mode must be minimized so that the component undergoes the smallest amount of damage possible at failure. Section 3.3 contains experimental results of local buckling tests, and they are compared to Euler's buckling formula in an attempt to understand the behavior from a mechanics point of view.

Web load distribution is an important issue in a non-symmetrical shape such as the one being studied, since it can be adjusted by orientating the diagonal stiffeners in various ways. In a local sense, orientation of the diagonal stiffeners between two components can be one of four ways, but only two of the four help to maintain structural symmetry. Of the two cases that maintain some degree of symmetry, the orientation that best serves to evenly distribute the load to the vertical portions of the web maximizes local stability and makes for a better structure. The orientation best suited for the task is found and discussed in section 3.4. 


\subsection{Torsion}

Torsion tests were performed on the polyester components shown in Figures B2 and B4 to determine their torsional rigidity. Also, tests were performed to determine the effect of torsional loads on the bending rigidity of polyester components under combined torsion and bending loads. Descriptions of the specimen preparation, instrumentation, test set-ups, and test procedures are given in the following sections.

\subsubsection{Specimen Preparation}

The only preparation necessary was to drill a 3 " diameter hole in the bottom flange of the test specimen to allow a strain gage to be mounted to the diagonal stiffener. The 3" diameter was chosen since it was the smallest hole that would allow a human hand to mount the gage.

\subsubsection{Test Set-Ups and Procedures}

\subsubsection{Torsion}

The set-up consisted of clamped ends and a clear span of 104". Each end was clamped 8" along its length. Wooden blocks were placed in the clamped portion of the component to prevent crushing of the specimen. The wood also served as a spacer to allow for proper alignment of steel angle brackets and testing frame. The instrumentation of the component can be seen in Figure 3.1, while the actual test setup is shown in Figure 3.2. The strain gages were attached according to (M-LINE ACCESSORIES 1979).

The component being tested was 24" wide, and the torsion machine being used was tailored to test samples 18" wide or less. As a result, several attempts were made to achieve the necessary fixed end conditions before testing. The end conditions were modified until a satisfactory set-up was reached. The original set-up contained pre-drilled holes (spaced 18" apart) in the top and bottom angle brackets, and steel rods were placed through these holes to achieve the desired end conditions. To compensate for not being able to use the steel rods, bar clamps were used to prevent rotation of the test specimen relative to the steel angle brackets (holding the component in place). This ensured the longitudinal axes of both the test specimen 
and testing frame were in alignment. It was determined that applying a very large force with the bar clamps in conjunction with bolts torqued to forces corresponding to finger tightness plus approximately 1/4 turn beyond finger tightness worked the best. Other noteworthy items discovered were that the alignment of the load cell needs to be very precise, and that the bottom angle brackets holding the component need to be level before insertion of the component

The test was performed with the aid of a load cell, strain indicators, and a hydraulic jack. The load was applied at a constant rate of approximately $500 \mathrm{lb} / \mathrm{min}$, with the strain and deflection data recorded at constant load intervals. The torque was applied by transferring the force from the stiff beam shown in Figure 3.2 to the turnbuckles at either end of the testing frame. The test was conducted only in the elastic region of the specimen.

\subsubsection{Torsion and Bending}

The test set-up in torsion and bending was similar to section 3.2.2.1, but there were two differences. They were the addition of a loading jack and load cell to apply the bending loads and the removal of the dial gages previously used to measure the angle of twist. All dimensions, boundary conditions, and instrumentation (with the exception of the dial gage removal) were the same as in the torsion test. The actual test set-up can be seen in Figure 3.3.

The test procedure for torsion and bending was vastly different from that of the torsion testing. First, a constant torque was applied to the specimen at a rate of $500 \mathrm{lb} / \mathrm{min}$. While maintaining the torque at a constant level, the bending load was applied to the central portion of the specimen at a rate of $1,000 \mathrm{lb} / \mathrm{min}$ and all data were taken at constant load intervals. The testing was performed only in the elastic region of the specimen. The test was administered with the help of strain indicators, load cells, and hydraulic jacks. 

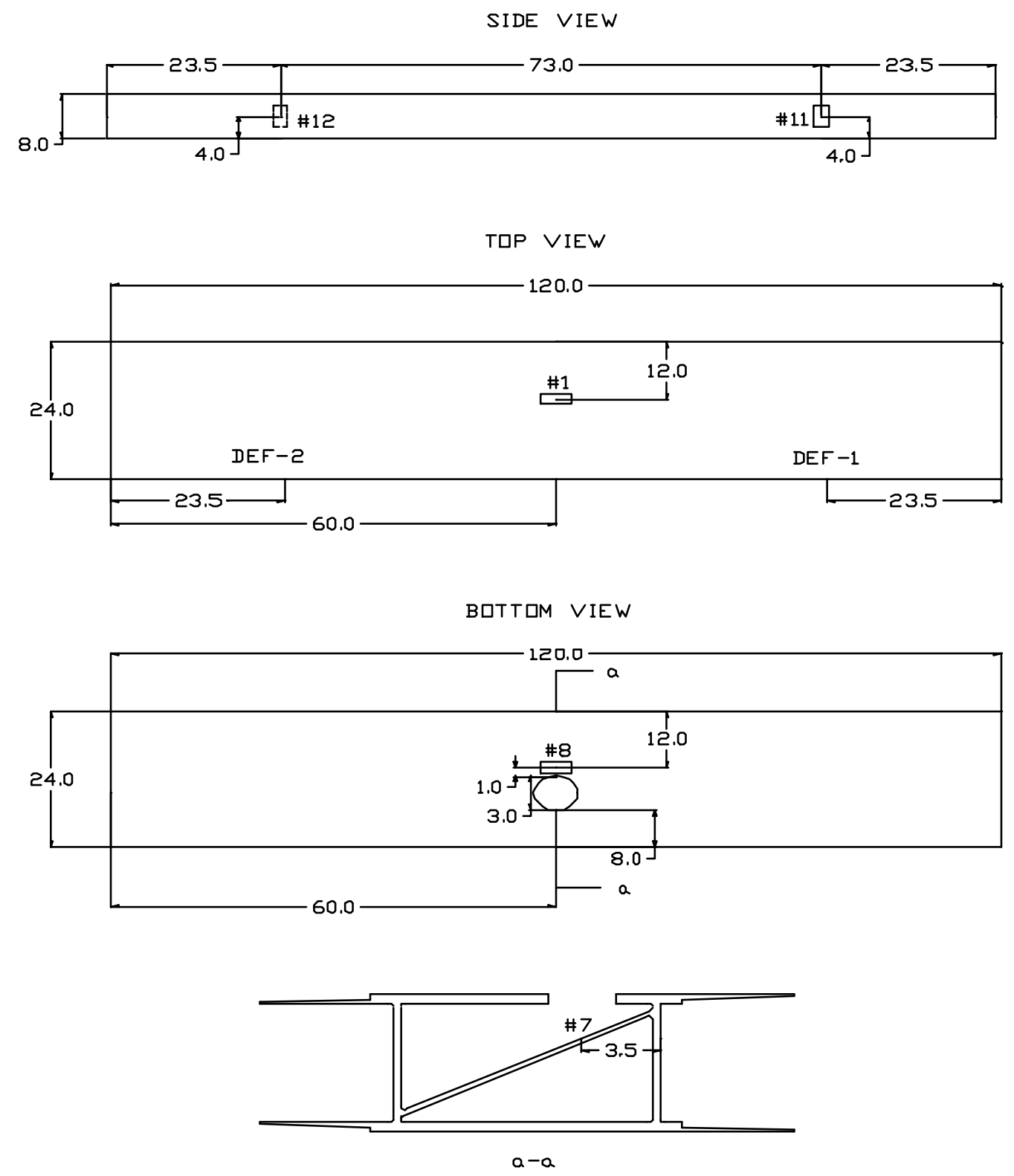

$\square$ Represents a strain gage

\#11 and \#12 are on opposite webs

All units are in inches-Not to scale

Figure 3.1-Instrumentation of Torsion Specimen 


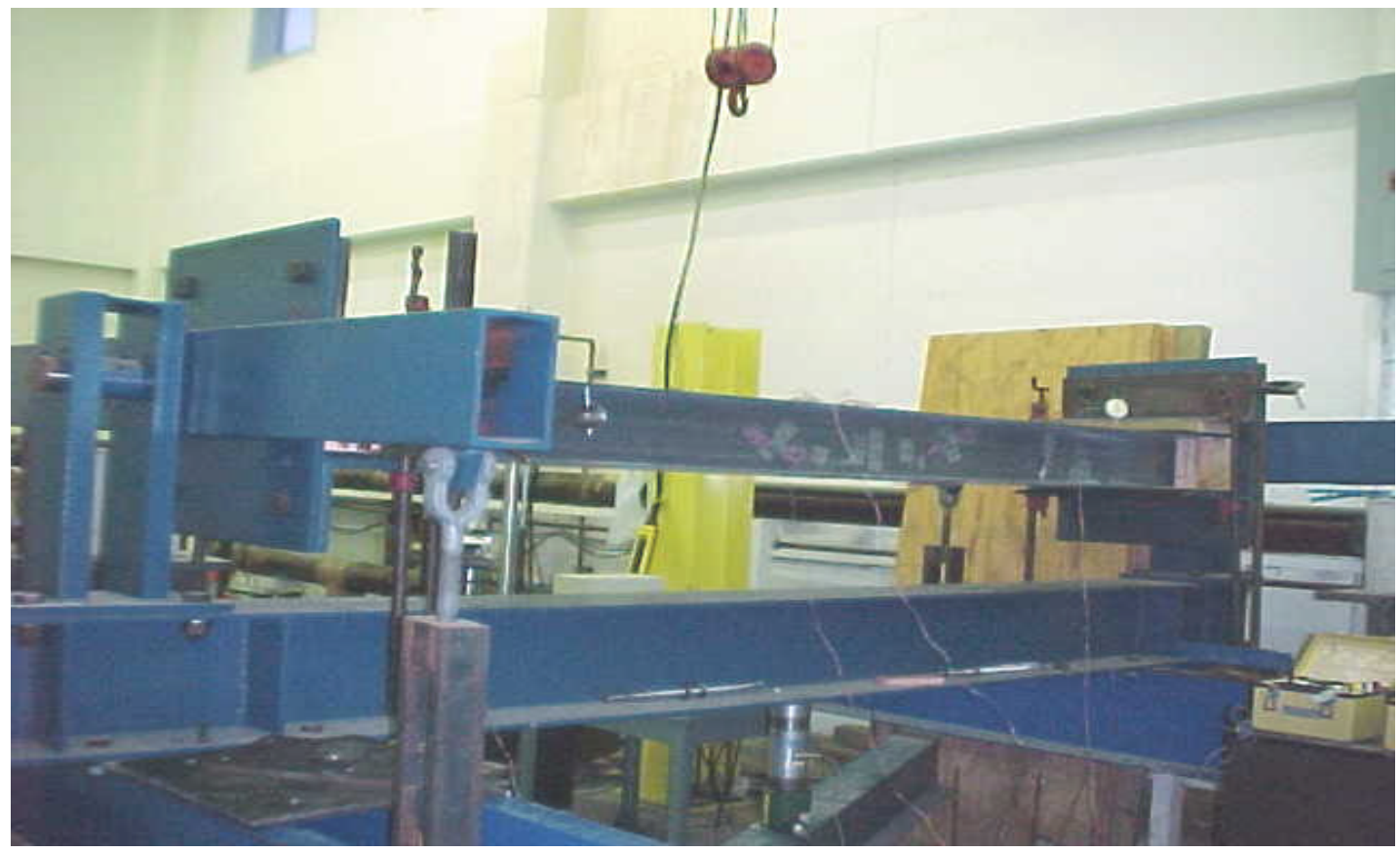

Figure 3.2-Torsion Test-Set-Up

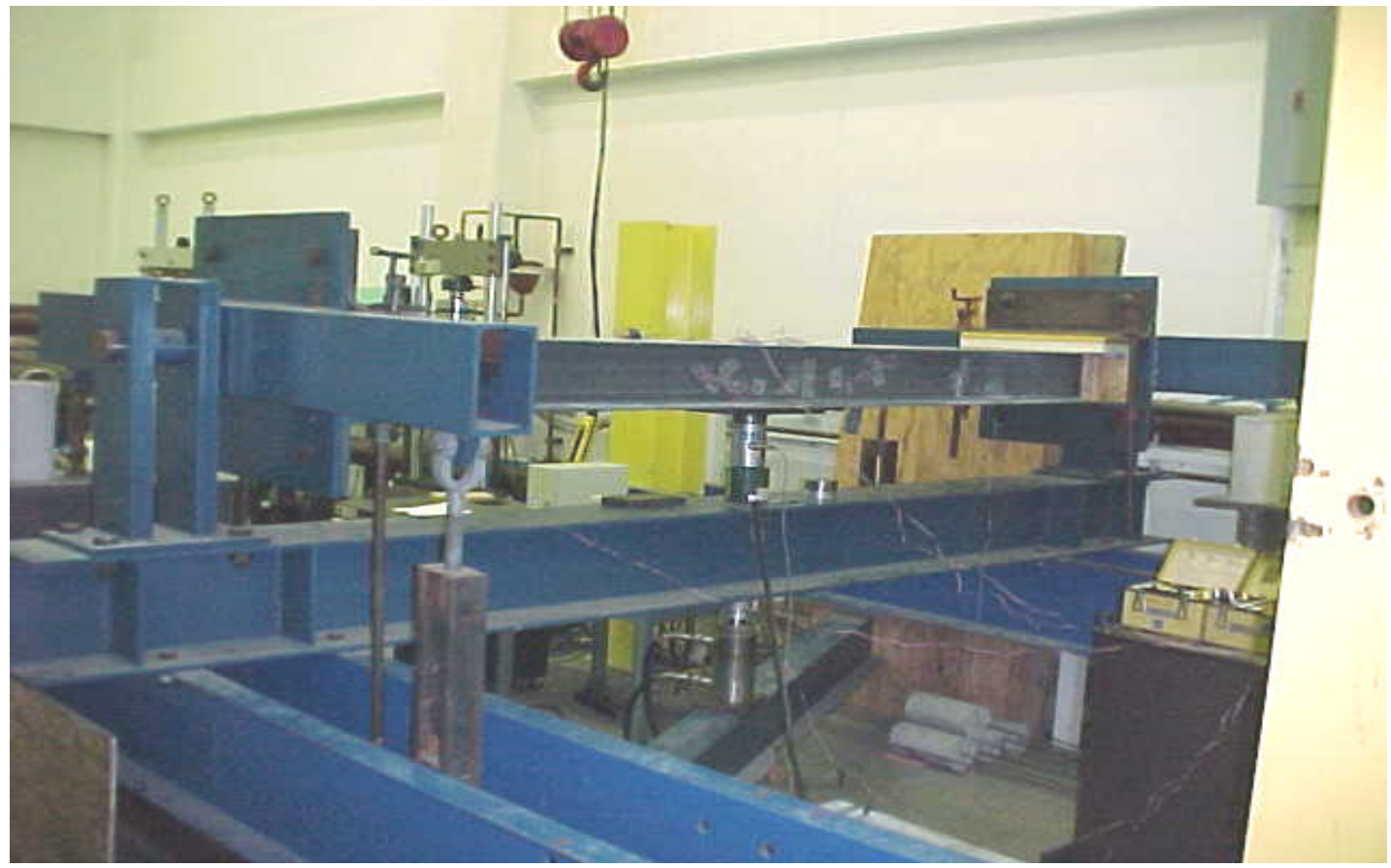

Figure 3.3-Torsion and Bending Test Set-Up 


\subsubsection{Test Results}

\subsubsection{Torsion}

Before discussing the actual test results, certain issues need to be addressed with regards to the material coordinate system implemented and the anisotropy of the components being studied. Figure 3.4 shows the material coordinate system adopted, and unlike an isotropic material such as steel, the shear properties vary depending upon the plane being considered. In steel only one shear modulus value $(\mathrm{G})$ is necessary since any plane of a steel specimen is exactly like any other plane in the specimen with respect to its material content. However, in an FRP specimen, one plane of the specimen rarely contains the same fiber content, fiber configuration, and resin content as another plane. As a result, in anisotropic (direction dependent) material such as an FRP bridge deck, $G_{x y} \neq G_{x z} \neq G_{y z}$.

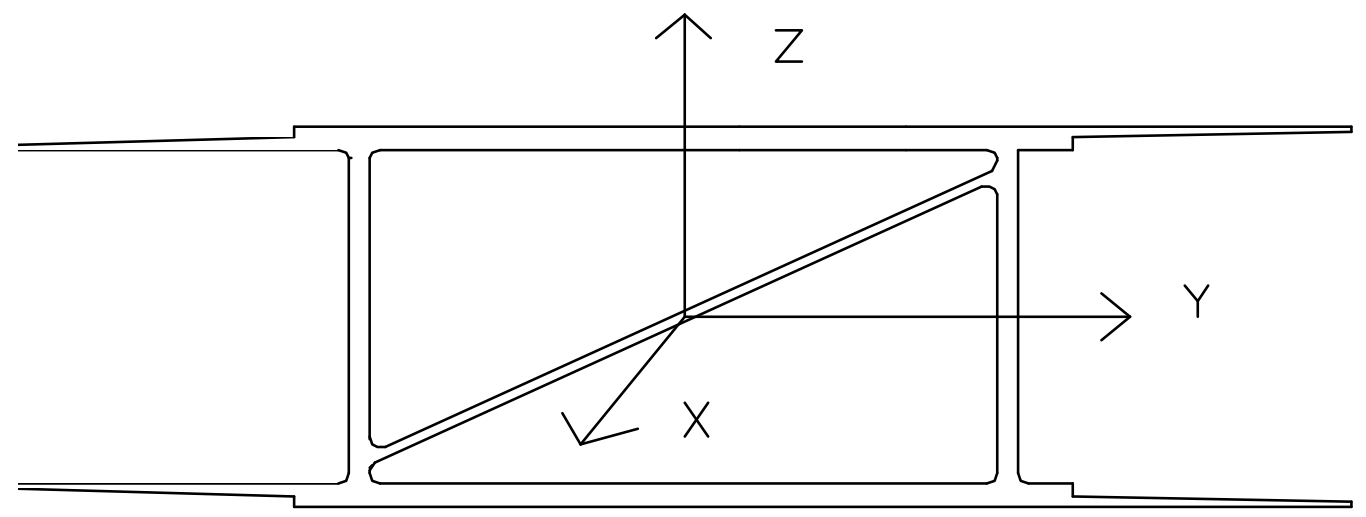

Figure 3.4-Definition of Material Coordinate System

Calculation of the applied torque on each end was determined by taking half of the jacking force and multiplying it by the distance between the turnbuckle and the pivot point of the testing frame as follows:

$$
T=\frac{P X}{2}
$$

Where,

$\mathrm{T}=$ torque applied at each end of the specimen

$\mathrm{P}=$ load applied at the center of the loading beam by the jacking force 
$\mathrm{X}=$ distance from turnbuckle to pivot point of testing frame (36")

The angle of twist was calculated using

$$
\phi_{i}=\sin ^{-1}\left[\frac{\psi_{i}}{b^{\prime}}\right]
$$

Where,

$\phi_{i}=$ angle of twist at point (i) expressed in radians

$\psi_{i}=$ deflection at point (i)

$b^{\prime}=$ distance from specimen centerline to position of dial gage (11.75”)

In an ideal situation, equal loading (P/2) would be applied to each turnbuckle, and the specimen would be placed such that its ends were equal distances from the end plates where the turnbuckle is positioned. However, an ideal set-up is never truly obtained. As a result, the angle of twist obtained from each of the two deflection measurements were averaged in an attempt to arrive at as accurate a value as possible since the test set-up has already been shown to be very sensitive (See 3.2.2.1).

$$
\phi_{\text {avg }}=\frac{\phi_{i=1}+\phi_{i=2}}{2}
$$

Using the values of $T$ and $\phi_{\text {avg }}$ obtained for each data point; a graph of torque versus average angle of twist was plotted. The slope of the linear portion of the curve was considered to calculate the torsional stiffness $\left(K_{y z}\right)$.

$$
K_{y z}=\left(\frac{\Delta T}{\Delta \phi_{a v g}}\right)\left(L^{\prime}\right)
$$

Where,

$$
\begin{aligned}
& \left(\frac{\Delta T}{\Delta \phi_{\text {avg }}}\right)=\text { slope of the linear portion of } \mathrm{T} \text { v/s } \phi_{\text {avg }} \text { curve } \\
& L^{\prime}=\text { distance between dial gages }\left(73^{\prime \prime}\right)
\end{aligned}
$$


The results of the FRP beam testing under torsion yielded values that were in close correlation with each other. Figure 3.5 shows the plots of the data.

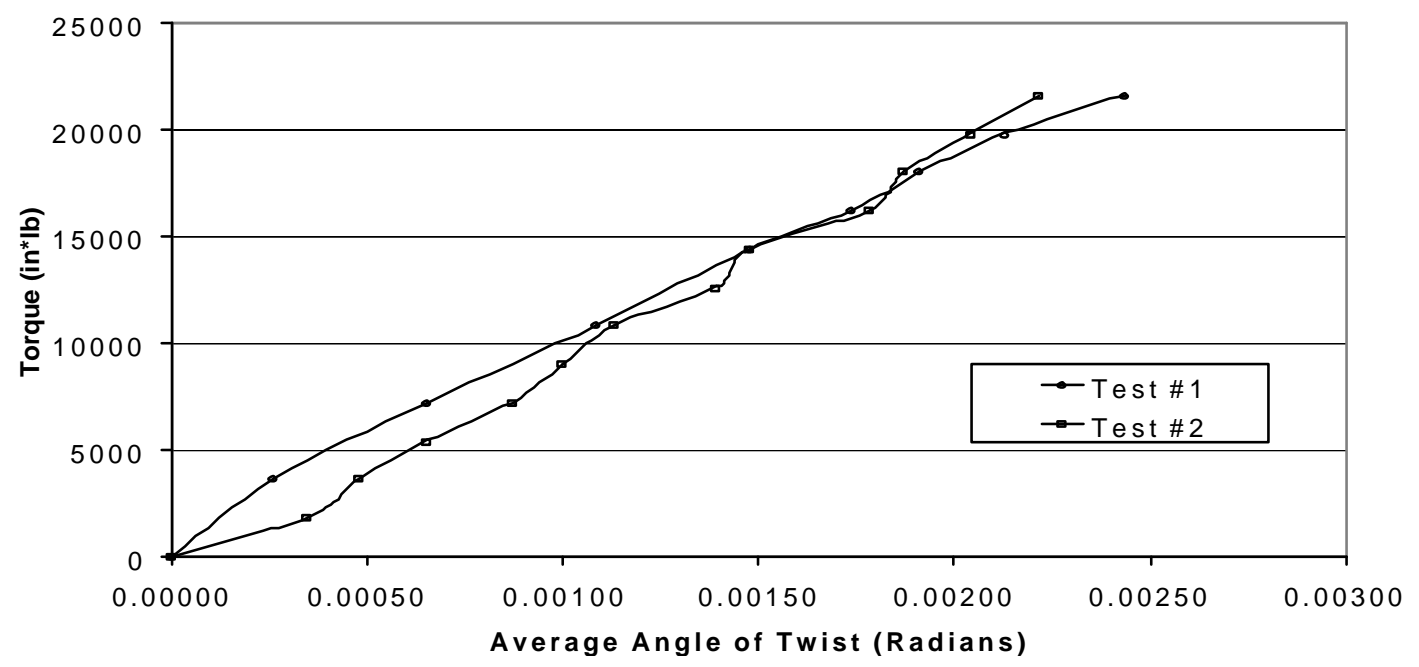

Figure 3.5-Torque v/s Average Angle of Twist (Polyester Component)

It should be noted that the values shown in Figure 3.5 have been zeroed relative to the actual test data. Slippage occurred during the initial loading of the specimen so the load where the slippage stopped was taken as the zero value. This is justified since the test is only measuring a relative value. The load that was taken as the zero value was $1800 \mathrm{lb}$ in both cases. The actual test data along with the adjusted values obtained can be seen in Table C1 of Appendix C. Using equation (3.4) and a gage length of 73", the following values were obtained.

$$
\begin{aligned}
& K_{y z(\text { Test } \# 1)}=6.81\left(10^{8}\right) \mathrm{lb} * \mathrm{in}^{2} \\
& K_{y z(\text { Test } \#)}=6.87\left(10^{8}\right) \mathrm{lb}^{2} \text { in }^{2}
\end{aligned}
$$

The polar moment of inertia was calculated as per equation 3.5 to determine the shear modulus in torsion. It should be noted that the method used in this work is only truly valid for circular homogenous and isotropic sections, of which this section is neither. Therefore, the calculation of the polar moment of inertia is an 
approximation. More detailed work has been performed with regards to composite behavior in torsion by authors such as Tsai (1990).

$$
\mathrm{J}=\mathrm{I}_{\mathrm{Y}}+\mathrm{I}_{Z}
$$

Where,

$\mathrm{J}=$ polar moment of inertia of the cross - section

$\mathrm{I}_{\mathrm{Y}}=$ moment of inertia about the $\mathrm{Y}$ - axis

$\mathrm{I}_{\mathrm{Z}}=$ moment of inertia about the $\mathrm{Z}$ - axis

And,

$$
K_{y z(i)}=\mathrm{G}_{\mathrm{yz}(\mathrm{i})} \mathbf{J}
$$

Where,

$G_{y z(i)}=$ out-of-plane shear modulus of test (i)

Using equations (3.5) and (3.6),

$$
\begin{gathered}
J=300 \mathrm{in}^{4}+990 \mathrm{in}^{4}=1290 \mathrm{in}^{4} \\
G_{y z(\text { Test } \# 1)}=0.528\left(10^{6}\right) \mathrm{psi} \\
\mathrm{G}_{\mathrm{yz}(\text { Test } \# 2)}=0.532\left(10^{6}\right) \mathrm{psi}
\end{gathered}
$$

These values are in close correlation to one another and are the same if rounded to two decimal places. As a result, the out-of plane shear modulus was found to be:

$$
\mathrm{G}_{\mathrm{yz}}=0.53\left(10^{6}\right) \text { psi. }
$$

It should be noted that the shear modulus $\left(\mathrm{G}_{\mathrm{yz}}\right)$ stated above is a conservative value. The influence of warping and secondary torsion was neglected in the calculations. As a result, the polar moment of inertia $(J)$ is conservative since the action of warping and secondary torsion lead to distortions causing the effectiveness 
of the shape to decrease. When a non-circular shape such as the one being investigated is subjected to torsion, three types of stresses generally result (Hotchkiss 1966). These stresses are: 1) torsional shear stresses, 2) torsional warping stresses, and 3) longitudinal torsional stresses. The calculations performed above assumed only torsional shear stress was present since decoupling the different phenomena, especially the distortion, is very difficult (Mentrasti 1990).

A theoretical comparison of $\mathrm{G}_{\mathrm{yz}}$ was made using a combination of micro mechanics and approximate classical lamination theory (ACLT). The calculations can be seen in Appendix B. The results of the theoretical approach yielded $\mathrm{G}_{\mathrm{yz}}=0.90$ $\left(10^{6}\right)$ psi. The difference in the two values was approximately $40 \%$, which supports the previous statements about the effects of warping and secondary torsion.

\subsubsection{Torsion and Bending}

The results of the torsion and bending tests showed the bending stiffness remained in the same order of magnitude as the results from the pure bending tests (see 4.5.1). Figure 3.6 shows the plots of load versus strain for gage \#1 (as seen in Figure 3.1) for the various torques.

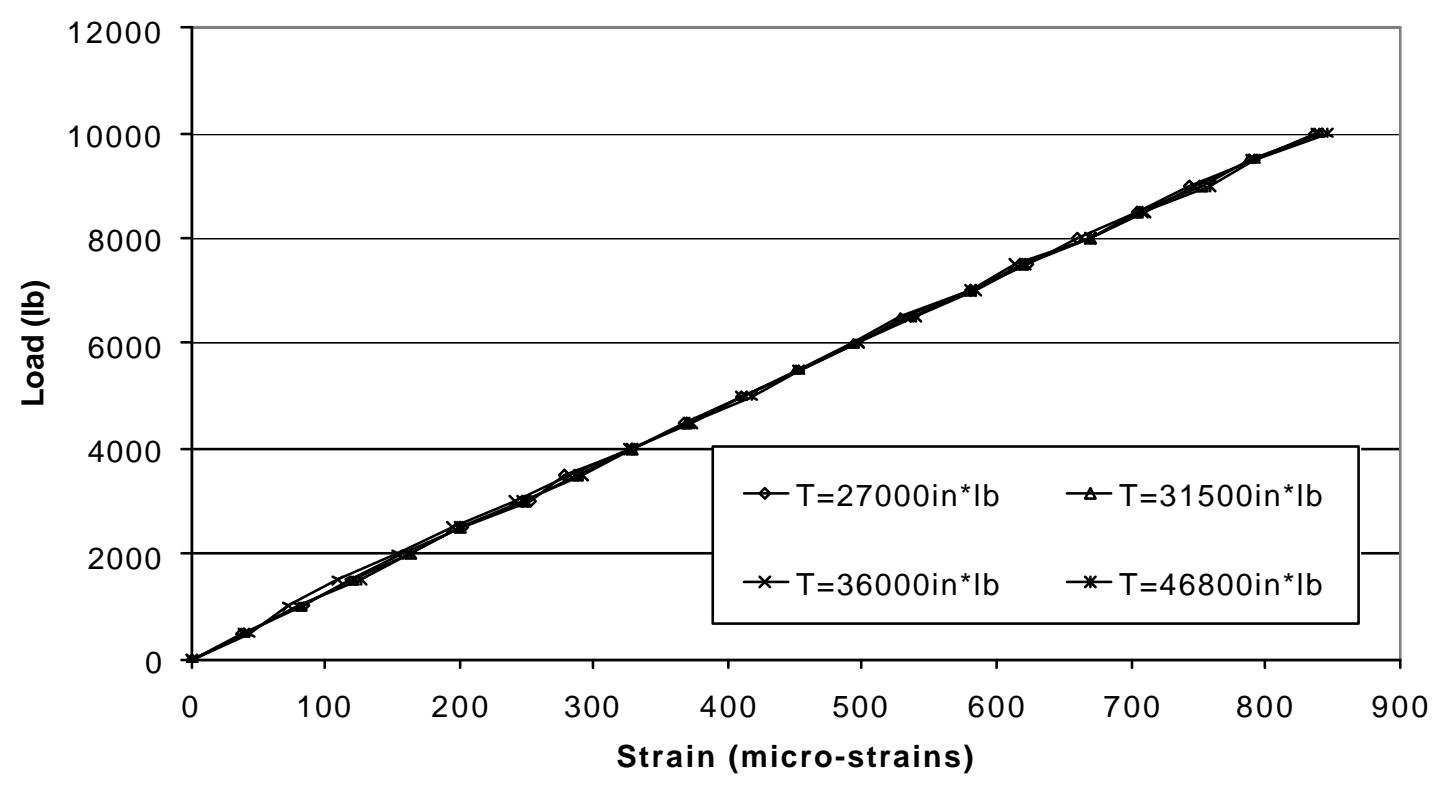

Figure 3.6 - Load v/s Strain (Torsion and Bending)-Polyester Component 
The bending stiffness (EI) was computed utilizing Hooke's Law and the flexure formula. For these calculations, plane sections were assumed to remain plane before and during loading such that:

$$
\begin{gathered}
\sigma=E \varepsilon=\frac{M c}{I} \\
M \approx \frac{P L}{6} \\
E I=\left(\frac{\Delta P}{\Delta \varepsilon}\right)\left(\frac{L c}{6}\right)
\end{gathered}
$$

Where,

$\sigma=$ normal stress

$E=$ modulus of elasticity

$\left(\frac{\Delta P}{\Delta \varepsilon}\right)=$ slope of load v/s strain curve

$L=$ clear $\operatorname{span}(104 ")$

$c=$ distance from the section centroid to the outermost fiber (4")

$M=$ centerline moment

The value of the moment $(\mathrm{M})$ was arrived at due to the end conditions. A factor of (1/4) would be used for simply supported end conditions, whereas (1/8) would be used for fixed end conditions. The end conditions of this test were taken as the average of these two cases since the true behavior could not be determined. Figure 3.6 clearly shows that the magnitude of torque applied during the experiment had very little, if any, effect on the bending stiffness at the maximum moment section of the member. However, comparing the values obtained from these tests with those of section 4.5.1 is impractical since the true end conditions are unknown. The fact that the results are of the same order of magnitude as those from section 4.5.1 is as accurate a conclusion as can be made. The average bending stiffness was computed and can be seen below. This value was computed with a partially fixed end condition, which was assumed for our computational purposes.

$$
\mathrm{EI} \approx 0.9\left(10^{9}\right) \mathrm{lb} * \mathrm{in}^{2}
$$




\subsection{Web Buckling}

Web buckling tests were conducted on 12" wide sections to determine the ultimate load and failure modes to be expected from the current designs. Both the polyester component (shown in Figures B2 and B4) and the vinyl ester component (shown in Figures B3 and B5) were tested to determine the integrity of the webs with respect to buckling. From this data, information pertaining to the local stability of the shapes was determined. Also, the experimental data was examined in conjunction with the Euler buckling formula to determine the correlation between the two. It should be noted hat the failure analysis of this section is limited to the criteria listed in section 5.1. These criteria describe the overall applicability and limits of the methods being discussed.

\subsubsection{Test Set-Up and Procedure}

Elastomeric padding was placed at the top and bottom of the specimen to ensure even load distribution across the closed portion of the width. A 10"x 20 " steel plate was placed at the top of the specimen to ensure pure compression was achieved throughout. Figure 3.7 shows the actual test set-up. The test was performed by applying load at a constant rate of $1,000 \mathrm{lb} / \mathrm{min}$ until failure occurred.

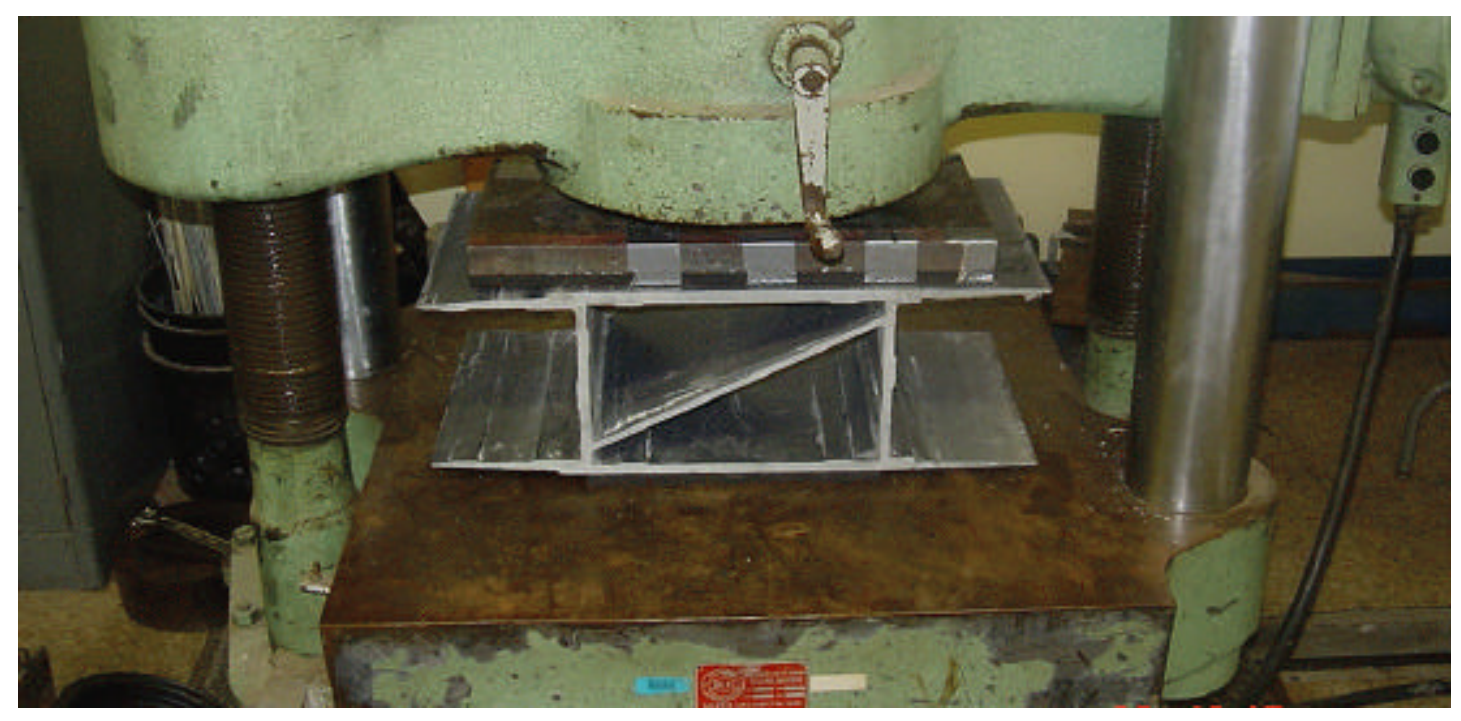

Figure 3.7-Test Set-Up for Web Buckling Specimens 


\subsubsection{Test Results}

A total of five specimens were tested for web buckling. Three were made from a polyester resin (see Figures B2 and B4), while two were made of a vinyl ester resin (See Figures B3 and B5). Table 3.1 contains the results of the testing of these five specimens. See Figure 3.8 for definition of webs, and Figure 3.9 and Figure 3.10 for the failure modes. Note that Figure 3.9 is representative of all three polyester failure modes, while Figure 3.10 is representative of both vinyl ester failure modes. It should be noted that the vinyl ester specimens actually experienced joint failure, but it was induced by buckling. As the specimen was loaded the vertical webs began to buckle inducing secondary moments onto the joint causing failure. Therefore, buckling of the web was again the cause of failure.

\begin{tabular}{|c|c|c|}
\hline Specimen & Ult. Load (k) & Description of Failure Mode \\
\hline Polyester \#1 & 45 & Buckling of web \#1 at midpoint of unbraced length \\
\hline Polyester \#2 $^{*}$ & 44 & Buckling of web \#2 at midpoint of unbraced length \\
\hline Polyester \#3 & 51 & Buckling of web \#1 at midpoint of unbraced length \\
\hline Vinyl Ester \#1 & 48 & Failure at joint connecting web \#1 and diagonal \\
\hline Vinyl Ester \#2 & 55 & Failure at joint connecting web \#1 and diagonal \\
\hline
\end{tabular}

* 0.5 "x 2" steel plates attached to each side of web \#1 at midpoint of unbraced length

** One $0.5 " \mathrm{x} 2$ " steel plate attached to each web at midpoint of unbraced length

Table 3.1-Results of Web Buckling Tests

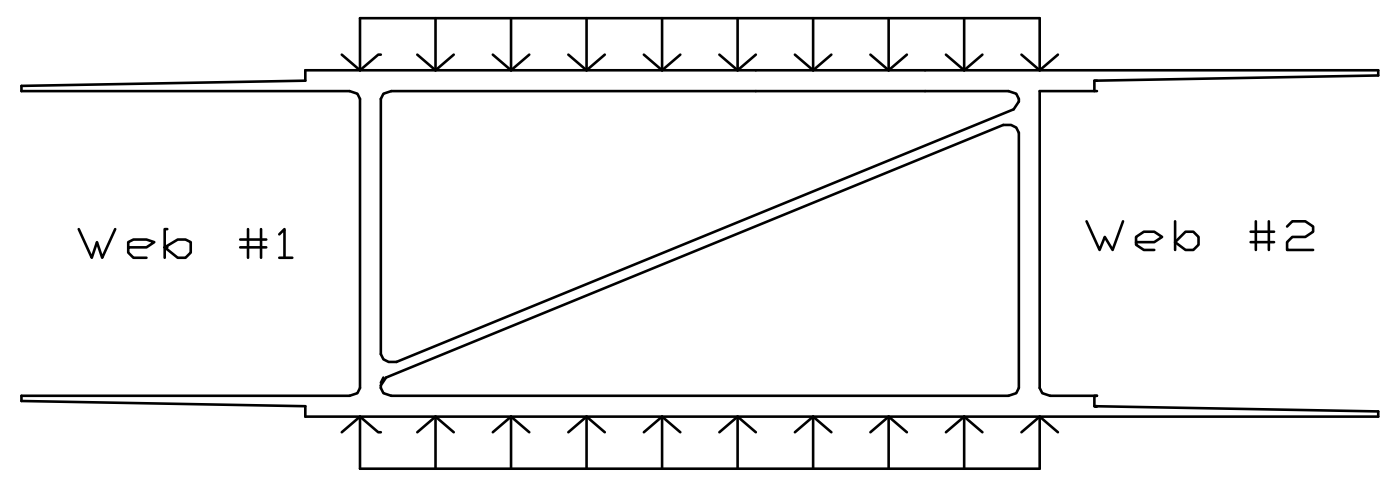

Figure 3.8-Definition of Webs for Buckling Tests 


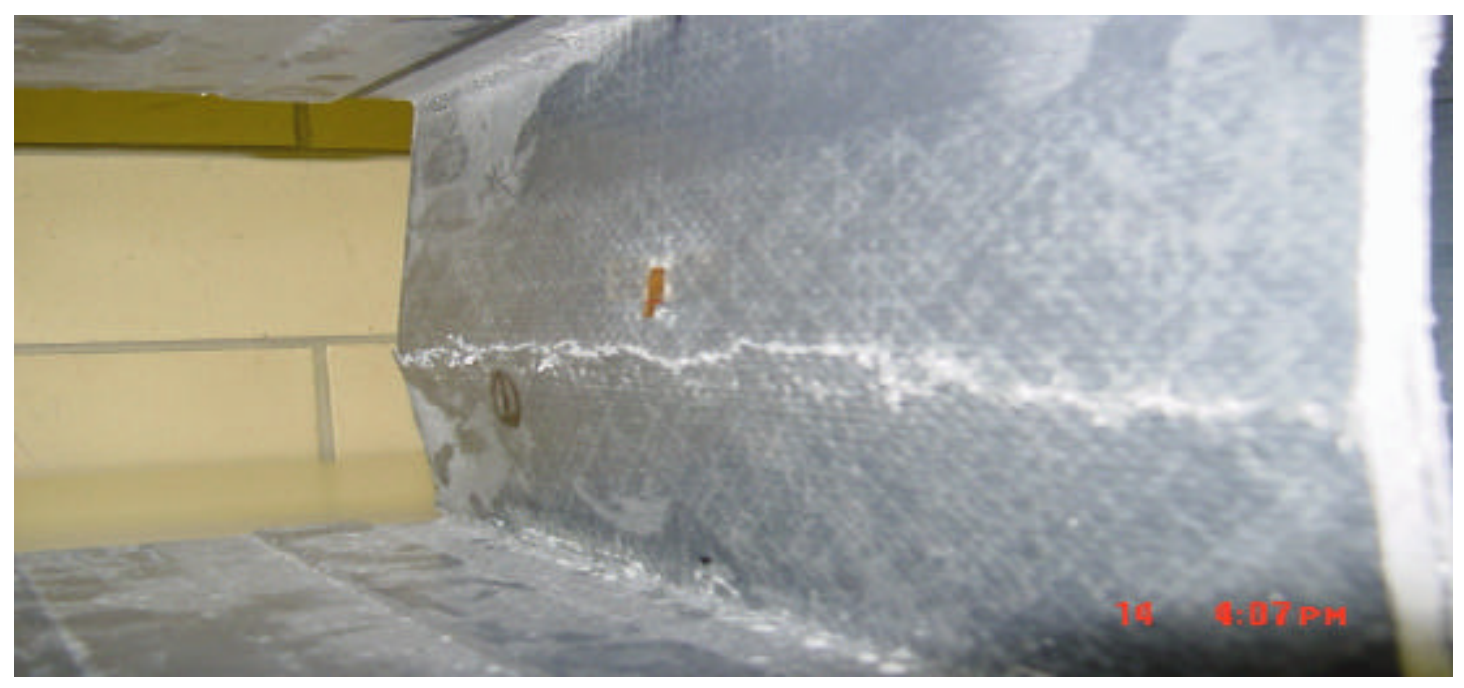

Figure 3.9-Failure Mode of Polyester Web Buckling Specimens

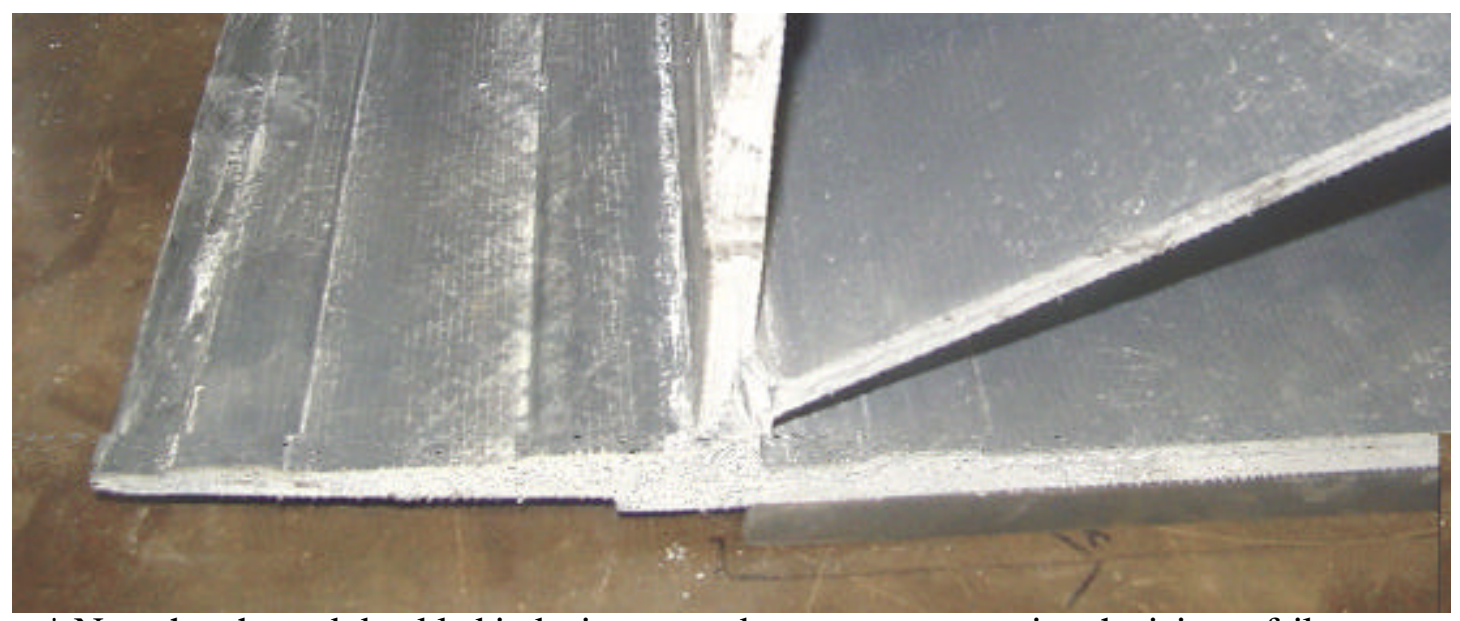

* Note that the web buckled inducing secondary moments causing the joint to fail

Figure 3.10-Failure Mode of Vinyl Ester Web Buckling Specimens

The results of the web buckling tests showed the vinyl ester specimens out performed the polyester specimens in both ultimate load and failure mode. The ultimate load of the vinyl ester specimens was higher and less catastrophic. It was also discovered that the addition of extra bracing to only one of the vertical webs of the polyester specimen did not increase the ultimate load. It merely shifted the failure to the other web. Since the section is symmetrical with respect to the webs (while in pure compression) the result was expected. It does, though, show that the section is behaving in a symmetrical manner with respect to local stability. On the other hand, the addition of 2 "deep steel stiffeners at the center of the unbraced length of both 
vertical webs increased the ultimate load of the polyester specimens by approximately $15 \%$.

\subsubsection{Incorporation of Results into the Euler Buckling Formula}

To analyze the web for buckling, the effective unbraced length of the vertical webs (KL) must be known. The coefficient (K) describes the joint behavior of the component in that it tells the degree of fixation caused by the joints. If both ends of the web are perfectly fixed, $(\mathrm{K})$ is equal to 0.5 . If both ends of the web are not fixed at all, $(\mathrm{K})$ is equal to 1.0. The purpose of this section is to determine the coefficient (K) based on experimental ultimate loads. The Euler buckling formula seen below is used to describe the buckling behavior of the webs (Boresi et.al. 1993). Again, this method is subject to the limitations of section 5.1

$$
P_{c r}=\frac{p^{2} E_{y} I}{(K L)^{2}}
$$

Where,

$\mathrm{P}_{\mathrm{cr}}=$ load necessary to induce buckling

$\mathrm{E}_{\mathrm{y}}=$ modulus of elasticity (See 4.5.3)

$\mathrm{I}=$ moment of inertia of web $\left(0.0429 \mathrm{in}^{4}\right)$

$\mathrm{L}=$ unbraced length of web (6.25 in)

$\mathrm{K}=$ effective length factor

Utilizing the data in Table 3.1, the average effective length factor was found to be

$(\mathrm{K}=0.7)$. The two specimens with steel plates attached to them were not used to determine the effective length factor. An effective length of 0.7 indicates partial fixity of the joints with respect to axial loading.

\subsection{Web Load Distribution}

The FRP bridge deck components being investigated in this study were not symmetrical. They contained a diagonal stiffener that could be oriented in different 
ways. The focus of this section was to determine the best orientation of these diagonals in the center portion of a deck module, or group of components.

\subsubsection{Test Set-Up and Procedure}

Figures 3.11 and 3.12 show the two possible orientations being investigated as well as the instrumentation for each. These two were the only combinations studied since they allow for the greatest degree of symmetry to be maintained throughout the remaining components.

The polyester components (see Figures B2 and B4) being studied were 12" wide, and the clear span was 39". Wooden blocks were placed at the supports to prevent shear failure. The load was applied at a constant rate of $500 \mathrm{lb} / \mathrm{min}$ with deflection and strain data taken at constant intervals. The strain gages were attached according to (M-LINE ACCESSORIES 1979).

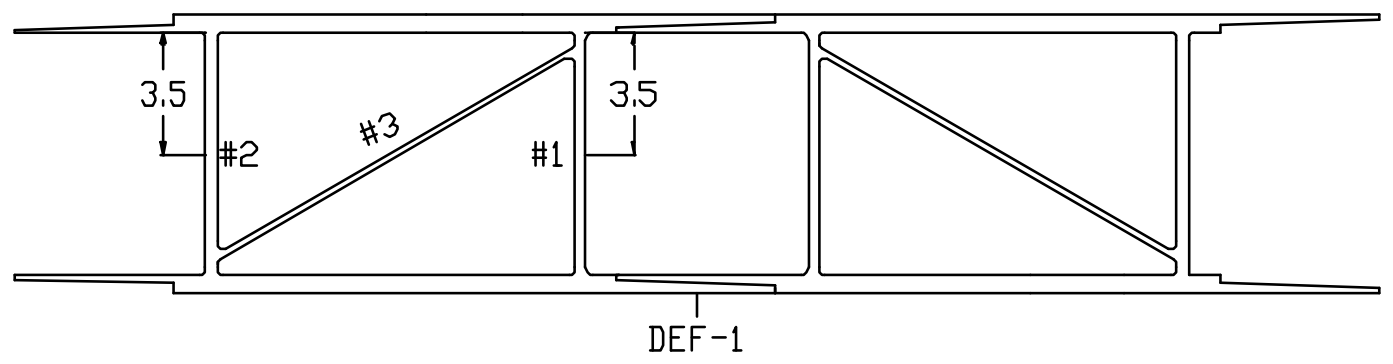

Figure 3.11-Web Load Distribution Orientation \#1 (Polyester Component)

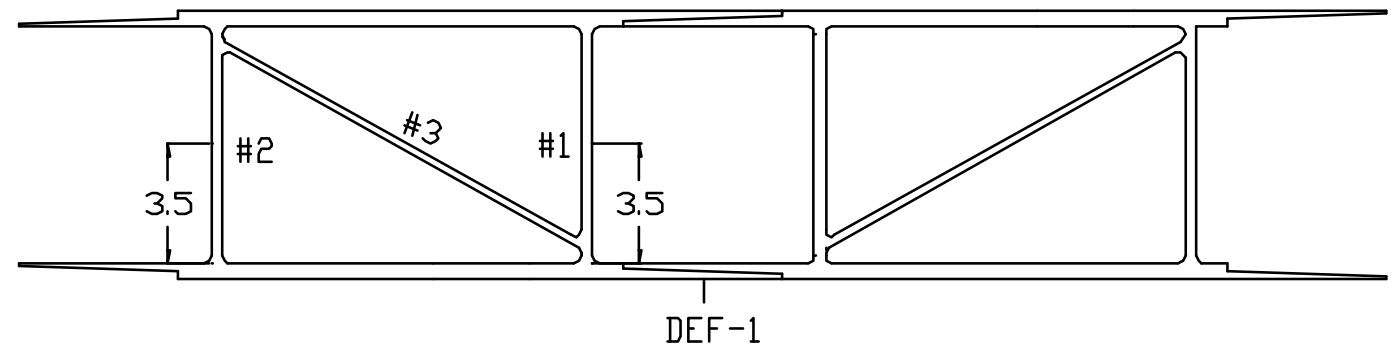

Figure 3.12-Web Load Distribution Orientation \#2 (Polyester Component) 


\subsubsection{Test Results}

The testing performed indicated that orientation \#1 was better than orientation \#2. The strain was more evenly distributed throughout the web. In orientation \#2, the vertical portions of the web were strained greater than in orientation \#1. Similarly, the maximum deflection experienced by orientation \#1 was less than that of orientation \#2. Also, the diagonal stiffener was strained greater in orientation \#1. The additional strain in the diagonal stiffener is also evidence that the first orientation is better. The stiffener is transferring force away from the loaded area of the specimen, which is very important with respect to local force transfer. The maximum deflection and strain values recorded can be seen in Table 3.2, and the data set can be seen in its entirety in Table C3 of Appendix C.

\begin{tabular}{|c|c|c|c|c|}
\hline \multicolumn{4}{|c|}{ Values Due to a 3000 lb Point Load at the Component Centerline } \\
\hline \multirow{2}{*}{ Orientation } & $\begin{array}{c}\text { Deflection } \\
\text { (milli-inches) }\end{array}$ & $\# 1$ & $\# 2$ & $\# 3$ \\
\cline { 3 - 5 } & 230 & 432 & 1221 & 933 \\
\hline$\# 1$ & 300 & 800 & 1885 & 779 \\
\hline$\# 2$ & & & & \multicolumn{3}{|c|}{ Strain (micro-strains) } \\
\hline
\end{tabular}

Table 3.2-Maximum Deflections and Strains for Web Load Distribution

\subsection{Conclusions}

\section{$\underline{\text { Torsion }}$}

- A very precise set-up is needed to arrive at accurate results.

- Bolts torqued to finger tightness plus $1 / 4$ turn beyond finger tightness in conjunction with bar clamps tightened to their maximum capacity allow for specimens wider than 18 " to be tested in torsion in the frame mentioned previously in the chapter.

- The average torsional stiffness $\left(\mathrm{K}_{\mathrm{yz}}\right)$ was found to be $6.84\left(10^{8}\right) \mathrm{lb}^{*} \mathrm{in}^{2}$. This value was found neglecting the effects of warping and secondary torsion. 
- The average out-of-plane shear modulus $\left(\mathrm{G}_{\mathrm{yz}}\right)$ was found to be $0.53\left(10^{6}\right)$ psi. The effects of warping and secondary torsion were again neglected in the computations.

- Theoretical analysis using a combination of micro mechanics and approximate classical lamination theory yielded $\mathrm{G}_{\mathrm{yz}}=0.9\left(10^{6}\right)$ psi. This was approximately $40 \%$ higher than the experimental value confirming suspicions of warping and secondary torsion effects.

\section{$\underline{\text { Torsion and Bending }}$}

- The magnitude of the applied torque had very little, if any, effect on the bending stiffness of the component.

- Due to inadequate understanding of the true behavior of the component boundary conditions, an accurate bending stiffness in conjunction with torsion could not be obtained. The bending stiffness reported in section 3.2.3.2 was arrived at assuming the behavior of the support boundaries. Therefore, stating that the bending stiffness remained on the same order of magnitude (when a torque was applied) as the results from section 4.5 .1 is as close a comparison as can practically be made.

\section{Buckling}

- The web is adequate to resist local buckling loads.

- Failure of the specimens occurred between 44-55 kips.

- Failure modes were web buckling at the center of the unbraced length for polyester specimens and joint failure induced by web buckling and secondary moments of the vinyl ester specimens.

- The vinyl ester specimens out performed the polyester specimens in that they had higher ultimate loads under the same conditions, and their failure mode was less catastrophic.

- The addition of steel bracing to only one vertical web did not increase the ultimate load of the polyester specimens, but the addition of steel bracing to both vertical webs increased the ultimate load by approximately $15 \%$. 
- The specimen behaved in a symmetrical manner under the pure compression of the buckling experiments.

- The effective length factor was found to be $(\mathrm{K}=0.7)$ which shows the joints are acting as partially fixed supports with respect to axial loading.

\section{$\underline{\text { Web Load Distribution }}$}

- The orientation shown in Figure 3.11 was the best choice to evenly distribute load throughout the web and allow for the highest degree of symmetry to be maintained throughout the bridge deck module. Note that a module is a group of components connected together. 


\section{CHAPTER 4 \\ TESTING AND EVALUATION OF FRP COMPONENTS UNDER BENDING}

\subsection{Introduction}

Strength and stiffness of FRP bridge deck components are of great importance in the performance of bridges utilizing composite technology. Adequate strength is necessary to prevent deck failures while adequate stiffness is necessary to prevent excessive deflection leading to problems such as wearing surface cracking and warping of the exterior steel stringers. This chapter presents experimental Young's Moduli in both longitudinal and transverse directions of a bridge deck. Also, failure modes and failure strengths of longitudinal deck components with different size patch loads are discussed. Furthermore, one of the longitudinal components was rehabilitated and tested for both elastic and failure properties and the results of the testing are presented and discussed.

From a theoretical standpoint, the stiffness properties of an individual lamina making up a composite were calculated utilizing micro/macro mechanics and the rules of mixture (See Appendix A). Making use of these properties, the stiffness was calculated by the approximate classical lamination theory (ACLT) approach (See Appendix B).

Failure properties of the components are also presented in this chapter. The results of these experiments are then used in Chapter 5 in order to attempt to quantify them in terms of section and material properties at the component level. It should be noted that the ultimate strain of a component can be less than half that of a coupon. Reasons include shape factors, stress concentrations, and shear lag. As a result, strain data at the component level is necessary for component failure computations. For this reason, the data obtained in this chapter with respect to failure is necessary for the computations of Chapter 5.

The scope of the testing given in this chapter can be divided into three major sections as follows: 
1) Testing of longitudinal components that have not been previously tested. This testing was labeled "Longitudinal Components".

2) Re-testing of one of the longitudinal components mentioned in 1) that was taken to failure. The re-testing of the component was labeled "Rehabilitated Longitudinal Component".

3) Testing of 12" wide components connected together to simulate a transverse component. This testing was labeled "Transverse Testing".

\subsection{Component Preparation}

\subsubsection{Longitudinal Components}

No preparation measures were necessary for the longitudinal components.

They were to be tested with no modifications.

\subsubsection{Rehabilitated Longitudinal Component}

The component chosen for rehabilitation was Polyester \#1. This component underwent a punching shear failure (See Figure 4.12) in which the area around the patch load was severely damaged. The exterior lap joints used to connect two contiguous modulus were damaged beyond repair. Immediately after the punching shear failure, the lap joints buckled in the longitudinal direction causing them to delaminate in the central portion of the component. As a result, they were removed with the aid of a circular saw. See Figure 4.1 for a description of the removal of the exterior lap joints.
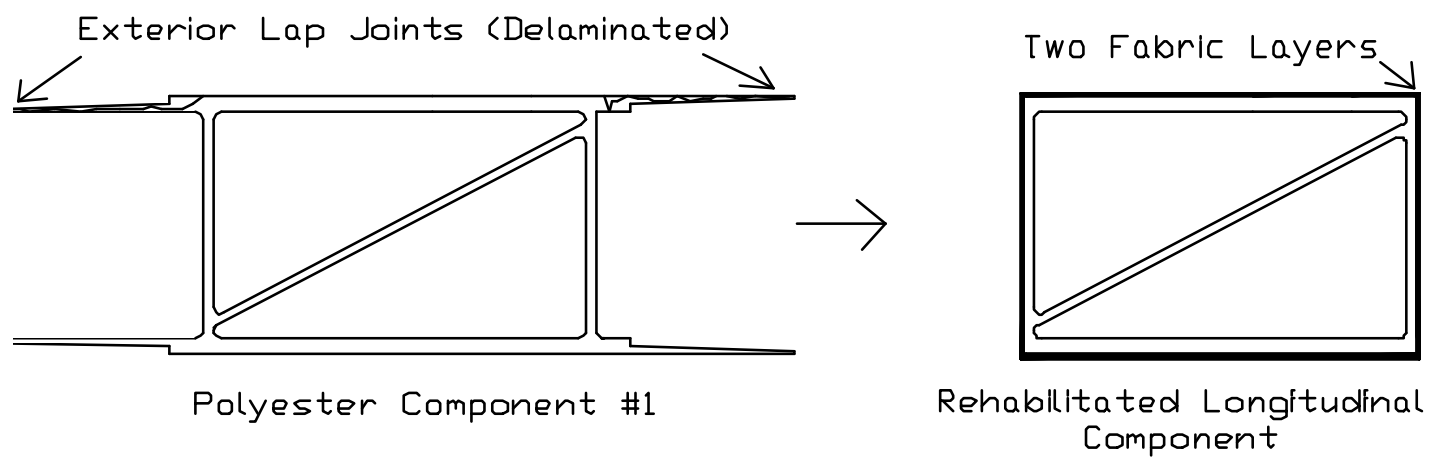

Centerliene Views

Figure 4.1-Work Plan for Rehabilitated Longitudinal Component 
The punching shear failure yielded visible damage to the component approximately 24" along its span. Two layers of $26 \mathrm{oz} / \mathrm{yd}^{2}$ E-glass fabric were wrapped around the specimen as shown in Figure 4.1 and placed 30" along the span to strengthen the locally weak area where the first failure took place. The fabric was placed by first sanding the area with 40-grit sandpaper, and removing the excess dust. The sanded area was then cleaned with acetone and left to sit undisturbed for twenty minutes before vacuuming the residue. MBRACE primer (parts a and b) was then applied to the cleaned area and allowed to cure for 24 hours. The component was then wrapped with two layers of $26 \mathrm{oz} / \mathrm{yd}^{2}$ glass fabrics.

The fabrics were thoroughly soaked by slowly pulling them through an MBRACE saturant (parts a and b) blue epoxy resin bath as they were being placed around the component. The fabrics were pulled through the bath (below the component) and wrapped by tightly pressing one face of the component before moving to the next. The pressing of the fabric to remove excess resin and air voids was performed using rollers. Finally, the rehabilitated component was allowed to cure for seven days before testing again.

\subsubsection{Transverse Component}

Three 12" wide sections were joined together using PLIOGRIP ${ }^{\circledR}-7779 / 300$. The joints were then overlaid with two layers of $26 \mathrm{oz} / \mathrm{yd}^{2}$ E-glass fabric. The fabric was placed by first sanding the area with 40-grit sandpaper, and removing the excess dust. The sanded area was then cleaned with acetone and left to sit undisturbed for twenty minutes before vacuuming the residue. MBRACE primer (parts a and b) was then applied to the cleaned area and allowed to cure for 24-hours. The fabrics were thoroughly soaked in MBRACE saturant (parts a and b), blue epoxy resin, before application to the joints. Once the fabrics were placed onto the joints, most of the excess resin and air voids were removed by the use of rollers. The component was then allowed to cure for seven days before testing. The glass fabric layer bonded directly to the component was 6" wide, with an additional layer of overlay being only 4" wide. 


\subsection{Test Set-Ups}

\subsubsection{Longitudinal Components}

All four components tested were placed on rigid supports and were under simply supported conditions. Also, wooden blocks were placed at the supports to prevent crushing of the specimen end. In addition, 24" web bracing was placed at the center portion of the span to mimic actual field conditions. The exterior lap joints of the component act in a more composite sense when placed side by side in a bridge deck, and the addition of the wooden bracing better achieves this effect versus testing without bracing. Furthermore, Table 4.1 shows the clear spans and patch loads that were used for each of the four tests. Figure 4.2 shows the actual test set-up, and Figures 4.3 through 4.5 show the instrumentation of the components. It should be noted that Figure 4.2 is representative of all the test set-ups with the exception of the variations outlined in Table 4.1.

\begin{tabular}{|c|c|c|}
\hline Component & Patch Load & Clear Span \\
\hline Polyester \#1 & $10 " x 20 "$ & $120 "$ \\
\hline Polyester \#2 & $15 " x 24 "$ & $108^{\prime \prime}$ \\
\hline Vinyl Ester \#1 & $10 " \times 20 "$ & $120 "$ \\
\hline Vinyl Ester \#2 & $15 " x 24 "$ & $120 "$ \\
\hline
\end{tabular}

Table 4.1-Clear Spans and Patch Loads of Longitudinal Components

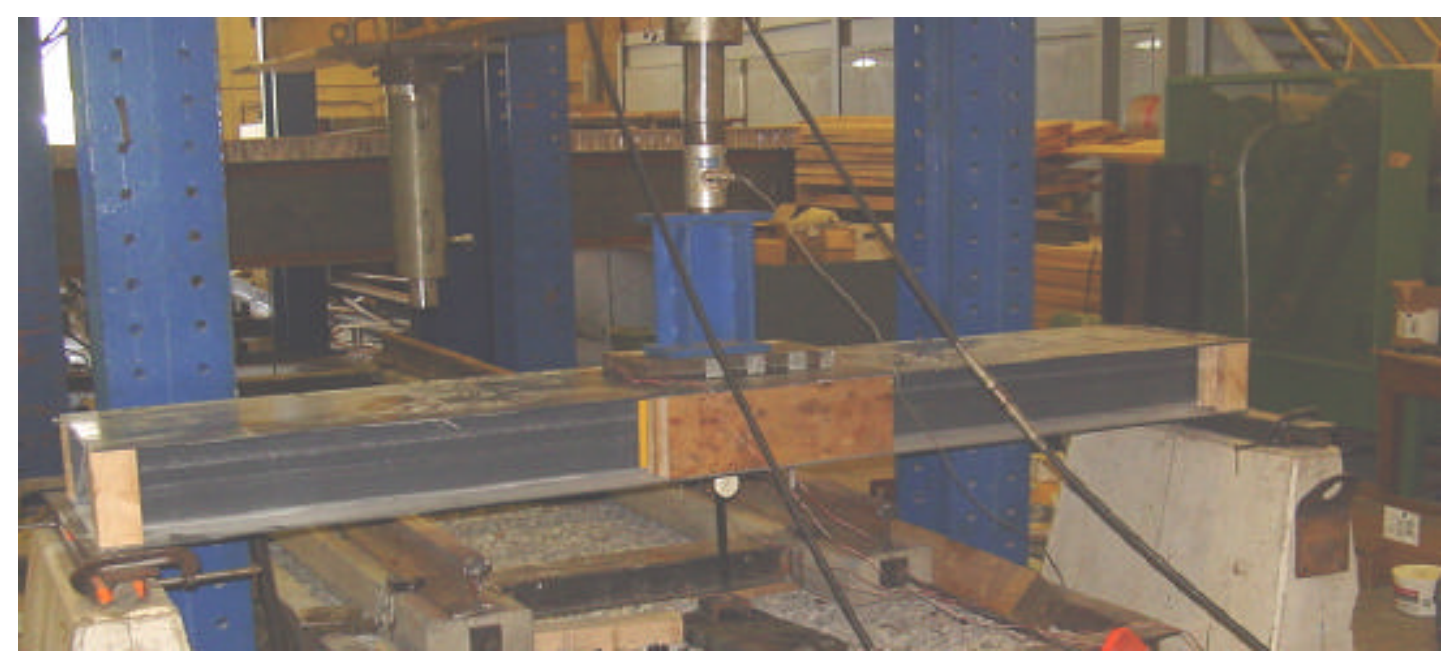

Figure 4.2-Test Set-Up for Longitudinal Experiments 
TIP VIEW

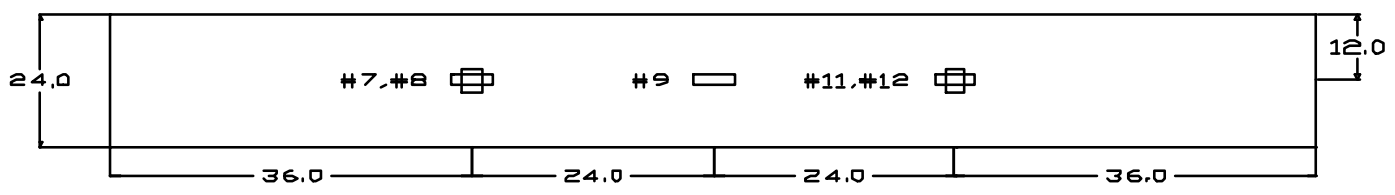

BDTTDM VIEW

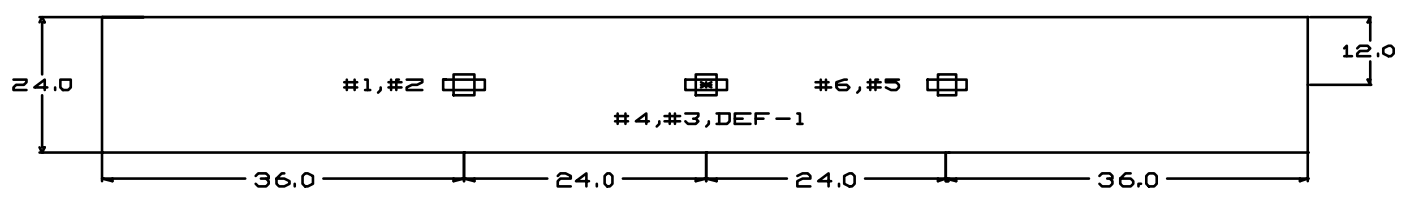

SIDE VIEW

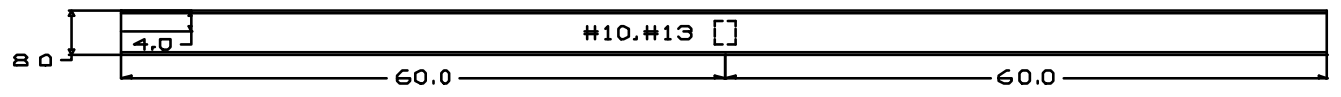

$\square$ Represents a strain sase

\#10 and \#13 are on opposite wels

DEF-1 represents a point of deflection

\#1,\#4,\#6,\#7,\#9,\#12 Measure strain in the 120 direction

All units are in inches-Not to scale

Figure 4.3-Instrumentation of Polyester Component \#1
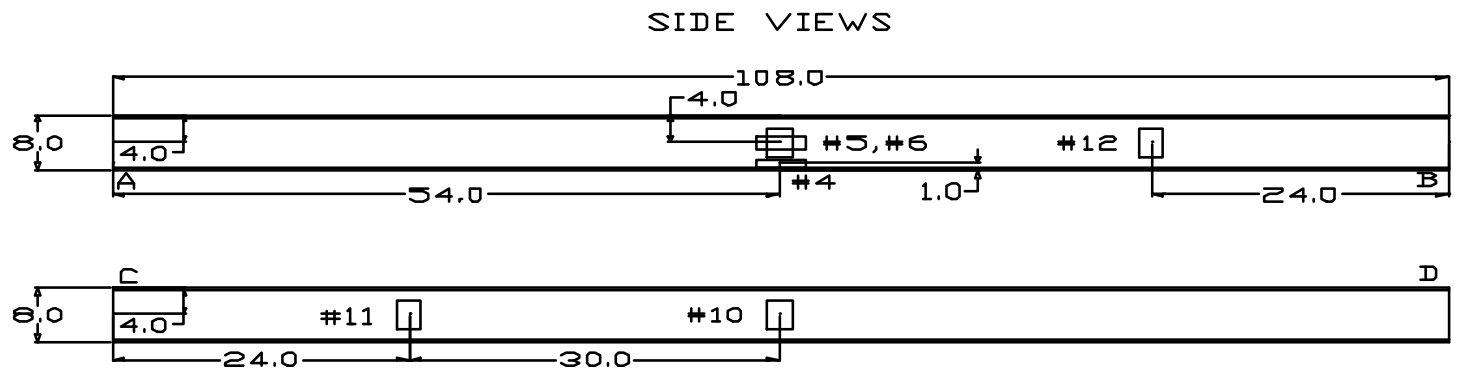

BᄆTTロM VIEW

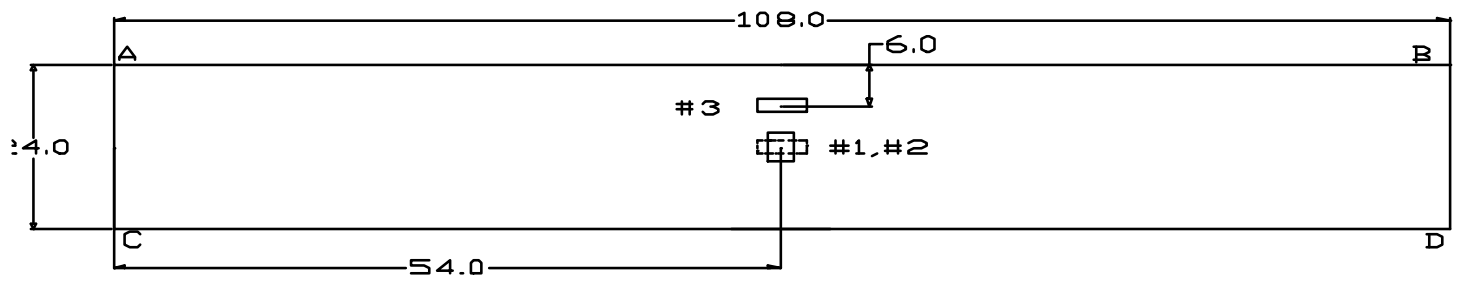

$\square$ Indicates a strain gage

\#8 Aligns with \#1 except it is on the top flange

\#1 and \#5 measure strain i $n$ the 108 inch dinection

Alion letters at the corners to create a $3 D$ image

All units are in inches-Not to scale

Figure 4.4-Instrumentation of Polyester Component \#2 

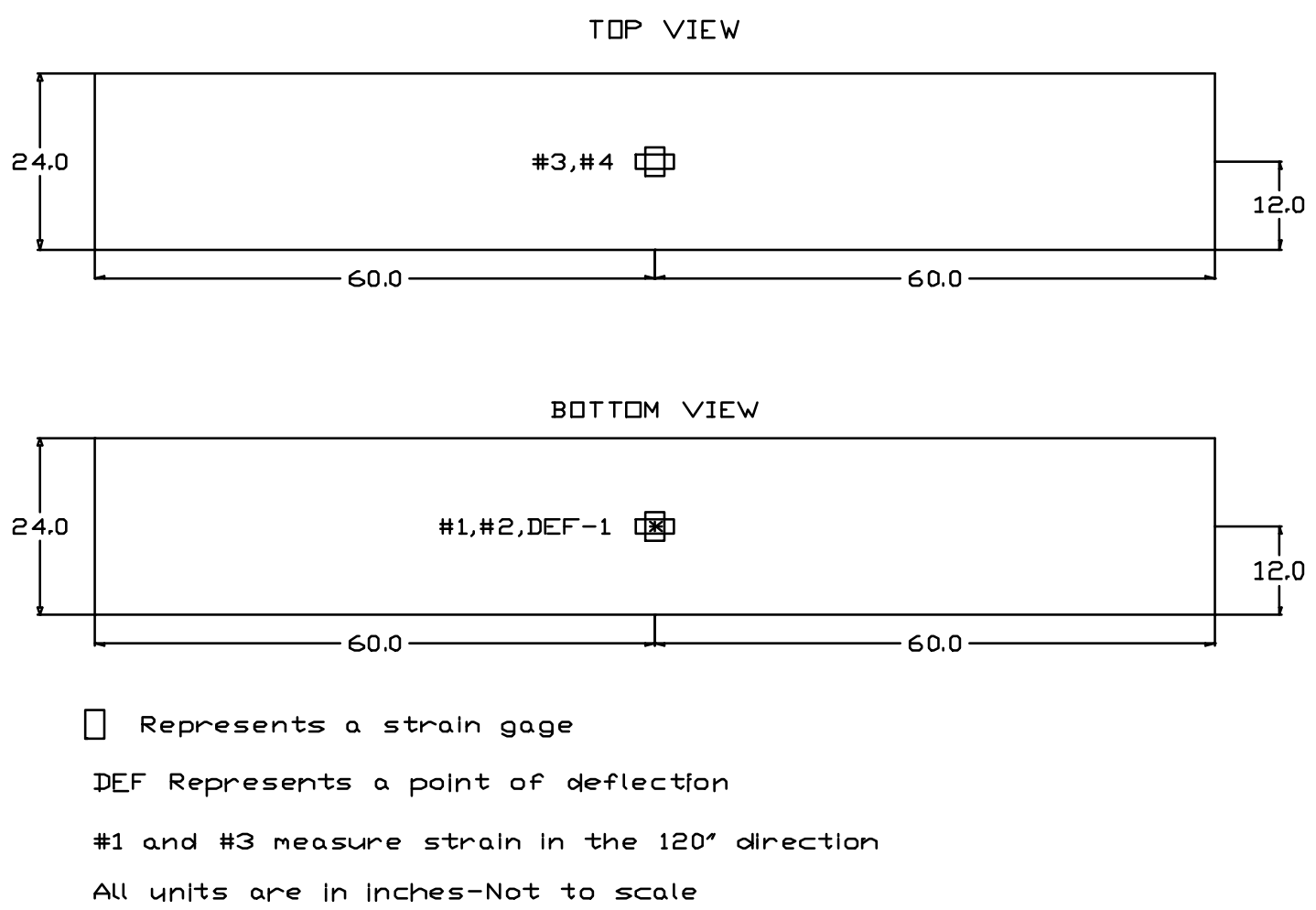

Figure 4.5-Instrumentation of Vinyl Ester Components \#1 and \#2

\subsubsection{Rehabilitated Longitudinal Component}

The testing of the rehabilitated component was performed in two phases. The first was to test the component in the elastic region with three different size patch loads (12"x 24", 6"x 24", and 12"x 12"). These patch loads were applied to the flange that initially experienced the local failure, and then to the opposite flange. The second phase was to again load the flange that experienced the initial failure (flange 1) to a punching shear failure using a 10"x 20" patch load. All testing was performed on a 108" span under simply supported conditions. Figure 4.6 shows the actual test set-up, and Figure 4.7 details the instrumentation used.

\subsubsection{Transverse Component}

Testing of the transverse component both with and without fabric strips over the joints was performed on a 50" span under simply supported conditions. Figure 4.8 shows the test set-up with the two layers of fabric attached. Also, Figure 4.9 provides the locations of the necessary instrumentation to collect the test data. 


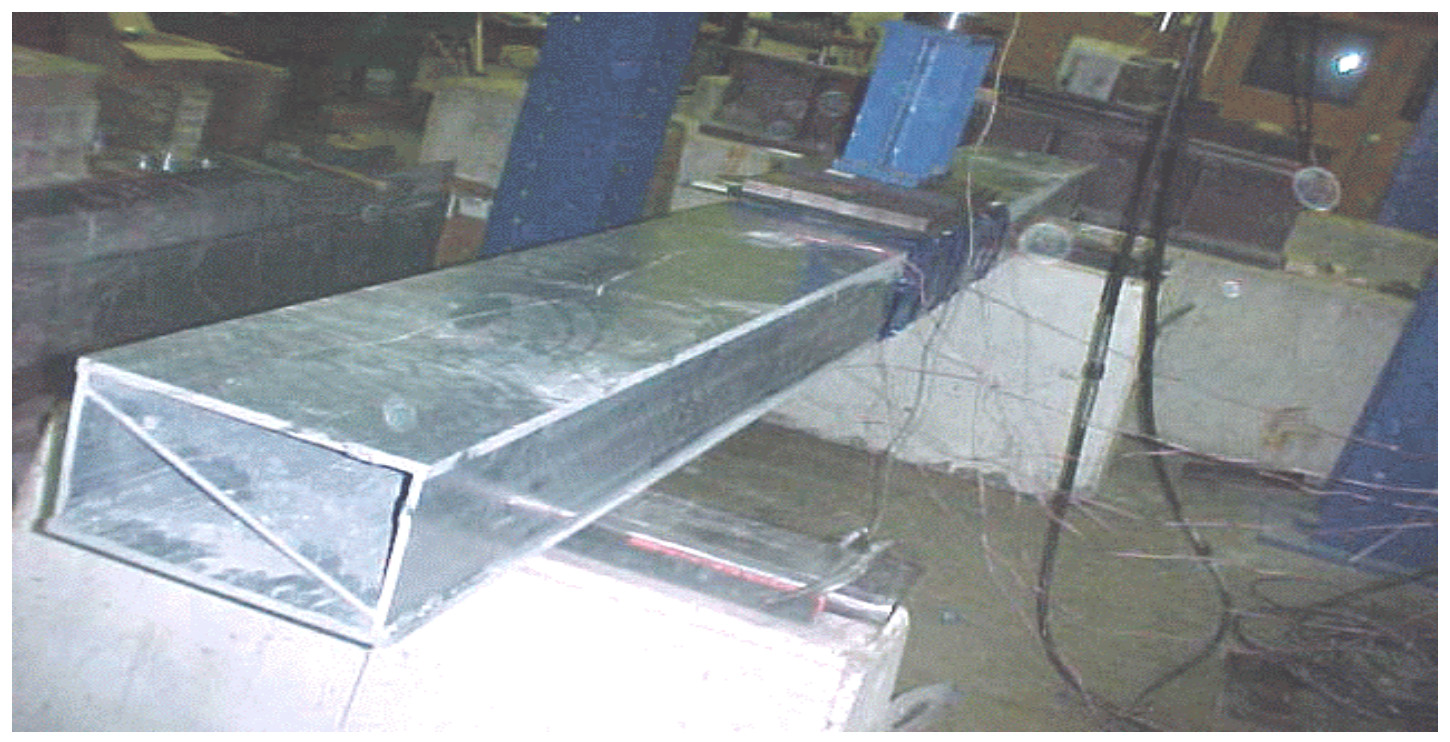

Figure 4.6-Test Set-Up for Rehabilitated Longitudinal Component

FLANGE 1

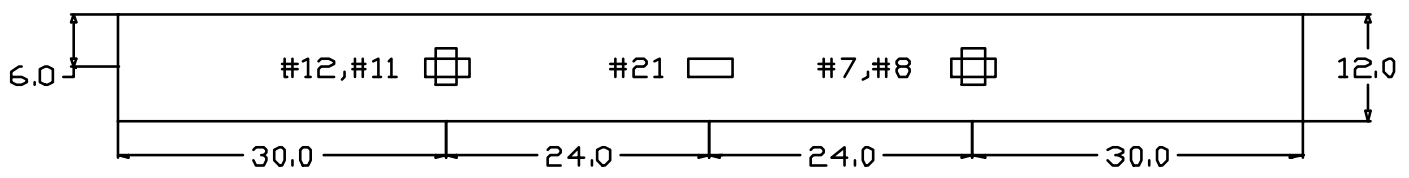

FLANGE 2
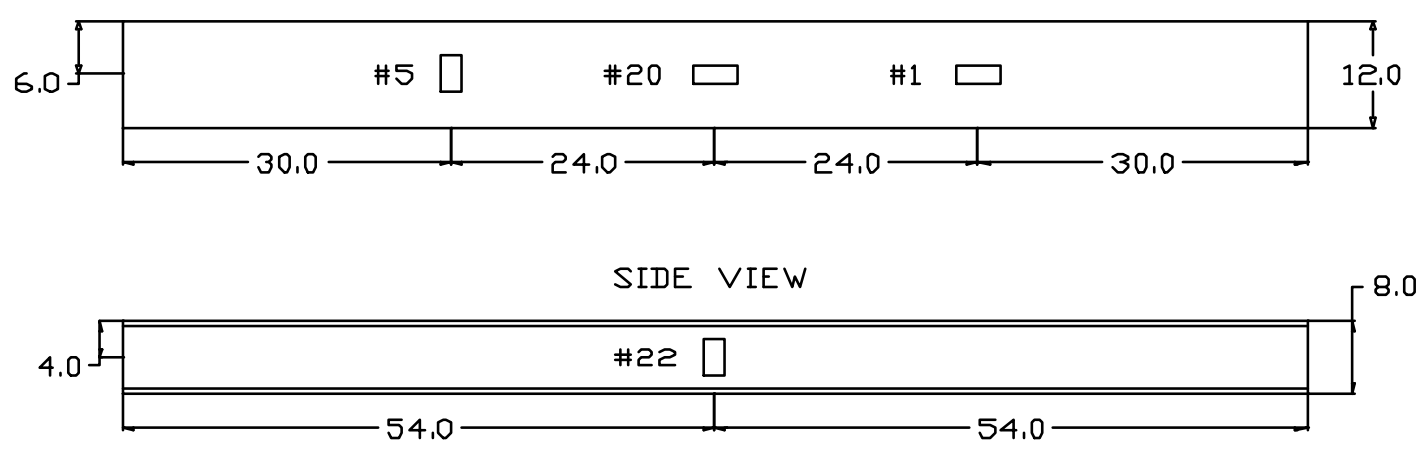

Represents a strain gage

\#11 and \#8 measure strain in the $12^{\prime \prime}$ direction

All units are in inches-Not to scale

Figure 4.7-Instrumentation of Rehabilitated Longitudinal Component 


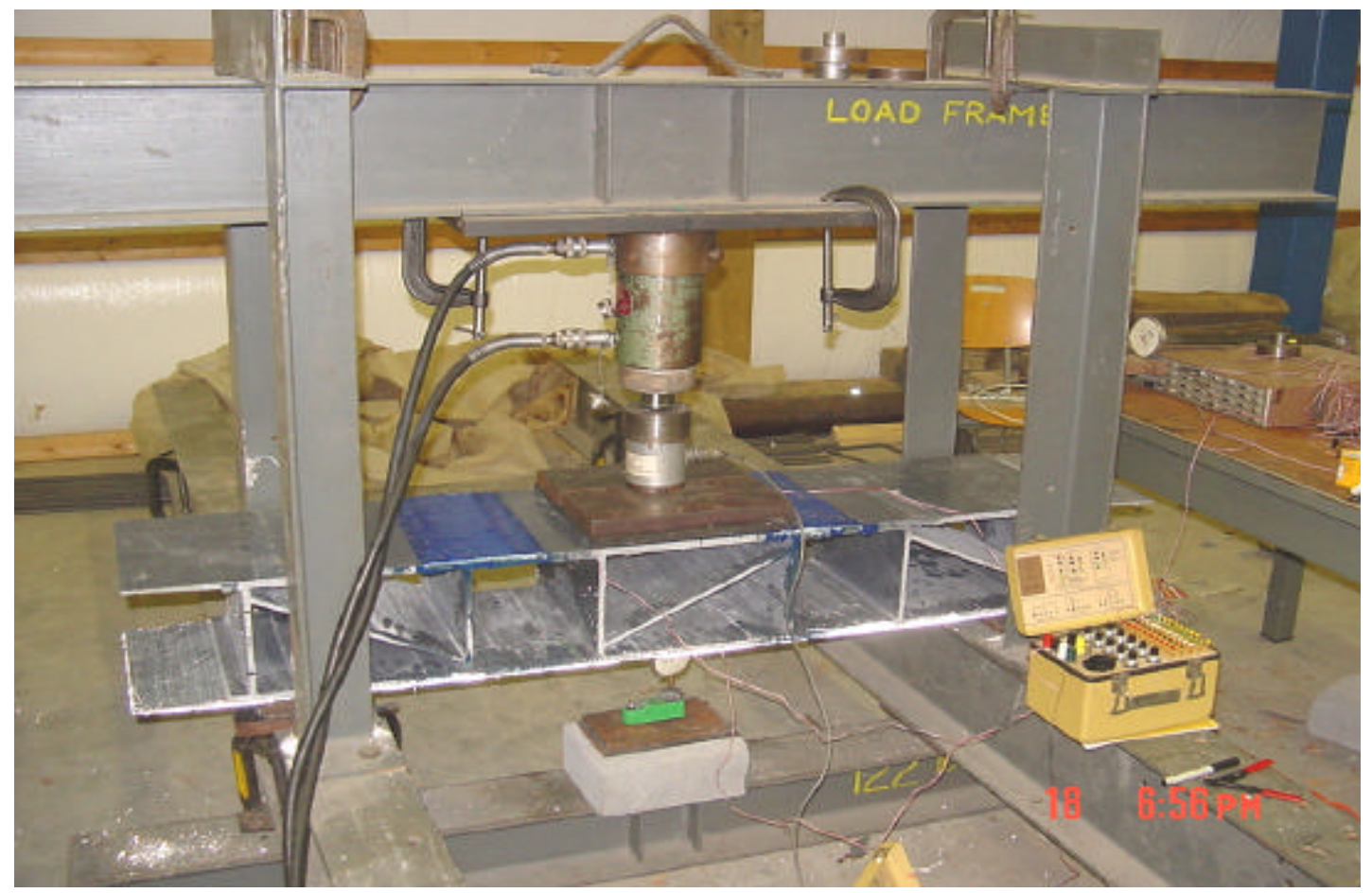

Figure 4.8-Test Set-Up for Transverse Experiments

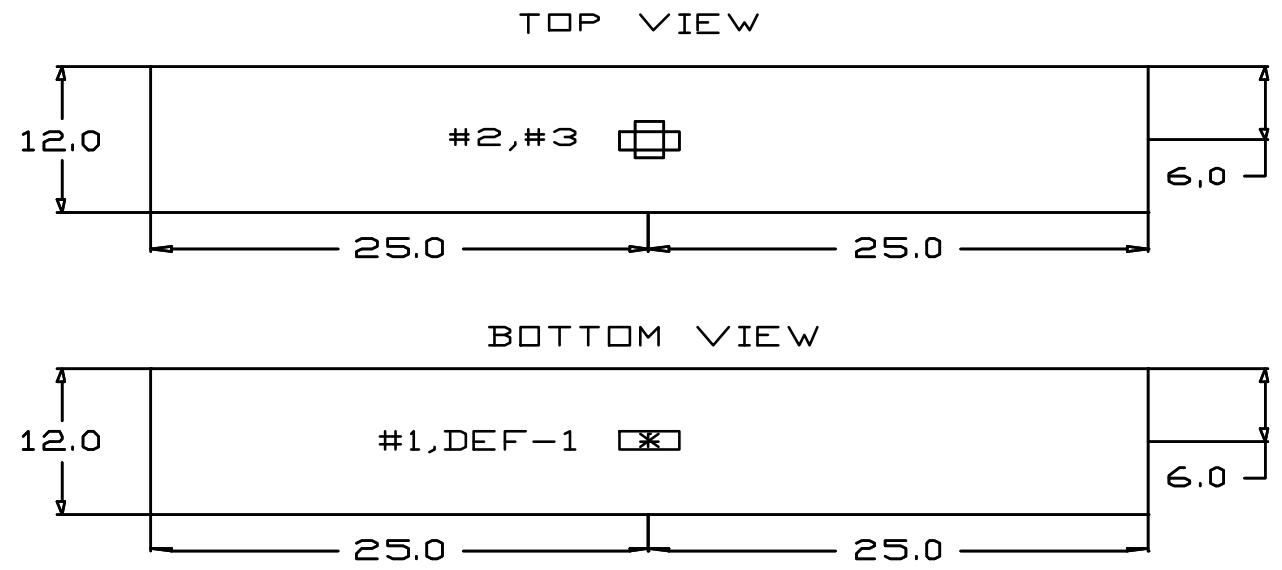

$\square$ Represents a strain gage

DEF Represents a point of deflection

\#1 and \#2 measure strain in the 50" directi

All units are in inches-Not to scale

Figure 4.9-Instrumentation of Transverse Component 


\subsection{Test Procedures}

The loading was applied with the aid of a hydraulic jack through a loading frame. Strain readings were taken using strain indicators, and a load cell was monitoring the magnitude of load. The load was applied at a constant rate of 1,000 $\mathrm{lb} / \mathrm{min}$, and all data was taken at constant load intervals.

\subsection{Test Results}

\subsubsection{Longitudinal Components}

\subsubsection{Elastic Properties of Longitudinal Components}

Figure 4.10 shows load versus deflection plots, while Figure 4.11 shows load versus maximum strain plots. From the plots, it can be seen that both load versus deflection and load versus strain plots were approximately linear until failure. Linear behavior in the inelastic region is a common trend for FRP composites. Other researchers such as Shekar (2000) and Nagaraj (1994) have also observed this type of behavior. Also, the plots from the various components do not deviate much from one another. The precision of the data is a promising indication that the components can be manufactured with a minimal tolerance with respect to bending stiffness.

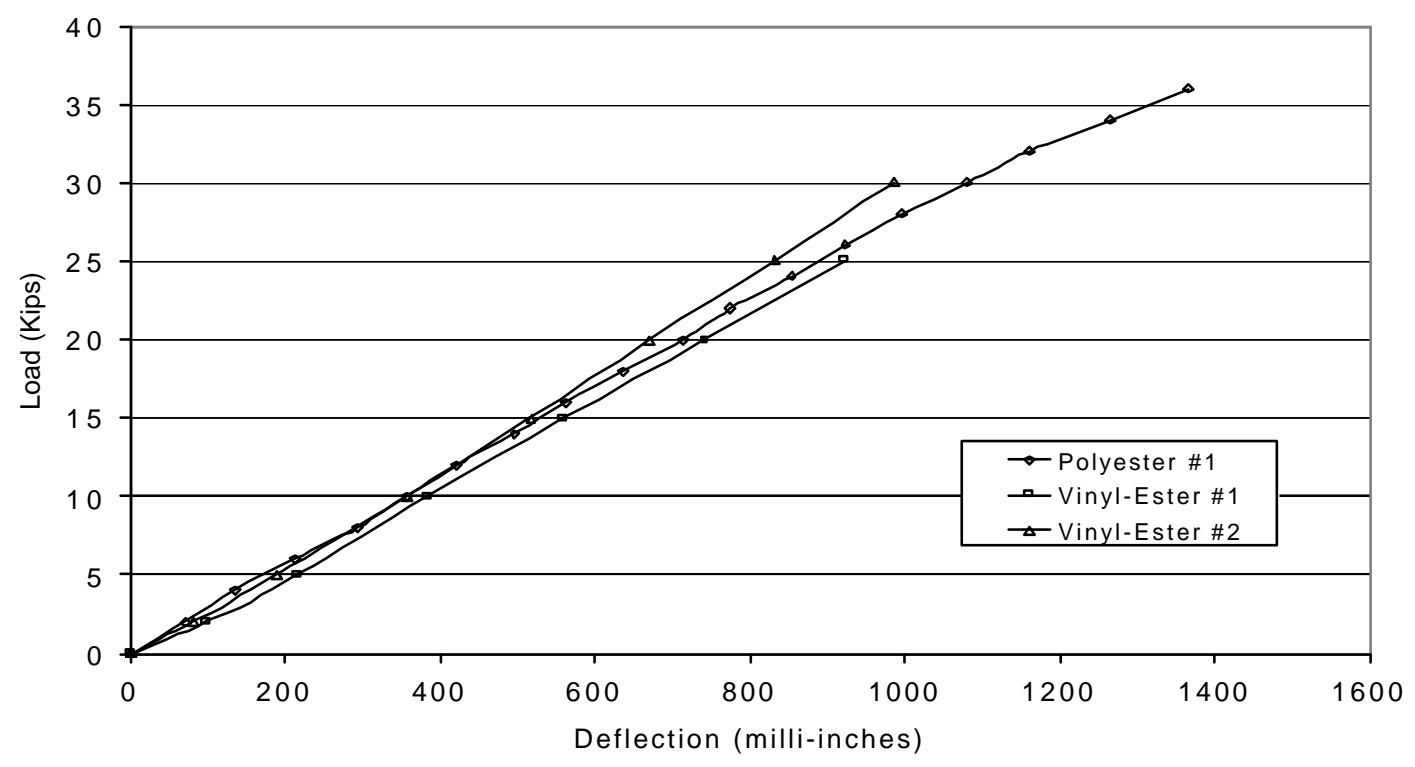

Figure 4.10-Load v/s Deflection for Longitudinal Components 


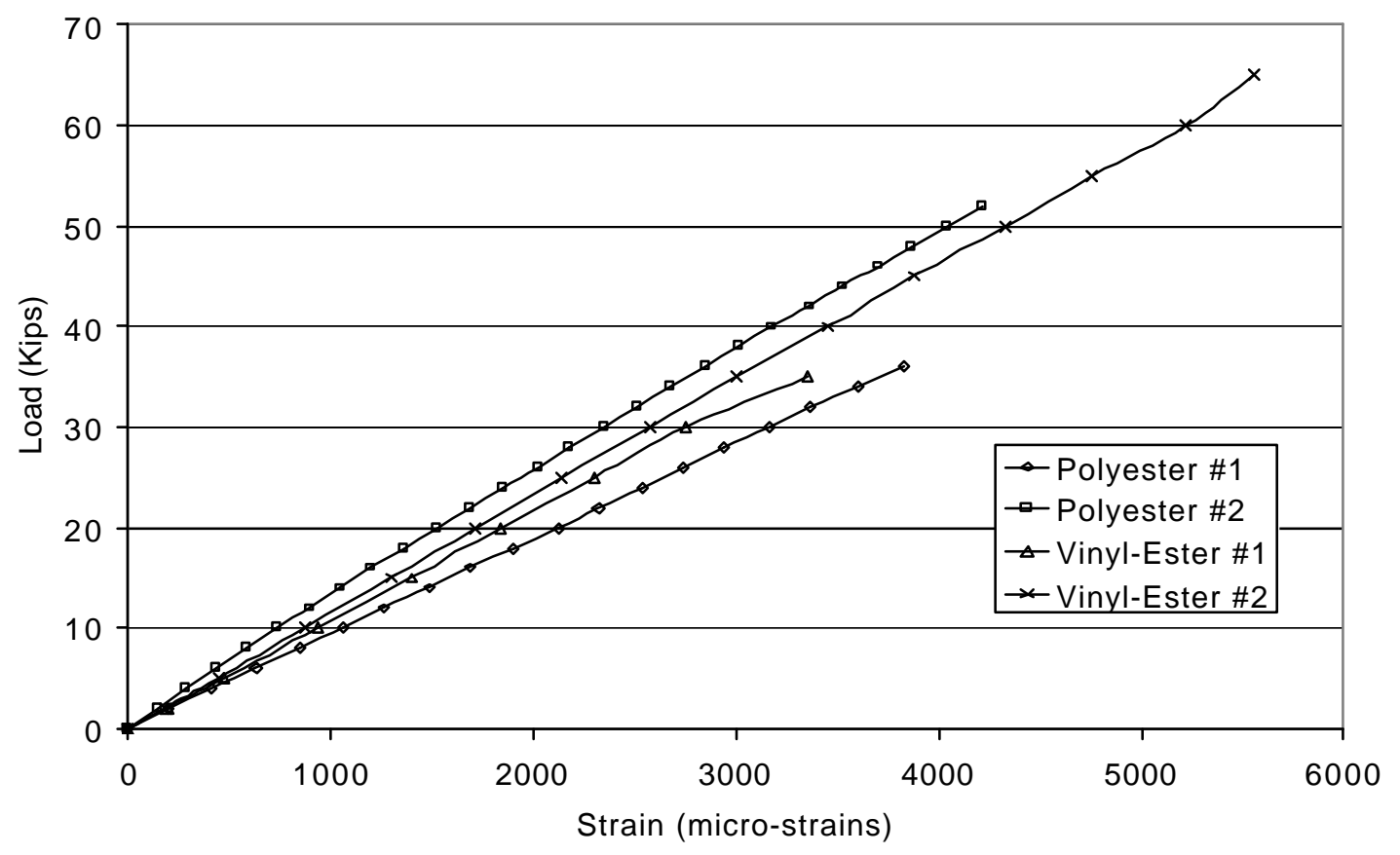

Figure 4.11-Load v/s Maximum Strain for Longitudinal Components

The bending stiffness and Young's Modulus were calculated based on Hooke's Law and basic mechanics of materials under bending for each of the four components. The details are given below:

$$
\begin{aligned}
& \Delta=\frac{P L^{3}}{48 E I} \\
& \sigma=\varepsilon E=\frac{M c}{I}
\end{aligned}
$$

Solving (4.1) and (4.2) for EI and substituting $M=\frac{P L}{4}$ :

$$
E I=\left(\frac{P}{\Delta}\right)\left(\frac{L^{3}}{48}\right)
$$

Or

$$
E I=\left(\frac{P}{\varepsilon}\right)\left(\frac{L c}{4}\right)
$$


Where,

$\frac{P}{\Delta}=$ slope of the linear portion of the load versus deflection curve

$\frac{P}{\varepsilon}=$ slope of the linear portion of the load versus strain curve

$L=$ clear span $($ See Table 4.1$)$

$E=$ modulus of elasticity or Young' s Modulus

$I=$ moment of inertia

$c=$ distance from the neutral axis to the outermost fiber (4")

Utilizing the slopes of the linear portions of Figures 4.10 and 4.11, as well as equations (4.3) and (4.4) the stiffness values were computed and can be seen in Table 4.2. Substituting $\mathrm{I}_{\mathrm{x}}=300 \mathrm{in}^{4}, \mathrm{E}_{\mathrm{x}}$ values were computed and shown in Table 4.3 (See Figure 6.8 for definition of the longitudinal or X-direction of the deck).

Tables 4.2 and 4.3 reveal that the strain data yielded higher values than the deflection data. Nagaraj (1994) concluded that the influence of shear deflection could be large (usually between $15-20 \%$ but as much as 36\%) and must be accounted for. The data in Tables 4.2 and 4.3 support Nagaraj's findings.

Such a high influence from shear deflection is not commonly seen in conventional materials such as steel. The shear modulus of steel is approximately $11\left(10^{6}\right)$ psi, while the shear moduli of a composite are at least one order of magnitude less than that of steel (See Chapters 3 and 7). Since the influence of shear deflection was not accounted for in the computations, the values obtained by deflection data naturally tend to be more conservative than those computed by strain data. The deflection data in Tables 4.2 and 4.3 have to be multiplied by a correction factor $(\approx 1.2)$ in order to yield a more realistic value.

If the values in Tables 4.2 and 4.3 are multiplied by a shear correction factor of 1.2, they correspond well with the findings of the strain data. As a result, the stiffness and elastic modulus values found from strain were taken as the correct values. 


\begin{tabular}{|c|c|c|c|}
\hline \multicolumn{4}{|c|}{ Bending Stiffness in Longitudinal Direction: $\mathrm{E}_{\mathrm{x}} \mathrm{I}_{\mathrm{x}}\left(10^{9}\right) l b^{*} i n^{2}$} \\
\hline Component & Based on Deflection & Based on Strain & \% Difference \\
\hline Polyester \#1 & 0.99 & 1.14 & $13 \%$ \\
\hline Polyester \#2 & NA & 1.36 & NA \\
\hline Vinyl Ester\#1 & 0.97 & 1.28 & $24 \%$ \\
\hline Vinyl Ester \#2 & 1.08 & 1.39 & $22 \%$ \\
\hline
\end{tabular}

* shear deflection was not accounted for in the results based on deflection

Table 4.2-Bending Stiffness of Longitudinal Components

\begin{tabular}{|c|c|c|c|}
\hline \multicolumn{4}{|c|}{ Modulus of Elasticity in Longitudinal Direction: $\mathrm{E}_{\mathrm{x}}\left(10^{6}\right) \mathrm{psi}$} \\
\hline Component & Based on Deflection & Based on Strain & $\%$ Difference \\
\hline Polyester \#1 & 3.3 & 3.8 & $13 \%$ \\
\hline Polyester \#2 & NA & 4.5 & NA \\
\hline Vinyl Ester\#1 & 3.2 & 4.2 & $24 \%$ \\
\hline Vinyl Ester\#2 & 3.6 & 4.6 & $22 \%$ \\
\hline
\end{tabular}

* shear deflection was not accounted for in the results based on deflection

Table 4.3-Modulus of Elasticity of Longitudinal Components

\subsubsection{Failure Modes of Longitudinal Components}

Table 4.4 shows the failure modes, ultimate loads, ultimate bending stresses, and ultimate strains of each of the four longitudinal components. Figures 4.12 through 4.14 show each of the types of failure modes that were observed through testing of the components. The components loaded with a 10"x 20" patch load (Polyester \#1 and Vinyl Ester \#1) had very similar failure properties. However, the components loaded with a 15"x 24" patch load (Polyester \#2 and Vinyl Ester \#2) experienced very different failure properties. The vinyl ester component had an ultimate load increase of slightly over $22 \%$, and an ultimate strain increase of slightly over $17 \%$. Also, the failure mode was quite different from the polyester component, 
which probably explains the vinyl ester's increase in ultimate load and strain relative to the polyester component.

The component Polyester \#1 failed due to excessive longitudinal shear stress at the web and flange junction. Figure 4.13 shows the failure from an end view. The flange and web were separated from the failed end to the specimen centerline. At the web and flange junction, the shear stress suddenly increases due to lowering of the cross-section thickness and the presence of a stress concentration, which greatly increases the stress levels. Figure 4.13 also reveals poor wet out of fabrics, which might have lead to such a sudden failure.

The shifting of the failure mode away from the web/flange junction allows for the excess capacity of the rest of the component (relative to this junction) to be maximized. The reason for the shift in failure mode was most likely due to better continuity between the web and flange. This continuity is achieved with architectures having fibers and fabrics continuing from the flange directly into the web. As a result, more fibers are present at the junction, which allows forces to be transferred to other areas of the component better equipped to handle the loads.

If a fiber architecture cannot adequately transfer forces away from the web and flange junction, the fibers present are exposed to high stress levels and can fail suddenly, prematurely, and without any warning signs. This was the case for Polyester Component \#2, but Vinyl Ester Component \#2 showed signs of weakening as failure approached.

\begin{tabular}{|c|c|c|c|c|}
\hline $\begin{array}{c}\text { Component } \\
\text { (Patch Load) }\end{array}$ & $\begin{array}{c}\text { Ultimate } \\
\text { Load (kips) }\end{array}$ & $\begin{array}{c}\text { Ult. Strain } \\
\text { (micro-strains) }\end{array}$ & $\begin{array}{c}\text { Ult. Bending } \\
\text { Stress (ksi) }\end{array}$ & $\begin{array}{c}\text { Description of } \\
\text { Failure Mode }\end{array}$ \\
\hline $\begin{array}{c}\text { Polyester \#1 } \\
(10 " x ~ 20 ")\end{array}$ & 36 & 3831 & 14.4 & Punching Shear \\
\hline $\begin{array}{c}\text { Polyester \#2 } \\
(15 " x 24 ")\end{array}$ & 52 & 4593 & 18.7 & $\begin{array}{c}\text { Web/Flange } \\
\text { Separation }\end{array}$ \\
\hline $\begin{array}{c}\text { Vinyl Ester \#1 } \\
(10 " x ~ 20 ")\end{array}$ & 37 & 3349 & 14.8 & Punching Shear \\
\hline $\begin{array}{c}\text { Vinyl Ester \#2 } \\
(15 " x ~ 24 ")\end{array}$ & 67 & 5561 & 26.8 & $\begin{array}{c}\text { Top Flange } \\
\text { Buckling }\end{array}$ \\
\hline
\end{tabular}

Table 4.4-Ultimate Load, Strain, and Failure Modes of Longitudinal Components 


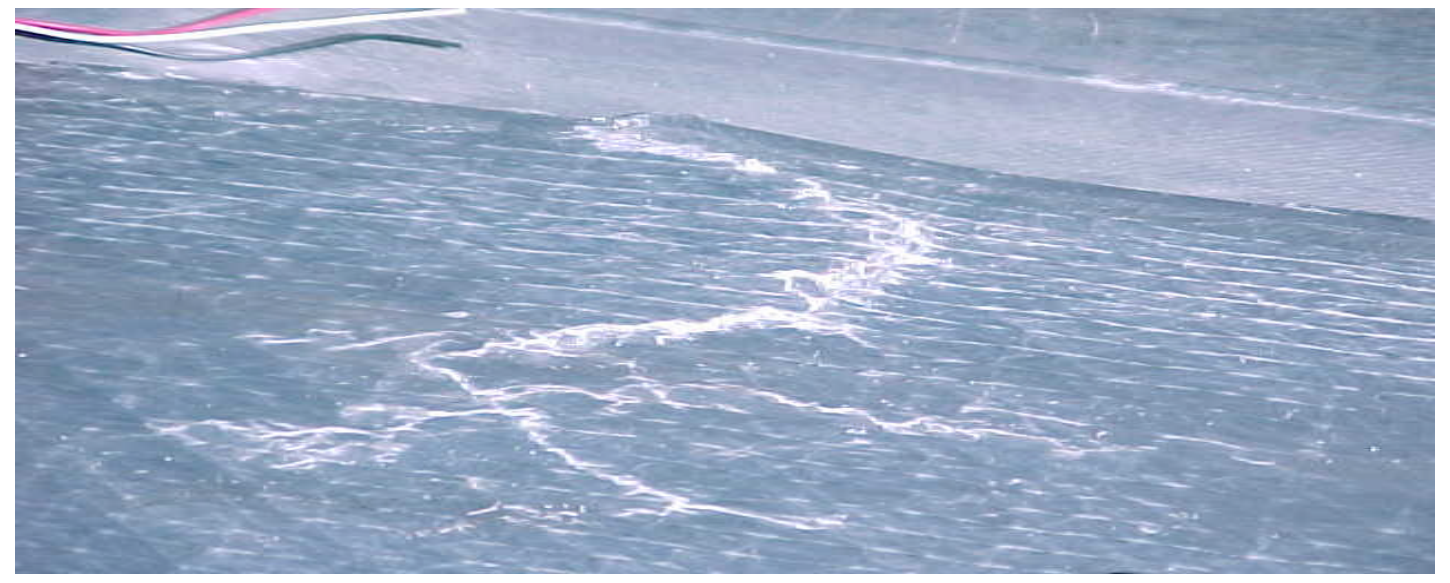

Figure 4.12-Damage due to Punching Shear Failure Mode

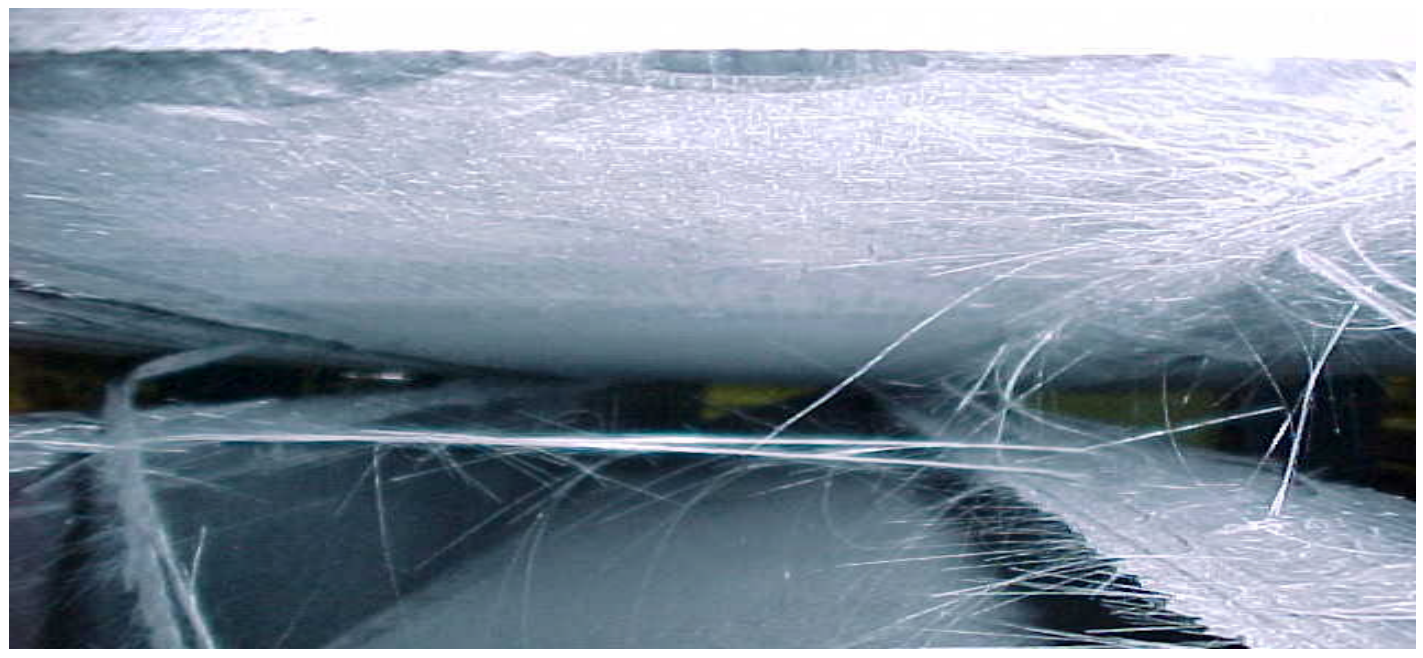

Figure 4.13-Damage due to Web/Flange Separation Failure Mode (End View)

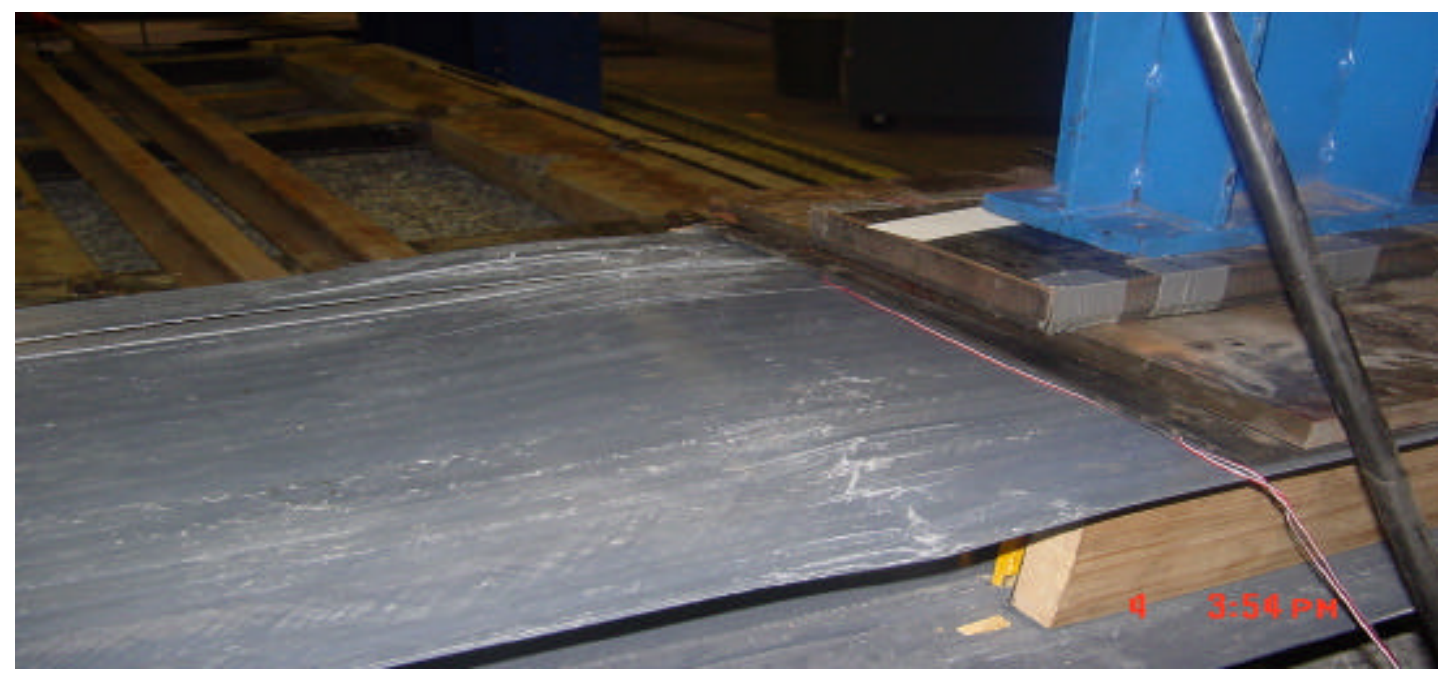

Figure 4.14-Damage due to Top Flange Buckling Failure Mode 


\subsubsection{Rehabilitated Longitudinal Component}

\subsubsection{Elastic Properties of Rehabilitated Longitudinal Component}

Figure 4.15 shows the plot of load versus strain from the failure test of the rehabilitated longitudinal component under a 10"x 20" patch load. Aside from the ultimate load, it corresponds well to its initial testing shown as Polyester Component \#1. Utilizing equation (4.4) and the slope of the linear portion of Figure 4.15, the stiffness of the rehabilitated longitudinal component was found to be $1.01\left(10^{9}\right) \mathrm{lb}^{*} \mathrm{in}^{2}$. Furthermore, the moment of inertia of the central portion of the specimen was found to be $267 \mathrm{in}^{4}$ after the application of the two layers of fabric. The resulting modulus of elasticity was found to be $3.8\left(10^{6}\right)$ psi. The experimental data showed a decrease in stiffness, but no decrease in the elastic modulus. The stiffness decrease was because the rehabilitated longitudinal component contained less area than did Polyester Component \#1 after the removal of the exterior lap joints (See Figure 4.1).

Elastic tests were also performed with patch loads other than 10 "x 20 " to determine the effect of these different patches on the behavior of the component. These patch loads were applied individually to each flange, and both the maximum compressive and tensile strains are shown for a 14 kip load in Table 4.5. In a global sense, the testing showed a maximum increase in strain of $6 \%$ and a maximum decrease in strain of $11 \%$ (relative to the 10"x 20" patch load). Also, the global performance of the component was almost the same regardless of which flange was being loaded. A maximum difference of $8 \%$ was seen with the 6"x 24" patch load. Local strain was only affected when the patch load was not wide enough to sit over the vertical webs (6"x 24" loading case).

\subsubsection{Failure Mode of Rehabilitated Longitudinal Component}

The failure of the rehabilitated longitudinal component was identical to the one tested as Polyester Component \#1 (See Figure 4.16). Punching shear was again the mode of failure. However, the failure load was less when compared to the initial testing. Table 4.6 shows the properties of the rehabilitated component as well as those of Polyester Component \#1. From Table 4.6, it can be seen that the rehabilitation did not perform well from an ultimate load point of view. Although the elastic properties did not change, the ultimate stress was reduced by $24 \%$ and the 
ultimate strain by $20 \%$. Reasons for the decreases can most likely be attributed to poor instillation of the fabrics used to rehabilitate the component. The fabric strips were applied to the component entirely by hand, and as a result, several areas of the FRP component were not efficient. Poor bonding of the fabrics to the component and the lack of removal of excess resin were the two main rehabilitation problems.

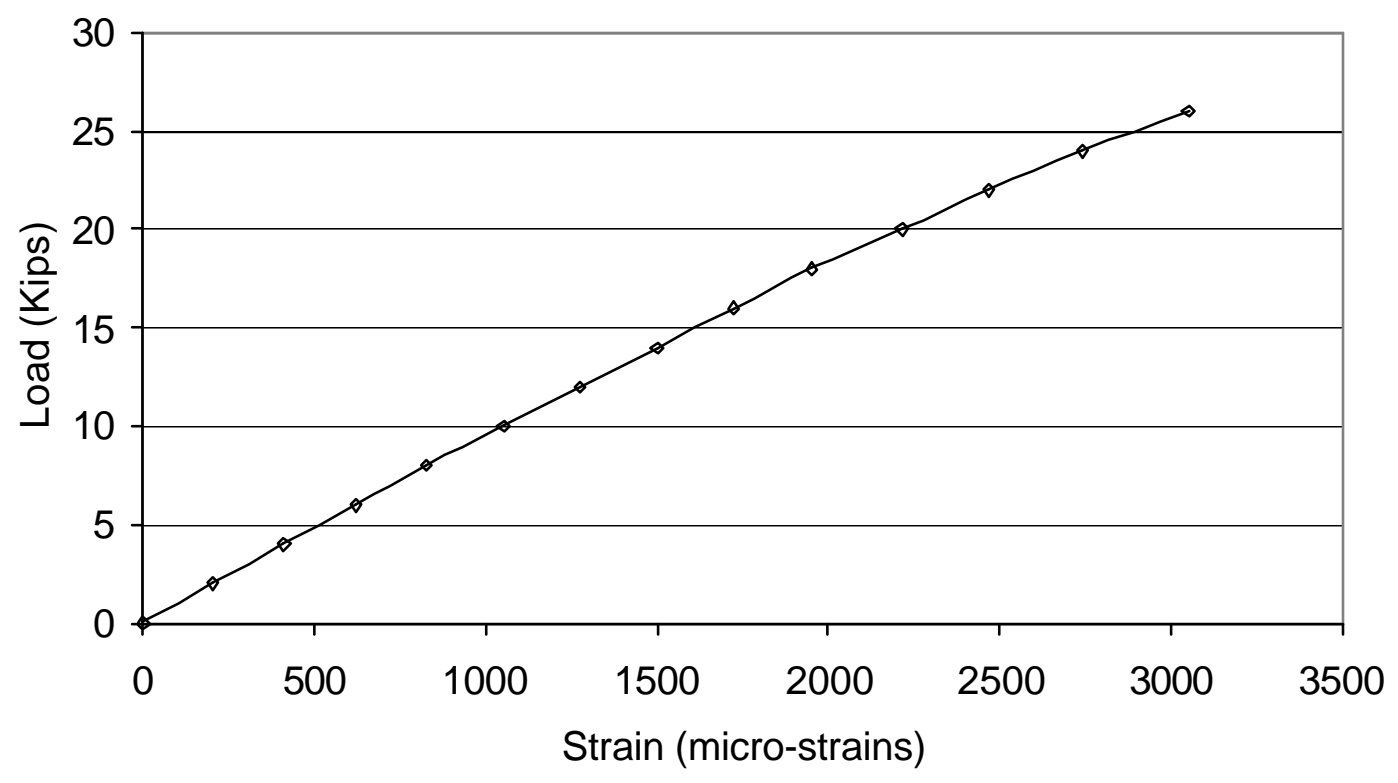

Figure 4.15-Load v/s Strain of Rehabilitated Longitudinal Component (10”x 20” Patch Load)

\begin{tabular}{|c|c|c|c|}
\hline \multicolumn{4}{|c|}{ Longitudinal Strains Under a 14 kip Load (micro-strains) } \\
\hline Patch Load & Loaded Flange & Max. Compressive & Max. Tensile \\
\hline 12"x 12" & 1 & 2189 & 1582 \\
\hline $12 " x ~ 12 "$ & 2 & 2084 & 1550 \\
\hline $12 " x$ 24" & 1 & 1207 & 1355 \\
\hline 12"x 24" & 2 & 1192 & 1342 \\
\hline 6"x 24" & 1 & 1531 & 1450 \\
\hline 6"x 24" & 2 & 1109 & 1499 \\
\hline 10"x 20" & 1 & 388 & 1336 \\
\hline
\end{tabular}

Table 4.5-Maximum Strains for Rehabilitated Longitudinal Component 


\begin{tabular}{|c|c|c|c|c|c|}
\hline Component & Span & $\begin{array}{c}\text { Ultimate } \\
\text { Load (kips) }\end{array}$ & $\begin{array}{c}\text { Ult. Strain } \\
\text { (micro-strains) }\end{array}$ & $\begin{array}{c}\text { Ult. Bending } \\
\text { Stress (ksi) }\end{array}$ & $\begin{array}{c}\text { Failure } \\
\text { Mode }\end{array}$ \\
\hline Polyester \#1 & $120 ”$ & 36 & 3831 & 14.4 & $\begin{array}{c}\text { Punching } \\
\text { Shear }\end{array}$ \\
\hline Rehabilitated & $108 ”$ & 27 & 3049 & 10.9 & $\begin{array}{c}\text { Punching } \\
\text { Shear }\end{array}$ \\
\hline
\end{tabular}

Table 4.6-Failure Characteristics of Rehabilitated Longitudinal Component and Polyester Component \#1

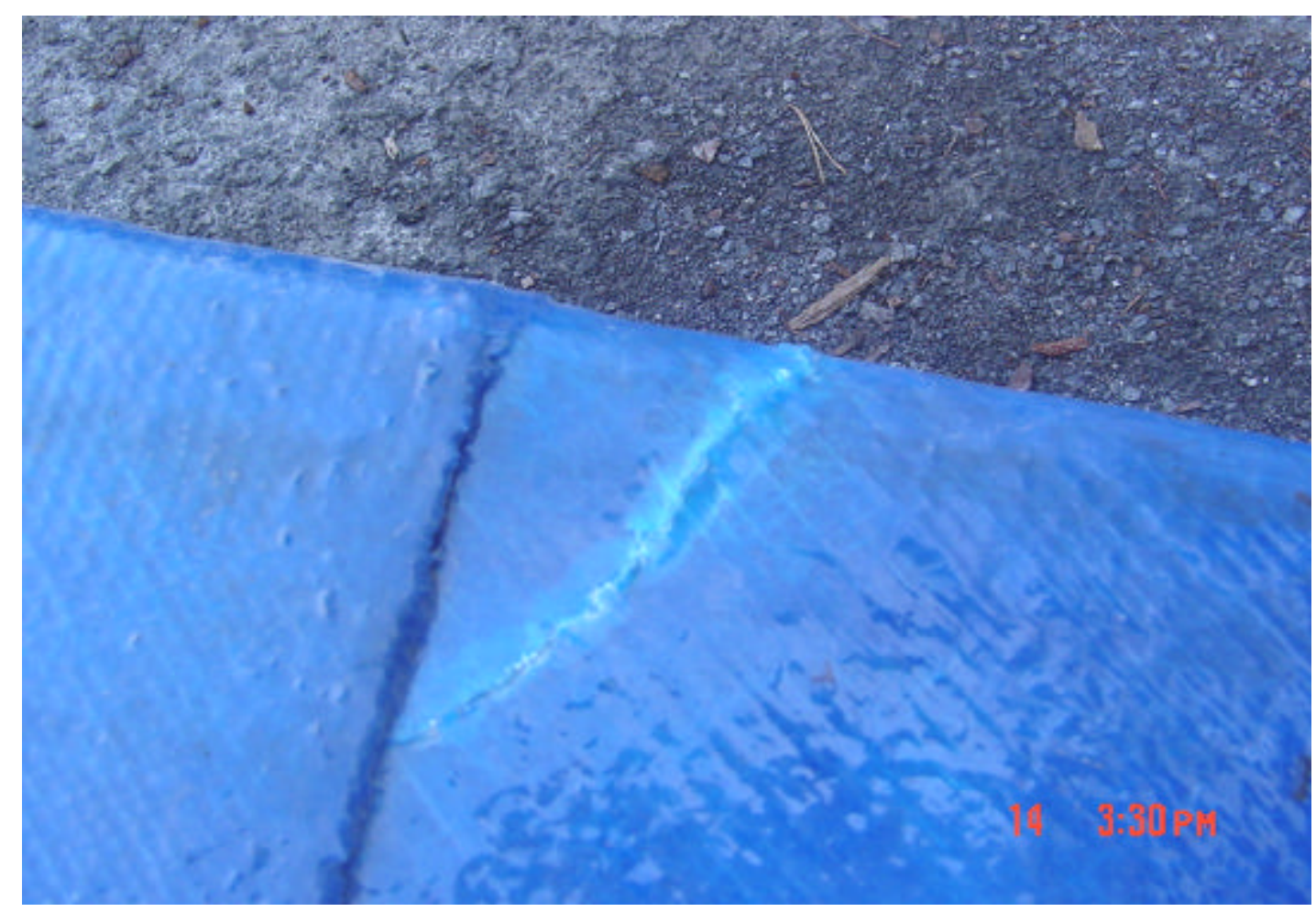

Figure 4.16-Failure Mode of Rehabilitated Longitudinal Component

\subsubsection{Elastic Testing of Transverse Component}

Elastic testing was performed on a polyester transverse component in two different phases. The first was the testing without fabric strips applied to the joints, and the second was with two strips of fabric applied to the joints. The load versus strain plots from these two tests can be seen in Figure 4.17. 


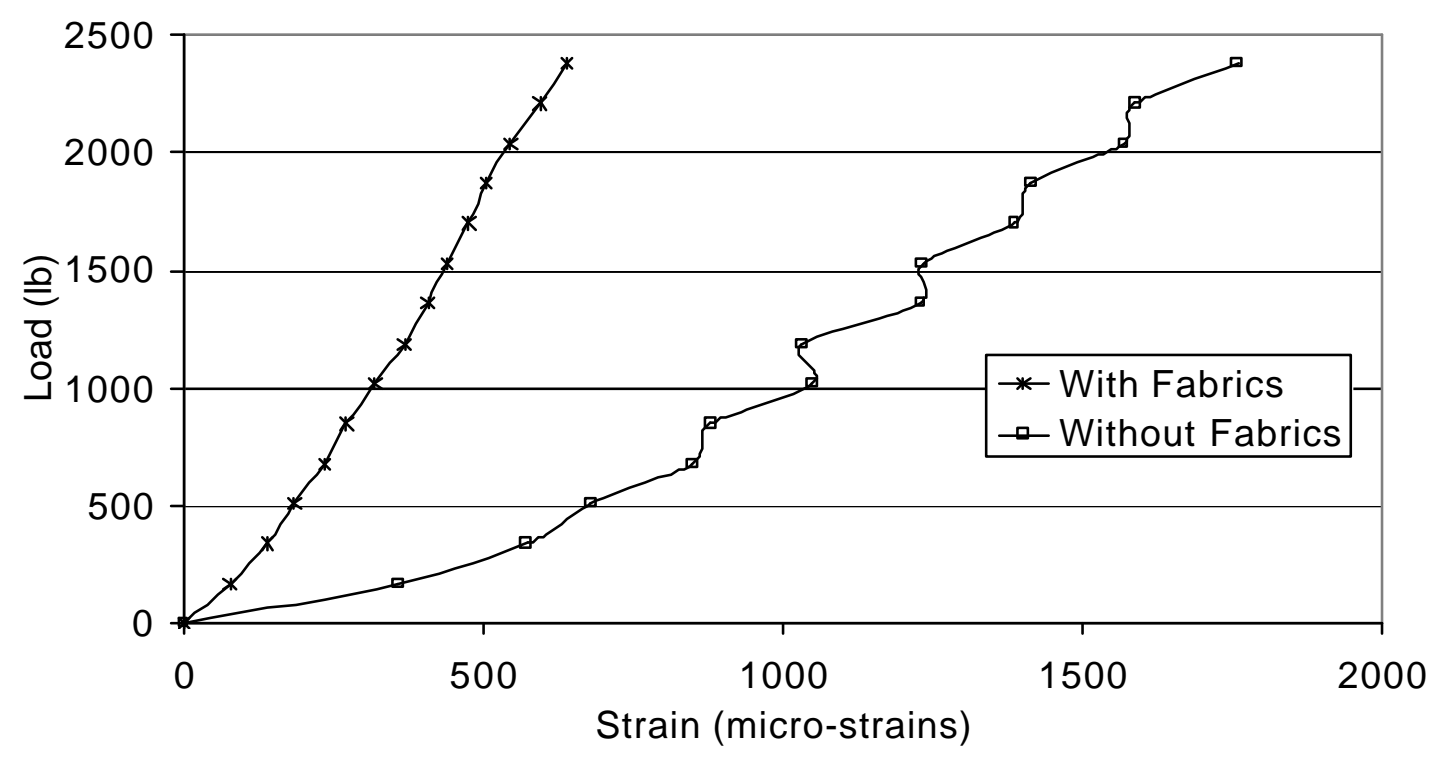

Figure 4.17-Load v/s Strain of Transverse Components

Utilizing Figure 4.17 along with equation (4.4), the transverse stiffness and modulus of elasticity were found both with and without fabrics and can be seen in Table 4.7. The moment of inertia in the transverse direction was found to be $169 \mathrm{in}^{4}$. It can be seen from Table 4.7 that the addition of the fabric strips over the joints increased the elastic properties by about 2.2 times (according to strain).

\begin{tabular}{|c|c|c|}
\hline Component & Stiffness: $\mathrm{E}_{\mathrm{y}} \mathrm{I}_{\mathrm{y}}\left(10^{8}\right) \mathrm{lb}^{*} \mathrm{in}^{2}$ & Elastic Modulus: $\mathrm{E}_{\mathrm{y}}\left(10^{6}\right) \mathrm{psi}$ \\
\hline With Fabrics & 1.96 & 1.16 \\
\hline Without Fabrics & 0.90 & 0.53 \\
\hline
\end{tabular}

Table 4.7-Elastic Properties of the Transverse Component

Severe rotation of the joints in the transverse component was observed. Therefore, a reliable stiffness value based on deflection was difficult to measure. The joints proved to be very poor in transferring shear, which forced the middle section of the component to deflect excessively. The amount of shear deflection present in the data would be very difficult to estimate due to the presence of the joints. As a result, the data from deflection only shows the joints have serious problems transferring 
forces in the transverse direction. The lack of force transfer by the joints plays a critical role in the amount of plate action present when these components are connected together in a bridge deck.

Due to the poor quality of the shear transfer at the joints, a 31" specimen was tested in the transverse direction to evaluate the decrease in deflection at a joint by applying a 3/8" thick polymer concrete wearing surface. The decrease was found at both the local and global levels. At the local level, application of the wearing surface decreased the joint deflection by $22 \%$, and the global deflection was reduced by approximately $8 \%$ at the joint. These values were obtained by applying the load directly to the joint. See Figure 4.18 for further description of the testing with the wearing surface.

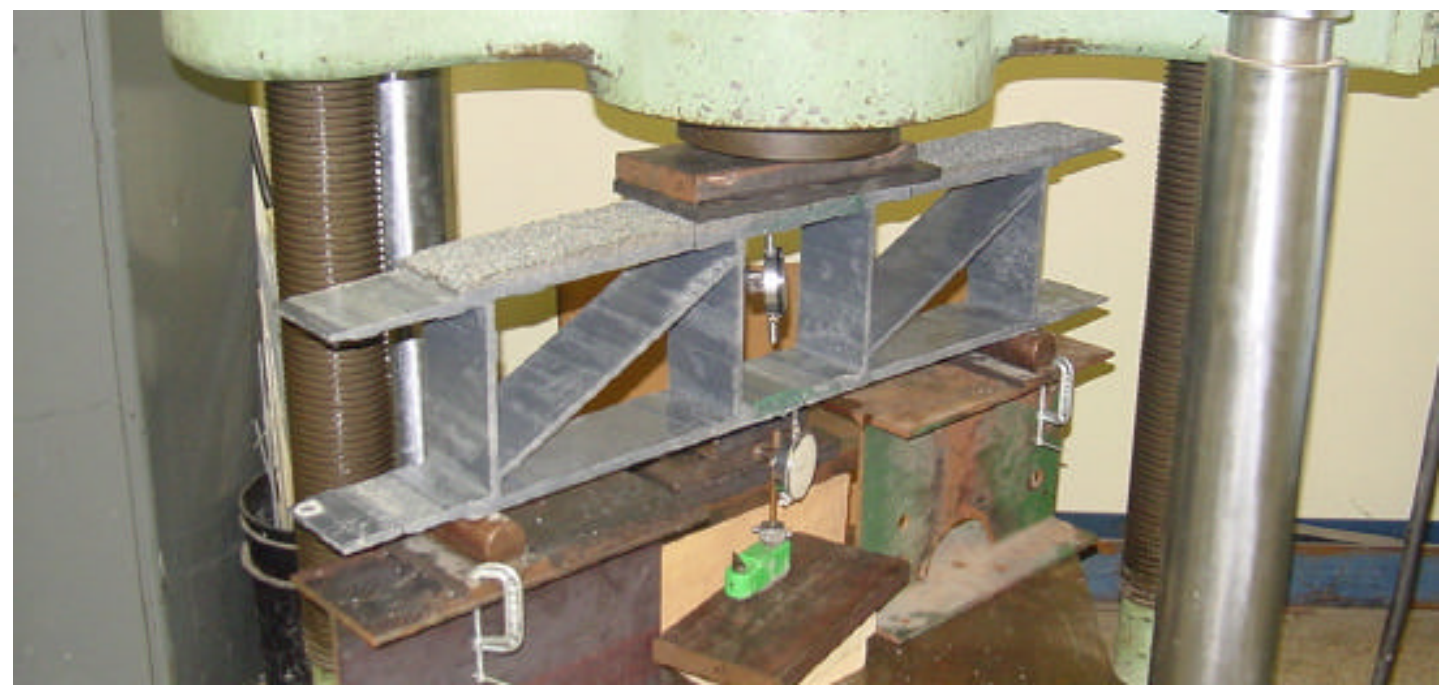

Figure 4.18-Transverse Test With 3/8” Wearing Surface

\subsection{Comparison of Experimental Stiffness Results and Theoretical Analysis}

The elastic properties of the components investigated in this study yielded somewhat similar results from theory and experiment. Stiffness values obtained from both strain and deflection data were compared to theoretical results from a combination of micro mechanics and approximate classical lamination theory.

Table 4.8 shows the experimental and theoretical comparisons. See Appendix B for details on the theoretical approach. The maximum difference between theory 
and experiment was $32 \%$. This difference was found between strain data and theory of Vinyl Ester \#2.

\begin{tabular}{|c|c|c|c|c|c|}
\hline \multirow[b]{2}{*}{ Component } & \multicolumn{2}{|c|}{ Experimental Results $\left(\mathrm{lb}^{*} \mathrm{in}^{2}\right)$} & \multirow{2}{*}{$\begin{array}{l}\text { Theoretical } \\
\text { Analysis } \\
\left(\mathrm{lb}^{*} \mathrm{in}^{2}\right)\end{array}$} & \multicolumn{2}{|c|}{$\%$ Difference } \\
\hline & $\begin{array}{l}\text { Based on } \\
\text { Deflection }\end{array}$ & $\begin{array}{c}\text { Based on } \\
\text { Strain }\end{array}$ & & $\begin{array}{l}\text { Based on } \\
\text { Deflection }\end{array}$ & $\begin{array}{c}\text { Based } \\
\text { on Strain }\end{array}$ \\
\hline Polyester \#1 & $0.99\left(10^{9}\right)$ & $1.14\left(10^{9}\right)$ & $1.36\left(10^{9}\right)$ & $27 \%$ & $16 \%$ \\
\hline Polyester \#2 & NA & $1.36\left(10^{9}\right)$ & $1.36\left(10^{9}\right)$ & NA & $0 \%$ \\
\hline Vinyl Ester \#1 & $0.97\left(10^{9}\right)$ & $1.28\left(10^{9}\right)$ & $1.05\left(10^{9}\right)$ & $8 \%$ & $22 \%$ \\
\hline Vinyl Ester \#2 & $1.08\left(10^{9}\right)$ & $1.39\left(10^{9}\right)$ & $1.05\left(10^{9}\right)$ & $3 \%$ & $32 \%$ \\
\hline Transverse $^{*}$ & $\mathrm{NA}$ & $1.96\left(10^{8}\right)$ & $1.91\left(10^{8}\right)$ & $\mathrm{NA}$ & $3 \%$ \\
\hline
\end{tabular}

* Transverse test with two layers of fabric bonded to the joints

Table 4.8-Stiffness Comparison of Experimental Results and Theoretical Analysis

\subsection{Conclusions}

\section{$\underline{\text { Longitudinal Components }}$}

- 10"x 20" patch loads caused local punching shear failures prior to global failure in all cases.

- When loaded with 10 "x 20 " patch loads, the behavior of the vinyl ester and polyester components was very similar.

- The vinyl ester component loaded with a 15"x 24" patch load had an ultimate bending stress $8 \mathrm{ksi}$ greater than the polyester component under the same conditions.

- The vinyl ester component loaded with a 15"x 24" patch load had a less catastrophic failure than did the polyester component.

- All plots of load v/s strain or deflection were linear until failure.

\section{$\underline{\text { Rehabilitated Component }}$}

- The ultimate bending stress was $3.5 \mathrm{ksi}$ less than the stress when the component was first tested. 
- The same failure mode occurred (punching shear) as the one when the component was first tested.

- The elastic behavior in a global sense was not greatly affected by the flange to which the load was applied.

- The local behavior was affected by the flange to which the load was applied only when the load patch was not wide enough to sit over the vertical webs.

\section{$\underline{\text { Transverse Component }}$}

- The application of bonded fabric strips at the joints increased the transverse stiffness by 2.2 times.

- The deflection data revealed severe joint rotation.

- In order to achieve good shear transfer across the joints, some type of mechanical fastener will probably have to be used to connect the components.

- The application of a 3/8" thick polymer concrete wearing surface decreased the joint deflection by $22 \%$ in a local sense and $8 \%$ in a global sense with the load applied directly to the joint.

\section{Theoretical Analysis}

- The use of micro mechanics in conjunction with approximate classical lamination theory (ACLT) predicted stiffness values within 0-32\% of those found from experiments. 


\section{CHAPTER 5}

\section{PHILOSOPHY OF COMPONENT LEVEL FAILURE MODES}

\subsection{Introduction}

The different failure modes of FRP composite bridge decks have to be fully understood before arriving at safe and economical deck systems. Conventional failure theories such as Tsai-Wu and Tsai-Hill are not predicting failure loads accurately. In an attempt to understand the failure behavior of composite bridge decks, a rudimentary approach has been adopted and presented in this chapter. Herein, strain to failure method has been used in conjunction with well-established failure strain and stability principles in order to describe the failure behavior as a function of section and material properties.

The goal of this chapter was to present some critical issues pertaining to material and section failures that were identified through current testing. It should be noted that each type of failure would need follow up work in order to properly quantify the behavior with a high degree of confidence. All failures are discussed with reference to one dimensional deck sections. In other words, no plate action is considered. Incorporating a two dimensional plate theory to predict deck failure greatly complicates the analysis and additional accuracies and advantages, obtained from doing so, have yet to be determined. On the other hand, use of conventional strain and stability principles (along with appropriate correction factors) to describe the complex behavior of FRP decks could lead to more simplistic design methods that are easily understood by design engineers.

Four major failure modes are discussed herein. They are: 1) web buckling, 2) shear, 3) bending, and 4) joint failure modes. While most of the failures discussed in this chapter have been referred to in other chapters, some of the failures are being revealed for the first time. The test details of these failure modes (that have not been previously discussed) have been provided. The experiments, explained in earlier chapters, have references to those sections of the text where they were first mentioned. Immediately following the four major sections, concluding remarks are 
given based on the knowledge gained from the testing and analysis of the failure modes presented in this chapter.

Before reading the remainder of the chapter, an understanding of the scope of the work herein needs to be carefully addressed. All work performed in this chapter is very limited in terms of its application. The following list must be satisfied and/or understood in order for these methods to have any merit in their current form.

1) Valid only for polyester and/or vinyl ester resins.

2) Valid only for 2-D fiber architectures with no pre-tensioned fibers.

3) Valid only for thin sections ( 0.5 " or less).

4) Valid only for E-glass fibers.

5) Only applicable to component level. Decks are not evaluated as a whole.

6) No plate action is considered.

7) All equations are an approximate equivalency not accounting for anisotropy of the material.

8) The work performed is of the exploratory type. No failures were studied with sufficient depth to achieve a high level of understanding and/or confidence.

\subsection{Failure due to Web Buckling}

The phenomenon of web buckling was examined in section 3.3 and is represented herein. Web buckling tests were conducted on 12" wide sections to determine the ultimate load and failure modes to be expected from the current designs. Both the polyester component (shown in Figures B2 and B4) and the vinyl ester component (shown in Figures B3 and B5) were tested to determine the integrity of the webs with respect to buckling.

Three specimens were tested under web buckling to determine the ultimate capacity of the webs. The experiments were conducted by placing elastomeric padding at the top and bottom of the specimen to ensure uniform distribution of compression throughout the 12" closed portion. Also, a 10"x 20" steel plate was placed above the specimen to insure the top flange was not subjected to bending. It should be noted that even though the steel plate was 20 " long, only 12 " of its length was resting on the padding while the remaining 8" was not in contact with the specimen. No load was placed on the exterior lap joints to prevent moment 
inducement. The test was performed by applying load at a rate of $1,000 \mathrm{lb} / \mathrm{min}$ until failure occurred. Figure 5.1 shows the actual test set-up.

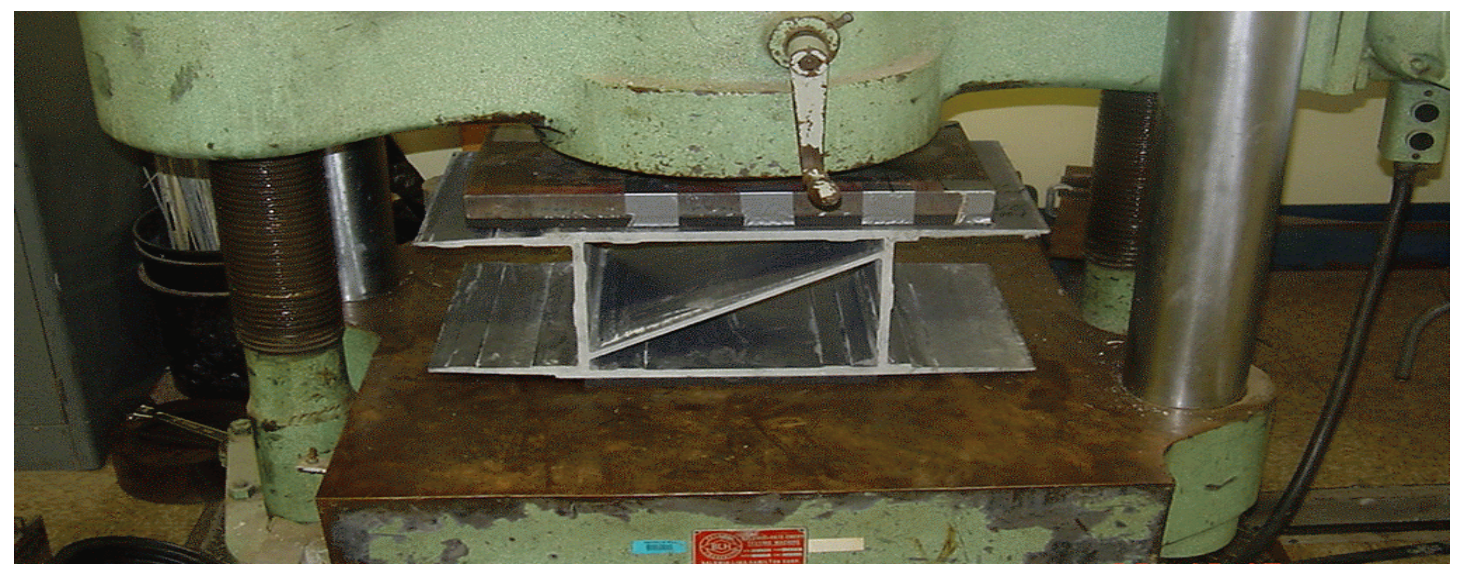

Figure 5.1-Test Set-Up for Web Buckling Specimens

The conventional method used to predict the buckling of long and slender members subjected to compression is the Euler buckling formula, given below (Boresi et.al. 1993). Note the qualifications at the end of section 5.1.

$$
P_{\mathrm{cr}}=\frac{\pi^{2} E_{y} I}{(K L)^{2}}
$$

Where,

$\mathrm{P}_{\mathrm{cr}}=$ load necessary to induce buckling

$\mathrm{E}_{\mathrm{y}}=$ modulus of elasticity about weak axis of web (see 4.5.3)

$\mathrm{I}=$ moment of inertia of web $\left(0.0429 \mathrm{in}^{4}\right)$

$\mathrm{L}=$ actual unbraced length of web (6.25 in)

$\mathrm{K}=$ effective length factor

The results of these experiments, along with the calculated correction factors, can be seen in Table 5.1. It should be noted that the value of (Pcr) shown in the table 
is assumed to be distributed evenly between the two vertical webs so that half the load is applied to each web. From Table 5.1 it can be seen that the average effective length factor $(\mathrm{K})$ was found to be approximately 0.7 . An effective length of $70 \%$ of the actual length shows partial fixity of the joints with respect to axial loading. The diagonal stiffener plays a key role in the satisfactory performance. The diagonals are able to minimize joint rotation of the web ends. As a result, the boundaries of the vertical webs have some degree of fixity to them. Figures 5.2 and 5.3 show the actual web buckling failure modes that were observed during the work.

It is of interest to note that the vinyl ester specimen did not experience a failure at the center of the web. One probable reason can be seen in the cross-section of Figure B3. Extra ribs were placed at the center of the vertical webs. As a result, when the web buckled, the central portion was reinforced and secondary moments, caused by web buckling, forced a joint failure instead. This type of behavior highlights the benefits of the ribs with respect to stability.

When dealing with vertical webs in FRP components such as bridge decks, the method proposed in this section should yield satisfactory results provided experiments are performed to determine the effective length factor $(\mathrm{K})$. The $(\mathrm{K})$ factor should be computed independently for each type of component being considered.

\begin{tabular}{|c|c|c|c|}
\hline Specimen & Pcr (k) & K & Description of Failure Mode \\
\hline Polyester \#1 & 45 & 0.728 & Buckling of web at midpoint of unbraced length \\
\hline Vinyl Ester \#1 & 48 & 0.705 & $\begin{array}{c}\text { Failure at joint connecting web and diagonal } \\
\text { induced by secondary moments as web buckled }\end{array}$ \\
\hline Vinyl Ester \#2 & 55 & 0.658 & \\
\hline
\end{tabular}

Table 5.1-Failure Behavior of Webs Exposed to Buckling Loads 


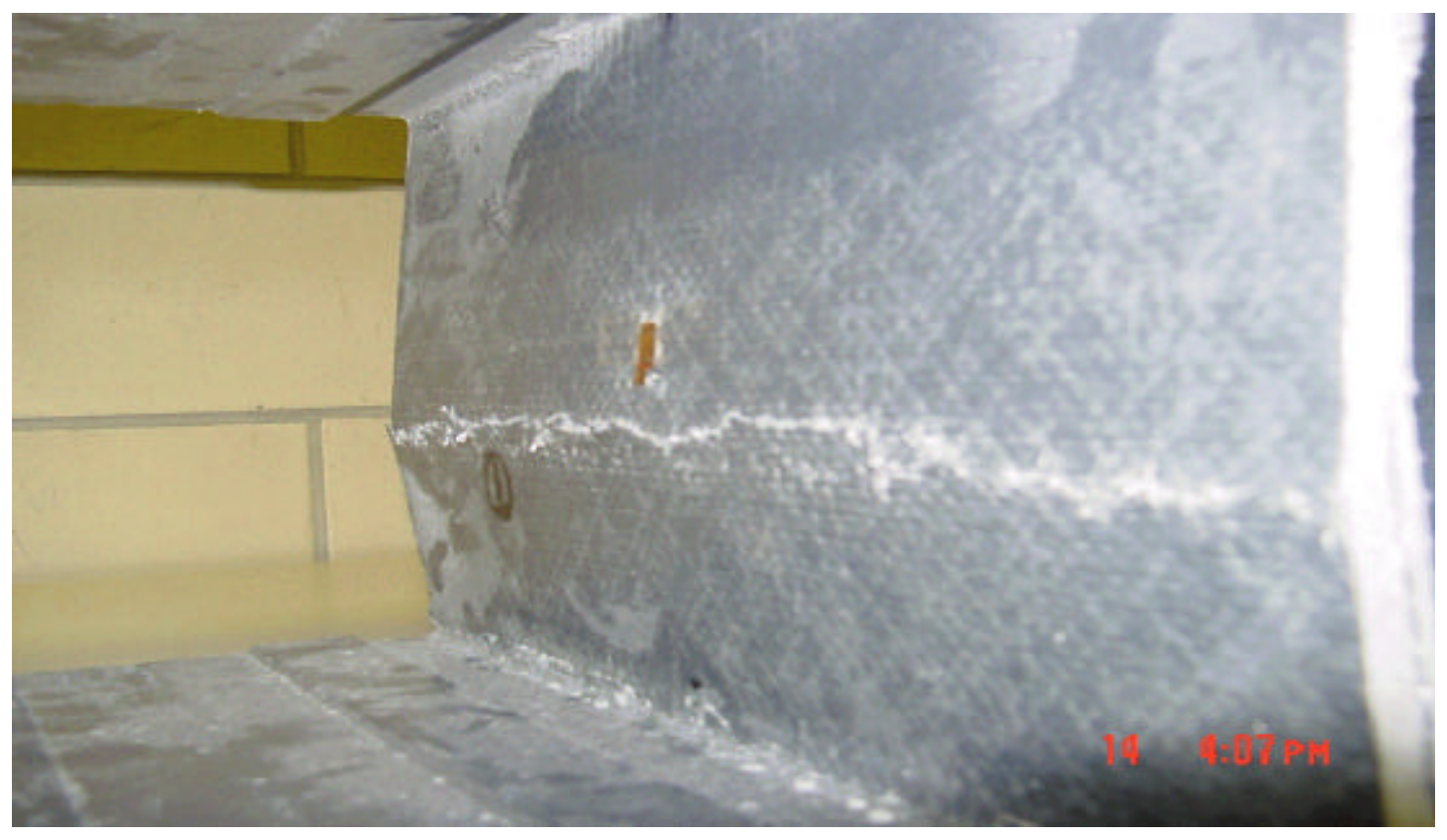

Figure 5.2-Failure Mode of Polyester Web Buckling Specimens

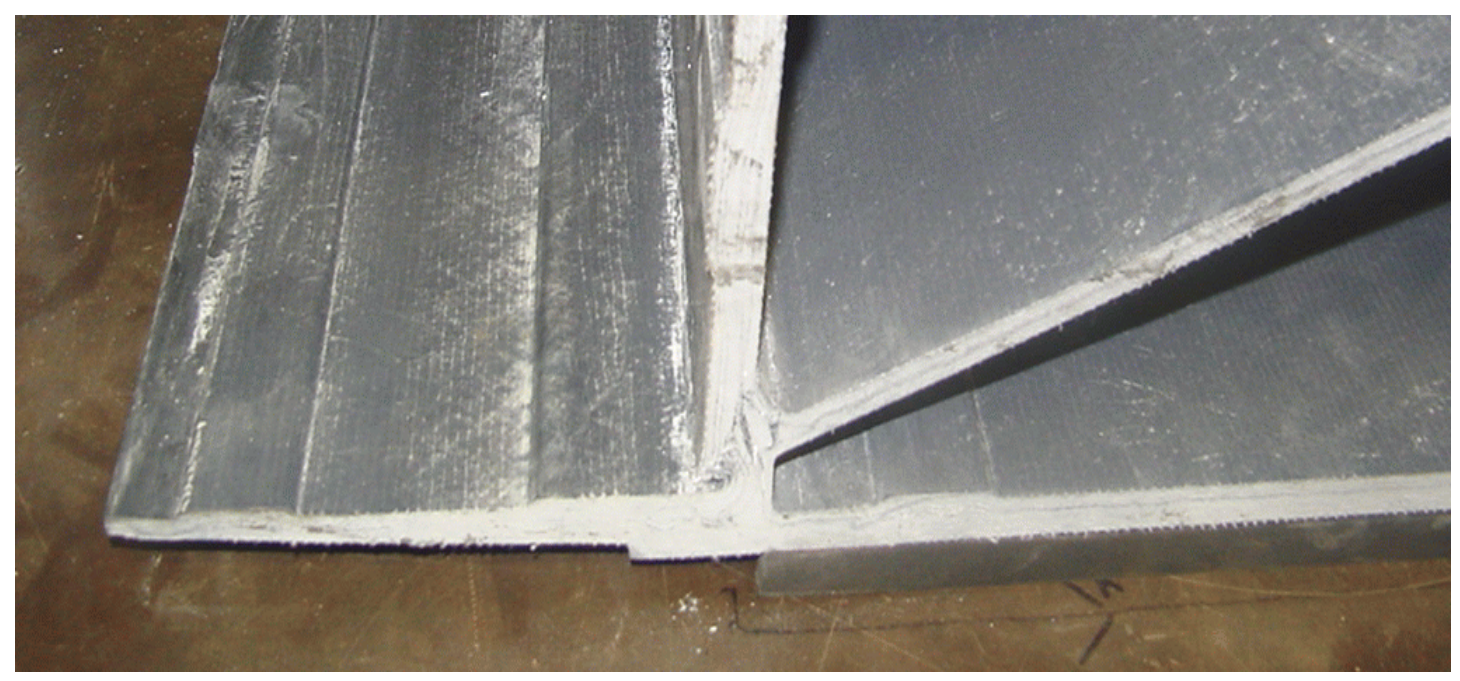

* Note that web buckled inducing secondary moments causing the joint to fail

Figure 5.3-Failure Mode of Vinyl Ester Buckling Specimens

\subsection{Failure due to Shear}

Of the four major types of failures observed in this study, shear failures were the most common and severe type. Four types of shear failure are possible in a bridge deck. They are listed below and can be seen in Figure 5.4 along with the material coordinate system. 
1) longitudinal/horizontal shear failure causing web/flange separation (XY plane),

2) punching shear failure ( $X Z$ and/or $Y Z$ plane),

3) racking shear (Y direction) causing bending or transverse web shear failures, and

4) torsional shear causing web failure (YZ plane).

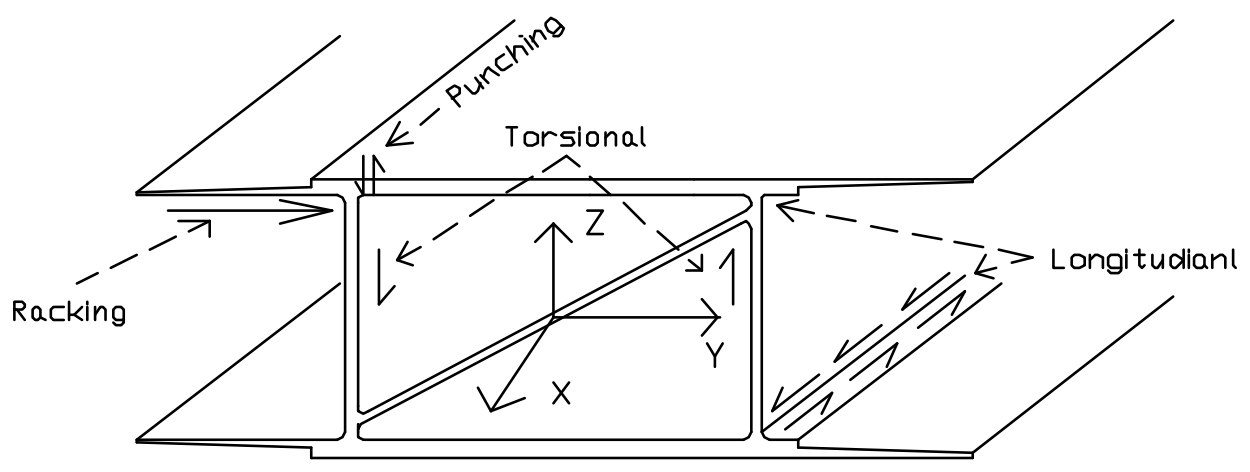

Figure 5.4-Description and Orientation of Possible Shear Failure Modes

Of the four possible types of shear failures depicted in Figure 5.4, three were observed during testing of the current lightweight bridge deck. A torsion failure could not be obtained due to the high stiffness of the component, i.e., a closed section. The torsion failure mode was mentioned only to shed light that the possibility of failure exists. All four failure modes should be checked to determine which will establish the most critical limit state; thus governing the design.

Shear failures were the most prevalent types of failure experienced in this study, primarily because of the fiber architecture of the components. Neither component type contained any fibers placed exclusively in the transverse (or $90^{\circ}$ ) direction. The only resistance to punching shear (as seen in 5.3.2) was the contribution of the $\pm 45^{\circ}$ fabrics and chopped strand mats. As a result, the punching shear resistance of the component was poor relative to the rest of its capacity.

Another major shortcoming of the fiber architecture of these two components (polyester and vinyl ester) was the lack of stitching in the vertical (or Z) direction-see Figure 5.4. Placing fibers in this direction (especially at the joints) would enhance the shear resistance to both punching and longitudinal shear, creating a component more resistant to shear failures than the one without Z-direction fibers. The following 
sections describe the shear failures observed during testing, and determine how well the strain to failure method predicts their failure stresses.

\subsubsection{Failure in the Longitudinal Direction due to Web/Flange Separation}

Separation of the web and flange due to excessive shear stress caused the failure of the component labeled Polyester \#2 (See 4.2.1, 4.3.1, and 4.5.1 for additional failure data). The test was performed on a 108" span under simply supported conditions. In addition, 24" web bracing was placed in the exterior lap joints to mimic actual field conditions. Figure 5.5 shows the test set-up.

Shear stress in the longitudinal/horizontal (or $\mathrm{X}$ ) direction caused by a shearing force in the vertical (or Z) direction can be predicted according to Hibbeler (1997) as per equation 5.2. See Figure 5.4 and note the qualifications at the end of section 5.1.

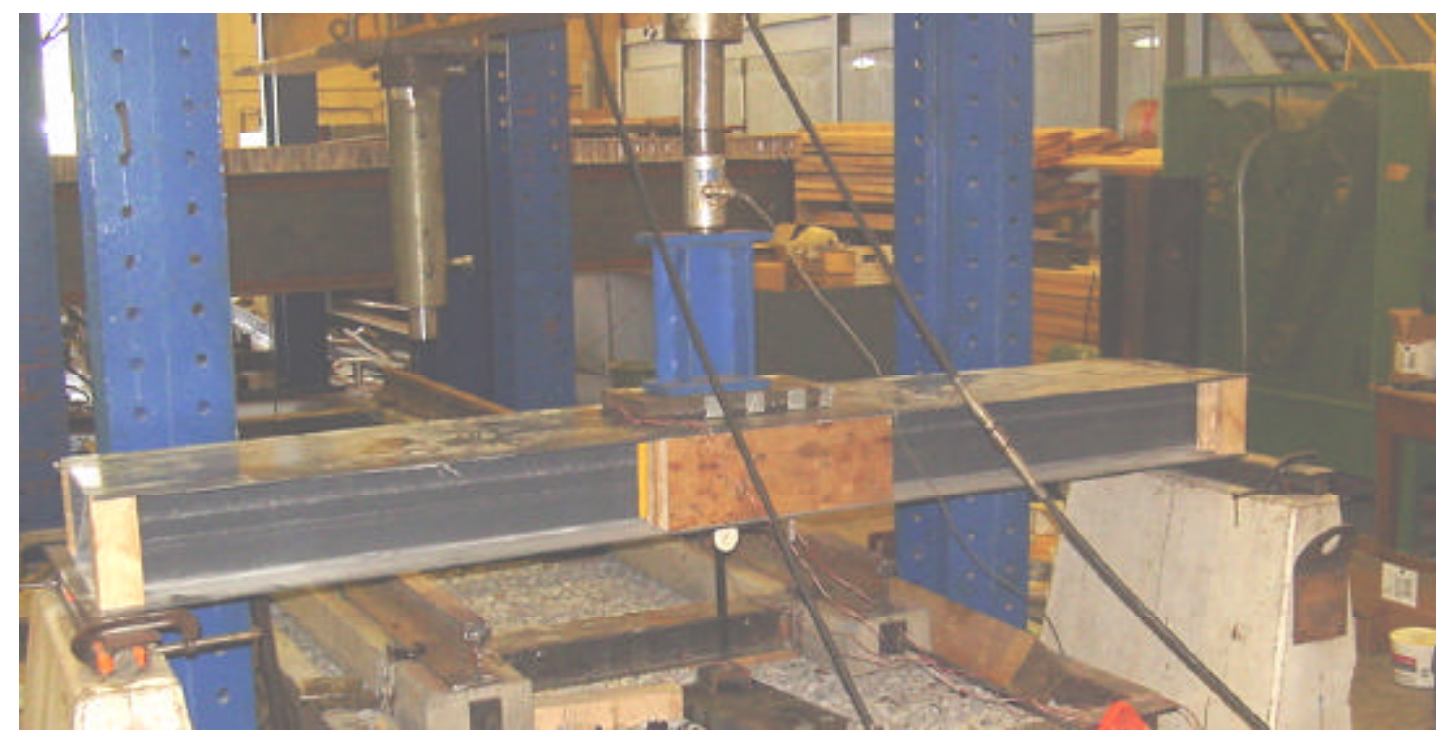

Figure 5.5-Representative Test Set-Up of Bending Components

$$
\tau_{\mathrm{ult}}=\frac{\mathrm{V}_{\mathrm{ult}} \mathrm{Q}}{\mathrm{I}_{\mathrm{x}} \mathrm{t}}
$$


Where,

$t_{\text {ult }}=$ ultimate shear stress

$\mathrm{V}_{\mathrm{ult}}=$ ultimate shearing force (26 kips)

$\mathrm{I}_{\mathrm{x}}=$ moment of inertia of cross-section $\left(300 \mathrm{in}^{4}\right)$

$\mathrm{t}=$ width of cross-section at the point where $\tau_{\text {ult }}$ is to be determined $(0.7 \mathrm{in})$

$\mathrm{Q}=\mathrm{y}^{\prime} \mathrm{A}$

Where,

$\mathrm{A}^{\prime}=$ area above (or below) the point where $\tau_{\text {ult }}$ is to be determined $\left(9.5 \mathrm{in}^{2}\right)$

$\mathrm{y}^{\prime}=$ distance from neutral axis to centroid of $\mathrm{A}^{\prime}$ (3.75 in)

The parameters shown in parenthesis beside the definition of terms in equation 5.2 are for Polyester \#2. Incorporating them into equation 5.2, the maximum longitudinal shear stress was found to be:

$$
\tau_{\text {ult }}=4.4 \mathrm{ksi} \text { (based on equation 5.2) }
$$

The ultimate shear stress obtained from equation 5.2 should lie somewhere in the vicinity of the value obtained from equation 5.3, since the specimen experienced linear behavior to failure. Equation 5.3 is Hooke's law for the shear behavior of materials. Note all qualifications stated in section 5.1 must be applied.

$$
t_{\mathrm{ult}}=\left(\mathrm{G}_{\mathrm{m}}\right)(2 \% \text { Elongation })
$$

Where,

$\mathrm{G}_{\mathrm{m}}=$ shear modulus of resin when combined with fibers $\left(2 * 10^{5} \mathrm{psi}\right)$

$2 \%$ Elongation $=$ shear strain to failure of resin 
It is of interest to note that $\mathrm{G}_{\mathrm{m}}$ is approximately half without the presence of fibers. The resin shear modulus generally lies in the neighborhood of $1\left(10^{5}\right)$ psi. The shear modulus of the resin matrix increases relative to the virgin resin since the fibers may contain whiskers and/or create higher frictional resistance between fiber and resin, which increases the effective shear capacity. 2(10 $)$ psi was obtained from Shekar (2000) and Nagaraj (1994).

Shear strain to failure of resin was found by referencing the works of Adams (no published year), MIL-HDBK-17-2E (1998), Wen (1999), and Wu (1990). Based on shear moduli, ultimate shear stresses and strains, and their relevant data, the $2 \%$ elongation value was found to be reasonable for polyester and vinyl ester resins. It should be noted that the $2 \%$ elongation value would vary greatly for different resins. Epoxies and urethane resins behave differently than polyester and vinyl ester resins, and their appropriate elongation values would need to be determined before utilizing equation 5.3. Incorporating $2 \%$ elongation and a shear modulus of $2\left(10^{5}\right)$ psi into equation 5.3, the following limit state was determined.

$$
t_{\mathrm{ult}}=4.0 \mathrm{ksi}(\text { based on equation 5.3) }
$$

As shown, the two methods only varied by $0.4 \mathrm{ksi}$, or approximately $9 \%$. Figure 5.6 shows the actual failure mode seen from an end view.

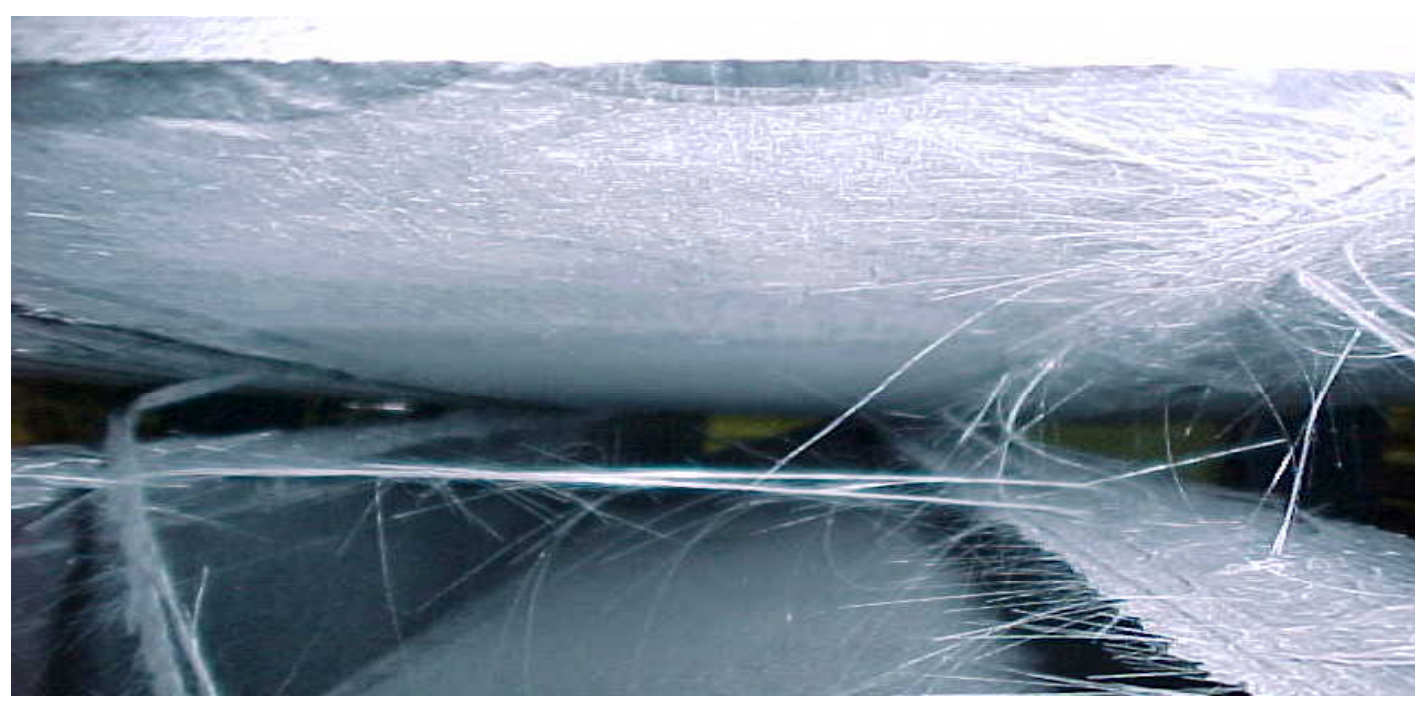

Figure 5.6- Damage due to Web/Flange Separation Failure Mode (End View) 


\subsubsection{Failure due to Punching Shear}

Shear stress around the area where the load is applied on to the specimen is one of the most critical areas in orthotropic (FRP) bridge decks. The patch load (tire impression of 10"x 20") creates a punching shear effect around its perimeter. When the shear stress around the perimeter of the load patch becomes too large, the load patch will punch through the top flange causing shear failure. Depending on the size of the load patch and the cross-sectional shape of the component, i.e., including webs that stiffen the top flange of the deck, the entire perimeter of the patch may or may not be effective at failure.

During testing, only the two 20" sides of the 10 "x 20 " load patches were effective. The reason for this behavior is that the vertical webs are spaced at a distance greater than the width of the patch (10"). As a result, the patch load could punch through the top flange by shearing only the two 20 " sides of the deck. At failure, the only damage was along the 20 " sides of the patch so it was concluded that the effective perimeter for the particular case studied was 40", not 60". It is recommended that a punching shear test be run on each type of component to determine the effective perimeter at failure for each patch load, both in terms of load intensity and perimeter of the patch load.

The experiment was conducted on a 120" span under simply supported conditions. Figure 5.5 shows the set-up of the experiments. Further details on the two components can be found in Chapter 4 (Sections 4.2.1, 4.3.1, and 4.5.1).

The shear stress at failure was determined as follows:

$$
\tau_{\text {ult }}=\frac{P_{\text {ult }}}{\left(p_{\text {eff }}\right)(t)}
$$

Where,

$\mathrm{P}_{\mathrm{ult}}=$ failure load applied to the patch

$\mathrm{p}_{\text {eff }}=$ effective perimeter of the patch (40")

$\mathrm{t}=$ composite thickness of the loaded area $\left(0.5^{\prime \prime}\right)$ 
The proposed limit state can be seen in equation 5.5. This equation is merely an area transformation of the bi-directional fibers and fabrics of the current design. The flange is transformed to an equivalent unidirectional composite in order to make a comparison with pre-established values. It should be noted that the maximum intralaminar shear stress was taken from Table 1.1 of Barbero (1998). The value given was for an E-glass composite with a fiber volume fraction of approximately $50 \%$. It is recommended that the maximum intralaminar shear stress be adjusted according to the type of composite considered since the value used in equation 5.5 is only valid for sections of 0.5 " thickness or less with a fiber volume fraction of approximately 50\%. Also, the terms defining the percentage of thickness contributed by either mats of $45^{0}$ fabrics can easily be determined using the product specification tables (A1 through A4) of Appendix A. Again, the qualifications mentioned in section 5.1 must be understood.

$$
\tau_{\text {ult }}=\tau_{\text {max uni }} \mathrm{V}_{\mathrm{f}}\left[\left(\mathrm{V}_{ \pm 45}^{\%}\right) \cos ^{2} \theta+\mathrm{V}_{\text {mat }}^{\%}\right]
$$

Where,

$\tau_{\max \text { uni }}=$ maximum intralaminar shear stress of unidirectional composite $(11 \mathrm{ksi})$

$\mathrm{V}_{\mathrm{f}}=$ fiber volume fraction of composite $(54 \%)$

$\mathrm{V}_{ \pm 45}^{\%}=$ percentage of flange thickness made up of $45^{\circ}$ fabrics

( $34 \%$ for polyester component and $40 \%$ for vinyl ester component)

$\mathrm{V}_{\text {mat }}^{\%}=$ percentage of flange thickness made up of mats

(11\% for polyester component and $13 \%$ for vinyl ester component)

Based on equation 5.5, the limit state for punching shear was found to be 1.7 ksi for the polyester component and $2 \mathrm{ksi}$ for the vinyl ester component.

Table 5.2 shows the results of the two components tested and their comparisons based on equations 5.4 and 5.5. From Table 5.2 it can be seen that the 
limit state predicted an ultimate stress approximately equal to the actual test data in both cases.

\begin{tabular}{|c|c|c|c|c|}
\hline Component & $\mathrm{P}_{\text {ult }}(\mathrm{k})$ & $\tau_{\text {ult }}($ Experiment $)$ & $\tau_{\text {ult }}$ (Theory) & $\%$ Difference \\
\hline Polyester \#1 & 36 & $1.8 \mathrm{ksi}$ & $1.7 \mathrm{ksi}$ & $6 \%$ \\
\hline Vinyl Ester \#1 & 37 & $1.9 \mathrm{ksi}$ & $2.0 \mathrm{ksi}$ & $5 \%$ \\
\hline
\end{tabular}

Table 5.2-Comparison of Punching Shear Failure Results with Limit States

It is important to note that equation 5.5 does not take into account the shear resistance of the resin because of its low value in relation to fibers. Also, effects of local fiber bending and kinks are neglected in the theory developed herein, and continuity effects of fabrics are neglected; i.e. one neglects the other. The only resistance accounted for is that of the fibers in the (XZ) plane. As a result, equation 5.5 should yield slightly conservative values. Furthermore, Figure 5.7 shows the actual failure mode.

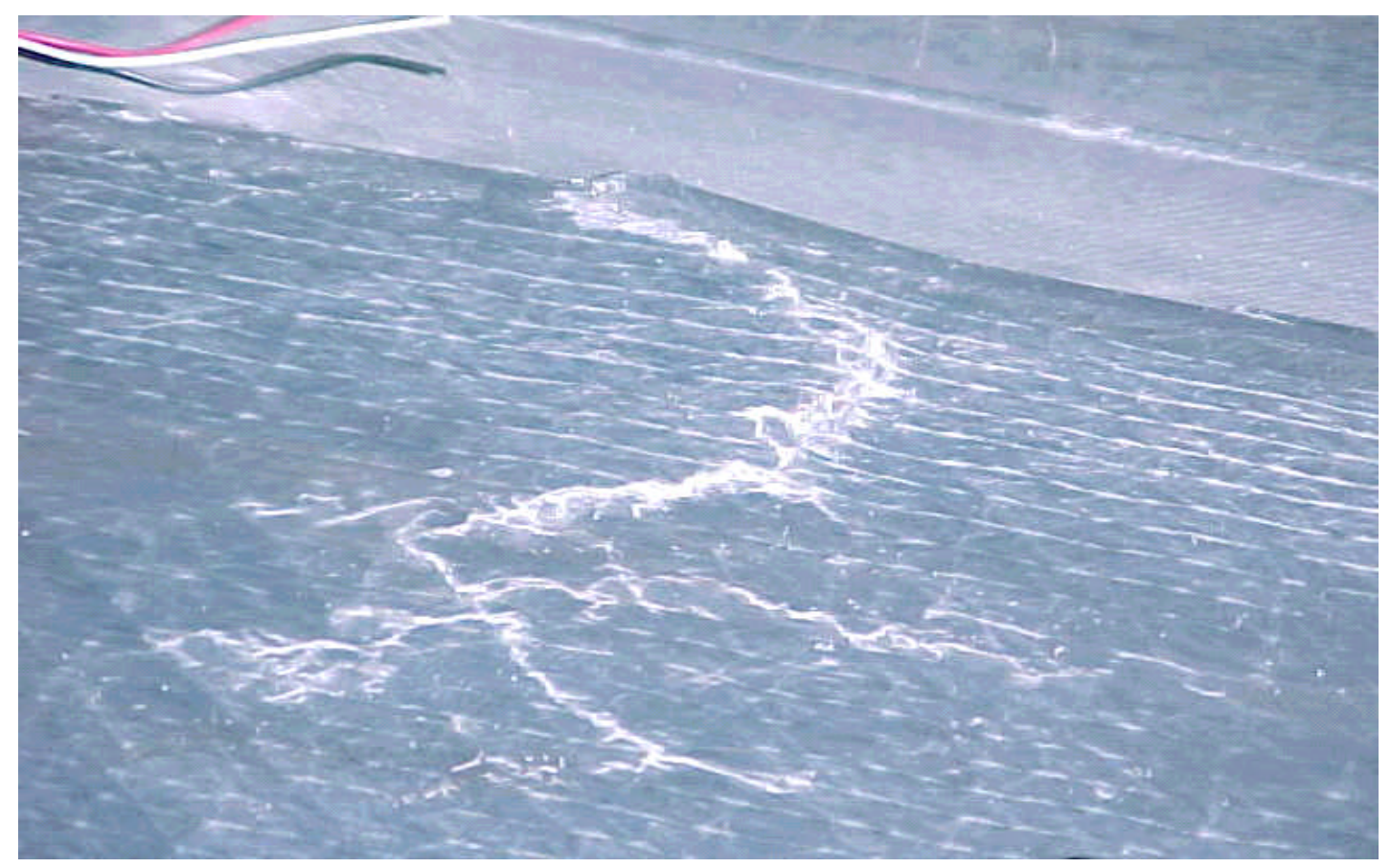

Figure 5.7-Damage due to Punching Shear Failure Mode 


\section{Evaluation of a 1" Wide Component to Determine the Shear Response}

Due to low shear stress resistance as shown in Table 5.2, a vinyl ester component cross-section 1" wide was tested to determine the shear stress that would cause failure at the intersection of the web and flange (See Figures B3 and B5 for further details). The test was performed to validate failure stresses due to punching shear found from the other two components whose failure mode was punching shear. A shearing force was applied 0.5 " from the web/flange junction. The experimental set-up and failure mode can be seen in Figure 5.8. The specimen was loaded to failure at a rate of $200 \mathrm{lb} / \mathrm{min}$. The failure load observed was slightly over $1000 \mathrm{lb}$.

Making use of equation 5.4 with a shear area $\left(p_{\text {eff }} t\right)$ of $0.5 \mathrm{in}^{2}$, the shear stress causing failure was determined to be approximately $2 \mathrm{ksi}$. This value agrees within $5 \%$ of the ultimate shear stresses determined via experimental data from the other vinyl ester component. The ultimate stress of $2 \mathrm{ksi}$ is equal to the limit of equation 5.5 when both are rounded to one decimal place.
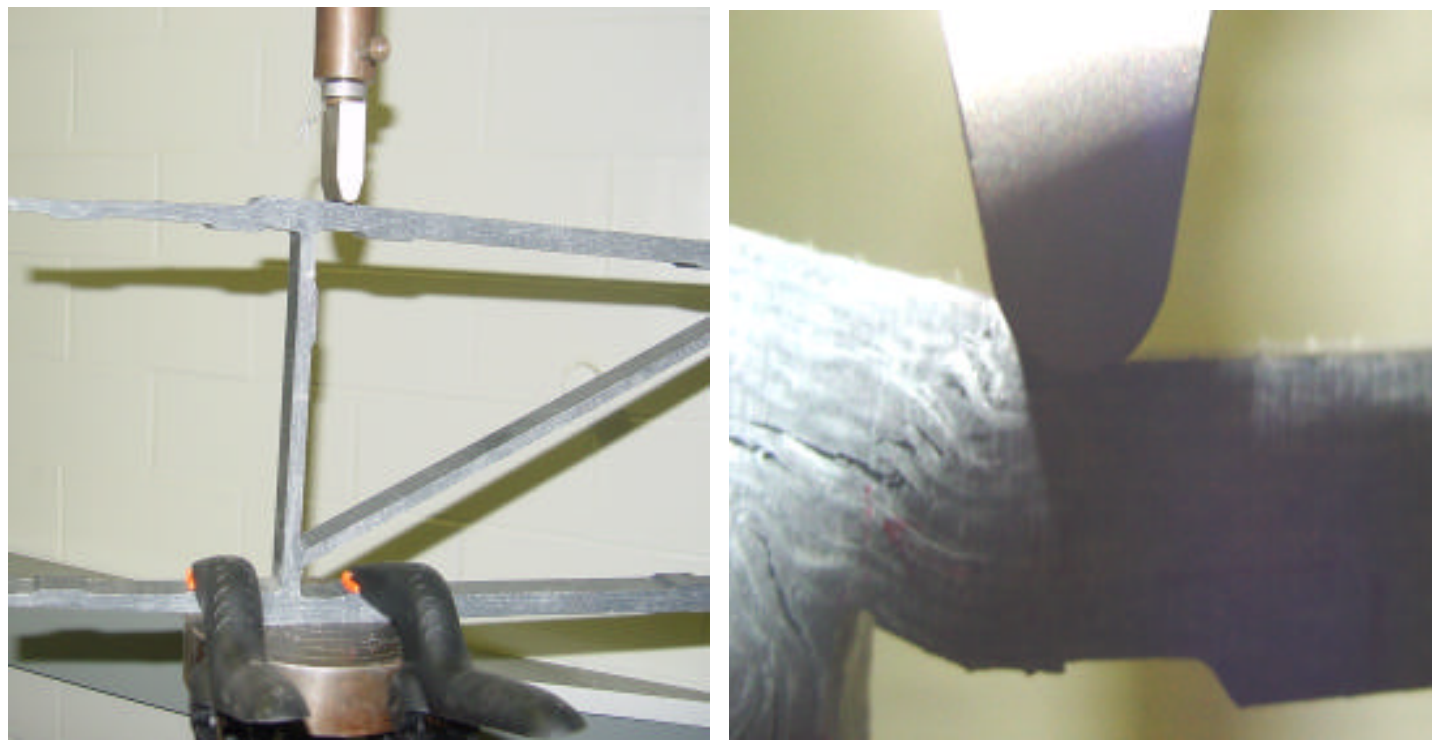

Figure 5.8-Test Set-Up and Failure Mode of 1" Wide Shear Component

\subsubsection{Failure due to Racking Shear}

Racking shear is a phenomenon caused by horizontal forces induced between vehicle tires and the deck wearing surface under either breaking or acceleration 
forces. These forces tend to distort the top flange of the component relative to the bottom flange since the bottom flange is connected to the stringers. This distortion induces potentially large forces into the components; especially the horizontal force effects being localized on the surface of the top flange.

A 4" wide vinyl ester component was tested for racking shear to determine its ultimate load and failure mode. The test set-up can be seen in Figure 5.9. As shown in the figure, one flange of the component was fixed to the column of the testing frame, while the other flange was free to move. The flange that was free to move inplane was equipped with a $3 / 8$ " thick polymer concrete wearing surface to simulate actual field conditions. However, the overall test set-up was much more severe than the actual loading conditions. In service, the FRP components would be joined together to create a continuous deck module. The continuity would serve to stiffen the top flange, whereas the experiment performed in this section treated the top flange as a freestanding element. Furthermore, the load was applied over a 1"x 4" steel plate starting at the top face of the loaded flange.

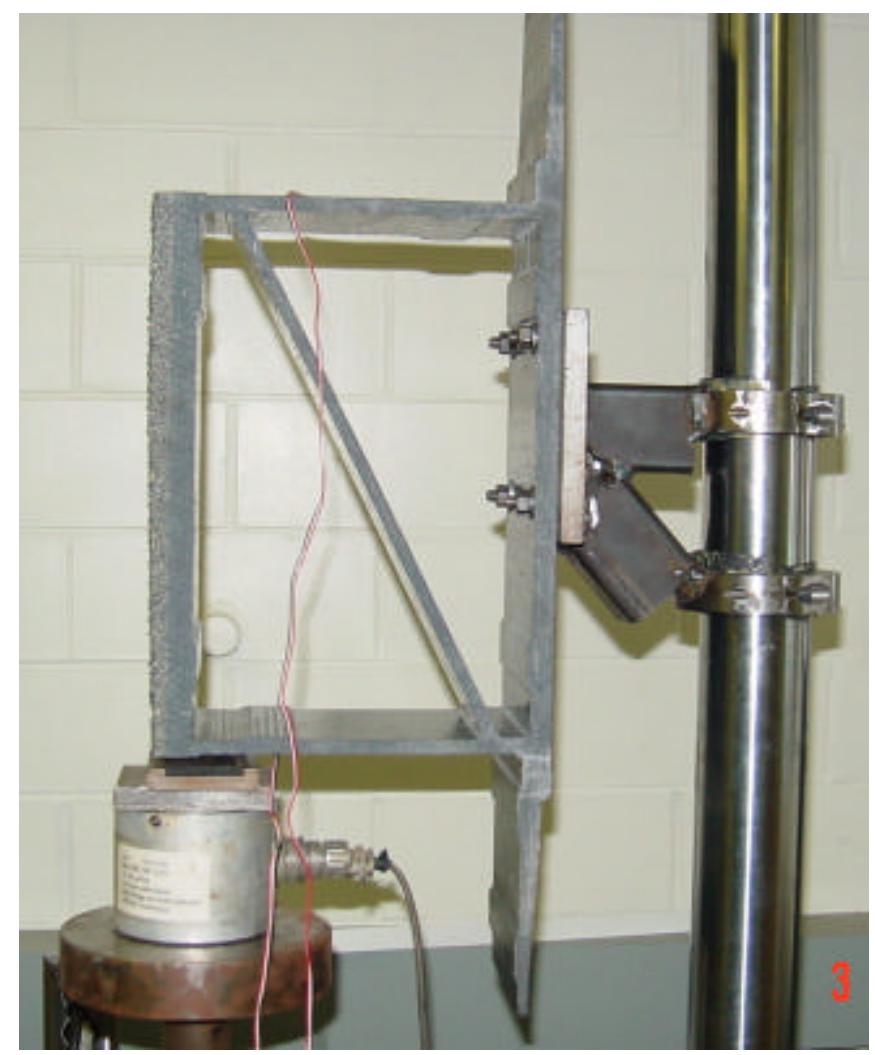

Figure 5.9-Test Set-Up of Racking Shear Component 
The testing resulted in an ultimate load of approximately $500 \mathrm{lb}$, and the failure mode was a bending failure at the web/diagonal junction furthest away from the load. The failure occurring in the web furthest from the load and not in he web nearest the load shows the influence of the top flange. For the web nearest the load, the top flange would act as both a stiffener and a load transfer mechanism. However, the flange furthest from the load had no such stiffener to help resist the loading, which allowed it to fail first.

It should be noted that the lack of stiffening of the web, which experienced failure, would not be true in service. Either another component or the bridge abutment, depending on its location in the bridge deck, would act as a stiffener. As a result, the large deformations observed in the current test, 3/4" at failure, would occur only if the top flange buckled. Buckling of the top flange in service would not occur at $500 \mathrm{lb}$. Figure 5.10 shows the actual failure mode.

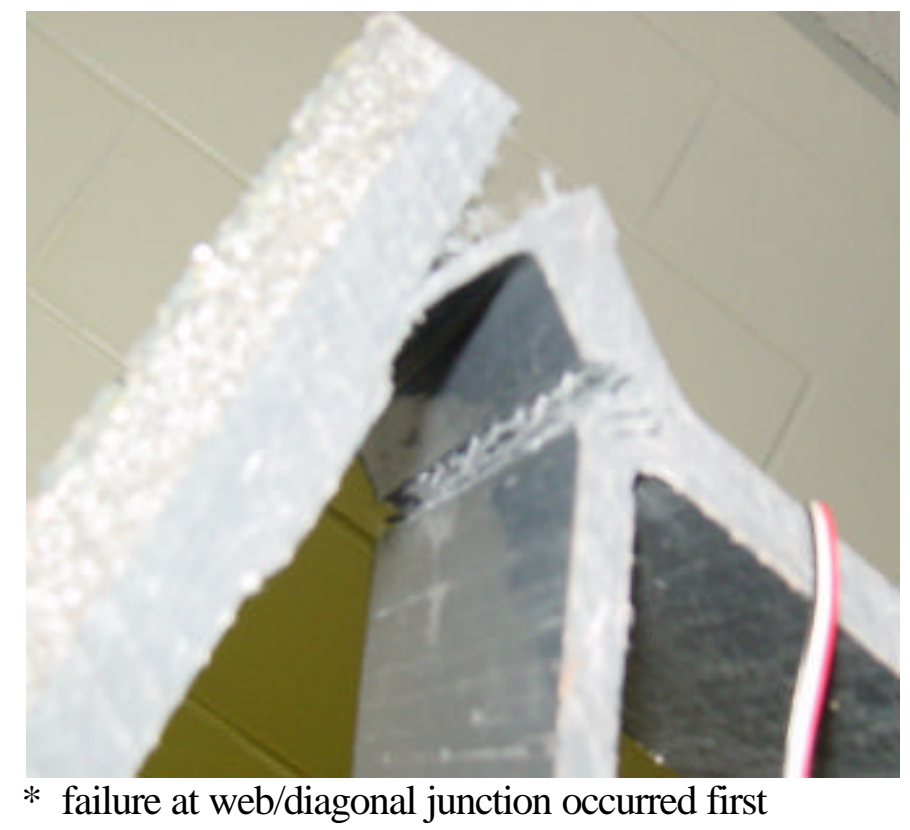

Figure 5.10-Failure Mode of Racking Shear Component

The ultimate bending stress of the web at failure was calculated using equation 5.6. 


$$
s=\frac{\mathrm{M}}{\mathrm{S}}
$$

Where,

$S=$ ultimate bending stress of web

$\mathrm{M}=$ ultimate bending moment of web at point of failure (500 in*lb)

$\mathrm{S}=$ section modulus of web $\left(0.1 \mathrm{in}^{3}\right)$

Based on equation 5.6, the ultimate bending stress of the web due to racking shear was found to be $5 \mathrm{ksi}$. As mentioned previously, the ultimate stress in service would be more than $5 \mathrm{ksi}$. This test was designed to create the worst-case scenario, which it successfully accomplished. The location where the bending failure occurred has limited fiber continuity between the web and diagonal, and the location also has stress concentrations. Both of these factors aided in the low ultimate stress value. However, as previously mentioned, the addition of stiffening behind the web, which experienced failure, would greatly help reduce the stresses induced in the web by a given in-plane breaking/acceleration force.

The experiment was performed with mechanical fasteners holding the bottom flange. The use of mechanical fasteners in a bridge deck system can limit the effects of racking shear to the top flange only. This is important to the overall behavior of the structure in that the racking shear effect is limited to a local level. Therefore, the overall stability of the structure is maintained at all times.

\subsubsection{Failure due to Torsional Shear}

No failures were observed due to the effects of torsion. The specimen could not be taken to failure due to the continuity of fabrics from the web to the flange. However, in bridge decks where no fiber continuity exists between the web and flange, torsion presents a serious problem, especially under sustained loads, and can lead to a probable failure mode. In such cases, resin and/or glue line failure limit states would have to be established. 


\subsection{Failure due to Bending}

As mentioned in section 5.3, the current design is dominated by shear with respect to failure. Only two bending failures were observed in this study. One was due to compression flange buckling, while the other was the failure of the top flange in the transverse direction of a 1" wide component. These two types of bending failures are described in the following two sections.

\subsubsection{Bending Failure due to Buckling of the Compression Flange}

The component named Vinyl Ester \#2 failed at 67 kips due to buckling of the compression flange in the longitudinal direction. The test was performed on a 120" span under simply supported conditions. Figure 5.5 shows a representative set-up of the bending experiments. This component was previously discussed in Chapter 4 (Sections 4.2.1, 4.3.1, and 4.5.1). As shown in Figure 5.11, the top flange of the specimen was damaged across its entire 24" width. Therefore, it can be concluded that, in this particular case, the entire top flange was effective in resistance to compression flange buckling. An applied load patch of 15"x 24" was placed on the specimen. The large size of the patch load most likely played an important role in allowing the entire flange to be effective against buckling in the longitudinal direction. As a result, it is recommended to test the specimen in question under a given set of conditions to determine the amount of the top flange that is effective against buckling.

To analyze the component for longitudinal buckling, Euler's buckling formula was utilized (Boresi et.al. 1993) along with the flexure formula. Since Euler's buckling formula deals with columns being axially loaded, it was necessary to determine the axial (or $\mathrm{X}$ direction according to Figure 5.4) effect on the top flange caused by the vertical (or $\mathrm{Z}$ direction according to Figure 5.4) loading. This was performed as follows, noting that this method is only approximately valid for sections 8 " deep or less under 3-point bending. Also, all qualifications of section 5.1 must be met. 


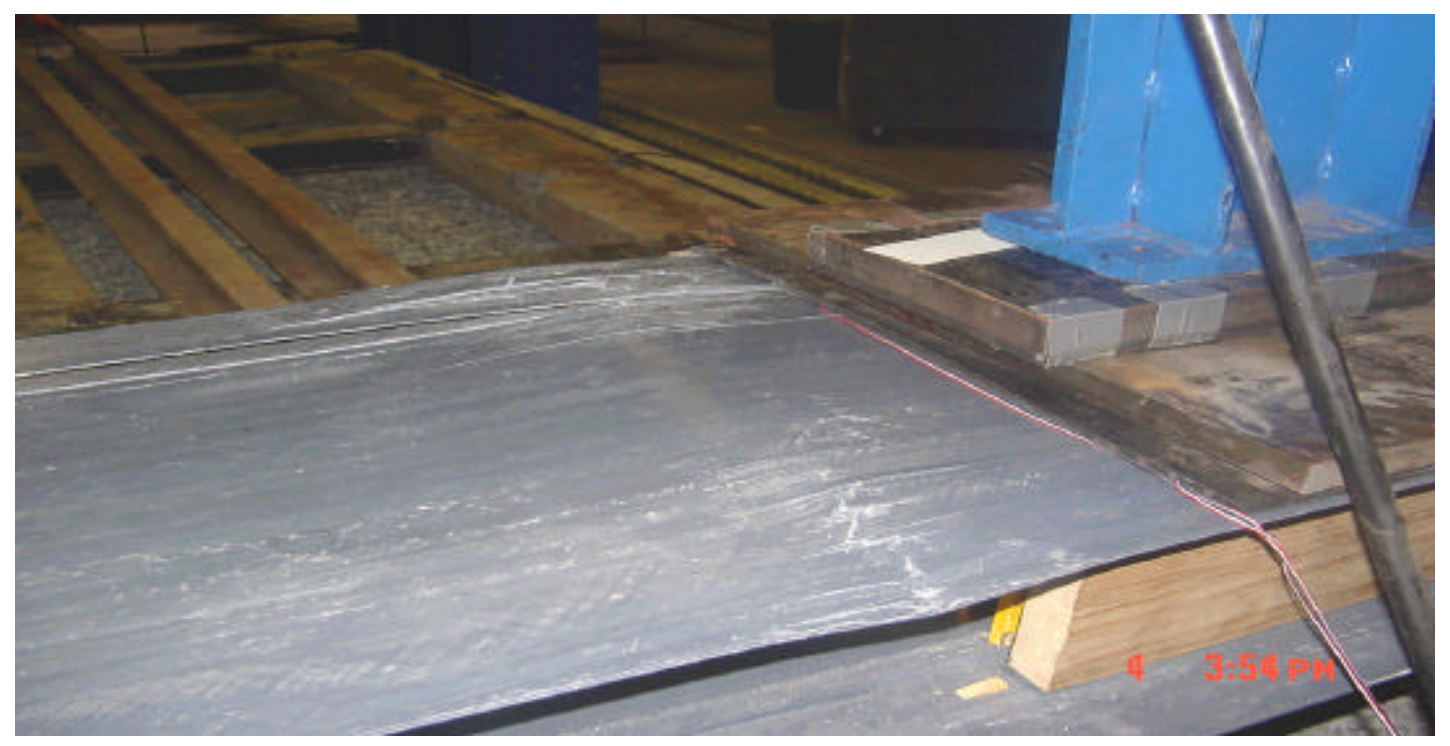

Figure 5.11- Damage due to Top Flange Buckling Failure Mode

1) Determine the maximum compressive stress acting on the top flange at failure using equation 5.7.

2) Assume the top flange of the component is now a column with an axial load equal to the maximum compressive stress of equation 5.7 multiplied by the area of the top flange $\left(\mathrm{A}_{\mathrm{eff}}\right)$-equation 5.8

3) Use the axial load $\left(\mathrm{P}_{\text {eff }}\right)$ obtained from equation 5.8 and calculate the effective length factor $(\mathrm{K})$ of the component using equation 5.9.

$$
\begin{gathered}
\sigma_{\text {max comp }}=\frac{M(c)}{I}=\frac{P_{v} L(c)}{4 I_{c s}} \\
\sigma_{\text {max comp }}=\frac{P_{\text {eff }}}{A_{\text {eff }}} \\
P_{\text {eff }}=\frac{\pi^{2} E_{x} I_{\text {eff }}}{(K L)^{2}}
\end{gathered}
$$


Where,

$\sigma_{\max \text { comp }}=$ compressive stress in top flange at failure (26.8 ksi-See Table 4.4)

$\mathrm{P}_{\mathrm{eff}}=$ effective axial load necessary to induce buckling in the compression flange

$\mathrm{A}_{\text {eff }}=$ effective area of the top flange $\left(9.5 \mathrm{in}^{2}\right)$

$\mathrm{P}_{\mathrm{v}}=$ actual vertical load applied to the specimen (67 kips)

$\mathrm{c}=$ distance from outermost compression fiber to neutral axis (4 in)

$I_{\mathrm{cS}}=$ moment of inertia of entire cross-section $\left(300 \mathrm{in}^{4}\right)$

$\mathrm{E}_{\mathrm{x}}=$ modulus of elasticity (See 4.5.1.1)

$\mathrm{I}_{\mathrm{eff}}=$ moment of inertia of top flange about neutral axis of component $\left(135 \mathrm{in}^{4}\right)$

$\mathrm{L}=$ actual length of top flange (120 in)

$\mathrm{K}=$ effective length factor

Equations 5.7 through 5.9 were then solved for their two unknowns $\mathrm{P}_{\text {eff }}(255$ kips) and $K$ (1.2). An effective length factor of 1.2 indicates the presence of sway in the flange at failure. The presence of sway was expected since the flange is not restrained against sway except by the connection to the web in the $(\mathrm{Z})$ direction. It should be noted that the stress in the top flange was assumed to be constant throughout the thickness. A small error results from this assumption since the stress actually decreases as one moves closer to the neutral axis, but the error will be small provided thin-walled sections are being used. In this particular case, if the stress reduction is properly accounted for across the flange thickness, the two unknowns are determined to be $\mathrm{P}_{\text {eff }}(239 \mathrm{kips})$ and $\mathrm{K}$ (1.24). It is recommended that the error in assuming constant stress through the thickness of the top flange be checked for any sections thicker than 0.5 ".

\subsubsection{Transverse Bending Failure of Top Flange}

In order to determine the capacity of the flange of the vinyl ester FRP bridge deck components in the transverse direction, two specimens were tested. The only difference in the two specimens was the width. One was 1" wide, while the other was 6" wide (See Figures B3 and B5 for further details). The top flange was under $3-$ 
point bending, and the ultimate load necessary to induce failure was recorded in each case. The experimental set-up and failure mode can be seen in Figure 5.12 noting that the 1" specimen is shown in the figure, while the 6" specimen had the same setup and failure mode. The test was performed by applying load at a constant rate of 50 $\mathrm{lb} / \mathrm{min}$ until failure occurred. The failure was due to tension in the flange directly under the load in each case. The only data recorded from the 1" wide specimen was the ultimate load, while the ultimate load, ultimate deflection, and ultimate strains were recorded for the 6" wide specimen. See Table 5.3 for the results of the experiments.

\begin{tabular}{|c|c|c|c|c|}
\hline Specimen & $\begin{array}{c}\text { Ult. Load } \\
\text { (lb) }\end{array}$ & $\begin{array}{c}\text { Ult. Deflection } \\
\text { (in) }\end{array}$ & $\begin{array}{c}\text { Ult. Strain* } \\
\text { (micro-strains) }\end{array}$ & $\begin{array}{c}\text { Joint Strain** } \\
\text { (micro-strains) }\end{array}$ \\
\hline 1" Wide & 300 & NA & NA & NA \\
\hline 6"Wide & 2200 & 0.9 & 10,500 & 1,000 \\
\hline
\end{tabular}

* Taken from bottom of flange directly under load

** Taken from top of flange directly over vertical web

Table 5.3-Results of Transverse Bending Failure Testing of Top Flange

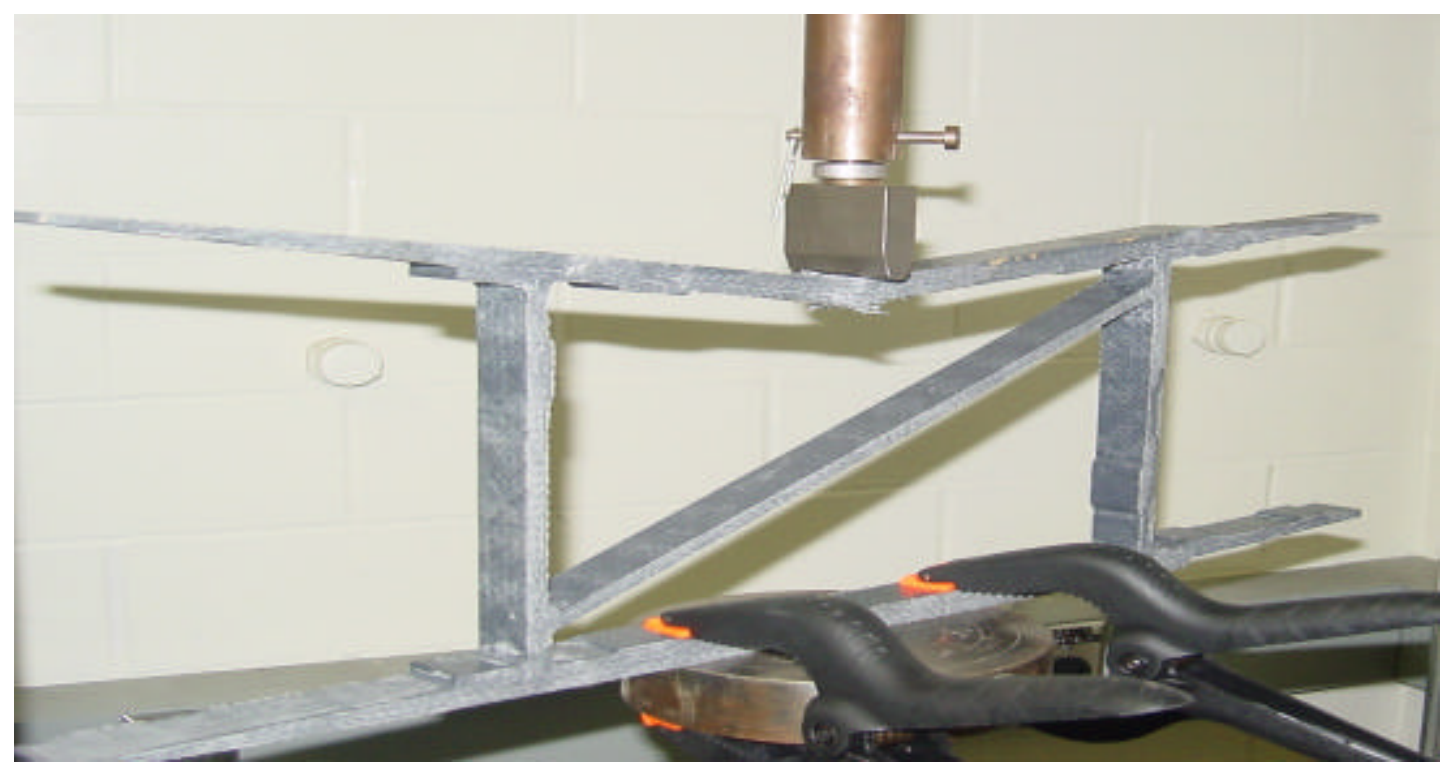

Figure 5.12-Test Set-Up and Failure Mode of Transverse Flange Experiment 
The flexure formula was again used to compute the ultimate stress as seen in equation 5.10 .

$$
\sigma_{\text {max }}=\frac{M(c)}{I}=\left(\frac{P L}{8}\right) \frac{c}{I}
$$

Where,

$\mathrm{M}=$ ultimate moment of flange

$\mathrm{c}=$ distance from neutral axis to outermost fiber $(0.25 \mathrm{in})$

$\mathrm{P}=$ ultimate load (See Table 5.3)

$\mathrm{L}=$ span of flange (11.65 in)

$\mathrm{I}=$ moment of inertia of cross-section $\left(0.0104 \mathrm{in}^{4} /\right.$ inch width $)$

Based on equation 5.10, the ultimate stress was found to be approximately $10.5 \mathrm{ksi}$ for the 1 " wide specimen and $12.8 \mathrm{ksi}$ for the 6 " wide specimen.

According to GangaRao and Shekar (2002), the strain to failure of the current case should be approximately 10,000 micro-strains under the conditions of section 5.1. Therefore, the ultimate stress of the flange can be approximated as follows:

$$
\sigma_{\max }=(10,000 \mu \mathrm{s})\left(\mathrm{E}_{y}\right)
$$

Where, $\mathrm{E}_{\mathrm{y}}=$ modulus of elasticity in transverse direction (See 4.5.3)

Based on equation 5.11, the ultimate stress was predicted to be $11 \mathrm{ksi}$, which differs from the experimental result of the 1 " wide specimen by approximately $5 \%$ and the 6" wide specimen by approximately $14 \%$.

\subsection{Joint Failure}

In the absence of a three dimensionally stitched fabric, continuity of fibers from web to flange is the only significant line of defense possessed by the joints of FRP composites (excluding the geometric shape). The continuous fibers in an FRP 
joint have a tendency to either break as a result of tensile forces or pull out from he web. Either failure causes an immediate loss of force transfer to the web from the flange, which consequently produces other failures in the component until all load carrying capacity has been lost.

In order to determine the type of failure that will occur in a specific component under a specific set of loading conditions, experiments need to be performed like the one shown in the schematic of Figure 5.13. In this particular joint test, the flange of a 4" wide vinyl ester component was cut at the centerline in order to induce tensile forces through bending into the continuous fibers of the joint (See Figures B3 and B5 for further details). The only resistance the joint has is contained in the continuous fibers on the tension side of the component. The continuous fibers in compression do not prevent any type of tensile or pullout failure.

Figure 5.14 shows the failure mode of the experiment shown in the schematic of Figure 5.13. The failure mode was breakage of the fibers continuing from web to flange on the tensile side. The load at failure was $130 \mathrm{lb}$, which was applied at 20 $\mathrm{lb} / \mathrm{min}$.

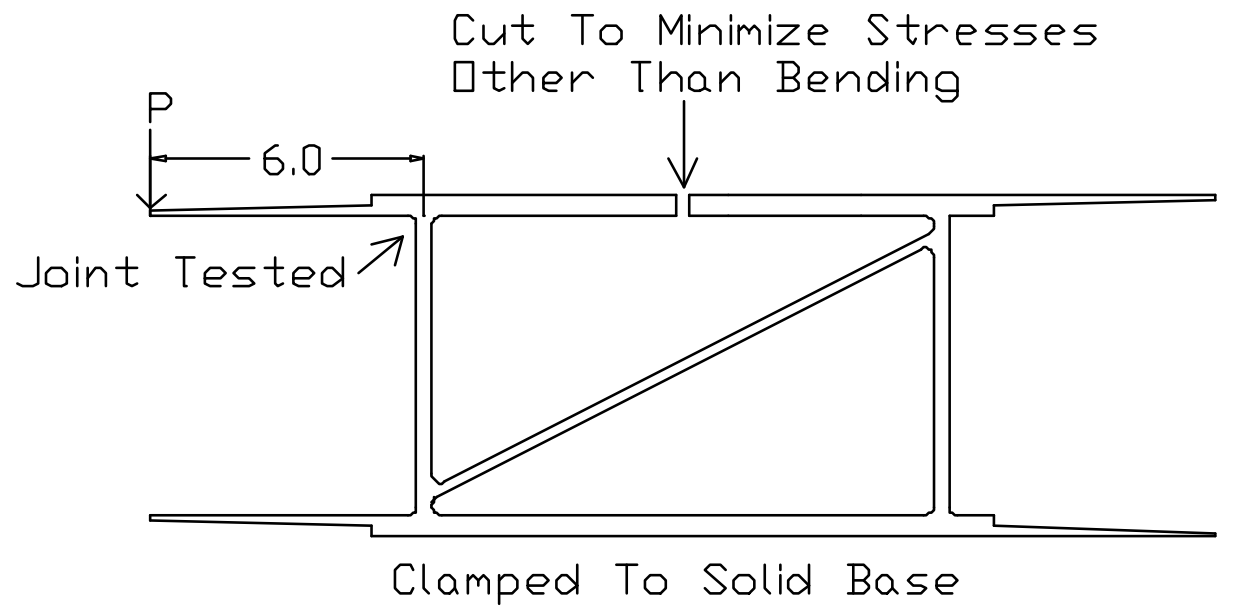

Figure 5.13-Joint Failure Schematic

The analysis of the data obtained from the tension failure was performed by isolating the portion of the web where the continuous fibers were located. The remaining portion of the web was neglected since it would not contribute significantly to the capacity of the joint under this type of loading. The stress analysis performed 
with equation 5.12 treats the web as if its thickness is only that of the three lamina that are continuous (See Figure B5 for description of lamina).

The web is then assumed to be the thickness of only those lamina and analyzed in bending under the moment caused by the vertical force applied a distance from the web.

$$
\sigma=\frac{M\left(c_{c}\right)}{I_{c}}=\frac{\operatorname{Pe}\left(t_{c} / 2\right)}{b\left(t_{c}\right)^{3} / 12}
$$

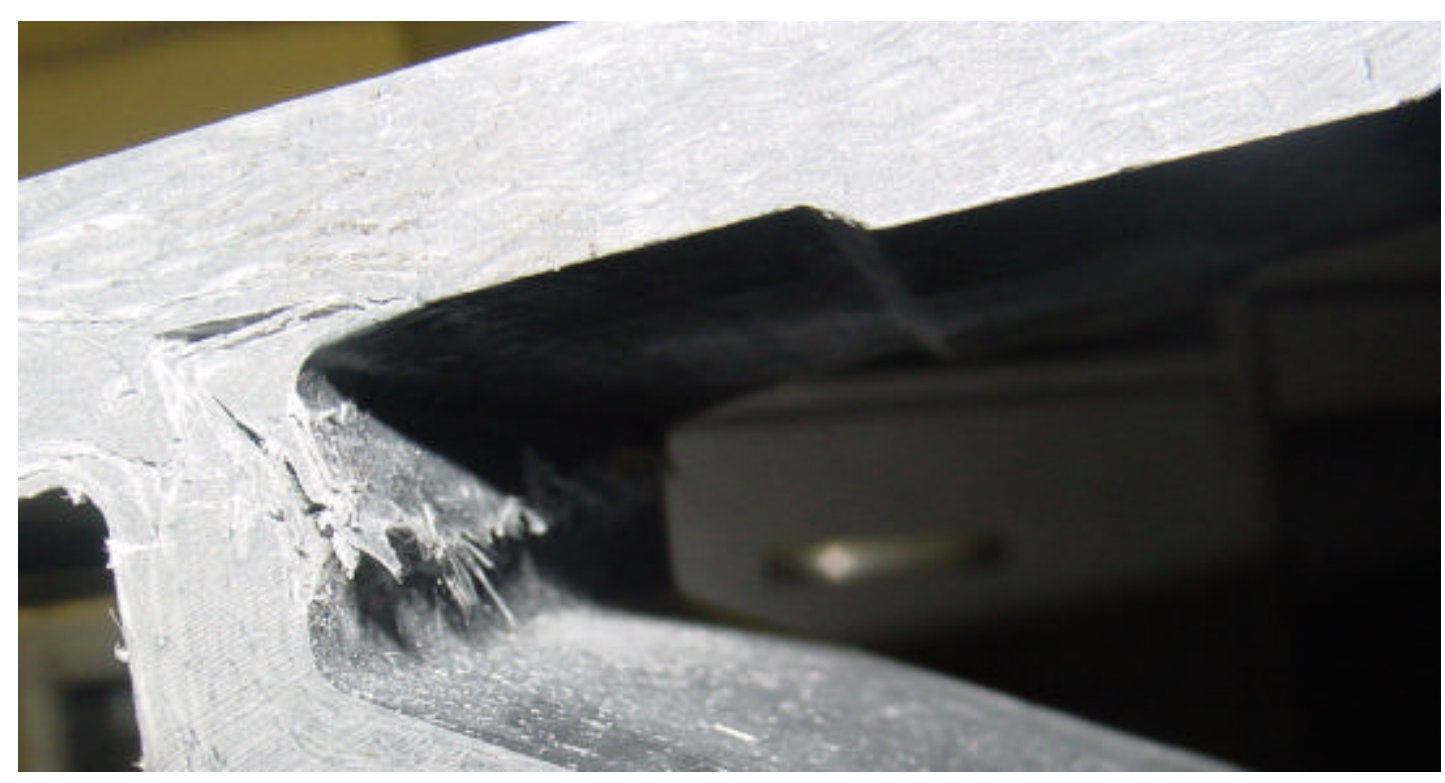

Figure 5.14-Failure Mode of Joint Test

Where,

$\mathrm{M}=$ ultimate moment at the joint

$\mathrm{c}_{\mathrm{c}}=$ distance from neutral axis of continuous tensile fibers to outermost tensile fiber

$\mathrm{I}_{\mathrm{c}}=$ moment of inertia of portion of web containing continuous tensile fibers

$\mathrm{P}=$ ultimate load $(130 \mathrm{lb})$

$\mathrm{e}=$ eccentricity of ultimate load with respect to web (6 in)

$\mathrm{t}_{\mathrm{c}}=$ thickness of continuous tensile lamina (0.14 in-See Tables A1 through A4)

$\mathrm{b}=$ width of web $(4 \mathrm{in})$ 
Based on equation 5.12, the ultimate stress of the area of the web containing continuous tensile fibers was found to be approximately $60 \mathrm{ksi}$.

The limit state of such a failure was established due to basic stress principles as follows:

$$
\sigma=\frac{\sigma_{\mathrm{fult}} \mathrm{V}_{\mathrm{f}}}{\mathrm{S}_{\mathrm{c}}}
$$

Where,

$\sigma_{\mathrm{fult}}=$ ultimate fiber stress $(500 \mathrm{ksi}-$ See Table 2.1$)$

$\mathrm{V}_{\mathrm{f}}=$ fiber volume fraction $(54 \%)$

$\mathrm{S}_{\mathrm{c}}=$ re-entrant angle stress concentration factor (2.6)

Based on the proposed limit state of equation 5.13, the ultimate stress was found to be $104 \mathrm{ksi}$. This value varies from that of equation 5.12 by approximately $40 \%$. The large differences of equations 5.12 and 5.13 show the presence of other forces in addition to bending. As a result, more in depth exploration of joint failures are necessary, especially those focusing on multiple loadings simultaneously.

It would also have been possible to have had a pullout type failure. Attempts were made to achieve this type of failure on the vinyl ester deck components, but no such quantifiable failure could be achieved. If fibers are pulling out of the joint, there are problems with the lap length of the fibers. Mallick (1993) proposed a method to address such issues and it is presented below. The values used to compute the required fiber length were taken from Mallick (1993), and do not necessarily represent the orientational properties of the component of this study.

$$
\text { lc }=\frac{\sigma_{\text {fult }}}{2 \tau_{i}} d_{f}
$$

Where,

$1_{c}=$ minimum fiber length required to achieve maximum fiber stress at midlength 
$\sigma_{\mathrm{fult}}=$ ultimate fiber stress $(500 \mathrm{ksi})$

$\mathrm{d}_{\mathrm{f}}=$ fiber diameter (393 micro-inches)

$\tau_{\mathrm{i}}=$ lesser of shear strength of the fiber-matrix interface or shear strength of matrix adjacent to interface $(0.6 \mathrm{ksi}-6 \mathrm{ksi}$ depending on additives, etc.)

The resulting range of minimum fiber lengths was found to be 0.0163 "'0.1630". From these values, it can be clearly seen that the three lamina that are continuous from web to flange in the vinyl ester component were more than adequate to resist fiber pullout.

\subsection{Conclusions and Recommendations}

\subsubsection{Conclusions}

\section{General}

- All failure modes discussed in this chapter were only studied very briefly. The objective was not to adequately quantify all failure modes, but to identify as many of them as possible and do as much quantification as the available data would allow.

- The equations presented in this chapter have the potential to have large errors in them if applied to any situation differing from those described. Again, the reason being little work was performed on each mode. Therefore, the qualifications of section 5.1 need to be properly understood.

- No combined stress effects were considered in this work. This limits the current usefulness of the methods proposed herein since almost all service loadings produce combined loadings.

\section{$\underline{\text { Web Buckling }}$}

- $\quad$ The effective length factor $(\mathrm{K})$ of the vertical webs was found to be 0.7 .

- Using Euler's buckling formula and back calculating $(\mathrm{K})$ proved to be a satisfactory method of web buckling analysis. 


\section{$\underline{\text { Longitudinal Shear Stress }}$}

- The ultimate longitudinal shear stress was found to be $4.4 \mathrm{ksi}$ based on experimental data.

- The ultimate shear stress was found to be $4.0 \mathrm{ksi}$ based on strain to failure limit state.

- The two methods differed by $9 \%$, an acceptable difference.

\section{Punching Shear}

- The ultimate punching shear stress was found to be 1.8-2.0 ksi based on three different experiments. Two experiments had 10"x 20' patch loads, while the other experiment was performed on a 1" wide specimen. All three agreed within $0.2 \mathrm{ksi}$.

- The failure mode of all three experiments mentioned in the above note were the same (punching shear).

- The ultimate stress predicted by the limit state was $1.7 \mathrm{ksi}$ for polyester specimens and $2.0 \mathrm{ksi}$ for vinyl ester specimens.

- Both the limit states predicted an ultimate stress very close to that found from experimental data. (6\% difference for polyester specimens and 5\% difference for vinyl ester specimens).

- Neglecting the shear capacity of the resin (as the proposed limit state does) did not cause a large discrepancy between theory and experiment.

\section{$\underline{\text { Racking Shear }}$}

- The ultimate bending stress in the web induced by racking shear was found to be $5 \mathrm{ksi}$. This value represents a worst-case scenario since the experiment was conducted only on one component, which prevented stiffening in the loading direction.

\section{$\underline{\text { Torsional Shear }}$}

- The closed section under investigation was too stiff to fail under the conditions of its testing. 
Longitudinal Buckling of the Compression Flange due to Bending

- Using Euler's bucking formula in conjunction with an effective axial loading based on the actual vertical loading arrived at a seemingly satisfactory result of an effective length factor of $(K=1.2)$.

\section{Transverse Bending Failure of Flange}

- The average ultimate transverse stress of the top flange was found to be $11.65 \mathrm{ksi}$.

- $\quad$ The failure mode of the top flange was a tensile failure at the center.

- $\quad$ The strain to failure limit state predicted an ultimate stress of $11 \mathrm{ksi}$.

- The difference in the limit state and average experimental findings was $6 \%$ (an acceptable value).

\section{$\underline{\text { Joint Failure }}$}

- The effective ultimate bending stress in the three tensile lamina continuing from the web to flange was found to be $60 \mathrm{ksi}$ by experiment.

- The effective ultimate bending stress in the three tensile lamina continuing from the web to flange was found to be $104 \mathrm{ksi}$ by the proposed limit state.

- The difference in the two was $40 \%$ (a large difference) with the limit state giving the higher value.

\subsubsection{Recommendations}

\section{General}

- Each failure discussed in this text needs a vast amount of work in order to be able to achieve proper understanding and quantification. Therefore, each failure mode needs to be studied individually and in great depth.

- Perform a large number of tests that reveal each failure mode. This will allow the failure mode under a specific set of conditions to be predicted with a high level of confidence. In turn, the following recommendations pertaining to performing experiments would have already been completed, which would increase design efficiency. 


\section{$\underline{\text { Web Buckling }}$}

- Test each type of component under all expected loading conditions and back calculate the effective length factor $(\mathrm{K})$ from Euler's formula. Use the calculated value in design.

\section{Punching Shear}

- Perform punching shear experiments with all combinations of patch loads and specimens that are of interest. Observe the perimeter around the load patch that is actually damaged at failure and take that length as the effective perimeter.

\section{Longitudinal Buckling of the Compression Flange due to Bending}

- Perform failure testing for each combination of loading patch and component of interest. Observe the failure mode of the top flange in compression. The width of the compression flange that is damaged is the width to be taken and used in all calculations. This width should vary greatly with the size of the loading patch.

- Once the effective width of the compression flange has been determined as per the above recommendation, back calculate the effective length factor $(\mathrm{K})$ for the specific case of interest and use that $\mathrm{K}$ and effective failure flange width in design.

\section{$\underline{\text { Joint Failure }}$}

- The actual failure mode will have to be established for each type of joint and/or loading case of interest. Once the failure mode has been established, methods of prediction can be incorporated. Two such methods were discussed (tension failure and fiber pullout failure), and the tension failure was observed and analyzed herein. The fiber pullout failure was not quantified herein, but a method for quantification was proposed pending the occurrence of a true pullout failure. 


\section{CHAPTER 6 \\ TESTING AND EVALUATION OF FRP DECKS STIFFENED BY STEEL STRINGERS}

\subsection{Introduction}

Testing of composite bridge deck systems (FRP deck with steel stringers) under out-of-plane bending loads was performed and the experimental results were compared with theoretical evaluations and/or deflection limit states. The objectives of these bending tests were to determine both the accuracy of theory proposed by authors such as (Lopez-Anido 1995) and the competence of the deck system. Of the two systems tested, the first contained a deck made from polyester resin, while the second was made from vinyl ester resin. Both deck modules were made from Eglass fibers and fabrics, but their fiber architectures and cross-sections were slightly different (See Figures B2 through B5 for cross-sections and architectures).

Static tests were performed on the two bridge deck systems in order to determine:

1) Transverse load distribution factors,

2) Global deflections,

3) Local deflections, *

4) Deck deflection relative to stringers, *

5) Degree of compositness between deck and stringers,

6) Effects of warping and secondary torsion,

7) Effective deck width, and

8) Effective flange width.

* The term local deflection represents the difference in deflection between the top and bottom flange. On the other hand, deck deflection relative to stringers is the bottom flange deck deflection minus the average deflection of the adjacent stringers.

\subsection{Deck and Stringer Preparation for Testing}

The preparation measures undertaken for the test set-ups of the deck with steel stringers were performed in three steps. These steps were: 
1) Surface preparation of deck,

2) Surface preparation of stringers, and

3) Connection of deck to stringers.

These three procedures are described in the following sections.

\subsubsection{Surface Preparation of Decks}

\subsubsection{Polyester Deck}

All joints were reinforced with glass fabrics to ensure proper shear transfer between components. These joints were sanded with 40-grit sandpaper, and the excess dust was removed through vacuum cleaning. The sanded area was then cleaned with acetone and left undisturbed for twenty minutes before vacuuming the residue. MBRACE primer (parts a and b) was then applied to the cleaned area and allowed to cure for 24 hours. The glass fabrics were then bonded over the deck joints with epoxy resin. The joints were reinforced with two layers of $26 \mathrm{oz} / \mathrm{yd}^{2}$ fabrics consisting of a 6" wide bottom layer and a 4" wide top layer.

The fabrics were thoroughly soaked by slowly pulling them through an MBRACE saturant (parts a and b blue epoxy resin) bath as they were being placed onto the deck. The fabric strips were pulled through the bath (at one end of the module) until the entire length had been immersed. One end of the strip was then clamped to the module and the strip was pulled tight and laid into position. The excess resin and air voids were removed by tightly pressing over the fabrics with rollers. Finally, the fabric strips were allowed to cure for seven days.

\subsubsection{Vinyl Ester Deck}

Bedford Reinforced Plastics, Inc. reinforced the joints of the vinyl ester deck prior to its arrival at the testing facility. As a result, the joint fabrics were applied somewhat differently than those of the polyester deck, but the overall effect was not changed. The surface of the deck was prepared much the same way as that of the polyester deck in that it was sanded and cleaned prior to application of the fabric.

Two 6" wide layers of triaxial fabric having a total density of $40 \mathrm{oz} / \mathrm{yd}^{2}$ with $16 \mathrm{oz} / \mathrm{yd}^{2}$ of rovings and $12 \mathrm{oz} / \mathrm{yd}^{2}$ in each of the 45 degree directions were placed 
on each joint. The resin used was VE 8084, which is a vinyl ester resin commonly used in the pultrusion industry.

\subsubsection{Surface Preparation of Stringers}

The top flanges of all stringers were sandblasted to ensure a clean and bondable surface. W10x39 stringers were used for both decks. A total of six stringers were used during testing; three for each of the two decks that were tested in this study.

\subsubsection{Connection of Deck to Stringers}

Prior to the connection of the deck and stringers, the area of the deck, to be in contact with the stringers, was sanded with 40-grit sandpaper. The excess dust was removed by vacuum cleaning, and acetone was applied and allowed twenty minutes to evaporate before vacuuming the residue. The deck was then connected to the stringers by using PLIOGRIP ${ }^{\circledR}-7779 / 300$. The adhesive was allowed to cure for 48 hours before the system was moved into the testing bay.

\subsection{Test Set-Ups}

Figure 6.1 shows a representative test set-up for the FRP deck and steel stringer systems. The variations in the set-ups, with respect to load application, are outlined in section 6.3.2.

\subsubsection{Support Conditions}

The system (FRP deck with steel stringers) was placed on rigid, 14" deep, steel supports to provide a firm base for static testing. Elastomeric pads were placed below the supports to ensure an even contact with the floor. Steel rollers were welded to the top of these supports to simulate simply supported conditions for the deck/stringer systems. The center to center span between the rollers was maintained at $88 "$. 


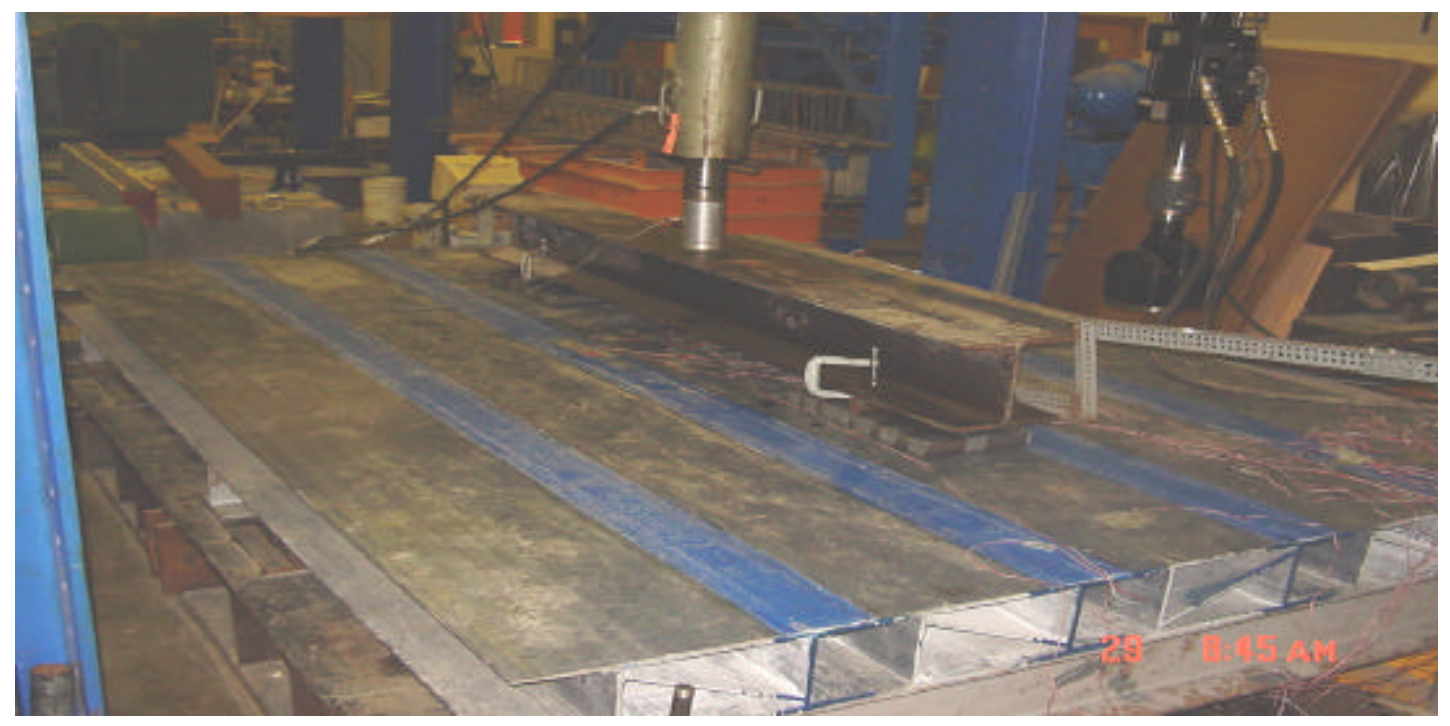

Figure 6.1-Test Set-Up for FRP Deck and Steel Stringer System

\subsubsection{Loading Conditions}

Patch Loads (10"x 20") were applied on the system through a hydraulic jack and were monitored by a load cell. The patch loads were either applied concentrically (single patch load at the center of the deck), or symmetrically (two patch loads placed 34" from the center of the middle stringer at the midspan of the deck). A total of three phases of loading were utilized during the testing as follows:

Phase I:

Two stringers at 136" center to center supporting the deck. The load was applied concentrically.

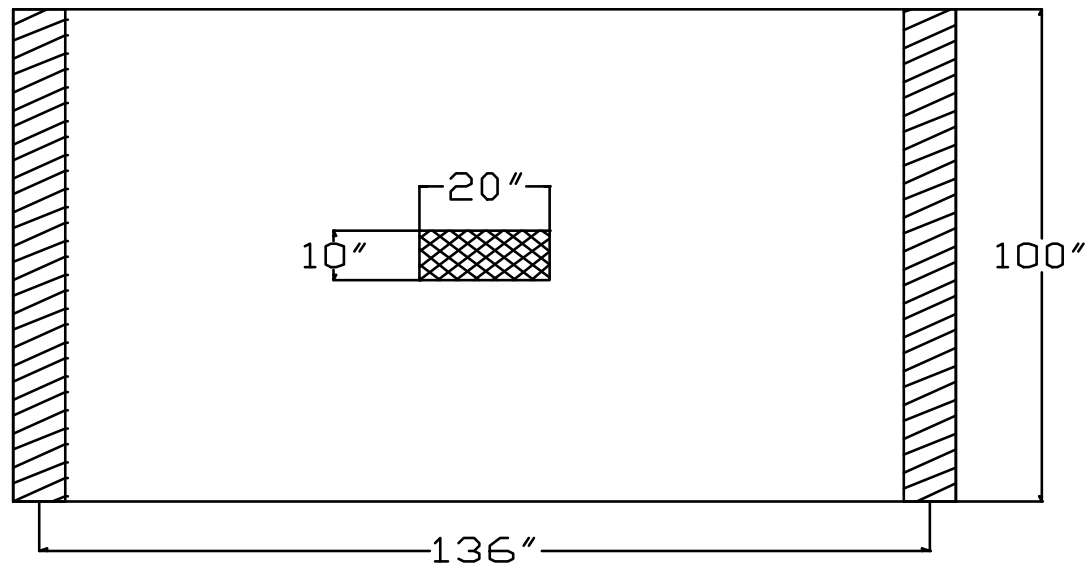

Figure 6.2-Phase I Loading Case-Concentric 


\section{$\underline{\text { Phase II: }}$}

Three stringers at 68 " center to center supporting the deck. The load was applied concentrically.

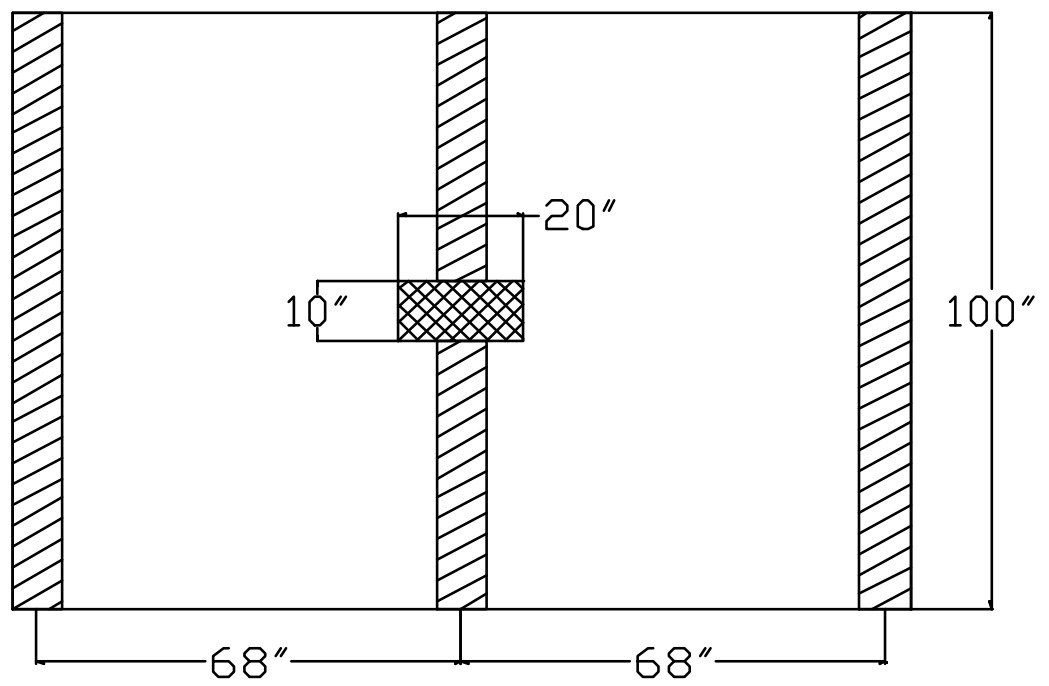

Figure 6.3-Phase II Loading Case-Concentric

\section{Phase III:}

Three stringers at 68 " center to center supporting the deck. The load was applied symmetrically.

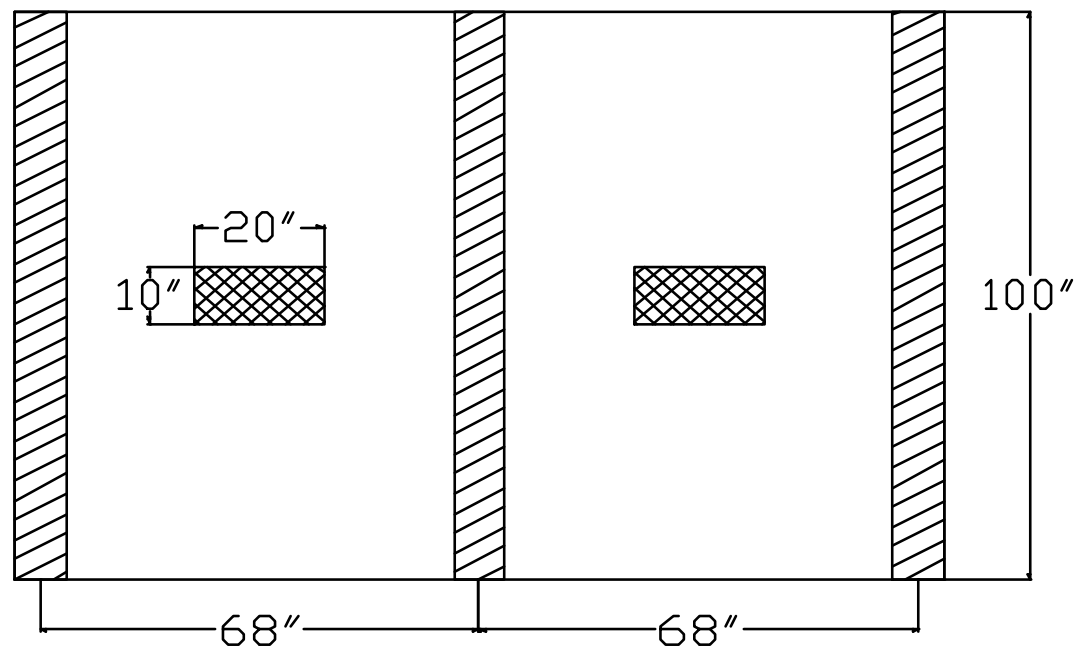

Figure 6.4-Phase III Loading Case-Symmetric 


\subsubsection{Instrumentation}

All strain gages were attached according to the procedures outlined in (M-

\section{LINE ACCESSORIES 1979).}

\subsubsection{Instrumentation of Polyester Deck}

The system was instrumented as shown in Figure 6.5a-Figure 6.5d. Table 6.1 breaks down which instruments were used for the parameters of interest.

\begin{tabular}{|c|c|c|}
\hline Parameter & $\begin{array}{c}\text { Deflection } \\
\text { Measurements }\end{array}$ & $\begin{array}{c}\text { Strain } \\
\text { Measurements }\end{array}$ \\
\hline $\begin{array}{l}\text { Transverse Load } \\
\text { Distribution Factor }\end{array}$ & DEF-1, DEF-2, DEF-4 & $\# 22, \# 25, \# 28$ \\
\hline Global Deflection & $\begin{array}{c}\text { DEF-1, DEF-2, DEF-3, } \\
\text { DEF-4 }\end{array}$ & NA \\
\hline Local Deflection & $\begin{array}{l}\text { DEF-2, DEF-5, DEF-7, } \\
\text { DEF-8, DEF-9, DEF-10 }\end{array}$ & $\begin{array}{c}\# 13, \# 14, \# 15, \# 16, \# 18, \# 19, \\
\# 1, \# 2, \# 3, \# 6, \# 8, \# 9\end{array}$ \\
\hline $\begin{array}{l}\text { Deck Deflection } \\
\text { Relative to Stringers }\end{array}$ & DEF-2, DEF-3, DEF-4 & $\# 4, \# 10$ \\
\hline Degree of Compositness & NA & $\begin{array}{c}\# 5, \# 7, \# 11, \# 12, \# 17, \# 20, \\
\# 23, \# 24, \# 26, \# 27, \# 29, \# 30\end{array}$ \\
\hline $\begin{array}{c}\text { Warping and Secondary } \\
\text { Torsion }\end{array}$ & NA & $\begin{array}{c}\# 5, \# 7, \# 11, \# 24, \# 27, \# 30, \\
\# 31, \# 32, \# 33, \# 34\end{array}$ \\
\hline Effective Deck Width & DEF-2, DEF-3, DEF-4 & NA \\
\hline
\end{tabular}

Table 6.1-Instrumentation Identification for Polyester Deck Testing 
BDTTOM VIEW WITH STRINGERS

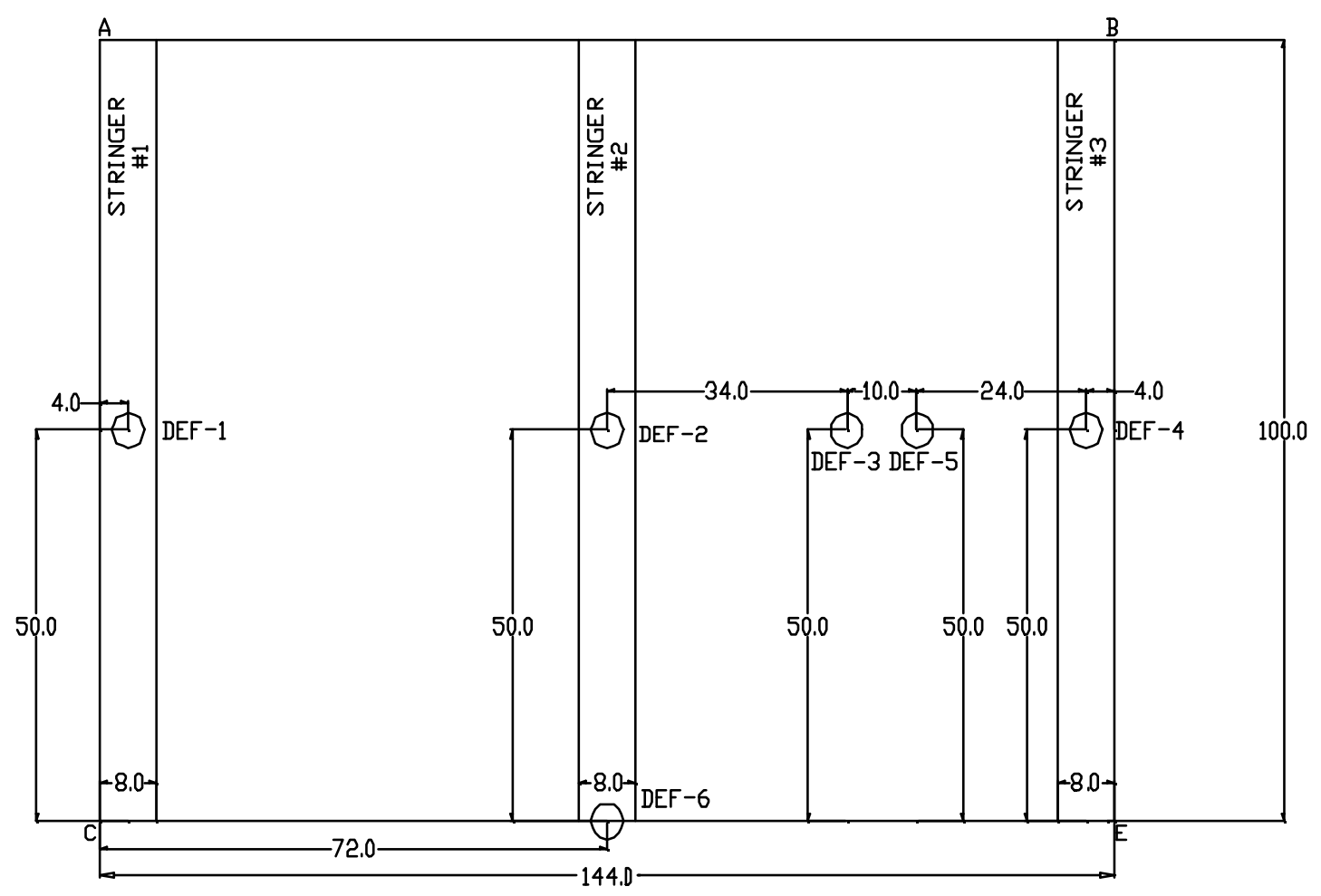

DEF REPRESENTS A POINT WHERE DEFLECTIDN WAS MEASURED

THE TOP DF THE DECK HAS FUUR POINTS WHERE DEFLECTION WAS MEASURED. ALL ARE CENTERED IN THE 100" DIRECTIDN. MEASURING FRDM THE QUTSIDE OF STRINGER \#3:

DEF-7: 28" FRDM END

DEF-8: 60" FRDM END

DEF-9: 61" FRDM END

DEF-10: 62" FRDM END

ALIGN THE LETTERS AT THE CORNERS TU CREATE A 3-D IMAGE. THESE MARKS ALSD APPEAR DN THE TOP VIEW DF THE DECK

ALL UNITS ARE IN INCHES - NDT TQ SCALE

Figure 6.5a-Location of Deflection Gages for Polyester Deck 


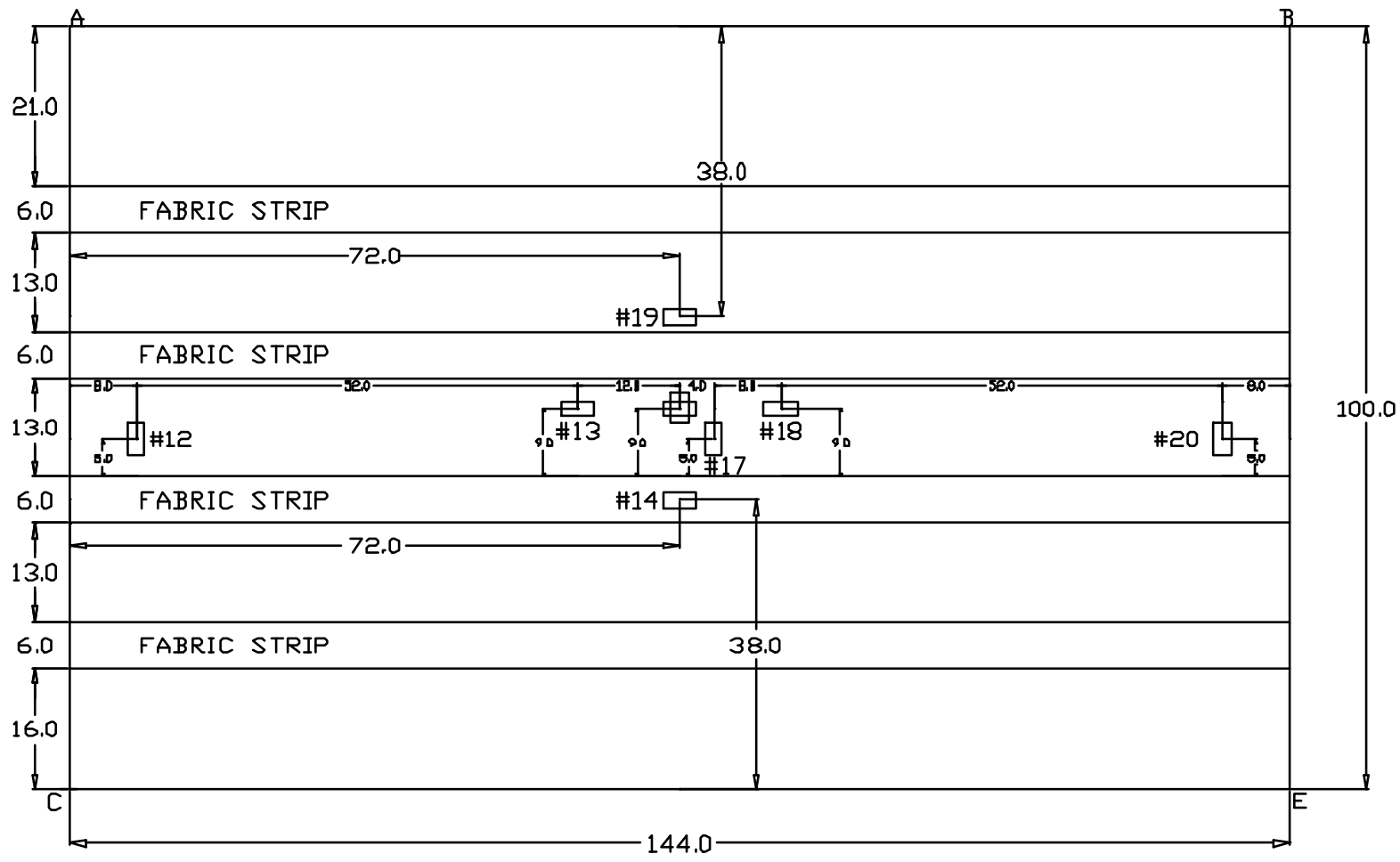

SIDE VIEW QF WEB

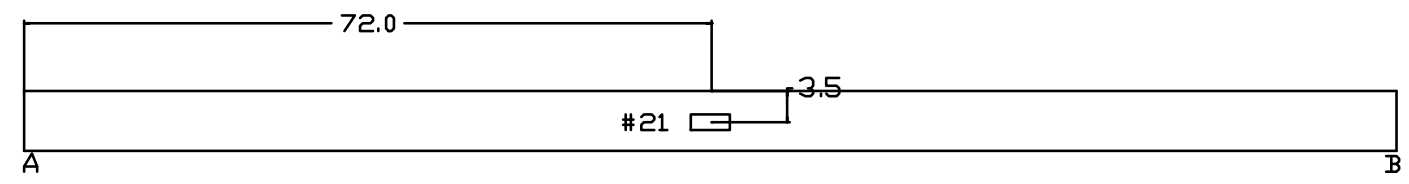

覀 REPRESENTS STRAIN GAGES \#15 AND \#16. \#15 IS IN THE 144" DIRECTIUN AND \#16 IS IN THE 100" DIRECTIDN

$\square$ REPRESENTS A STRAIN GAGE

ALIGN THE LETTERS AT THE CDRNERS TU CREATE A 3-D IMAGE. THESE MARKS ALSD APPEAR QN THE BOTTOM VIEW OF THE DECK

ALL UNITS ARE IN INCHES - NDT TO SCALE

Figure 6.5b-Location of Strain Gages for Polyester Deck

(Top View) 


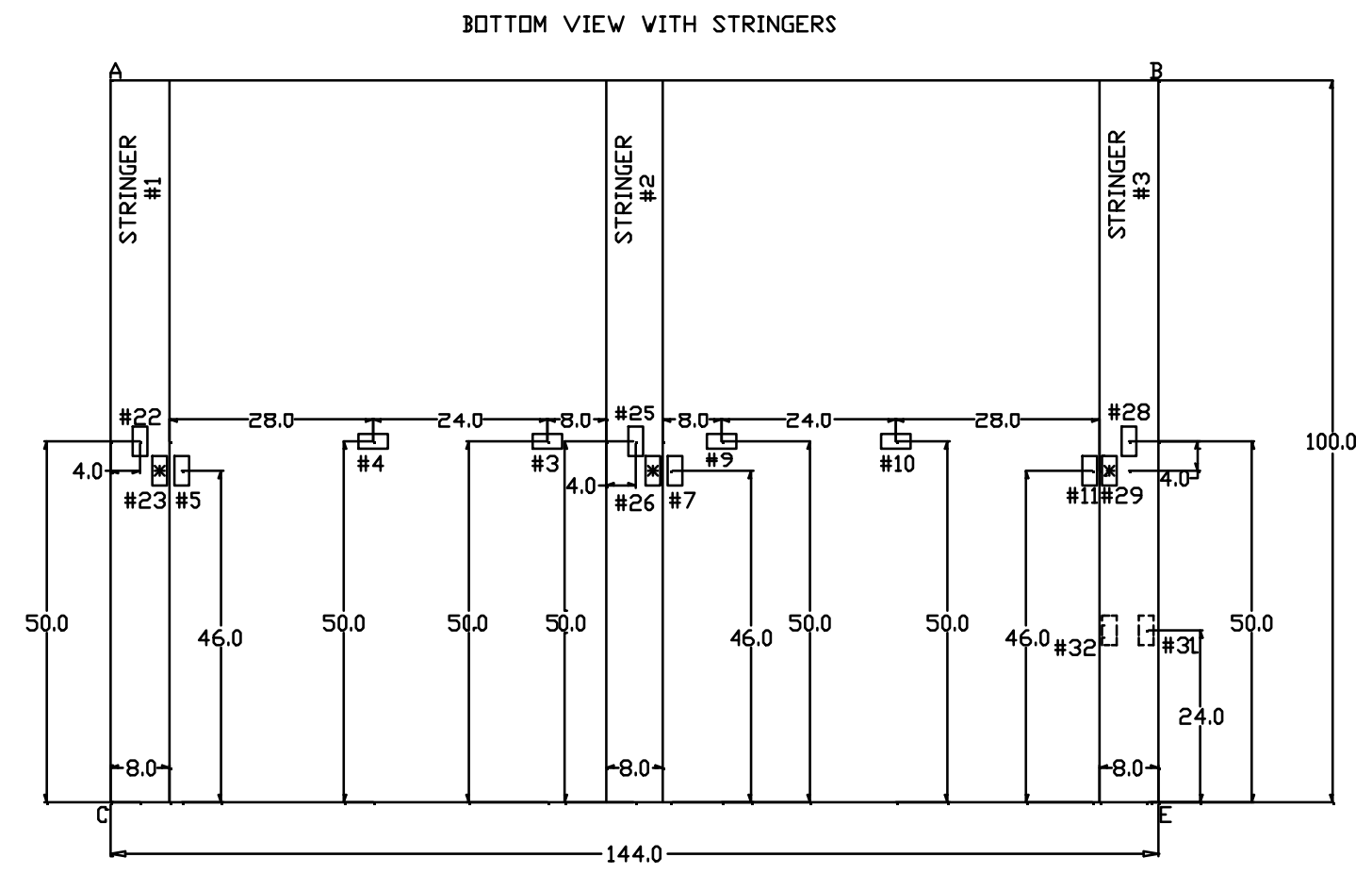

QUTSIDE VIEV DF STRINGER \#3-WEB GAGES SHDWN

\#33 MEASURES STRAIN IN THE 100" DIRECTILN

\#34 MEASURES STRAIN IN THE 10" DIRECTION.

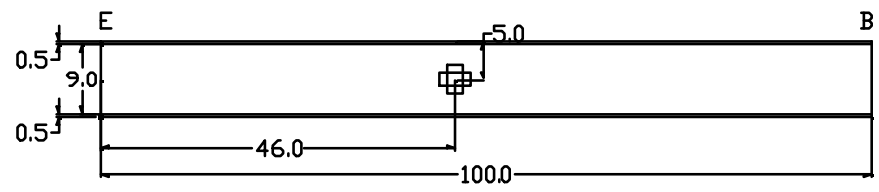

7] REFERS TO GAGES DN THE FLANGE BDNDED TO THE DECK. THEY ARE DN THE SAME

L' SIDE DF THE SAME FLANGE AS GAGES \#24, \#27, AND \#30.

INDICATES A GAGE DIRECTLY UNDER THE DNE SHDWN DN THE BDTTOM FLANGE. ALL

冈 THREE DF THESE GAGES ARE LDCATED DN THE SIDE DF THE FLANGE NDT BDNDED TD

THE DECK, \#30 IS BELDW \#29. \#24 IS BELDW \#23. AND \#27 IS BELDW \#26

D REPRESENTS A STRAIN GAGE

GAGES \#1, \#2, \#6, AND \#8 ARE UNDER STRINGER \#2. THEIR POSITIUNS CAN BE SEEN IN THE VIEW DF THE BDTTUM DF THE DECK WITHDUT THE STRLNGERS ATTACHED.

ALIGN THE LETTERS AT THE CDRNERS TU CREATE A 3-D IMAGE. THESE MARKS ALSD APPEAR DN THE TDP VIEW DF THE DECK

ALL UNITS ARE IN INCHES - NDT TO SCALE

Figure 6.5c-Location of Strain Gages for Polyester Deck

(Bottom View with Stringers) 
BDTTOM VIEW WITHOUT STRINGERS

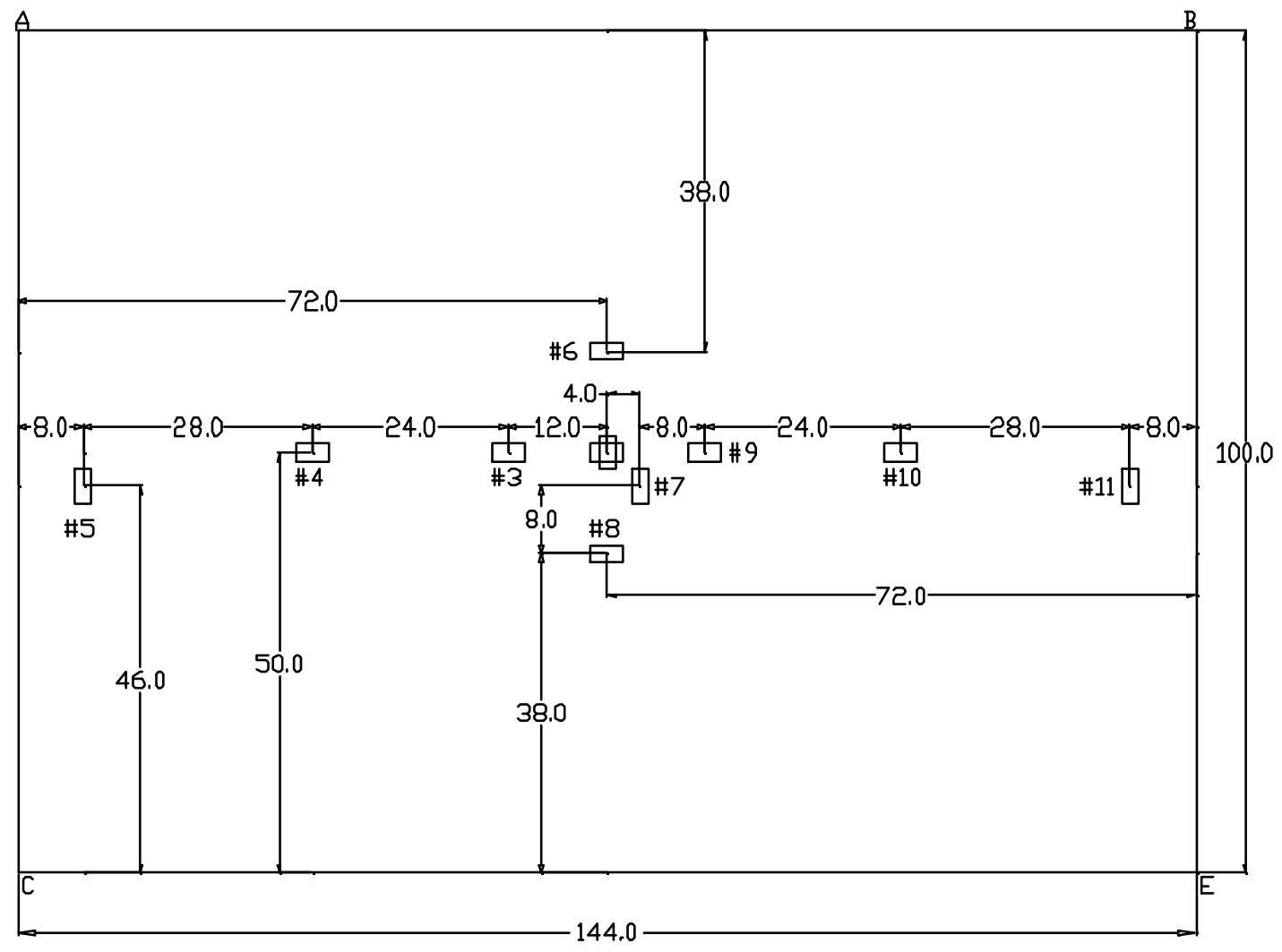

REPRESENTS GAGES \#1 AND \#2. \#1 IS IN THE 144" DIRECTION AND \#2 IS IN THE 100" DIRECTIDN

$\square$ REPRESENTS A STRAIN GAGE

ALIGN THE LETTERS AT THE CDRNERS TU CREATE A 3-D IMAGE, THESE MARKS ALSD APPEAR DN THE TOP VIEW DF THE DECK

ALL UNITS ARE IN INCHES - NDT TI SCALE

Figure 6.5d-Location of Strain Gages for Polyester Deck

(Bottom View without Stringers) 


\subsubsection{Instrumentation of Vinyl Ester Deck}

The system was instrumented for strains and deflections with the gage locations shown in Figure 6.6a and Figure 6.6b. Table 6.2 provides a break down of instruments used for the parameters of interest.

\begin{tabular}{|c|c|c|}
\hline Parameter & Deflection Measurements & Strain Measurements \\
\hline $\begin{array}{c}\text { Transverse Load } \\
\text { Distribution Factor }\end{array}$ & DEF-1, DEF-2, DEF-5 & $\# 1, \# 2, \# 10$ \\
\hline Global Deflection & DEF-1, DEF-2, DEF-5 & NA \\
\hline Local Deflection & DEF-4, DEF-6 & $\# 6-\# 9, \# 12-\# 15$ \\
\hline $\begin{array}{c}\text { Deck Deflection } \\
\text { Relative To Stringers }\end{array}$ & DEF-2, DEF-3, DEF-5 & $\# 6, \# 7$ \\
\hline Degree of Compositness & NA & \#3-\#5, \#11 \\
\hline Effective Deck Width & DEF-2, DEF-3, DEF-5 & NA \\
\hline
\end{tabular}

Table 6.2-Instrumentation Identification for Vinyl Ester Deck Testing

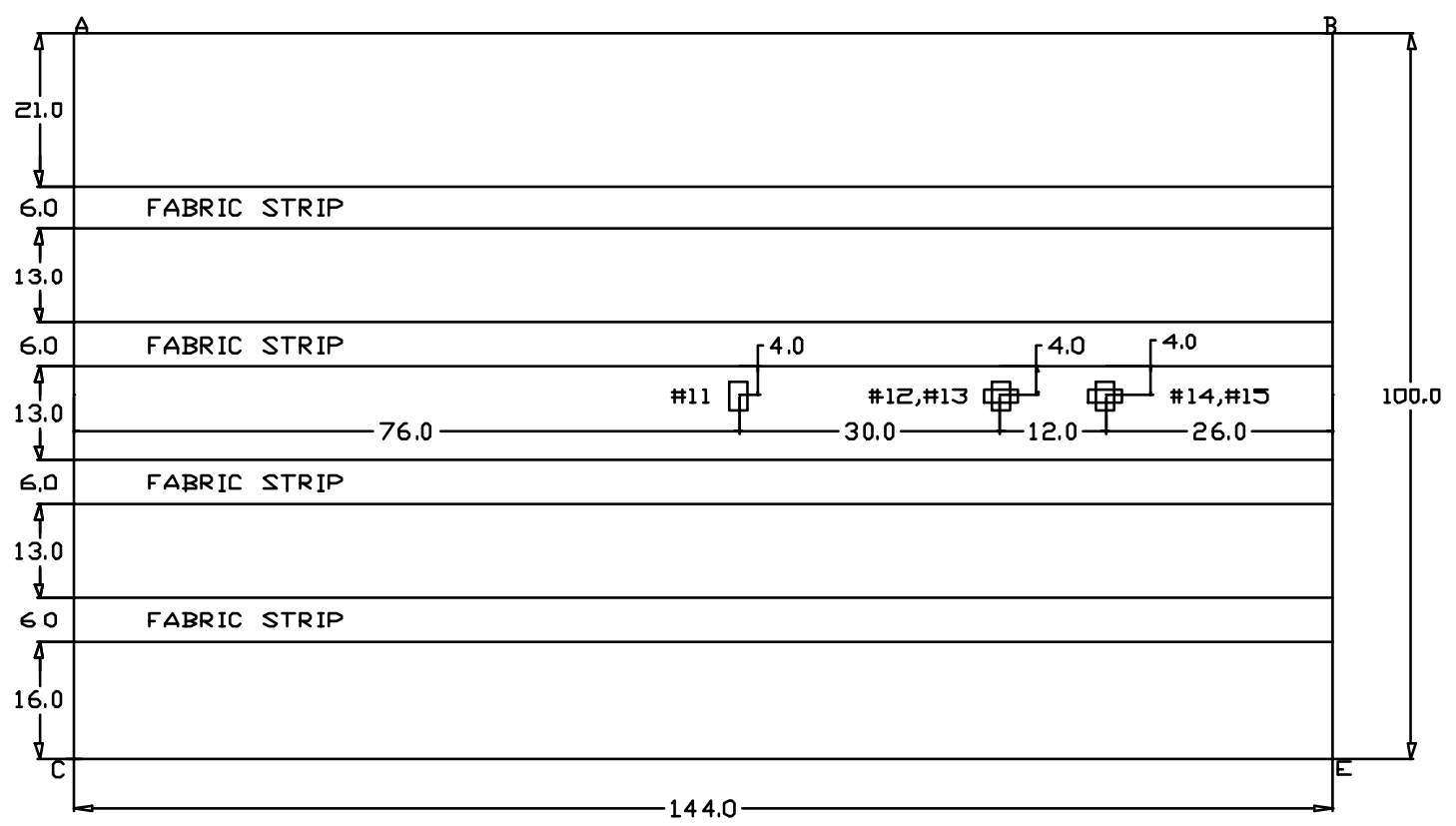

$\square$ REPRESENTS A STRAIN GAGE

\#13 AND \#15 MEASURE STRAIN IN THE 100" DIRECTIIN

ALIGN THE LETTERS AT THE CDRNERS TU CREATE A 3-D IMAGE. THESE MARKS ALSD APPEAR DN THE BDTTAM VIEW QF THE DECK

ALL UNITS ARE IN INCHES - NDT TO SCALE

Figure 6.6a-Instrumentation of Vinyl Ester Deck (Top View) 

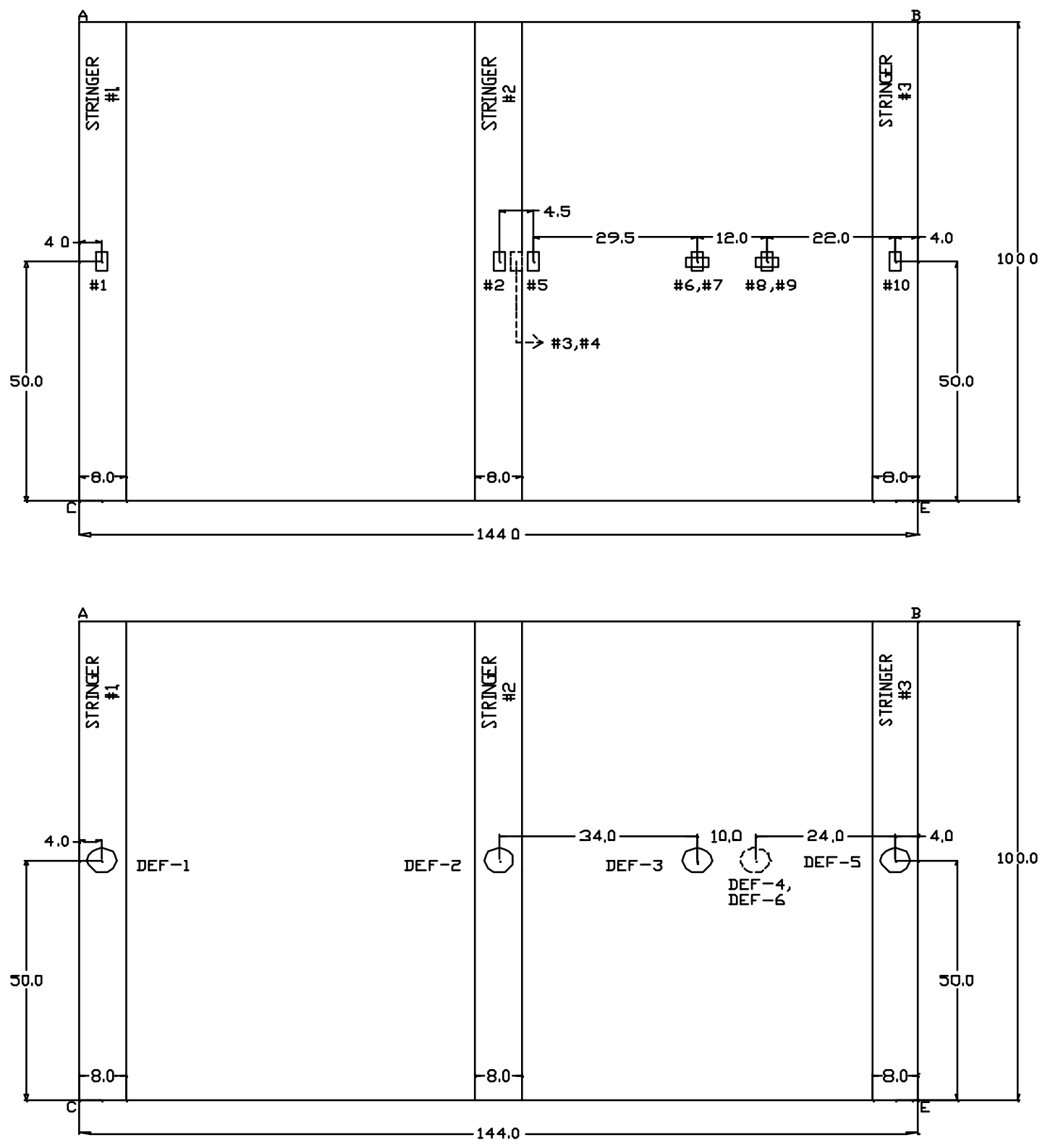

$\square$ REPRESENTS A STRAIN GAGE

\#7 AND \#9 MEASURE STRAIN IN THE 100" DIRECTION

\#3 IS IN BOTTUM FLANGE AND \#4 IS DIRECTLY UNDER \#3 UN TUP FLANGE

DEF REPRESENTS A PIINT WHERE DEFLECTION WAS MEASURED

DEF-4 IS aN THE BDTtuM FLANGE AND DEF-6 IS DN THE TUP FLANGE

ALIGN THE LETTERS AT THE CIRNERS TU CREATE A 3-D IMAGE, THESE MARKS ALSD APPEAR DN THE TOP $V I E W$ DF THE DECK

ALL UNITS ARE IN INCHES - NOT TO SCALE

Figure 6.6b-Instrumentation of Vinyl Ester Deck (Bottom View) 


\subsection{Test Procedures}

The testing was performed with the aid of a hydraulic jack, loading frame, strain indicators, and dial gages. The actual test procedure followed was that of GangaRao and Shekar (2002), which is similar to ASTM standards (See 2.4). The load was applied at a constant rate of $1,000 \mathrm{lb} / \mathrm{min}$, and all data were taken at constant load increments.

\subsection{Test Results}

Strain and deflection data obtained from testing of the polyester and vinyl ester decks were used to determine the structural behavior of the systems. The structural behavior includes: 1) transverse load distribution factors, 2) global deflections, 3) local deflections, 4) deck deflection relative to stringers, 5) degree of compositness between deck and stringers, 6) effects of warping and secondary torsion, 7) effective deck width, and 8) effective flange width. The results for each of the two decks can be seen in the remainder of this section. Also, Tables C13-C16 of Appendix $\mathrm{C}$ contain the raw test data.

\subsubsection{Transverse Load Distribution Factor}

The evaluation of the transverse load distribution factor $\left(g_{i}\right)$ for the ith stringer can be found according to GangaRao, Sotiropoulos, and Mongi (1994) by either equation 6.1 or 6.2 .

$$
\begin{gathered}
g_{d i}=\frac{\delta_{i}}{\sum_{j=1}^{n} \delta_{j}} \\
g_{s i}=\frac{\varepsilon_{i}}{\sum_{j=1}^{n} \varepsilon_{j}}
\end{gathered}
$$

Where,

$g_{d i}=$ transverse load distribution factor of stringer (i) according to deflection 
$g_{s i}=$ transverse load distribution factor of stringer (i) according to strain

$\delta_{i}=$ deflection of stringer (i)

$\delta_{j}=$ deflection of any stringer

$\varepsilon_{i}=$ strain of stringer (i)

$\varepsilon_{j}=$ strain of any stringer

$\mathrm{n}=$ number of stringers

The load distribution factors were computed for each stringer in each of the two deck/stringer systems, and their values can be seen in Table 6.3

\begin{tabular}{|c|c|c|c|c|c|c|}
\hline \multirow{2}{*}{$\begin{array}{c}\text { Phase of } \\
\text { Testing }\end{array}$} & \multicolumn{2}{|c|}{ Stringer \#1 } & \multicolumn{2}{c|}{ Stringer \#2 } & \multicolumn{2}{c|}{ Stringer \#3 } \\
\cline { 2 - 7 } & As per & $\begin{array}{c}\text { As per } \\
\text { strain }\end{array}$ & $\begin{array}{c}\text { As per } \\
\text { strain }\end{array}$ & $\begin{array}{c}\text { As per } \\
\text { deflection }\end{array}$ & $\begin{array}{c}\text { As per } \\
\text { strain }\end{array}$ & $\begin{array}{c}\text { As per } \\
\text { deflection }\end{array}$ \\
\hline I & $60 \%$ & $77 \%$ & NA & NA & $40 \%$ & $23 \%$ \\
\hline II & $8 \%$ & $22 \%$ & $90 \%$ & $58 \%$ & $2 \%$ & $20 \%$ \\
\hline III & $18 \%$ & $31 \%$ & $69 \%$ & $45 \%$ & $13 \%$ & $24 \%$ \\
\hline *III & $23 \%$ & $31 \%$ & $50 \%$ & $43 \%$ & $27 \%$ & $26 \%$ \\
\hline
\end{tabular}

* indicates vinyl ester deck

Table 6.3-Transverse Load Distribution Factors of Deck/Stringer Systems

The results of the testing revealed that the center stringer carried the highest percentage of load for loading phases II and III. Due to symmetry of loading, the response was along the expected lines. However, the distribution factors vary somewhat depending on whether deflection or strain values are utilized. For example, Stringer \#1 yielded higher distribution factors based on deflection for all loading cases of both the polyester and vinyl ester decks, while Stringer \#2 showed higher load distribution factors based on strains.

Furthermore, comparison of Phase III loading of the polyester and vinyl ester decks are of maximum interest to this study. Phase I loading is much too severe to be 
practical due to the wide stringer spacing. Phase $\mathrm{I}$ is primarily of interest when discussing the effects of warping and secondary torsion (See 6.5.4). Phase II is a loading case which does not allow a true picture of transverse load distribution to be obtained since the load is being applied directly over the central stringer.

Taking into account both deflection and strain readings, transverse load distribution of the vinyl ester deck was more evenly dispersed than in the polyester deck. Strain readings of the polyester deck placed a higher percentage of the load on the central stringer than those of the vinyl ester deck, but the deflection readings of the two were almost identical. Both decks performed well with respect to their load distribution abilities in the transverse direction.

Another indication of the performance of the current deck and stringer system can be made based on the typical load distribution of concrete decks. This value is typically taken as the spacing of the stringers (expressed in feet) divided by 5.5. Our testing resulted in a value of the spacing of stringers (expressed in feet) divided by 5.7 for testing of the vinyl ester deck. These values are very similar and show that this particular deck/stringer system has transverse load distribution characteristics similar to concrete bridge decks.

\subsubsection{Deflection}

There are three types of deflections that are of interest for a designer when dealing with an FRP deck and steel stringer system. They are: 1) global deflection, 2) local deflection, and 3) deflection of deck relative to stringers (See 6.1). The results of each case are shown separately in the three following sections.

\subsubsection{Global Deflection}

The maximum global deflection of each of the three stringers can be seen in Table 6.4. The load shown in the table is that applied by the hydraulic jack. For Phase III, half the load shown is acting on each patch.

The global deflection limit of FRP bridge decks placed on steel stringers was taken from GangaRao and Shekar (2002). 


\begin{tabular}{|c|c|c|c|c|}
\hline Testing Phase & Total Load (k) & Stringer \#1 & Stringer \#2 & Stringer \#3 \\
\hline I & 25 & $0.130 "$ & NA & $0.038 ”$ \\
\hline II & 25 & $0.029 "$ & $0.076 ”$ & $0.027 ”$ \\
\hline III & 40 & $0.061 ”$ & $0.087 ”$ & $0.046 ”$ \\
\hline *III & 40 & $0.075 "$ & $0.103 "$ & $0.062 "$ \\
\hline
\end{tabular}

* indicates vinyl ester deck

Table 6.4-Maximum Global Deflections of Deck/Stringer Systems

$$
\Delta_{\text {max }}=\frac{\mathrm{L}}{800}
$$

Where,

$\Delta_{\max }=$ maximum allowable global deflection of FRP deck and steel stringer system $\mathrm{L}=$ clear span of FRP deck and steel stringer system (88")

Based on equation 6.3, the global deflection limit of the system was found to be 0.11". From Table 6.4, it can be seen that the only violation of this limit was for Phase I loading of the polyester deck. Again, Phase I loading is much too severe a loading case for practical designs. Furthermore, it should be noted that the average deflection of the two stringers from Phase I loading would meet the deflection requirement. The extremely large difference in the deflection readings of these two stringers again shows the presence of warping and/or secondary torsion that is discussed in greater detail in section 6.5.4.

When comparing the phase III loading of the polyester and vinyl ester decks, it can be seen that the vinyl ester deck system deflected more than the polyester deck system. The difference was in the $15-20 \%$ range. The most probable reason for the difference was each deck system made use of its own set of stringers. While both decks utilized W10x39 stringers, the potential exists for the stringers to vary slightly with respect to their geometry and mechanical properties. However, both met the deflection requirement, which indicates no problems are present with the current 
designs from a global deflection point of view. If global deflection problems do arise in the future, larger steel stringers would easily remedy the problem. Most bridge deck systems use larger stringers than those used in this study, but the basic behavior of the deck systems would be similar.

\subsubsection{Local Deflection}

The maximum local deflections that were recorded are given in Table 6.5. In addition, the maximum local strain values are also recorded in the same table. They too provide a good measure of the degree to which local effects are present. Taking a deflection or strain value at the top of the deck and subtracting the corresponding value at the bottom of the deck obtained the values in the table. Again, the load shown in Table 6.5 is the total load applied by the hydraulic jack.

\begin{tabular}{|c|c|c|c|c|}
\cline { 3 - 5 } \multicolumn{2}{c|}{} & \multicolumn{3}{|c|}{ Maximum Difference For the Given Parameter } \\
\hline Phase & Load (k) & Deflection & $\begin{array}{c}\text { Strain Directly Under } \\
\text { Patch (micro-strains) }\end{array}$ & $\begin{array}{c}\text { Strain 1' From Center of } \\
\text { Patch (micro-strains) }\end{array}$ \\
\hline I & 25 & $0.107 "$ & 3022 & 537 \\
\hline II & 25 & $0.112 "$ & 4829 & 664 \\
\hline III & 40 & $0.184 "$ & NA & NA \\
\hline *III & 40 & $0.215 "$ & 2797 & 2010 \\
\hline
\end{tabular}

* indicates vinyl ester deck

Table 6.5-Maximum Local Deflections of Deck/Stringer Systems

Local deflection proved to be more severe than global deflection. The measured deflection near the patch loads was significantly higher on the top flange than on the bottom one. Also, deflections tapered off very quickly as the measurements moved away from the patch. While these values are not surprising, they do show the local issues of this deck deserve special attention.

The local strain and deflection limits according to GangaRao and Shekar (2002) are as follows:

$$
\Delta_{\max }=\frac{\mathrm{S}}{100}
$$




$$
\varepsilon_{a}=0.2 \varepsilon_{\mathrm{ult}}
$$

Where,

$\Delta_{\max }=$ maximum allowable local deflection

$\mathrm{S}=$ actual center to center spacing of vertical webs supporting top flange (11.65")

$\varepsilon_{\mathrm{a}}=$ allowable local strain

$e_{\mathrm{ult}}=$ ultimate local strain $(\approx 10,000$ micro-strains $)$ - See section 5.4.2

Utilizing equations 6.4 and 6.5 , the local deflection limit was found to be 0.117", and the local strain limit was found to be 2,000 micro-strains. At least one of these limits was violated for all three testing phases. Neither the polyester deck system nor the vinyl ester deck system met the limits. See Chapter 8 for potential remedies to the local deflection problems.

For Phase III loading, the polyester deck violated the deflection limit by a factor of 1.6, and the vinyl ester deck violated the limit by a factor of 1.8. While performing better than the vinyl ester deck with respect to deflection, the polyester deck had much more difficulty in handling local strains.

As seen in Table 6.5, the polyester deck performed very poorly with respect to local strains. Obviously, the fiber architecture of the polyester component lacked sufficient local resistance to strain in at least one direction (primarily the transverse direction). Phase II loading clearly shows the limit being violated by a factor of approximately 2.4. This is one of the reasons why the polyester design was abandoned in favor of the vinyl ester design.

The vinyl ester component also violated the local strain limit, but it was only over the strain limit state by a factor of 1.4 during Phase III loading. As a result, it can be concluded that the overall local performance of the vinyl ester deck was better than that of the polyester deck. Correcting the local strain problems of the polyester deck would be very difficult and is one of the reasons it was abandoned in favor of the vinyl ester design. 
The local effects on the two decks would have been lower if a polymer concrete wearing surface had been present during testing, as it would be in a service application. The addition of a polymer concrete wearing surface would help to reduce local strain effects in three ways. They are:

1) Increasing local stiffness,

2) Increasing effective local area, and

3) Providing a higher strain to failure than that of FRP bridge decks.

It is also of interest to note that the ultimate strain value used in the limits was found from a component level experiment. Often, ultimate strain values are determined from coupon level testing. Typically, coupon level strain to failure values are about twice those found from component level testing. Therefore, coupon level strain data would make both the deflection and strain limits increase by a factor of about two, which would allow for weaker deck systems to meet the limits.

\subsubsection{Deck Deflection Relative to stringers}

The maximum deck deflection relative to stringers can be seen in Table 6.6. The values were obtained by taking the maximum deck deflection and subtracting the average maximum stringer deflection of the two stringers supporting the portion of the deck of interest.

\begin{tabular}{|c|c|c|c|c|}
\cline { 3 - 5 } \multicolumn{2}{c|}{} & \multicolumn{3}{c|}{ Deflection Readings } \\
\hline Phase & Total Load (k) & Avg. Stringer & Total Deck & Relative Deck \\
\hline I & 25 & $0.084 ”$ & $0.590 ”$ & $0.506 "$ \\
\hline II & 25 & $0.052 ”$ & $0.072 ”$ & $0.020 ”$ \\
\hline III & 40 & $0.067 ”$ & $0.203 "$ & $0.136 "$ \\
\hline *III & 40 & $0.083 ”$ & $0.205 ”$ & $0.122 ”$ \\
\hline
\end{tabular}

* indicates vinyl ester deck

Table 6.6-Maximum Relative Deflection of Deck to Stringers

According to GangaRao and Shekar (2002), the deflection limit of an FRP bridge deck relative to its stringers is expressed in equation 6.6. 


$$
\Delta_{\text {max }}=\frac{S_{\mathrm{c}-\mathrm{c}}}{500}
$$

Where,

$\Delta_{\max }=$ maximum allowable deflection of FRP deck relative to stringers

$\mathrm{S}_{\mathrm{c}-\mathrm{c}}=$ center to center spacing of stringers $\left(68^{\prime \prime}\right)$

Based on equation 6.6, the deflection limit of the deck relative to stringers was found to be 0.136". This limit was violated only in Phase I loading due to the excessive stringer spacing. As expected, Phase II loading had a relative deck deflection near zero. Furthermore, the most practical loading case was Phase III, and both decks met the deflection limit under this loading case. The polyester deck had a deflection exactly equal to the limit while the vinyl ester deck had a deflection of approximately $90 \%$ the limit.

\subsubsection{Degree of Composite Action Between Deck and Stringers}

The deck-stringer stiffness is dependent, in part, on the degree the two types of elements act as a unit. Moment transfers, strain distributions, and stress distributions all increase in uniformity with increased compositness. As a result, the system slightly increases in efficiency. Even though current bridge design methods generally do not take advantage of any degree of composite action, its presence serves as an extra safety factor.

The degree of composite action can be defined in terms of the strain values obtained at the bottom of the deck and the bottom face of the top flange. Neglecting the thickness of the flange, these values should be equal for a system with 100\% composite action. As a result, the approximate degree of composite action can be defined as per equation 6.7 .

$$
\% \text { Composite Action }=\frac{\varepsilon_{f l i}}{\varepsilon_{b d i}}(100)
$$


Where,

$\varepsilon_{b d i}=$ strain at bottom of deck next to stringer $\mathrm{i}$

$\varepsilon_{f l i}=$ strain at top flange of stringer $\mathrm{i}$

Using data obtained from Phase III loading, the degree of composite action of the central stringer was found to be $42 \%$ for the polyester deck and $58 \%$ for the vinyl ester deck. It can be seen that the degree of composite action possessed by the central stringer of each of the current decks was better than the $39 \%$ obtained by Sotiropoulos (1995) (See 2.4.2). $\quad$ Figure 6.7 shows the actual strain distribution and location of the neutral axis for the above mentioned case at 40 kips.

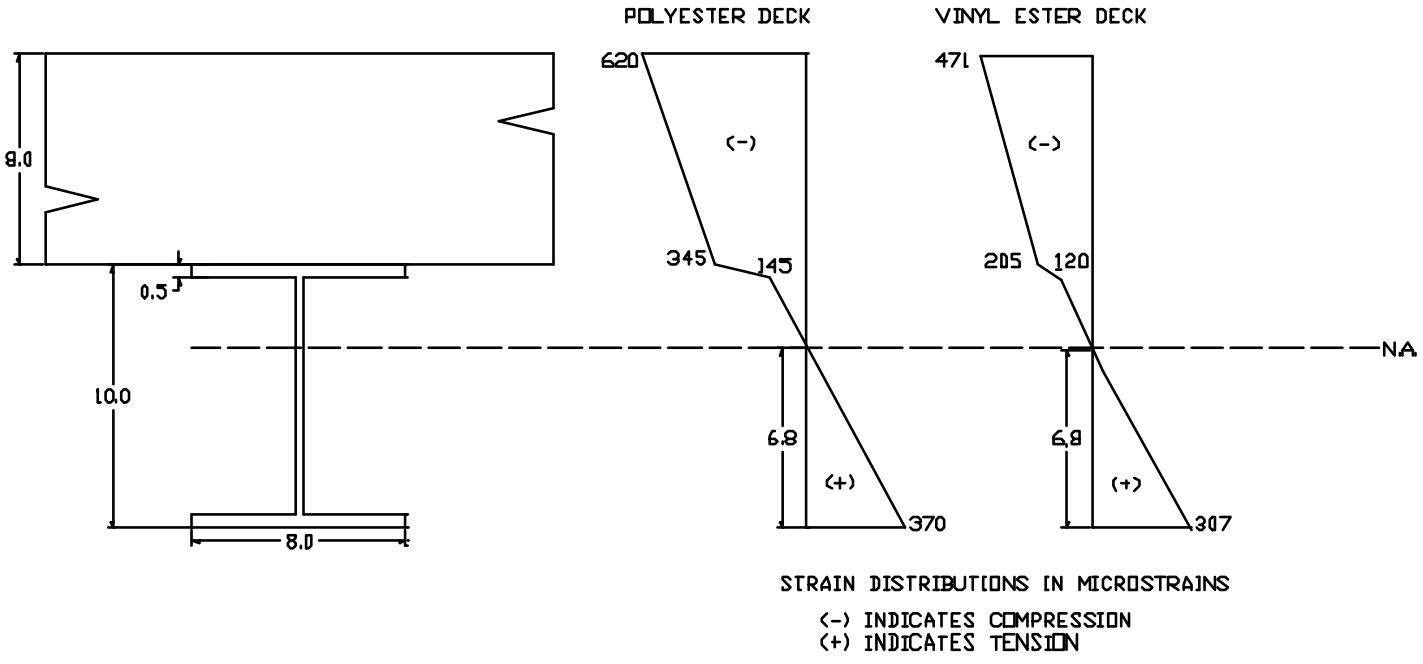

Figure 6.7-Strain Distributions of Central Stringer-Stringer \#2

The degree of composite action reported in the previous paragraph has the potential to vary greatly. Since the deck and stringers are bonded to one another using only an adhesive, local placement of adhesive around the location of the strain gages would cause the composite action reading to increase. On the other hand, the lack of adhesive around the location of the strain gages would cause the composite action reading to decrease. While adhesive was not intentionally placed around the 
location of any gage to alter the readings, it is possible the two decks had adhesive variations around the small area where the strain gages were attached. As a result, two values are not enough to report composite action with a high degree of accuracy, but they do give a general range in which the degree of composite action resides for a system with a similar ratio of stiffness to span length.

\subsubsection{Effects of Warping and Secondary Torsion}

Warping of stringers due to lateral torsional effects can induce high stresses and strains in the flanges and reduce the stiffness of the system. These effects can easily be seen in polyester deck loading phases I and II. The actual data can be seen in the following paragraphs.

In Phase I, the center to center spacing of the stringers was 136". As expected, the magnitude of warping in the stringers was severe due to excessive spacing and lack of lateral stability provided by diaphragms. As seen in Tables C13C15 of Appendix C, the top flanges of the exterior steel stringers actually strained more than the deck where the two were connected. While this phenomena was observed in the exterior stringers of all three polyester deck loading cases, the magnitude was more severe in phase I. An example of this can be made using stringer \#1. At 25 kips, stringer \#1 experienced twice as much strain as did the deck for Phase I loading, while the difference was 1.8 times for Phase II loading.

While the previous paragraph discusses warping and secondary torsion effects, a more clear representation can be obtained from multiple strain readings on the flange of a single stringer. Stringer \#3 had two strain gages mounted 24" from its end. These gages were mounted at the edge of the flange, one on each side of the web (See Figure 6.5c). Without the effects of warping and secondary torsion, these gages should yield approximately the same value. However, the test data were far from uniform. Table 6.7 shows the strain readings. From Table 6.7, it can be seen that the difference in strain of one side of the flange relative to the other side was as high as 7.4 times and never lower than 3.2 times. One side of the flange carrying such a high percentage of the total load could potentially cause problems in that the design of the stringer would assume uniform stress across the width if warping and secondary torsion were ignored. Therefore, their effects are noteworthy and deserve 
special attention when selecting stringer sizes. It should be noted that while the strain ratios presented above seem very alarming, the magnitude of strain was relatively small as shown in Table 6.7. Typical strain to yield values are at least one, if not two orders of magnitude higher than the values shown in the table.

\begin{tabular}{|c|c|c|c|c|}
\hline \multirow{2}{*}{$\begin{array}{c}\text { Loading } \\
\text { Phase }\end{array}$} & \multirow{2}{*}{ Load (K) } & \multicolumn{2}{|c|}{ Strain (micro-strains) } & \multirow{2}{*}{$\begin{array}{c}\text { Ratio } \\
\text { (\#32 / \#31) }\end{array}$} \\
\cline { 3 - 4 } & 25 & $\# 31$ & $\# 32$ & 7.4 \\
\hline I & 25 & 32 & 119 & 3.2 \\
\hline II & 40 & 93 & 22 & 4.2 \\
\hline III & & & & \\
\hline
\end{tabular}

Table 6.7-Warping and Secondary Torsion Properties

\subsubsection{Effective Deck Width}

The effective deck width is a parameter that describes the $\mathrm{Y}$ direction width (as in Figure 6.8) that is actively resisting the load applied by a given patch. In other words, the effective deck width is an approximate method to describe the amount of plate action. This plate action increases the deck stiffness relative to the behavior that would be observed in the same type of deck if it were tested as a narrow specimen, i.e., the loading patch crossing the entire width.

Determining the effective width of the deck was performed in a fairly simple manner. Since the moment of inertia of the section on a unit width basis is known, basic structural analysis can be applied to the deck assuming the stringers act as simple supports. This procedure is outlined in the following equations.

$$
\begin{array}{r}
\Delta=\frac{P\left(\mathrm{~S}_{\mathrm{c}-\mathrm{c}}\right)^{3}}{48 \mathrm{E}_{\mathrm{x}} \mathrm{I}_{\mathrm{EDW}}} \\
\mathrm{I}_{\mathrm{EDW}}=\frac{\mathrm{P}\left(\mathrm{S}_{\mathrm{c}-\mathrm{c}}\right)^{3}}{48 \mathrm{E}_{\mathrm{x}} \Delta}
\end{array}
$$




$$
\mathrm{EDW}=\frac{\mathrm{I}_{\mathrm{EDW}}}{\mathrm{I}_{\text {Unit Width }}}
$$

Where,

$\Delta=$ deck deflection relative to stringers (See 6.5.2.3)

$\mathrm{P}=$ load applied to patch (20 kips for Phase III)

$\mathrm{S}_{\mathrm{c}-\mathrm{c}}=$ clear span of deck (68")

$\mathrm{E}_{\mathrm{x}}=$ elastic modulus in direction of bending (See 4.5.1)

$\mathrm{I}_{\mathrm{EDW}}=$ moment of inertia over the effective deck width

$\mathrm{I}_{\text {Unit Width }}=$ moment of inertia per unit width $\left(15.8 \mathrm{in}^{4}\right)$

Utilizing equations 6.8 through 6.10 , the effective deck width was found to be 17" for the vinyl ester deck, and 15" for the polyester deck. These numbers clearly show that the deck is not benefiting from the effects of plate action. Reasons for the poor transfer can most likely be attributed to a combination of two factors. The lack of sufficient transverse (or $\mathrm{Y}$ direction according to Figure 6.8) fiber reinforcement and poor load transfer across the joints are limiting the plate action of the deck. As a result, the individual components are acting as if they were being loaded individually and not as a part of a deck system. It should also be noted that the computations neglected the effects of shear deflection. The effects of shear deflection were approximated to be $17 \%$ in section 4.5.1.1. Accounting for shear deflection, the effective deck widths would increase to 20 " for the vinyl ester deck and 18 " for the polyester deck.

\subsection{Theoretical Evaluation}

\subsubsection{Effective Flange Width}

Due to the large number of phenomena that occur simultaneously in a bridge deck system, longitudinal strain measurements are often a mixture of several parameters. As a result, decoupling the strains becomes difficult and was not performed for the FRP deck and steel stringer systems. In place of this type of analysis, an alternate approach proposed by Lopez-Anido was implemented and can be seen in the following equations (Lopez-Anido 1995). 


$$
\begin{gathered}
b_{m}=\left[\frac{s}{2}\right]\left[\frac{\left(v_{x y}\right)(s / L)^{2}+1}{(s / L)^{2}\left(E_{y} / G_{x y}\right)+1}\right] \\
\mathrm{EFW}=2 \mathrm{~b}_{\mathrm{m}}+t_{w}
\end{gathered}
$$

Where,

$$
\begin{aligned}
& ?_{x y}=\text { Poisson' s ratio }(0.227) \\
& \mathrm{s}=\text { center to center spacing of stringers }\left(68^{\prime \prime}\right) \\
& \mathrm{L}=\text { clear span of stringers }\left(88^{\prime \prime}\right) \\
& \mathrm{EFW}=\text { effective flange width } \\
& \mathrm{E}_{\mathrm{y}}=\text { elastic modulus in }(\mathrm{Y}) \text { direction: See Figure } 6.8 \text { and section } 4.5 .3 \\
& \mathrm{G}_{\mathrm{xy}}=\text { in-plane shear modulus: See Figure } 6.8 \text { and Section } 7.5
\end{aligned}
$$
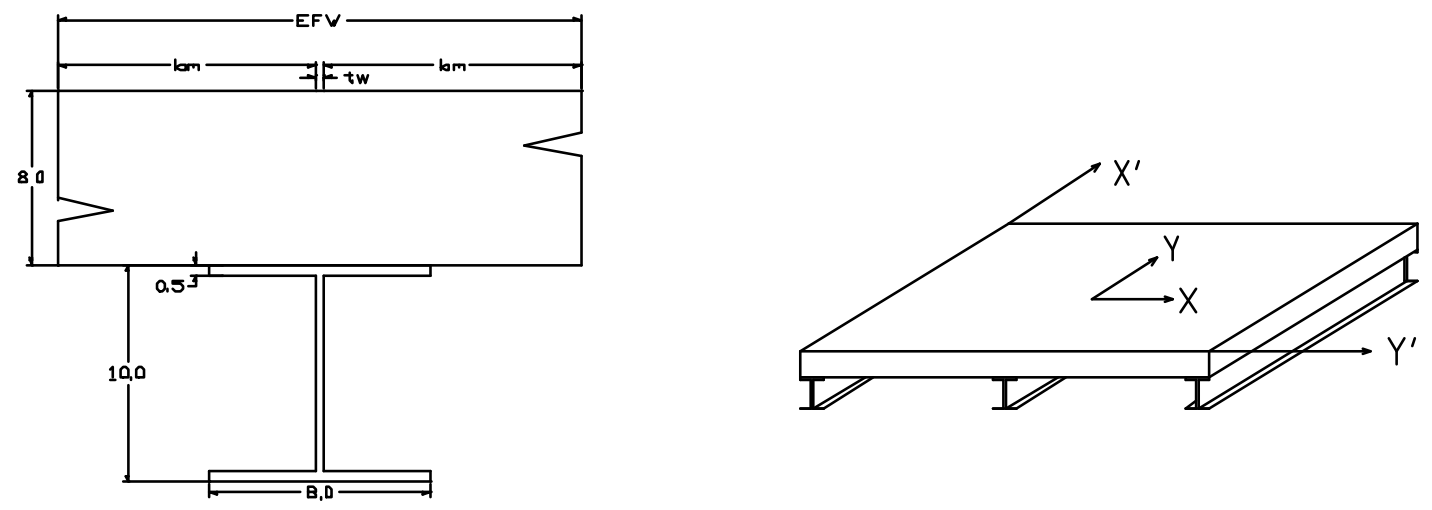

Figure 6.8-Effective Flange Width Dimensioning and Coordinate System Definition

Using equations 6.11 and 6.12, the effective flange width (EFW) was found to be approximately 35". This value was then used to determine the theoretical transverse load distribution factor.

\subsubsection{Transverse Load Distribution Factor}

Lopez-Anido (1995), utilized a first term approximation of Fourier series in a macro-approach to determine the solution of orthotropic stiffened plates. In this 
procedure, the maximum transverse load distribution factor, or TLDF, was determined as follows:

$$
\max \left(\mathrm{g}_{\mathrm{i}}{ }^{s}\right)=\frac{1+\mathrm{C}_{\mathrm{e}}{ }^{s}}{\left(\frac{2}{\pi}+C_{e}{ }^{s}\right) N_{b}-\left(\frac{2}{\pi}\right)}
$$

Where,

$$
C_{e}^{s}=\frac{1}{p ?}\left(\frac{\frac{D_{\mathrm{yy}}}{?^{2}}+D_{x y}+4 D_{s s}}{\frac{E l_{c}}{L}}\right)
$$

$\max \left(\mathrm{g}_{\mathrm{i}}^{\mathrm{S}}\right)=$ maximum transverse load distribution factor for a given system

$?=$ deck aspect ratio $(144 " / 88 ")$

$\mathrm{D}_{\mathrm{yy}}=$ deck stiffness per unit width $=\mathrm{E}_{\mathrm{y}} \mathrm{I}_{\mathrm{y}}\left(0.016 * 10^{9} \mathrm{lb}^{*} \mathrm{in}^{2}\right)$

$\mathrm{EI}_{\mathrm{c}}=$ composite bending stiffness over EFW $\left(9.3 * 10^{9} \mathrm{lb}^{*} \mathrm{in}^{2}\right)$

$N_{\mathrm{b}}=$ number of stringers (3)

$D_{x y}=\mathrm{v}_{\mathrm{xy}} D_{x x}$

$D_{s s}=$ torsional rigidity per unit width $\left(0.036 * 10^{9} \mathrm{lb}^{*} \mathrm{in}^{2}\right)$

To determine the composite bending stiffness of the deck and stringer over the effective flange width, the FRP deck flanges were transformed into equivalent steel plates as per equation 6.15 .

$$
\mathrm{b}_{\text {equiv }}=\left(\mathrm{E}_{\mathrm{y}} / \mathrm{E}_{\mathrm{s}}\right) \mathrm{EFW}
$$

Where,

$\mathrm{b}_{\text {equiv }}=$ transformed deck width $(1.3 ”)$ 
$\mathrm{E}_{\mathrm{y}}=$ elastic modulus of deck (See 4.5.3)

$\mathrm{E}_{\mathrm{s}}=$ elastic modulus of steel $\left(29 * 10^{6} \mathrm{psi}\right)$

$\mathrm{EFW}=$ effective flange width as per section 6.6.1 (35”)

A schematic of the transformed section can be seen in Figure 6.9, and the moment of inertia of the transformed section was then calculated based on the idealized transformed areas in the figure.

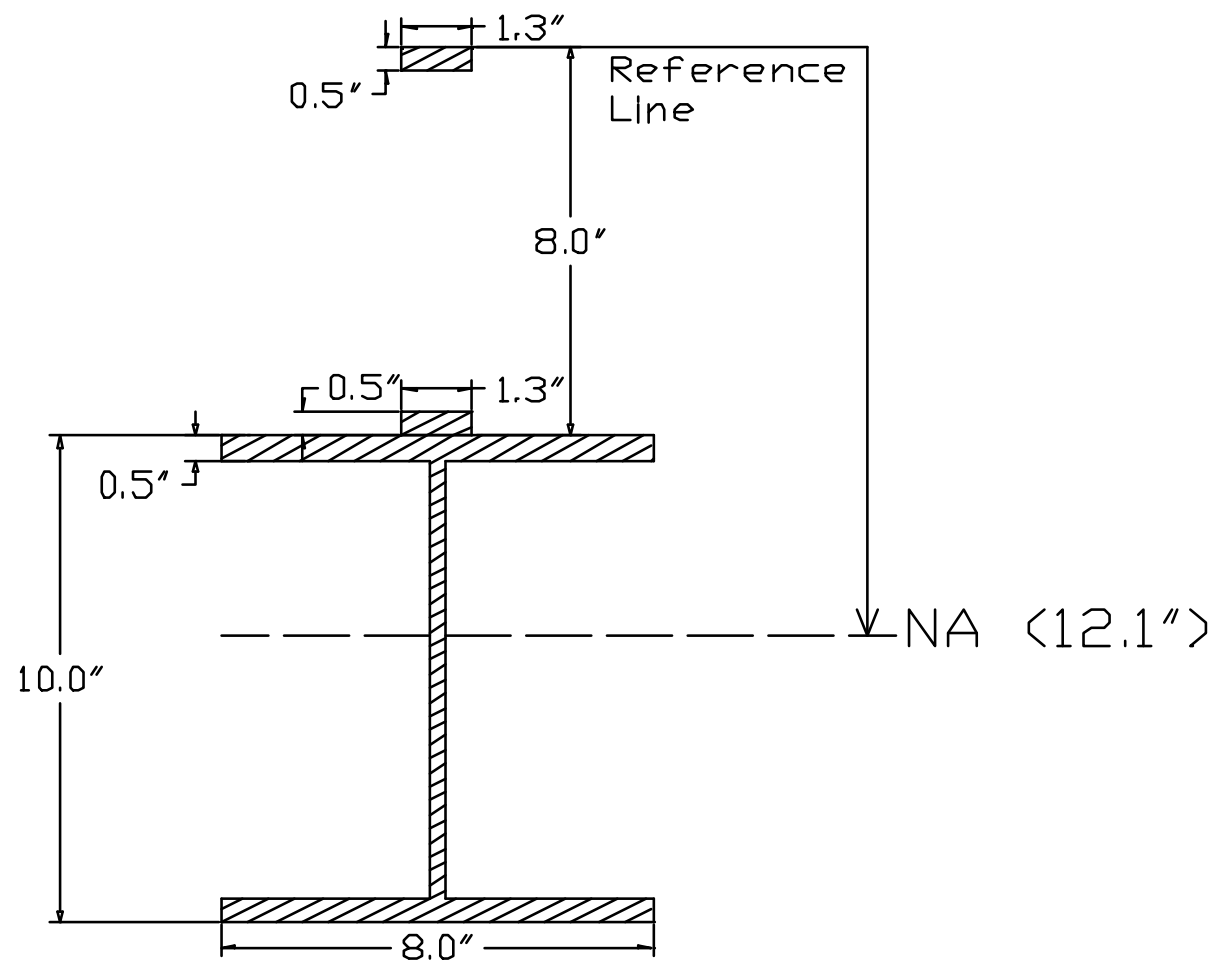

Figure 6.9-Schematic of Equivalent Steel Section over EFW

$$
\mathrm{NA}=\frac{\sum_{\mathrm{i}=1}^{\mathrm{N}} \mathrm{M}_{\mathrm{i}} \mathrm{A}_{\mathrm{i}}}{\sum_{\mathrm{i}=1}^{\mathrm{N}} \mathrm{A}_{\mathrm{i}}}
$$




$$
\begin{aligned}
& \mathrm{I}_{\mathrm{NA}}=\sum_{\mathrm{i}=1}^{\mathrm{N}}\left(\frac{\mathrm{b}_{\mathrm{i}} \mathrm{h}_{\mathrm{i}}{ }^{3}}{12}+\mathrm{A}_{\mathrm{i}} \mathrm{d}_{\mathrm{i}}^{2}\right) \\
& \mathrm{EI}_{\mathrm{c}}=\mathrm{E}_{\mathrm{s}} \mathrm{I}_{\mathrm{NA}}
\end{aligned}
$$

Where,

$\mathrm{NA}=$ distance from reference line to neutral axis of system as seen in Figure 6.9

$\mathrm{M}_{\mathrm{i}}=$ distance from centroid of portion (i) to reference line seen in Figure 6.9

$\mathrm{A}_{\mathrm{i}}=$ area of portion (i)

$b_{i}=$ width of portion (i) measured parallel to reference line

$\mathrm{h}_{\mathrm{i}}=$ height of portion (i) measured perpendicular to reference line

$\mathrm{d}_{\mathrm{i}}=$ distance from centroid of portion (i) to NA

$\mathrm{I}_{\mathrm{NA}}=$ moment of inertia of entire system shown in Figure 6.9 about neutral axis (NA)

Performing the necessary computations, equations 6.13 through 6.18 resulted in the values shown in Table 6.8. It should be noted that the $\mathrm{D}_{\mathrm{s}}$ term of equation 6.14 is not well understood. This term is intended to describe the shear behavior of the deck, but shear behavior of non-isotropic materials such as FRP bridge decks are not as of yet properly understood.

\begin{tabular}{|c|c|c|c|c|c|}
\hline $\max \left(\mathrm{g}_{\mathrm{i}}^{\mathrm{s}}\right)$ & $\mathrm{C}_{\mathrm{e}}{ }^{\mathrm{s}}$ & $\mathrm{b}_{\text {equiv }}$ & $\mathrm{NA}$ & $\mathrm{I}_{\mathrm{NA}}$ & $\mathrm{EI}_{\mathrm{c}}$ \\
\hline $60 \%$ & 0.283 & 1.3 in & $12.1 \mathrm{in}$ & $322 \mathrm{in}^{4}$ & $9.3\left(10^{9}\right) \mathrm{lb}^{*} \mathrm{in}^{2}$ \\
\hline
\end{tabular}

Table 6.8-Results of Theoretical Determination of TLDF

When compared to experimental results of Phase III loading, the theoretical prediction was higher than values found from experimental data of the two deck systems. Taking the average TLDF (based on strain and deflection) for each of the two decks during Phase III loading, a difference of 3\% was found for the polyester deck, with the vinyl ester deck having a difference of $13 \%$. 
The trend of predicting maximum transverse load distribution factors above that found from experimental data was not surprising. This same method proposed by Lopez-Anido has also been applied to actual in service bridges with FRP decks. Two examples are Laurel Hill Run bridge (seven stringers supporting the deck) and Wickwire Run bridge (four stringers supporting the deck). In both cases, the theoretical method predicted a transverse load distribution factor above that found from experimental data.

\subsection{Conclusions}

\section{Transverse Load Distribution Factor (TLDF)}

- Transverse load distribution was more evenly dispersed in the vinyl ester deck than in the polyester deck.

- The average TLDF of strain and deflection data was $57 \%$ for the polyester deck and $47 \%$ for the vinyl ester deck.

- The TLDF for the vinyl ester deck can also be expressed as spacing of stringers (in feet) divided by 5.7. Concrete decks are designed with the spacing divided by 5.5 .

- Theoretical methods proposed by Lopez-Anido yielded an effective flange width (EFW) of 35" and a maximum TLDF of $60 \%$.

- Lopez-Anido's method resulted in values that followed the same trend as had been seen when applied to in service bridges containing FRP decks. The method also predicted a maximum TLDF higher than experimental data in the case of Laurel Hill Run and Wickwire Run bridges.

\section{$\underline{\text { Deflection }}$}

- For Phase III loading, both the polyester and vinyl ester deck systems met the global deflection requirement of the clear span divided by 800 .

- Neither the polyester or vinyl ester deck system met the local deflection or strain requirements of section 6.5.2.2.

- The vinyl ester deck performed better than the polyester deck with respect to overall local resistance. 
- Local deflection/strain issues are directly related and are one of the most critical issues to be addressed in the current system. The application of a polymer concrete wearing surface will help improve the local performance of these decks.

- For Phase III loading, both the polyester and vinyl ester deck systems met the deck deflection limit relative to stringers, i.e., spacing of stringers divided by 500 .

- The polyester deck deflection was equal to the limit, and the vinyl ester deck deflection was $90 \%$ of the limit. Therefore, the vinyl ester deck performed better than the polyester deck in deflection with respect to stringers.

\section{Degree of Composite Action Between Deck and Stringers}

- The degree of composite action between deck and stringers was found to be $42 \%$ for the polyester deck and $58 \%$ for the vinyl ester deck.

- More data would be necessary to accurately state that the above values are accurate since the local placement of glue around the strain gages has a major effect on the results.

\section{Warping and Secondary Torsion}

- Warping and secondary torsion effects were seen in strain data taken during testing. In some instances, data showed the steel stringer actually straining more than the deck where the two were connected.

- Phase I loading showed excessive warping issues. The stringers were intentionally spaced very far apart (136") for this loading phase to observe the severity of the warping and secondary torsional effects.

- Two strain gages mounted on each side of the flange of one of the exterior stringers 24" from its end recorded values differing by a factor of 7.4 for Phase I loading. For phases II and III, where a third stinger was added, the difference was about half that seen in Phase I. In the absence of warping and secondary torsion, the ratio of the two readings would be 1.0. However, the magnitudes of these strain values were relatively small. 


\section{Effective Deck Width}

- The effective deck widths of the polyester and vinyl ester specimens were approximately equal to the width of one component.

- An effective deck width approximately equal to one component shows poor load transfer across the joints. As a result, the components act as if they are being loaded individually and not as part of a deck system. No strength benefits of plate action are present when the joints do not perform properly. Some type of mechanical fastener may be necessary to help correct the problem. 


\section{CHAPTER 7 \\ FRP DECK RESPONSE TO IN-PLANE SHEAR}

\subsection{Introduction}

Determining the in-plane shear modulus $\left(\mathrm{G}_{\mathrm{xy}}\right)$ is an important step in understanding the behavior of a structural system as a whole. This parameter is utilized not only in shear calculations, but also in the determination of other parameters related to bending. Section 6.6 of this report utilizes $G_{x y}$ in theoretical computation of both the effective flange width and transverse load distribution factor. Therefore, this chapter discusses a proposed method to arrive at an approximate value of $\mathrm{G}_{\mathrm{xy}}$.

Currently, most researchers use the torsional shear modulus discussed in Chapter $3\left(\mathrm{G}_{\mathrm{yz}}\right)$ as the in-plane shear modulus $\left(\mathrm{G}_{\mathrm{xy}}\right)$. While this substitution may or may not lead to large errors, the two moduli are philosophically different since they are in different planes of an anisotropic material. Due to the anisotropy and inhomogeneity of FRP composites, resistance varies from one type of shear to another. See Figure 7.1 for the material coordinate system used to differentiate one shear modulus from another.

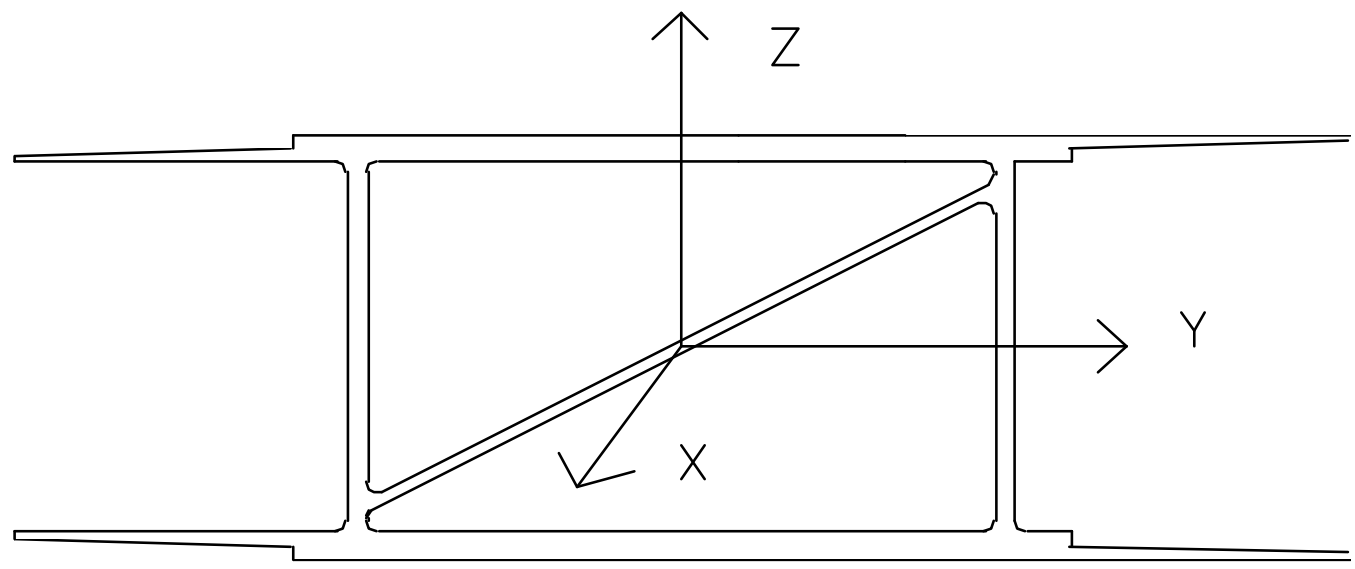

Figure 7.1-Material Coordinate System 
One possible reason for the use of $G_{y z}$ in place of $G_{x y}$ is that $G_{y z}$ is easier to obtain experimentally. Experimental evaluation of $\mathrm{G}_{\mathrm{xy}}$ for a deck module poses several potential problems for adequate quantification. Some of the problems to be overcome are: 1) partial support fixity leading to specimen slippage, 2) local effects, and 3) decoupling of bending and shear responses. Once these problems have been properly addressed and accounted for, more standard testing procedures could be developed which would ease the required effort to obtain the true in-plane shear modulus $\mathrm{G}_{\mathrm{xy}}$.

The experiments conducted in this chapter are merely a starting point to accurately determine $\mathrm{G}_{\mathrm{xy}}$. Additional experiments and analysis are planned for the future. Eventually, the goal is to be able to arrive at a consistent and accurate experimental approach for determining the in-plane shear modulus.

\subsection{Specimen Preparation}

All joints of the vinyl ester deck were reinforced with glass fabrics to ensure proper shear transfer between components. The fabrics were applied to the joints by Bedford Reinforced Plastics, Inc. The joints were sanded with 40-grit sandpaper and the excess dust removed by vacuuming. The sanded area was then cleaned with acetone and left undisturbed for twenty minutes before vacuuming the residue.

Two layers of triaxial fabrics having a total density of $40 \mathrm{oz} / \mathrm{yd}^{2}$ (16 $\mathrm{oz} / \mathrm{yd}^{2}$ of rovings and $12 \mathrm{oz} / \mathrm{yd}^{2}$ in each of the 45 degree directions) were placed at each joint. A 4" wide strip was placed next to the deck, and a 6" wide strip was placed directly over the top of the 4" strip. The resin used was VE 8084, which is a vinyl ester resin commonly used in the pultrusion industry.

\subsection{Instrumentation}

The instrumentation of this experiment consisted of strain gages and dial gages. The strain gages were mounted to the deck according to the specifications of (M-LINE ACCESSORIES 1979). Figure 7.2 shows the locations of the necessary instrumentation. The arrows in the figure indicate which direction the particular dial gage was measuring deflection. 


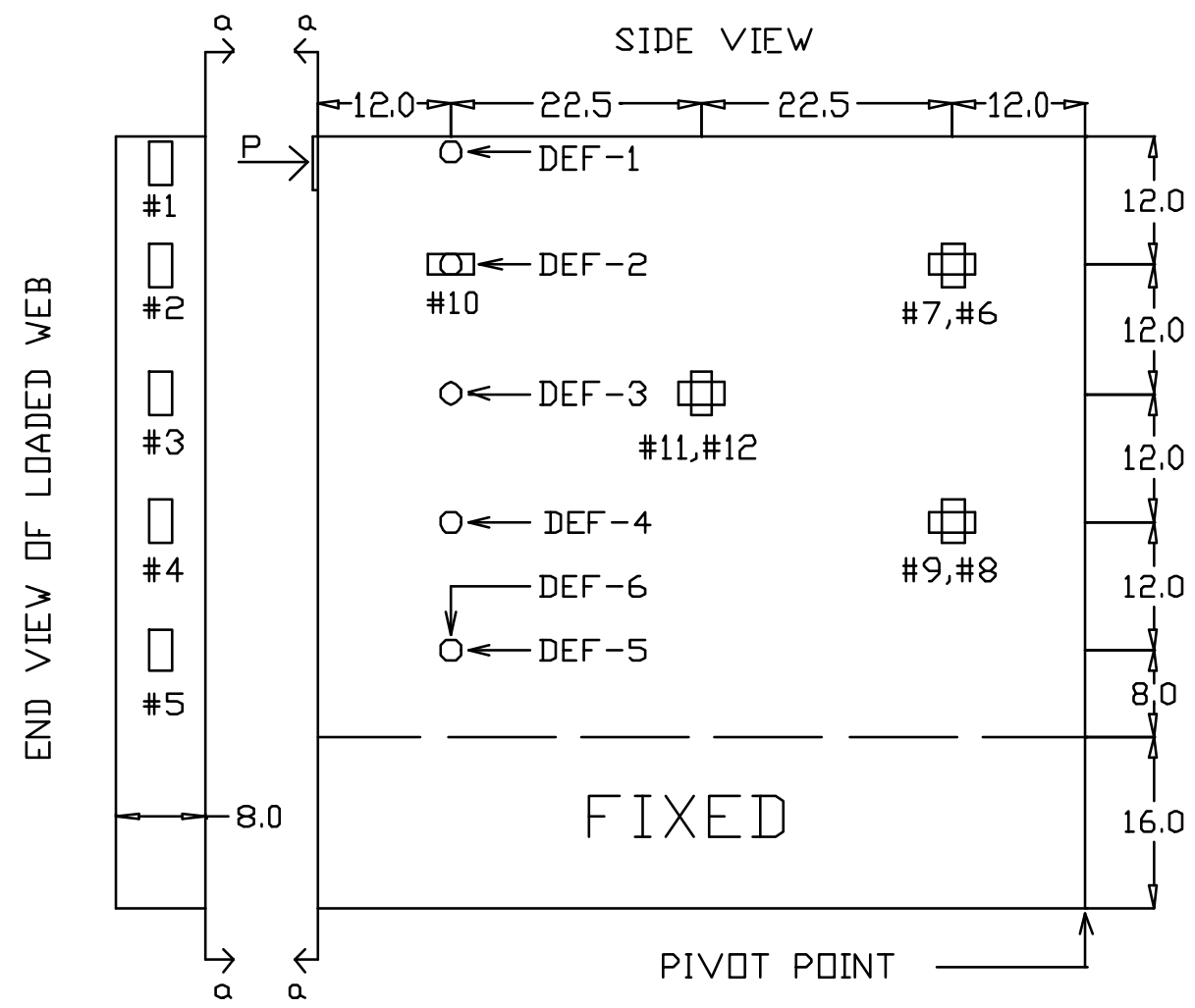

$\square$ REPRESENTS A STRAIN GAGE

O REPRESENTS A PUINT WHERE DEFLECTIIN WAS MEASURED

\#7, \#9, \#10, AND \#11 MEASURE STRAIN IN THE 69 INCH DIRECTIUN

ALL UNITS ARE IN INCHES-NOT TO SCALE

Figure 7.2-Instrumentation of In-Plane Shear Deck

\subsection{Test Set-Up and Procedure}

The test set-up for the in-plane shear test can be seen in Figure 7.3. The deck rested on 1" thick elastomeric padding across its 8 " thickness to allow rotation and/or displacement in downward direction to take place. A total of four \#6 DYWIDAG THREADBAR'S $^{\circledR}$ were used to prevent translation of the base of the deck. Two bars

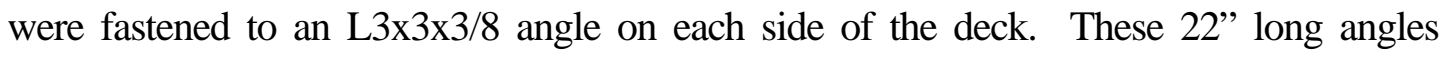
were then bolted to the frame using five $1-1 / 8$ " bolts spaced $41 / 4$ " on center. The other end of the DYWIDAG rods were fastened to a 24" wide channel (C15x33.9). Holes were drilled in the channel and bolts were placed behind the channel in order to 
be able to apply tension to the rods. The tension in the DYWIDAG rods forced the channel to tighten towards the deck and clamp its bottom to the other column in much the same way as a standard vice grip mechanism. Furthermore, 24" high wooden blocks had been placed at the end of the deck to be in contact with the column to act as a spacer so the top portion of the deck could translate and not hit the column. These blocks were in contact with both the deck and column, which made the clamping action at the base of the deck possible.

When the DYWIDAG rods had been sufficiently tightened, there was approximately $1 / 2$ " gap between the channel and adjacent column. The other end of the deck was firmly in contact with its adjacent column, but the small gap in the setup was a potential problem. While the rods were preventing horizontal translation, the gap would potentially allow vertical slippage in the system. A first trial of the experiment was conducted with nothing in the vacant space. As expected, excessive vertical slip occurred making the deflection data unusable.

To remedy the above said problem, a wedge was placed into the $1 / 2$ " gap. As a result, when the system began to slip in the vertical direction, the wedge would become more tightly lodged in the gap. While this did not totally eliminate the vertical slip on the left bottom corner, the wedge did minimize the slip enough so that it could be recorded and accounted for in analysis. The addition of wedges in the second trial of the experiment only affected deflection data. The strain readings were almost identical between the two trials. Therefore, data from the second trial were synthesized for analytical purposes and the first trial data discarded.

A hydraulic jack mounted to the column applied the horizontal force as seen in Figure 7.3. This jack was placed onto a steel plate and subsequently clamped to the column so that it could apply the necessary horizontal force. The force was applied to a 6"x 7"x 1/2" steel plate, which rested on elastomeric padding fastened to the deck.

As shown in Figure 7.3, the test was performed with the aid of dial gages, strain gages, strain indicators, a load cell, and a bydraulic jack. The load was applied at a constant rate of $250 \mathrm{lb} / \mathrm{min}$, with strain and deflection data taken at constant load intervals. No standard test methods were available in the literature to conduct inplane shear testing; hence our own method of testing was devised. 


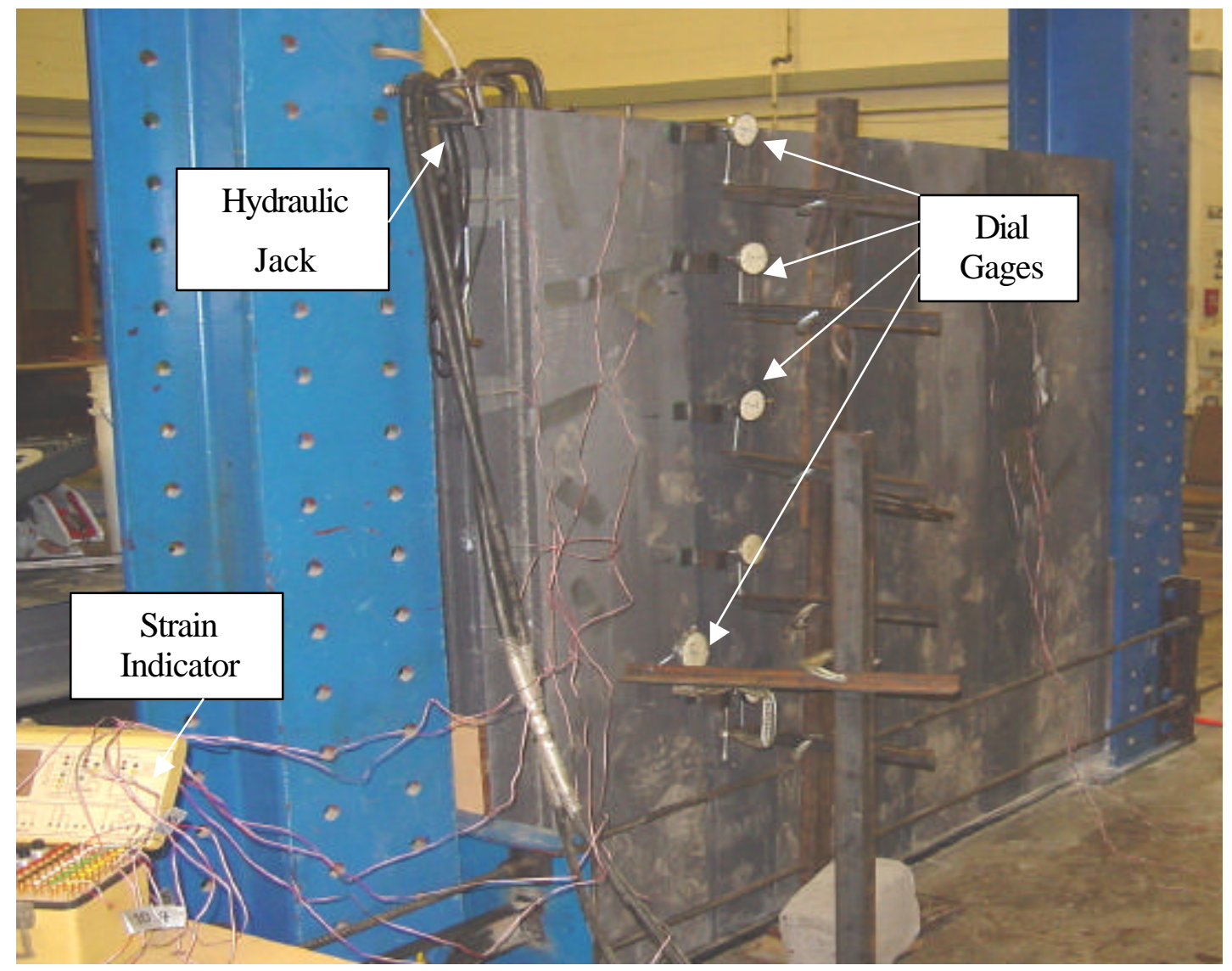

Figure 7.3-Test Set-Up for In-Plane Shear

\subsection{Test Results}

Quantifiable results were obtained based on deflection data only. The recorded strain readings proved to be too complex to analyze as per the current knowledge base of anisotropic shear behavior at a system level. However, the strain readings in the vertical direction of the deck did prove useful to interpret the deflection data. The following explains the basic philosophy of the deflection calculations.

A one dimensional analysis was conducted based on deflection data. This type of analysis neglects the benefits of plate action. Applying strain gages in the vertical direction checked the validity of neglecting plate action. As expected, the readings of the vertical gages were approximately zero, which indicates almost the entire load is being resisted/transferred in the horizontal direction. Therefore, the 
analysis was carried out in a one dimensional fashion. See Table C17 of Appendix C for the raw test data from both strain and deflection.

Based on deflection data, $\mathrm{G}_{\mathrm{y}}$ was obtained in a fairly straightforward manner. The basis of the analysis was prior work performed by GangaRao and Luttrell (1979). Therein, the shear displacement of wood diaphragms was investigated, and an equation to predict their shear displacement was suggested. Based on GangaRao and Luttrell's equation, seen in an approximate form in equation 7.1, a revised method to determine $\mathrm{G}_{\mathrm{xy}}$ for an FRP bridge deck was determined and can be seen immediately following equation 7.1 .

$$
\Delta=\left(\frac{\mathrm{a}}{\mathrm{b}}\right)\left(\frac{\mathrm{P}}{\mathrm{G}_{\mathrm{xy}} \mathrm{t}_{\mathrm{e}}}\right)+\text { Internal Slippage }
$$

In the case of an FRP bridge deck such as the one under consideration, internal slippage would be negligible and was taken as zero. Equation 7.1 was originally written for wooden diaphragms where nail slippage could have a significant effect on the overall system behavior. Rearranging terms and neglecting internal slippage, equation 7.1 can be re-written as:

$$
\mathrm{G}_{\mathrm{xy}}=\left(\frac{\mathrm{P}}{\Delta}\right)\left(\frac{\mathrm{a}}{\mathrm{b}}\right)\left(\frac{1}{\mathrm{t}_{\mathrm{e}}}\right)
$$

Where,

$\mathrm{G}_{\mathrm{xy}}=$ in-plane shear modulus

$\frac{\mathrm{P}}{\Delta}=$ slope of linear portion of load versus shear deflection curve

$\mathrm{t}_{\mathrm{e}}=$ effective panel thickness (1" in elastic range of specimen)

$\mathrm{a}=$ width of specimen (69")

$\mathrm{b}=$ height of specimen (56") 
The recorded deflection data was modified before implementation into equation 7.2. As mentioned in section 7.4, vertical slippage of the experimental setup caused a percent of the horizontal deflection to be identified with boundary slippage, not shear. As a result, the recorded deflection data were decoupled. The decoupling was accomplished by assuming all slip deflection occurred as a result of rigid body motion; while all shear deflection occurred in the form of specimen distortion. As shown in Figure 7.2, vertical deflection was measured at a distance of 57 " from the pivot point of the deck. This deflection value was used along with basic geometry to correct all recorded values. The principle observation was that most, if not all, vertical deflection was due to slip, which forced the width of the deck to have an angle with respect to the horizontal. Also, for a rigid body, the height of the deck must have the same angle with respect to the vertical. This relationship is shown in equation 7.3. It allows the slip to be corrected at any load level for each height of interest.

$$
\tan ^{-1}\left(\frac{\Delta_{\text {slip }}(\mathrm{i})}{\mathrm{a}^{\prime}}\right)=\tan ^{-1}\left(\frac{\Delta_{\text {corr (i) }}}{\mathrm{L}}\right)
$$

Rearranging,

$$
\begin{gathered}
\Delta_{\text {corr (i) }}=\frac{\Delta_{\text {slip(i) }} \mathrm{L}}{\mathrm{a}^{\prime}} \\
\Delta_{\text {(i) }}=\Delta_{\text {act (i) }}-\Delta_{\text {corr (i) }}
\end{gathered}
$$

Where,

$$
\Delta_{\text {corr (i) }}=\text { deflection correction necessary to account for vertical slip at load (i) }
$$


$\Delta_{\text {slip(i) }}=$ vertical deflection of deck at a distance (a') from pivot point at load (i)

$\Delta_{\text {(i) }}=$ deflection due to shear at load (i)

$\Delta_{\text {act (i) }}=$ actual horizontal deflection recorded during testing at load (i)

$\mathrm{a}^{\prime}=$ distance from pivot point to point of measured vertical deflection (57')

$\mathrm{L}=$ distance from line of true fixity to deflection measurement (See Table 7.1)

The procedure outlined in equations 7.3 through 7.5 was applied to the deflection data taken in the horizontal direction. In other words, every data point for the five horizontal deflection values (DEF-1-DEF-5) was corrected. After the data correction, the analysis was completed and the results are shown in Table 7.1.

\begin{tabular}{|c|c|c|c|}
\hline DEF & L (in) & $\mathrm{P} / \Delta(\mathrm{lb} / \mathrm{in})$ & $\mathrm{G}_{\mathrm{xy}}(\mathrm{psi})$ \\
\hline 1 & 56 & $453\left(10^{3}\right)$ & $0.558\left(10^{6}\right)$ \\
\hline 2 & 44 & $586\left(10^{3}\right)$ & $0.722\left(10^{6}\right)$ \\
\hline 3 & 32 & $227\left(10^{3}\right)$ & $0.280\left(10^{6}\right)$ \\
\hline 4 & 20 & $458\left(10^{3}\right)$ & $0.564\left(10^{6}\right)$ \\
\hline 5 & 8 & $462\left(10^{3}\right)$ & $0.569\left(10^{6}\right)$ \\
\hline
\end{tabular}

Table 7.1-Results of In-Plane Shear Testing Based on Deflection Data

The average value of $\mathrm{G}_{\mathrm{xy}}$ based on deflection was determined to be $0.54\left(10^{6}\right)$ psi. Even though the results varied as much as $0.44\left(10^{6}\right)$ psi, three of the five values were very close to one another. For a first trial, the data was fairly consistent. However, much improvement is anticipated as the work of this chapter is continued in the future.

\subsection{Conclusions}

- The experimental set-up used herein has the potential to be developed into a standardized test to determine $\mathrm{G}_{\mathrm{xy}}$. However, more improvements are needed 
before the test can extract an accurate in-plane shear modulus with a high level of confidence.

- Two of the most important issues that need to be improved with respect to the existing set-up are an attempt for further reduction in vertical slip and to determine efficient extraction methods of the data necessary to determine $G_{x y}$. The experiment discussed in this chapter utilized many instruments to arrive at the in-plane shear modulus $\left(\mathrm{G}_{\mathrm{xy}}\right)$.

- Results based on deflection yielded an average $G_{x y}$ of $0.54\left(10^{6}\right)$ psi. This value was based on five deflection measurements, with three of the five being very close to the average. Of the other two, one was considerably higher than the average, while the other was considerably lower than the average.

- From Chapter 3, the out-of-plane shear modulus $\mathrm{G}_{\mathrm{yz}}$ was found to be 0.53 $\left(10^{6}\right)$ psi for the polyester component. This value was deemed too low due to the effects of warping and secondary torsion not accounted for in the analysis. Theoretically $\mathrm{G}_{\mathrm{yz}}$ was determined to be $0.86\left(10^{6}\right)$ psi (vinyl ester) and 0.9 $\left(10^{6}\right)$ psi (polyester). Therefore, the potential that $\mathrm{G}_{\mathrm{xy}} \neq \mathrm{G}_{\mathrm{yz}}$ for FRP deck systems is very likely due to their anisotropy and in-homogeneity. 


\section{CHAPTER 8 \\ CONCLUSIONS AND RECOMMENDATIONS}

\subsection{Introduction}

Two 8 inch deep multicellular FRP bridge deck designs with fiber volume fractions of approximately 54\% have been evaluated for static response under varying load types, i.e. shear, bending, torsion, and buckling. These two bridge decks are the newest versions in a series of iterations created and evaluated by the Constructed Facilities Center at West Virginia University. Two of the previous iterations were generations one and two of the Superdeck ${ }^{\mathrm{TM}}$. The testing and evaluation of the polyester and vinyl ester decks have yielded much valuable information.

This chapter contains conclusions drawn from experimental and theoretical work as well as recommendations on further testing, further evaluation, fiber architecture modifications, and shape modifications. These conclusions and recommendations will then be considered in further refinements of the vinyl ester bridge deck system.

The current vinyl ester deck is scheduled to be implemented on a few low volume roads throughout the state of West Virginia. While these roads are not rated for HS25 truck traffic, the use of the decks is a good starting point. After the modifications suggested in the recommendations portion of this chapter are manufactured and tested, the bridge deck system should be able to adequately withstand AASHTO’s HS25 loads.

\subsection{Conclusions}

\section{GENERAL}

- Lack of adequate local strength prevented the current deck systems from meeting AASHTO's HS25 loading case. However, the application of a polymer concrete wearing surface on the deck could possibly have provided enough additional local strength to meet the requirements.

- The current component to component connection scheme consists only of bonding between exterior lap joints with glass fabrics placed over these joints. 
This system did not provide adequate load transfer from component to component in any of the experiments.

- Response to all conditions was satisfactory with the exceptions stated above.

- The current design does not appear to have any problems that cannot be fixed in a safe and economical manner.

\section{COMPONENT LEVEL}

\section{$\underline{\text { Torsion }}$}

- For the polyester component, the average torsional stiffness $\left(\mathrm{K}_{\mathrm{yz}}\right)$ was found to be $6.84\left(10^{8}\right) \mathrm{lb}^{* \mathrm{in}^{2}}$, and the average out-of-plane shear modulus $\left(\mathrm{G}_{\mathrm{yz}}\right)$ was found to be $0.53\left(10^{6}\right)$ psi. These values were found neglecting the effects of warping and secondary torsion.

- Theoretical analysis using a combination of micro mechanics and approximate classical lamination theory yielded $\mathrm{G}_{\mathrm{yz}}=0.9\left(10^{6}\right)$ psi for the polyester component. This was approximately $40 \%$ higher than the experimental value, confirming suspicions of warping and secondary torsion effects.

\section{$\underline{\text { Torsion and Bending }}$}

- The magnitude of the applied torque had very little, if any, effect on the bending stiffness of the polyester component at low load levels.

\section{Buckling}

- The webs were adequate to resist local buckling loads.

- Failure of the specimens occurred between 44-55 kips.

- Failure modes were web buckling at the center of the unbraced length for polyester specimens and joint failure induced by web buckling and secondary moments of the vinyl ester specimens.

- The vinyl ester specimens out performed the polyester specimens in that they had higher ultimate loads under the same conditions, and their failure mode was less catastrophic.

- The effective length factor of the components tested was found to be $(\mathrm{K}=0.7)$. 


\section{Longitudinal Bending Components}

- 10"x 20" patch loads caused local punching shear failures prior to global failure in all cases.

- The modulus of elasticity in the major bending direction of the deck $\left(E_{x}\right)$ was determined to be $4\left(10^{6}\right)$ psi based on theoretical and experimental results.

- When loaded with 10 "x 20 " patch loads, the behavior of the vinyl ester and polyester components was very similar.

- The vinyl ester component loaded with a 15"x 24" patch load had an ultimate stress of $18.7 \mathrm{ksi}$, which is $8 \mathrm{ksi}$ greater than the polyester component under the same conditions.

- The vinyl ester component loaded with a 15"x 24" patch load had a less catastrophic failure than did the polyester component.

- All plots of load v/s strain or deflection were linear until failure.

\section{$\underline{\text { Rehabilitated Bending Component }}$}

- The same failure mode occurred (punching shear) as in the virgin component testing.

- The ultimate stress of $10.9 \mathrm{ksi}$ was $3.5 \mathrm{ksi}$ less than in the virgin component.

\section{Transverse Bending Component}

- The application of bonded fabric strips at the joints increased the transverse stiffness by 2.2 times.

- The deflection data revealed severe joint rotation problems both with and without the fabric strips.

- For the polyester component, the elastic modulus in the transverse direction $\left(\mathrm{E}_{\mathrm{y}}\right)$ was found to be approximately $1.1\left(10^{6}\right)$ psi by both theory and experiment. 


\section{Theoretical Analysis of Bending Components}

- The use of micro mechanics in conjunction with approximate classical lamination theory (ACLT) predicted stiffness values within $0-32 \%$ of those found from experiments. Note that some of the experimentally determined values did not account for shear deflection.

\section{$\underline{\text { Longitudinal Shear Failures }}$}

- The ultimate longitudinal shear stress of the polyester component was found to be $4.4 \mathrm{ksi}$ based on experimental data.

- The ultimate shear stress was found to be $4.0 \mathrm{ksi}$ based on strain to failure limit state.

- The two methods differed by $9 \%$, an acceptable difference.

\section{$\underline{\text { Punching Shear Failures }}$}

- The ultimate punching shear stress was found to be $1.8-2.0 \mathrm{ksi}$.

- The ultimate stress predicted by the limit state was $1.7 \mathrm{ksi}$ for polyester specimens and $2.0 \mathrm{ksi}$ for vinyl ester specimens.

- Both the limit states predicted an ultimate stress very close to that found from experimental data $(6 \%$ difference for polyester specimens and $5 \%$ difference for vinyl ester specimens).

\section{Racking Shear Failures}

- The ultimate bending stress in the web induced by racking shear was found to be $5 \mathrm{ksi}$. This value represents a worst-case scenario since the experiment was conducted only on one component, which prevented stiffening in the loading direction.

\section{SYSTEM LEVEL}

\section{Transverse Load Distribution Factor (TLDF)}

- Transverse load distribution was more evenly dispersed in the vinyl ester deck than in the polyester deck. 
- The average TLDF of strain and deflection data was $57 \%$ for the polyester deck and $47 \%$ for the vinyl ester deck.

- The TLDF for the vinyl ester deck can also be expressed as spacing of stringers (in feet) divided by 5.7. Concrete decks are designed with the spacing divided by 5.5 .

- Theoretical methods proposed by Lopez-Anido yielded an effective flange width (EFW) of 35" and a maximum TLDF of $60 \%$.

- Lopez-Anido's method resulted in values that followed the same trend as had been seen when applied to in service bridges containing FRP decks. The method also predicted a maximum TLDF higher than experimental data in the case of Laurel Hill Run and Wickwire Run bridges.

\section{$\underline{\text { Deflection }}$}

- For Phase III loading, both the polyester and vinyl ester deck systems met the global deflection requirement of the clear span divided by 800 .

- Neither the polyester or vinyl ester deck system met the local deflection or strain requirements of section 6.5.2.2.

- The vinyl ester deck performed better than the polyester deck with respect to overall local resistance.

- Local deflection/strain issues are directly related and are one of the most critical issues to be addressed in the current system. The application of a polymer concrete wearing surface will help improve the local performance of these decks.

- For Phase III loading, both the polyester and vinyl ester deck systems met the deck deflection limit relative to stringers, i.e., spacing of stringers divided by 500 .

- The polyester deck deflection was equal to the limit, and the vinyl ester deck deflection was $90 \%$ of the limit. Therefore, the vinyl ester deck performed better than the polyester deck in deflection with respect to stringers. 


\section{Degree of Compositness Between Deck and Stringers}

- The degree of compositness between deck and stringers was found to be $42 \%$ for the polyester deck and $58 \%$ for the vinyl ester deck.

- More data would be necessary to accurately state the above values are accurate since the local placement of glue around the strain gages has a major effect on the results.

\section{Warping and Secondary Torsion}

- Warping and secondary torsion effects were seen in strain data taken during testing. In some instances, data showed the steel stringer actually straining more than the deck where the two were connected.

\section{Effective Deck Width}

- The effective deck widths of the polyester and vinyl ester specimens were approximately equal to the width of one component.

- An effective deck width approximately equal to one component shows poor load transfer across the joints. As a result, the components act as if they are being loaded individually and not as part of a deck system. No strength/stiffness benefits of plate action are present when the joints do not perform properly. Some type of mechanical fastener may be necessary to help correct the problem.

\section{$\underline{\text { In-Plane Shear Modulus }\left(G_{\underline{x y}}\right)}$}

- The experimental set-up used herein has the potential to be developed into a standardized test to determine $\mathrm{G}_{\mathrm{xy}}$. However, more improvements are needed before the test can extract an accurate in-plane shear modulus with a high level of confidence.

- Results based on deflection yielded an average $\mathrm{G}_{\mathrm{xy}}$ of $0.54\left(10^{6}\right)$ psi. 


\subsection{Recommendations}

- The local capacity of the design is one major area for improvement. Extra strength is needed to resist local shear effects and minimize local strain and deflection. Some possible solutions to these problems can be seen in the following list:

1) Stitch the fabrics in the thickness direction, especially at the joints. This should allow for much better transfer of shear from the flange to the web.

2) Embed extra lamina over the joints. These lamina should be long enough to cross the joint with a small overhang to the outside, while reaching into the closed cellular portion $2-3$ inches. The total length of the embedded strips would probably need to be 3-5 inches, and the lamina would lie in the XY plane. These additional lamina would probably need to consist of some type of tri-axial or quadra-axial fabric containing as many $90^{\circ}$ strands as possible.

3) Increase the thickness of the top flange by approximately $0.1 "$. This increase would allow for the placement of fibers in the transverse or $\left(90^{0}\right)$ direction of the components. Placement of $90-100 \mathrm{oz} / \mathrm{yd}^{2}$ of transverse fibers should approximately double the shear capacity of the existing vinyl ester design. Also, the increased thickness would help to stiffen the top flange and decrease local strains and deflections.

- The joints of the current design need to be improved in order to maximize structural efficiency. The method of connection used in the present study was adhesive (PLIOGRIP $\left.{ }^{\circledR}-7779 / 300\right)$ over a 5" lap length. It is recommended that some type of system be developed to complement the current adhesive connection of one component to another. Two suggestions are given below.

1) Use some type of mechanical fastener in conjunction with PLIOGRIP $^{\circledR}$. The fastener could be in the form of bolts, rivets, or others. Under this proposed method, the type of fastener, size of fastener, and necessary spacing would have to be determined. 
2) Place additional fabrics between the components at the lap joint. These fabrics could prove advantageous in transferring forces across the joint. The fabrics would provide some degree of rigidity to the PLIOGRIP $^{\circledR}$ which would help minimize the local rotation issues seen during transverse testing.

- Much more work needs to be performed in order to adequately quantify the failure modes of the current design. Each failure mode needs to be isolated and studied until a satisfactory understanding has been reached. The phenomena of shear failures was the most common type of failure, and probably deserves special attention. Also, studies on the effects of combined stresses need to be performed.

- Use the work performed in this study as a starting point to determine the inplane shear modulus $\left(\mathrm{G}_{\mathrm{xy}}\right)$ in an accurate and efficient manner. Testing needs to be performed on different size decks to determine the benefits of plate action for different aspect ratios. Also, finite element modeling and orthotropic plate theories need to be implemented to achieve adequate quantification. 


\section{BIBLIOGRAPHY}

ACI Committee 318. (1999), "Building Code Requirements for Structural Concrete (318-99) and Commentary (318R-99)," Farmington Hills, Michigan, USA.

Adams, Donald. (no published year), "Test Methods for Composite Materials: Seminar Notes," Technomic Publishing Company, Lancaster, PA, USA.

American Association of State Highway and Transportation Officials (AASHTO). (1996), "Standard Specifications for Highway Bridges," Washington, DC.

American Association of State Highway and Transportation Officials (AASHTO). (1998), “LRFD Bridge Design Specifications-2 ${ }^{\text {nd }}$ Edition,” Washington, DC.

Altizer, Derek. (1996), "Mechanical Properties of GFRP Bars for Varying Parameters," Department of Civil and Environmental Engineering, West Virginia University, Morgantown, WV 26506, USA.

Barbero, E.J. (1998), "Introduction to Composite Materials Design," Taylor \& Francis Inc.: Philadelphia, PA., USA.

Boresi, Arthur, Richard Schmidt, Omar Sidebottom (1993), “Advanced Mechanics of Materials," John Wiley \& Sons, Inc., New York, NY., USA.

Busel, John. (2000), "Product Selection Guide: FRP Composite Products for Bridge Applications," Market Development Alliance: Harrison, NY, USA.

Freed, Adam. (2002), "Modeling the Pultrusion Process to Obtain Low Void Fraction Composites," M.S. Thesis, Department of Civil and Environmental Engineering, West Virginia University, Morgantown, WV 26506, USA. 
GangaRao, Hota, L.D. Luttrell (1979), "Preliminary Investigation into the Response of Timber Diaphragms," Proceedings of a Workshop on Design of Horizontal Wood Diaphragms, Applied Technology Council, Publication ATC-7-1.

GangaRao, Hota, S. Sotiropoulos, A. Mongi (1994), “Theoretical and Experimental Evaluation of FRP Components and Systems," Journal of Structural Engineering, v120, n2, February, pp.464-485.

GangaRao, Hota, Vimala Shekar (2002), "Specifications for FRP Highway Bridge Applications: Acceptance Test Specifications for FRP Decks and Superstructures," CFC Report to USDOT-FHWA, West Virginia University, Morgantown, WV 26506, USA.

GangaRao, Hota, Hemanth Thippeswamy, Vimala Shekar, Carl Craigo (1999), "Development of Glass Fiber Reinforced Polymer Composite Bridge Deck," SAMPE Journal, v35, n4.

Hotchkiss, J.G. (1966), "Torsion of Rolled Steel Sections in Building Structures," AISC Engineering Journal, January, pp 19-33.

Hibbeler, Russell. (1997), "Mechanics of Materials: Third Edition," Prentice Hall, Inc.: Upper Saddle River, NJ., USA.

Howdyshell, Paul A., Jonathon C. Trovillion, Hota V.S. GangaRao, and Roberto Lopez-Anido (1998), US Army Corps of Engineers "Development and Demonstration of Advanced Design Composite Structural Components," Champaign, IL, USA.

Jones, R.M. (1975), "Mechanics of Composite Materials," Hemisphere Publishing Co. 
Lopez-Anido, Roberto, Piyush Dutta, John Bouzoun, Steve Morton, Bahram Shahrooz, Issam Harik (1999), "Proceedings of the $44^{\text {th }}$ National SAMPE Symposium,” Vol 44, Azusa, CA, pp.1666-1675.

Lopez-Anido, Roberto. (1995), “Analysis and Design of Orthotropic Plates Stiffened by Laminated Beams for Bridge Superstructures," Ph.D Dissertation, Dept. of Civil and Environmental Engineering, West Virginia University, Morgantown, WV 26506, USA.

Maji, A.K, Lorena Sanchez, Robert Acree (1999), "Processing Variables and Their Effects on Pultruded Composites," Journal of Advanced Materials, Volume \#3, pp. 14-26.

Mallick, P.K. (1993), "Fiber Reinforced Composites: Materials, Manufacturing, and Design," Marcel Dekker, Inc.: New York, USA.

Mentrasti, L. (1990), "Distortion (and Torsion) of Rectangular Thin-Walled Beams," Thin-Walled Structures, v10, pp175-193.

MIL-HDBK-17-2E. (1998), “Department of Defense Handbook: Composite Materials Handbook: Polymer Matrix Composites, Materials, Properties," Volume 2, USA.

"M-LINE ACCESSORIES Instruction Bulletin B-137-16: Strain Gage Applications with M-Bond AE-10, AE-15, and GA-2 Adhesive Systems," Micro-Measurements Division-MEASUREMENTS GROUP, INC., Raleigh, NC 27611, USA.

Nagy, Geza. (1996), "Experimental Study of the Performance of Pultruded-Core Sandwich Deck Panels," Technical Report, University of California, San Diego La Jolla, CA 92093-0085, USA. 
Nagaraj, V. (1994), "Static and Fatigue Response of Pultruded FRP Beams Without and With Splice Connections," M.S Thesis, Department of Civil and Environmental Engineering, West Virginia University, Morgantown, WV 26506, USA.

Qiao, Pizhong. (1997), “Analysis and Design Optimization of Fiber-Reinforced Plastic (FRP) Structural Beams," Ph.D Dissertation, Dept. of Civil and Environmental Engineering, West Virginia University, Morgantown, WV 26506, USA.

Reiner, M.W., Bahram M. Shahrooz, Victor J. Hunt, Andy R. Neumann, Arthur J. Helmicki, Makrarand Hastak (2002), "A Close Look at Installation Issues and Performance of Four Fiber Reinforced Polymer Composite Bridge Decks," Information Through Personal Contact.

Shekar, Vimala. (2000), “Advancement in FRP Composites Using 3-D Stitched Fabrics and Enhancement in FRP Bridge Deck Component Properties," M.S. Thesis, Department of Civil and Environmental Engineering, West Virginia University, Morgantown, WV 26506, USA.

Sotiropoulos S. (1995), "Performance of FRP Components and Connections for Bridge Deck Systems," Ph.D Dissertation, Dept. of Civil and Environmental Engineering, West Virginia University, Morgantown, WV 26506, USA.

Stone, D., A. Nanni, J. Myers (2001), "Field and Laboratory Performance of FRP Bridge Panels," University of Missouri-Rolla, Rolla, Missouri, USA.

Sonti S.S. (1997), "Evaluation of Joint Efficiency and Performance of Multi-Cellular Deck Panel," M.S. Thesis, Department of Civil and Environmental Engineering, West Virginia University, Morgantown, WV 26506, USA.

Taly, Narendra. (1998), "Design of Modern Highway Bridges," McGraw-Hill Companies, Inc.: USA. 
Troitsky, M.S. (1987), “Orthotropic Bridges; Theory and Design,” James F. Lincoln Arc Welding Foundation: Cleveland, Ohio, USA.

Tsai, C., I. M. Daniel, G. Yaniv (1990), "Torsional Response of Rectangular Composite Laminates," Journal of Applied Mechanics, Volume 57.

Wen, Edward. (1999), “Compressive Strength Prediction For Composite Unmanned Aerial Vehicles," M.S. Thesis, Department of Mechanical/Aerospace Engineering, West Virginia University, Morgantown, WV 26506, USA.

Wu, Wei-Pin. (1990), "Thermomechanical Properties of Fiber Reinforced Plastic (FRP) Bars," Dissertation, West Virginia University, Morgantown, WV 26506, USA.

Vedam, V.R. (1997), "Characterization of Composite Material Bridge," M.S. Thesis, Department of Civil and Environmental Engineering, West Virginia University, Morgantown, WV 26506, USA. 


\section{APPENDIX A \\ COMPUTATION OF LAMINA PROPERTIES}

\section{A.1 Introduction}

The computation of lamina properties is an essential first step in the determination of the behavior of the component as a whole. These properties define the interaction between the fibers and resin matrix of the composite. Theory used to accomplish this task is a combination of the rule of mixtures and micro mechanics. The equations necessary in order to use these methods are shown in this appendix, along with the product specifications of the lamina making up the FRP bridge deck components being researched. Also, the component cross-sections and fiber architectures studied can be seen in Figures B2 through B5 of Appendix B.

\section{A.2 Material Properties}

Certain properties of the constituent materials (fibers and matrix) are needed in order to compute the lamina properties. Most of these properties are generally obtained from the manufacturer, while the remaining terms necessary can be computed based on the given information. The properties needed from the manufacturer or some other source are:

1) Modulus of elasticity of fiber (psi) $=\mathrm{E}_{\mathrm{f}}\left(10.5^{*} 10^{6} \mathrm{psi}\right)$

2) Modulus of elasticity of matrix (psi) $=\mathrm{E}_{\mathrm{m}}\left(4.9 * 10^{5} \mathrm{psi}\right)$

3) Shear modulus of fiber $(\mathrm{psi})=\mathrm{G}_{\mathrm{f}}\left(4 * 10^{6} \mathrm{psi}\right)$

4) Shear modulus of matrix ( $\mathrm{psi})=\mathrm{G}_{\mathrm{m}}\left(2 * 10^{5} \mathrm{psi}\right)$

From the above properties, Poisson's ratio for both the fibers and matrix can be obtained as (Jones 1975).

$\begin{array}{ll}\text { Poisson' s ratio of matrix : } & v_{\mathrm{m}}=\frac{E_{m}}{2 G_{m}}-1 \\ \text { Poisson' s ratio of fiber : } & ?_{f}=\frac{E_{f}}{2 G_{f}}-1\end{array}$ 


\section{A.3 Fiber Volume Fraction}

The calculation of the fiber volume fraction depends on whether the fiber reinforcement is in the form of rovings, mats, and/or fabrics. The terms $n, \rho_{\mathrm{f}}$, and $\mathrm{Y}$ are typically obtained from the manufacturer.

\section{For Rovings}

$$
V_{f}=\frac{n \pi D^{2}}{4 b t}
$$

Where,

$n=$ number of bundles

$b=$ width of laminate (in)

$t=$ thickness of composite layer (in)

$D=$ diameter of fiber $=\sqrt{\frac{1}{\rho_{f} Y 9 \pi}}$

$\rho_{f}=$ density of fiber $\left(0.094 \mathrm{lb} / \mathrm{in}^{3}\right)$

$\mathrm{Y}=$ yield (a number in yards which weighs $1 \mathrm{lb}$ )

\section{For CSM (Continuous Strand Mat) and Fabric}

$$
V_{f}=\frac{W_{f}}{\rho_{f} L_{v}}
$$

Where,

$W_{f}=$ weight of CSM/fabric per square foot (lb)

$L_{v}=$ volume of $1^{\prime} \mathrm{x} 1^{\prime}$ composite laminate $\left(\mathrm{in}^{3}\right)$

$\rho_{f}=$ density of CSM or fabric $\left(0.094 \mathrm{lb} / \mathrm{in}^{3}\right)$ 


\section{A.4 Lamina Properties}

\section{Properties for Fabric and Rovings}

Longitudinal Modulus (psi)

$$
E_{11}=E_{f} V_{f}+E_{m}\left(1-V_{f}\right)
$$

Transverse Modulus (psi)

$$
E_{22}=\frac{E_{f} E_{m}}{E_{f}\left(1-V_{f}\right)+E_{m} V_{f}}
$$

In-plane Shear Modulus (psi)

$$
G_{12}=\frac{G_{f} G_{m}}{G_{f}\left(1-V_{f}\right)+G_{m} V_{f}}
$$

In-plane Poisson's Ratio's

$$
\begin{aligned}
& v_{12}=v_{f} V_{f}+v_{m}\left(1-V_{f}\right) \\
& v_{21}=\frac{v_{12} E_{22}}{E_{11}}
\end{aligned}
$$

\section{For Continuous Strand Mat}

Elastic Modulus (psi)

$$
E_{\text {ran }}=\frac{3}{8} E_{11}+\frac{5}{8} E_{22}
$$

Shear Modulus (psi)

$$
G_{\text {ran }}=\frac{1}{8} E_{11}+\frac{1}{4} E_{22}
$$

Poisson's Ratio (psi)

$$
\mathrm{v}_{\text {ran }}=\left(\frac{E_{\text {ran }}}{2 G_{\text {ran }}}\right)-1
$$

Note: Continuous Strand Mats are assumed to behave in an isotropic manner, so only one set on modulus values is needed. 


\section{A.5 Lamina Product Specifications}

The two bridge decks being studied contained five different types of lamina as seen below.

1) 56-Yield Rovings (3 per inch)

2) TVM-3408/Version 1001

3) NEMP 120/2001

4) $\mathrm{CDBM} 3415$

5) CDB400

It is of interest to note that with the exception of the rovings, all other lamina had more than one type of fiber configuration. For example, TVM-3408/Version 1001 contains both fabrics and a mat. Employing the superposition principle, each different component will be computed separately using the equations that have been previously given. They will then be treated as separate lamina all having the same centroidal axis as that of the true lamina. While an approximation, separating the true lamina into the sum of its individual components is justified since the thickness of the lamina are small. The needfulness of the previous superposition statements becomes apparent in Appendix B.

Tables A1 through A4 summarize the product specifications of the polyester and vinyl ester deck lamina. It should be noted that a very small percentage of stitched yarn is also included in each, but its structural properties are negligible.

\begin{tabular}{|c|c|c|c|c|}
\hline Fiber Type & $\begin{array}{c}\text { Nominal Wt. } \\
\left(\mathrm{oz} \mathrm{yd}^{2}\right)\end{array}$ & $\begin{array}{c}\text { Thickness } \\
(\mathrm{in})\end{array}$ & $\begin{array}{c}\mathrm{w}_{\mathrm{f}} \\
(\mathrm{lb})\end{array}$ & $\begin{array}{c}\mathrm{L}_{\mathrm{v}} \\
\left(\mathrm{in}^{3}\right)\end{array}$ \\
\hline $0^{0}$ Fabrics & 16.90 & 0.0135 & 0.1174 & 1.94 \\
\hline${ }^{+} 45^{0}$ Fabrics & 9.05 & 0.0073 & 0.0629 & 1.05 \\
\hline${ }^{4} 45^{0}$ Fabrics & 9.19 & 0.0074 & 0.0638 & 1.06 \\
\hline Mat $($ CSM $)$ & 6.75 & 0.0054 & 0.0469 & 0.778 \\
\hline Totals & $\mathbf{4 1 . 8 9}$ & $\mathbf{0 . 0 3 3 6}$ & $\mathbf{0 . 2 9 1 0}$ & $\mathbf{4 . 8 3}$ \\
\hline
\end{tabular}

Table A1-TVM-3408/Version 1001 Product Specifications 


\begin{tabular}{|c|c|c|c|c|}
\hline Fiber Type & $\begin{array}{c}\text { Nominal Wt. } \\
\left(\mathrm{oz} / \mathrm{yd}^{2}\right)\end{array}$ & $\begin{array}{c}\text { Thickness } \\
(\mathrm{in})\end{array}$ & $\begin{array}{c}\mathrm{w}_{\mathrm{f}} \\
(\mathrm{lb})\end{array}$ & $\begin{array}{c}\mathrm{L}_{\mathrm{v}} \\
\left(\mathrm{in}^{3}\right)\end{array}$ \\
\hline${ }^{+} 45^{0}$ Fabrics & 6.11 & 0.005 & 0.0423 & 0.72 \\
\hline${ }^{-} 45^{0}$ Fabrics & 6.11 & 0.005 & 0.0423 & 0.72 \\
\hline Totals & $\mathbf{1 2 . 2 2}$ & $\mathbf{0 . 0 1}$ & $\mathbf{0 . 0 8 4 6}$ & $\mathbf{1 . 4 4}$ \\
\hline
\end{tabular}

Table A2-NEMP 120/2001 Product Specifications

\begin{tabular}{|c|c|c|c|c|}
\hline Fiber Type & $\begin{array}{c}\text { Nominal Wt. } \\
\left(\mathrm{oz}^{\mathrm{yd}}{ }^{2}\right)\end{array}$ & $\begin{array}{c}\text { Thickness } \\
(\mathrm{in})\end{array}$ & $\begin{array}{c}\mathrm{w}_{\mathrm{f}} \\
(\mathrm{lb})\end{array}$ & $\begin{array}{c}\mathrm{L}_{\mathrm{v}} \\
\left(\mathrm{in}^{3}\right)\end{array}$ \\
\hline $0^{0}$ Fabrics & 15.71 & 0.0184 & 0.109 & 2.65 \\
\hline${ }^{+} 45^{0}$ Fabrics & 9.04 & 0.0106 & 0.063 & 1.53 \\
\hline$-45^{0}$ Fabrics & 9.04 & 0.0106 & 0.063 & 1.53 \\
\hline Mat $($ CFM) & 13.5 & 0.0159 & 0.094 & 2.29 \\
\hline Totals & $\mathbf{4 7 . 3}$ & $\mathbf{0 . 0 5 5 5}$ & $\mathbf{0 . 3 2 9}$ & $\mathbf{7 . 9 9}$ \\
\hline
\end{tabular}

Table A3-CDBM3415 Product Specifications

\begin{tabular}{|c|c|c|c|c|}
\hline Fiber Type & $\begin{array}{c}\text { Nominal Wt. } \\
\left(\text { oz } / \mathrm{yd}^{2}\right)\end{array}$ & $\begin{array}{c}\text { Thickness } \\
\text { (in) }\end{array}$ & $\begin{array}{c}\mathrm{w}_{\mathrm{f}} \\
(\mathrm{lb})\end{array}$ & $\begin{array}{c}\mathrm{L}_{\mathrm{v}} \\
\left(\mathrm{in}^{3}\right)\end{array}$ \\
\hline $0^{0}$ Fabrics & 16.58 & 0.0195 & 0.115 & 2.81 \\
\hline${ }^{+} 45^{0}$ Fabrics & 12.19 & 0.0144 & 0.085 & 2.07 \\
\hline$-45^{0}$ Fabrics & 12.19 & 0.0144 & 0.085 & 2.07 \\
\hline Totals & $\mathbf{4 0 . 9 6}$ & $\mathbf{0 . 0 4 8 3}$ & $\mathbf{0 . 2 8 5}$ & $\mathbf{6 . 9 5}$ \\
\hline
\end{tabular}

Table A4-CDB400 Product Specifications 


\section{APPENDIX B \\ COMPUTATION OF BENDING AND SHEAR STIFFNESS}

\section{B.1 Introduction}

The classical lamination theory (CLT) approach is one way to arrive at the global bending stiffness of a composite. However, this method is fairly involved and requires many computations. A simplified approach known as the approximate classical lamination theory (ACLT) (Nagaraj 1994) was developed and is used for the computations of this project. The differences in results are relatively small, and the approximate method provides adequate accuracy when estimating the bending and shear stiffness of an FRP composite. The procedure involves a series of steps that lead to the stiffness of the component. These steps are outlined in this appendix, along with the results of the computations that were performed on the FRP components being investigated.

\section{B.2 Elastic Modulus}

The elastic modulus of a lamina in a given direction is determined in an approximate manner (Nagaraj 1994) as follows:

$$
\begin{aligned}
& E_{x} \approx E_{11} \cos ^{4}(\theta) \\
& E_{y} \approx E_{11} \cos ^{4}(90-\theta)
\end{aligned}
$$

Where ' $\theta$ ' is the angle of fiber orientation with respect to the $\mathrm{X}$-axis. The global and material coordinate systems are represented in Figure B1.

\section{B.3 In-Plane and Extensional-Bending Coupling Stiffness ([A] and [B])}

$$
A_{f}=A_{w}=b \sum_{k=1}^{N}\left(E_{i}\right)_{k} t_{k}
$$




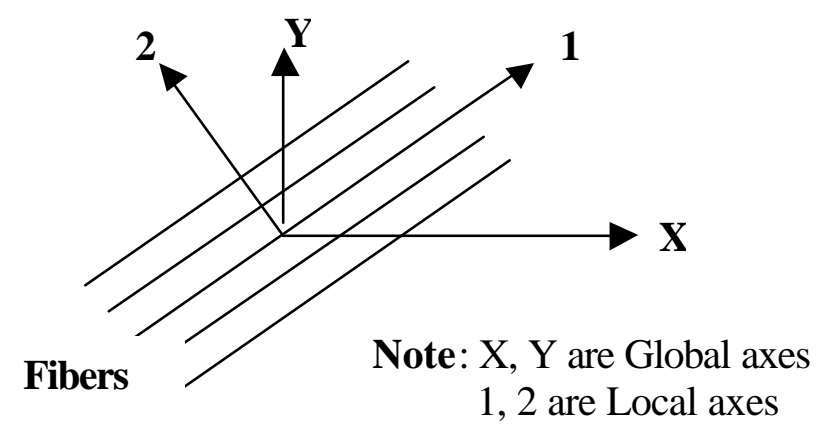

Figure B1-Local and Global Coordinate Systems

$$
B_{f}=B_{w} \approx b \sum_{k=1}^{N}\left(E_{i}\right)_{k} t_{k} Z_{k}
$$

Where,

$A_{f}=A_{w}=$ in-plane stiffness

$B_{f}=B_{w} \approx$ extensional-bending coupling stiffness

$\left(E_{i}\right)_{k}=E_{i}$ in $\mathrm{k}^{\text {th }}$ layer, where 'i' corresponds to global axis

$\mathrm{t}_{\mathrm{k}}=$ thickness of the $\mathrm{k}^{\mathrm{th}}$ layer (in)

$\mathrm{b}=$ width of laminate (in)

$\mathrm{Z}_{\mathrm{k}}=$ distance of mid-surface of $\mathrm{k}^{\text {th }}$ lamina from the centroid of the section

Notes: The subscript ' $f$ ' corresponds to flange, while ' $w$ ' refers to web. $b$ is in the vertical direction for web computations, and in the horizontal direction for the flange computations.

\section{B.4 Flange and Web Bending Stiffness}

For flange (Nagaraj 1994):

$$
D_{f} \approx b \sum_{k=1}^{N}\left(E_{i}\right){ }_{k}\left[t_{k} Z_{k}^{2}+\frac{t_{k}^{3}}{12}\right]
$$


For web (Lopez 1995):

$$
D_{w} \approx b \sum_{k=1}^{N}\left(E_{i}\right)_{k}\left[\left(\frac{t_{k}^{3}}{12}+t_{k} Z_{k}^{2}\right) \cos ^{2}(\phi)+\left(\frac{b^{2} t_{k}}{12}\right) \sin ^{2}(\phi)\right]
$$

Where, ' $\phi$ ' is the angle of the component with respect to the horizontal; ' $\mathrm{f}$ ' refers to flange and 'w' refers to web.

\section{B.5 Global Bending Stiffness}

$$
E I \approx \sum_{f=1}^{n}\left[D_{f}+A_{f} e_{f}^{2}\right]+\sum_{w=1}^{m}\left[D_{w}+A_{w} e_{w}^{2}\right]
$$

Where,

$\mathrm{n}=$ number of flanges

$\mathrm{m}=$ number of webs

$e_{\mathrm{f}}=$ eccentricity of a flange from the mid-surface of component

$e_{w}=$ eccentricity of a web from the mid-surface of component

\section{B.6 Global Shear Stiffness in YZ Plane}

$$
G_{\mathrm{yz}} A=d \sum_{k=1}^{N}\left(G_{\mathrm{y}}\right)_{k} t_{k}
$$

Where,

$\left(G_{\mathrm{y}}\right) \approx E_{11} \sin ^{2} \theta \cos ^{2} \theta+G_{12}\left(\sin ^{2} \theta-\cos ^{2} \theta\right)^{2}$ valid only for $\theta= \pm 45^{0}$

$\left(G_{\mathrm{y}}\right)=\mathrm{G}_{12}$ for $\theta=0^{0}$

$\left(G_{\mathrm{y}}\right)=\mathrm{G}_{\mathrm{ran}}$ for mats

$\left(G_{\mathrm{y}}\right)_{k}=$ shear in $\mathrm{k}^{\text {th }}$ layer $(\mathrm{psi})$

$\mathrm{t}_{\mathrm{k}}=$ thickness of $\mathrm{k}^{\mathrm{th}}$ layer (in)

$\mathrm{d}=$ depth of the laminate (in)

$A=d \sum t_{k}$ 
See Figures 3.4 and 6.8 for definition of the global YZ plane, while the local axes 1 and 2 can be seen in Figure B1.

\section{B.7 Theoretical Bending and Shear Stiffness Results}

Utilizing the information in Appendix A regarding lamina properties and product specifications along with the method proposed in this appendix, the theoretical bending stiffness was calculated in both the $\mathrm{X}$ and $\mathrm{Y}$ directions. See Figure 6.8 for definition of $\mathrm{X}$ and $\mathrm{Y}$ directions. Similarly, the shear stiffness $\left(\mathrm{G}_{\mathrm{yz}}\right)$ was calculated based on the same information. Table B1 shows the results of the bending stiffness calculations, while Table B2 shows the results of the shear stiffness calculations.

\begin{tabular}{|c|c|c|c|c|}
\hline Component & $\mathrm{E}_{\mathrm{x}} \mathrm{I}_{\mathrm{x}}\left(\mathrm{lb}^{*}{ }^{2}{ }^{2}\right)$ & $\mathrm{E}_{\mathrm{x}}(\mathrm{psi})$ & $\mathrm{E}_{\mathrm{y}} \mathrm{I}_{\mathrm{y}}\left(\mathrm{lb}\right.$ *in $\left.^{2}\right)$ & $\mathrm{E}_{\mathrm{y}}(\mathrm{psi})$ \\
\hline Polyester & $1.36\left(10^{9}\right)$ & $4.49\left(10^{6}\right)$ & $1.91\left(10^{8}\right)$ & $1.13\left(10^{6}\right)$ \\
\hline Vinyl Ester & $1.05\left(10^{9}\right)$ & $3.50\left(10^{6}\right)$ & $1.60\left(10^{8}\right)$ & $0.95\left(10^{6}\right)$ \\
\hline
\end{tabular}

Table B1-Theoretical Bending Stiffness Values

\begin{tabular}{|c|c|c|}
\hline Component & $\mathrm{G}_{\mathrm{yz}} \mathrm{A}(\mathrm{lb})$ & $\mathrm{G}_{\mathrm{yz}}(\mathrm{psi})$ \\
\hline Polyester & $44.1\left(10^{5}\right)$ & $0.90\left(10^{6}\right)$ \\
\hline Vinyl Ester & $47.8\left(10^{5}\right)$ & $0.86\left(10^{6}\right)$ \\
\hline
\end{tabular}

Table B2-Theoretical Shear Stiffness Values 


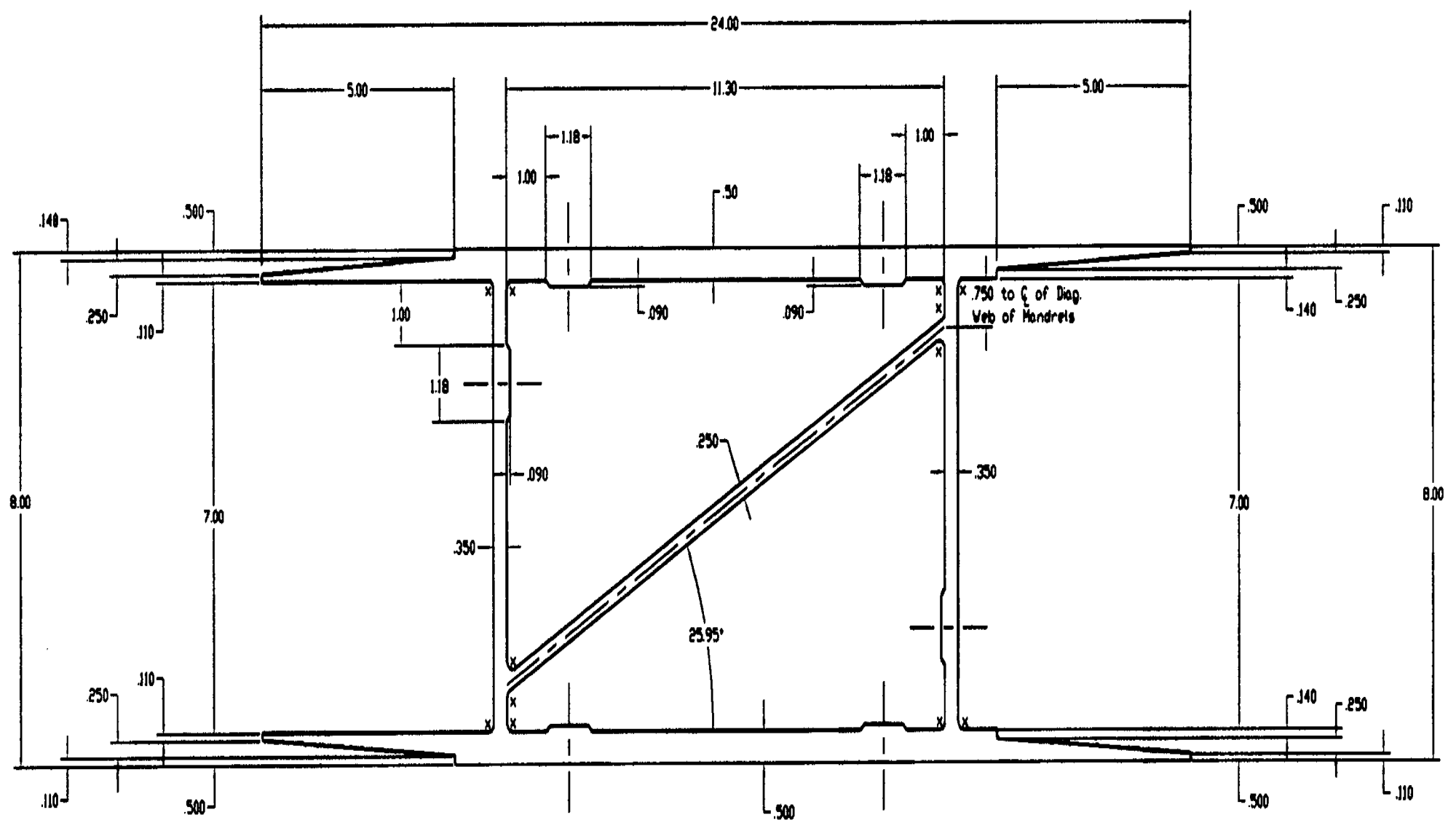

Figure B2-Cross-Section of Polyester Component 


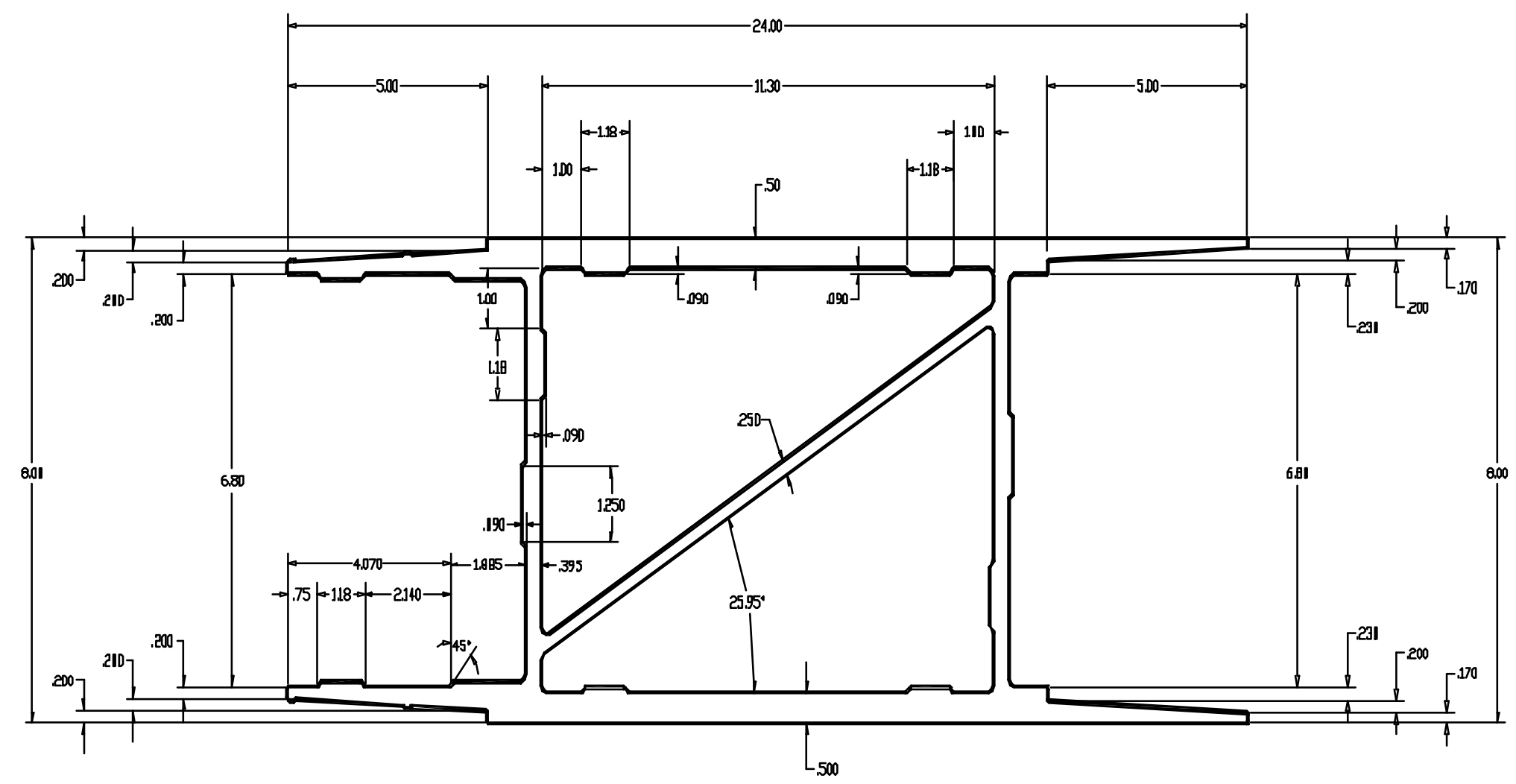

Figure B3-Cross-Section of Vinyl Ester Component 


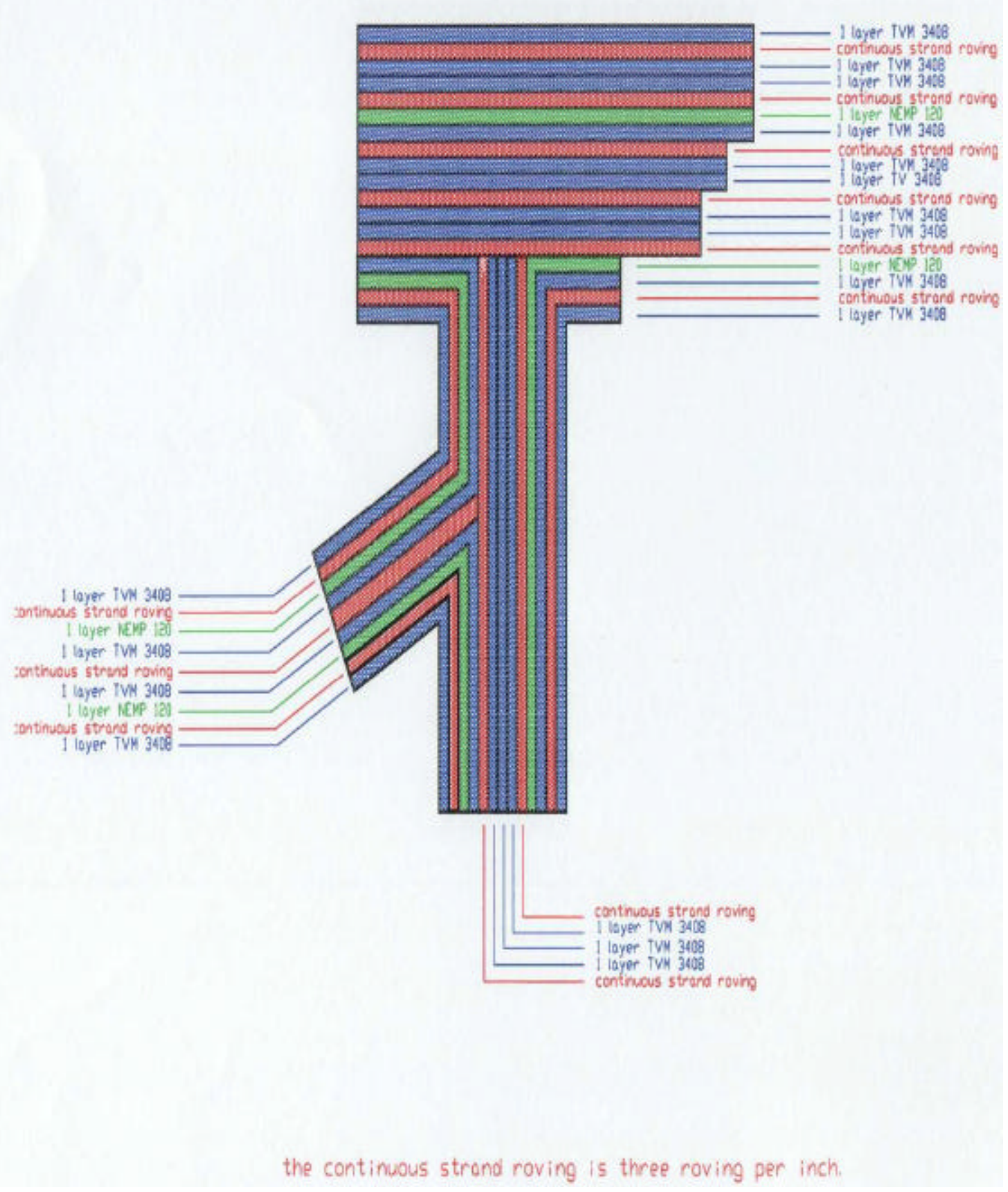

Figure B4-Fiber Architecture of Polyester Component

Note: It is believed this drawing contains approximately four too many lamina, but the suspicion could not be verified. As a result, the drawing was used as shown above. 
This Page Was Intentionally Left Blank at the Request of the Manufacturer

Figure B5-Fiber Architecture of Vinyl Ester Component 


\section{APPENDIX C}

\section{RAW TEST DATA}

\begin{tabular}{|c|c|c|c|c|c|c|c|c|c|}
\hline \multirow{2}{*}{\begin{tabular}{|c|}
$\begin{array}{c}\text { Torsion Test } \\
\# 1\end{array}$ \\
Load (lb)
\end{tabular}} & \multicolumn{2}{|c|}{ Values in milli-inches } & \multicolumn{2}{|c|}{$\begin{array}{c}\text { Torsion Test } \\
\text { \#2 }\end{array}$} & \multicolumn{2}{|c|}{ Values in milli-inches } & \multicolumn{3}{|c|}{ Strain values in micro-strains } \\
\hline & DEF-1 & DEF-2 & \multicolumn{2}{|c|}{ Load (Ib) } & DEF-1 & DEF-2 & $\# 7$ & $\# 11$ & $\# 12$ \\
\hline 0 & 0 & 0 & \multicolumn{2}{|c|}{0} & 0 & 0 & 0 & 0 & 0 \\
\hline 540 & 4 & 14 & \multicolumn{2}{|c|}{500} & 8 & 0 & 7 & 2 & 4 \\
\hline 1000 & 53 & 32 & \multicolumn{2}{|c|}{1000} & 41 & 21 & 10 & 14 & 8 \\
\hline 1340 & 75 & 42 & \multicolumn{2}{|c|}{1500} & 68 & 34 & 11 & 34 & 54 \\
\hline 1800 & 94 & 45 & \multicolumn{2}{|c|}{1700} & 74 & 36 & 11 & 44 & 67 \\
\hline 2000 & 99 & 44 & \multicolumn{2}{|c|}{1800} & 81 & 36 & 11 & 49 & 72 \\
\hline 2200 & 105 & $\overline{41}$ & 19 & 00 & 88 & 35 & 13 & 55 & 78 \\
\hline 2400 & 112 & 38 & 20 & 00 & 90 & 34 & 13 & 60 & 81 \\
\hline 2600 & 117 & 34 & 21 & 00 & 93 & 33 & 14 & 65 & 85 \\
\hline 2700 & 121 & 32 & 22 & 00 & 97 & 32 & 15 & 71 & 90 \\
\hline 2800 & 122 & 29 & 23 & 00 & 99 & 31 & 15 & 76 & 96 \\
\hline 2900 & 124 & 26 & 24 & 00 & 101 & 30 & 15 & 79 & 99 \\
\hline 3000 & 128 & 23 & 25 & 00 & 106 & 29 & 16 & 85 & 105 \\
\hline 3100 & 131 & 18 & 26 & 00 & 108 & 29 & 17 & 90 & 110 \\
\hline 3200 & 129 & 16 & 27 & 00 & 113 & 27 & 19 & 98 & 118 \\
\hline & & & 28 & 00 & 114 & 26 & 18 & 100 & 11 \\
\hline & & & 29 & 00 & 116 & 24 & 19 & 105 & 126 \\
\hline & & & 30 & 00 & 118 & 22 & 19 & 111 & 132 \\
\hline $\begin{array}{r}\text { Torsion T } \\
\text { becom }\end{array}$ & $\begin{array}{l}\text { t \#1: Value } \\
\text { zero value }\end{array}$ & $\begin{array}{l}\text { djusted } \\
\text { ue to the }\end{array}$ & $\begin{array}{l}\text { ch that } 18 \\
\text { itial end } \mathrm{s}\end{array}$ & $\begin{array}{l}00 \mathrm{lb} \text { loa } \\
\text { ippage }\end{array}$ & $\begin{array}{r}\text { Torsion } \\
\text { becc }\end{array}$ & $\begin{array}{l}\text { est \#2: Vc } \\
\text { es zero v }\end{array}$ & $\begin{array}{l}\text { s adjuste } \\
\text { due to } t\end{array}$ & $\begin{array}{l}\text { such that } 1 \\
\text { initial end }\end{array}$ & $\begin{array}{l}800 \mathrm{lb} \text { load } \\
\text { slippage }\end{array}$ \\
\hline Torque & Value & $n$ milli-inc & & $\begin{array}{c}\text { Avg } \\
\text { Angle }\end{array}$ & Torque & Valı & in milli-in & & Avg Angle \\
\hline$\left(\mathrm{in}^{*} \mid \mathrm{b}\right)$ & DEF-1 & DEF-2 & Average & of Twis & $\mathrm{t} \quad\left(\mathrm{in}{ }^{\star} \mathrm{lb}\right)$ & DEF-1 & DEF-2 & Average & of Twist \\
\hline 0 & 0 & 0 & 0 & 0.00000 & 0 & 0 & 0 & 0 & 0.00000 \\
\hline 3600 & 5 & 1 & 3 & 0.00026 & 1800 & 7 & 1 & 4 & 0.00035 \\
\hline 7200 & 11 & 4 & 7.5 & 0.00065 & 3600 & 9 & 2 & 5.5 & 0.00048 \\
\hline 10800 & 18 & 7 & 12.5 & 0.00109 & 5400 & 12 & 3 & 7.5 & 0.00065 \\
\hline 14400 & 23 & 11 & 17 & 0.00148 & 7200 & 16 & 4 & 10 & 0.00087 \\
\hline 16200 & 27 & 13 & 20 & 0.00174 & 9000 & 18 & 5 & 11.5 & 0.00100 \\
\hline 18000 & 28 & 16 & 22 & 0.00191 & \begin{tabular}{l|l|}
1 & 10800
\end{tabular} & 20 & 6 & 13 & 0.00113 \\
\hline 19800 & 30 & 19 & 24.5 & 0.00213 & \begin{tabular}{|l|l|}
3 & 12600 \\
\end{tabular} & 25 & 7 & 16 & 0.00139 \\
\hline 21600 & 34 & 22 & 28 & 0.00243 & 14400 & 27 & 7 & 17 & 0.00148 \\
\hline 23400 & 37 & 27 & 32 & 0.00278 & 16200 & 32 & 9 & 20.5 & 0.00178 \\
\hline 25200 & 35 & 29 & 32 & 0.00278 & 18000 & 33 & 10 & 21.5 & 0.00187 \\
\hline & & & & & 19800 & 35 & 12 & 23.5 & 0.00204 \\
\hline & & & & & 21600 & 37 & 14 & 25.5 & 0.00222 \\
\hline
\end{tabular}

Table C1-Torsion 


\begin{tabular}{|c|c|c|c|c|c|}
\hline \multicolumn{6}{|c|}{ Torsion and Bending-12"x 12" steel plate used } \\
\hline \multicolumn{6}{|c|}{$2000 \mathrm{lb}$ load for torque of $36000 \mathrm{in}^{*} \mathrm{lb}$} \\
\hline Bending & \multicolumn{5}{|c|}{ Strain values in micro-strains } \\
\hline Load (lb) & $\# 1$ & $\# 7$ & $\# 8$ & $\# 11$ & $\# 12$ \\
\hline 0 & 0 & 0 & 0 & 0 & 0 \\
\hline 500 & 44 & 54 & 597 & 7 & 5 \\
\hline 1000 & 73 & 81 & 802 & 10 & 4 \\
\hline 1500 & 110 & 120 & 1026 & 16 & 8 \\
\hline 2000 & 154 & 166 & 1218 & 20 & 8 \\
\hline 2500 & 195 & 237 & 1395 & 25 & 13 \\
\hline 3000 & 242 & 263 & 1546 & 30 & 12 \\
\hline 3500 & 282 & 311 & 1663 & 34 & 18 \\
\hline 4000 & 326 & 353 & 1766 & 39 & 17 \\
\hline 4500 & 374 & 405 & 1880 & 45 & 22 \\
\hline 5000 & 409 & 440 & 1952 & 50 & 21 \\
\hline 5500 & 452 & 485 & 2043 & 55 & 25 \\
\hline 6000 & 497 & 532 & 2135 & 61 & 20 \\
\hline 6500 & 532 & 576 & 2228 & 68 & 20 \\
\hline 7000 & 580 & 621 & 2312 & 74 & 14 \\
\hline 7500 & 613 & 661 & 2398 & 80 & 12 \\
\hline 8000 & 670 & 722 & 2504 & 85 & 8 \\
\hline 8500 & 711 & 764 & 2587 & 89 & 5 \\
\hline 9000 & 747 & 804 & 2669 & 92 & 6 \\
\hline 9500 & 790 & 851 & 2756 & 100 & 3 \\
\hline 10000 & 839 & 904 & 2847 & 102 & 2 \\
\hline \multicolumn{6}{|c|}{$2600 \mathrm{lb}$ load for torque of $46800 \mathrm{in}{ }^{\star} \mathrm{lb}$} \\
\hline Bending & \multicolumn{5}{|c|}{ Strain values in micro-strains } \\
\hline Load (lb) & $\# 1$ & \#7 & $\# 8$ & $\# 11$ & $\# 12$ \\
\hline 0 & 0 & 0 & 0 & 0 & 0 \\
\hline 500 & 40 & 43 & 598 & 8 & 6 \\
\hline 1000 & 80 & 80 & 857 & 11 & 7 \\
\hline 1500 & 127 & 145 & 1118 & 16 & 12 \\
\hline 2000 & 164 & 165 & 1261 & 20 & 13 \\
\hline 2500 & 201 & 224 & 1441 & 23 & 17 \\
\hline 3000 & 247 & 270 & 1594 & 28 & 19 \\
\hline 3500 & 292 & 320 & 1720 & 44 & 12 \\
\hline 4000 & 328 & 358 & 1817 & 49 & 12 \\
\hline 4500 & 371 & 405 & 1920 & 54 & 16 \\
\hline 5000 & 417 & 441 & 2014 & 62 & 13 \\
\hline 5500 & 452 & 498 & 2101 & 65 & 18 \\
\hline 6000 & 498 & 539 & 2202 & 68 & 20 \\
\hline 6500 & 539 & 574 & 2288 & 70 & 24 \\
\hline 7000 & 585 & 629 & 2373 & 73 & 27 \\
\hline 7500 & 622 & 666 & 2467 & 78 & 31 \\
\hline 8000 & 670 & 724 & 2562 & 83 & 34 \\
\hline 8500 & 708 & 752 & 2642 & 87 & 34 \\
\hline 9000 & 758 & 804 & 2731 & 91 & 29 \\
\hline 9500 & 792 & 861 & 2809 & 96 & 27 \\
\hline 10000 & 847 & 904 & 2904 & 102 & 35 \\
\hline
\end{tabular}




\begin{tabular}{|c|c|c|c|c|c|}
\hline \multicolumn{6}{|c|}{$1500 \mathrm{lb}$ load for torque of $27000 \mathrm{in} * \mathrm{lb}$} \\
\hline \multirow{2}{*}{$\begin{array}{l}\text { Bending } \\
\text { Load (lb) }\end{array}$} & \multicolumn{5}{|c|}{ Strain values in micro-strains } \\
\hline & $\# 1$ & $\# 7$ & \#8 & $\# 11$ & $\# 12$ \\
\hline 0 & 0 & 0 & 0 & 0 & 0 \\
\hline 500 & 37 & 40 & 565 & 7 & 2 \\
\hline 1000 & 85 & 86 & 852 & 11 & 2 \\
\hline 1500 & 119 & 120 & 1029 & 16 & 7 \\
\hline 2000 & 157 & 162 & 1206 & 19 & 10 \\
\hline 2500 & 203 & 213 & 1382 & 24 & 10 \\
\hline 3000 & 252 & 267 & 1558 & 30 & 8 \\
\hline 3500 & 278 & 303 & 1658 & 34 & 4 \\
\hline 4000 & 328 & 353 & 1769 & 41 & 3 \\
\hline 4500 & 367 & 393 & 1861 & 47 & 1 \\
\hline 5000 & 409 & 438 & 1956 & 54 & -2 \\
\hline 5500 & 452 & 483 & 2050 & 59 & -5 \\
\hline 6000 & 495 & 528 & 2139 & 67 & -6 \\
\hline 6500 & 537 & 575 & 2231 & 73 & -8 \\
\hline 7000 & 580 & 619 & 2321 & 79 & -10 \\
\hline 7500 & 623 & 665 & 2417 & 86 & -11 \\
\hline 8000 & 660 & 705 & 2496 & 92 & -12 \\
\hline 8500 & 705 & 752 & 2590 & 99 & -12 \\
\hline 9000 & 744 & 794 & 2672 & 105 & -9 \\
\hline 9500 & 792 & 848 & 2773 & 111 & -7 \\
\hline 10000 & 837 & 893 & 2863 & 116 & -3 \\
\hline \multicolumn{6}{|c|}{$1750 \mathrm{lb}$ load for torque of $31500 \mathrm{in}{ }^{*} \mathrm{lb}$} \\
\hline Bending & \multicolumn{5}{|c|}{ Strain values in micro-strains } \\
\hline Load (lb) & $\# 1$ & $\# 7$ & $\# 8$ & $\# 11$ & $\# 12$ \\
\hline 0 & 0 & 0 & 0 & 0 & 0 \\
\hline 500 & 39 & 51 & 586 & 8 & 6 \\
\hline 1000 & 83 & 95 & 871 & 12 & 6 \\
\hline 1500 & 120 & 132 & 1069 & 15 & 12 \\
\hline 2000 & 163 & 178 & 1255 & 20 & 14 \\
\hline 2500 & 201 & 223 & 1421 & 24 & 18 \\
\hline 3000 & 249 & 272 & 1566 & 29 & 12 \\
\hline 3500 & 287 & 315 & 1673 & 35 & 13 \\
\hline 4000 & 328 & 359 & 1769 & 41 & 8 \\
\hline 4500 & 369 & 404 & 1868 & 48 & 6 \\
\hline 5000 & 410 & 447 & 1961 & 54 & 2 \\
\hline 5500 & 451 & 492 & 2055 & 62 & 0 \\
\hline 6000 & 494 & 538 & 2144 & 67 & 5 \\
\hline 6500 & 528 & 583 & 2237 & 73 & 6 \\
\hline 7000 & 581 & 628 & 2322 & 82 & 10 \\
\hline 7500 & 620 & 669 & 2404 & 87 & 11 \\
\hline 8000 & 669 & 721 & 2499 & 95 & 13 \\
\hline 8500 & 705 & 761 & 2580 & 101 & 13 \\
\hline 9000 & 753 & 811 & 2671 & 107 & 17 \\
\hline 9500 & 789 & 856 & 2755 & 113 & 16 \\
\hline 10000 & 840 & 911 & 2852 & 119 & 15 \\
\hline
\end{tabular}

Table C2-Torsion and Bending 


\begin{tabular}{|c|c|c|c|c|c|c|c|c|c|}
\hline \multicolumn{10}{|c|}{ Web Load Distribution } \\
$\begin{array}{c}\text { Orientation } \\
\# 1\end{array}$ & $\begin{array}{c}\text { Strain values in } \\
\text { micro-strains }\end{array}$ & (milli-inches) & $\begin{array}{c}\text { Orientation } \\
\# 2\end{array}$ & \multicolumn{2}{|c|}{$\begin{array}{c}\text { Strain values in } \\
\text { micro-strains }\end{array}$} & (milli-inches) \\
\hline Load (lb) & $\# 1$ & $\# 2$ & $\# 3$ & DEF-1 & Load (lb) & $\# 1$ & $\# 2$ & $\# 3$ & DEF-1 \\
\hline 0 & 0 & 0 & 0 & 0 & 0 & 0 & 0 & 0 & 0 \\
\hline 500 & 85 & 126 & 113 & 48 & 500 & 130 & 34 & 141 & 52 \\
\hline 1000 & 166 & 262 & 221 & 86 & 1000 & 317 & 391 & 256 & 93 \\
\hline 1500 & 246 & 422 & 346 & 120 & 1500 & 457 & 527 & 377 & 128 \\
\hline 2000 & 313 & 585 & 472 & 155 & 2000 & 587 & 764 & 506 & 163 \\
\hline 2500 & 383 & 782 & 623 & 188 & 2500 & 709 & 1216 & 658 & 214 \\
\hline 3000 & 432 & 1221 & 933 & 230 & 3000 & 800 & 1885 & 779 & 300 \\
\hline
\end{tabular}

Table C3-Web Load Distribution

\begin{tabular}{|c|c|c|c|c|c|c|c|c|c|c|c|c|c|c|}
\hline \multicolumn{10}{|c|}{ Polyester Component \#1: Test Date 12-20-01: 10"x 20" patch load: 10' span } \\
\hline \multicolumn{10}{|c|}{ Punching shear failure at 36 kips } \\
\hline $\begin{array}{c}\text { Load } \\
\text { (lb) }\end{array}$ & $\begin{array}{c}\text { DEF } \\
(1)\end{array}$ & $\# 1$ & $\# 2$ & $\# 3$ & $\# 4$ & $\# 5$ & $\# 6$ & $\# 7$ & $\# 8$ & $\# 9$ & $\# 10$ & $\# 11$ & $\# 12$ & $\# 13$ \\
\hline 0 & 0 & 0 & 0 & 0 & 0 & 0 & 0 & 0 & 0 & 0 & 0 & 0 & 0 & 0 \\
\hline 2000 & 72 & 126 & 42 & 30 & 201 & 57 & 138 & 127 & 9 & 8 & 361 & 20 & 122 & 15 \\
\hline 4000 & 136 & 252 & 91 & 72 & 406 & 111 & 274 & 255 & 24 & 17 & 387 & 35 & 242 & 35 \\
\hline 6000 & 212 & 384 & 140 & 118 & 628 & 173 & 421 & 389 & 49 & 34 & 425 & 61 & 367 & 72 \\
\hline 8000 & 295 & 513 & 186 & 167 & 845 & 237 & 567 & 521 & 78 & 45 & 490 & 92 & 485 & 118 \\
\hline 10000 & 357 & 642 & 231 & 227 & 1059 & 300 & 720 & 650 & 110 & 46 & 579 & 126 & 606 & 157 \\
\hline 12000 & 421 & 763 & 279 & 290 & 1261 & 361 & 848 & 769 & 144 & 35 & 674 & 154 & 713 & 190 \\
\hline 14000 & 497 & 893 & 329 & 366 & 1482 & 432 & 990 & 898 & 193 & 18 & 769 & 194 & 829 & 220 \\
\hline 16000 & 563 & 1017 & 379 & 449 & 1688 & 496 & 1126 & 1021 & 245 & 16 & 858 & 233 & 937 & 241 \\
\hline 18000 & 636 & 1141 & 430 & 541 & 1901 & 568 & 1270 & 1147 & 310 & 58 & 944 & 281 & 1043 & 257 \\
\hline 20000 & 714 & 1268 & 484 & 646 & 2119 & 642 & 1415 & 1274 & 387 & 101 & 1025 & 333 & 1150 & 264 \\
\hline 22000 & 775 & 1392 & 541 & 761 & 2320 & 715 & 1555 & 1392 & 465 & 149 & 1077 & 387 & 1250 & 267 \\
\hline 24000 & 853 & 1518 & 598 & 888 & 2535 & 794 & 1711 & 1513 & 563 & 197 & 1126 & 450 & 1354 & 272 \\
\hline 26000 & 924 & 1640 & 661 & 1024 & 2740 & 871 & 1849 & 1628 & 653 & 279 & 1161 & 506 & 1443 & 280 \\
\hline 28000 & 997 & 1763 & 724 & 1180 & 2939 & 949 & 1987 & 1733 & 771 & 491 & 971 & 566 & 1511 & 284 \\
\hline 30000 & 1081 & 1892 & 797 & 1344 & 3160 & 1035 & 2131 & 1849 & 902 & 692 & 932 & 633 & 1585 & 419 \\
\hline 32000 & 1160 & 2017 & 865 & 1507 & 3365 & 1124 & 2288 & 1951 & 1050 & 949 & 910 & 703 & 1646 & 510 \\
\hline 34000 & 1264 & 2167 & 969 & 1783 & 3605 & 1249 & 2484 & 2037 & 1217 & 1468 & 867 & 744 & 1681 & 554 \\
\hline 36000 & 1367 & 2281 & 1074 & 2082 & 3831 & 1355 & 2710 & 2145 & 1462 & 2318 & 875 & 939 & 1739 & 270 \\
\hline
\end{tabular}

Table C4-Polyester Component \#1 


\begin{tabular}{|c|c|c|c|c|c|c|c|c|c|}
\hline \multicolumn{8}{|c|}{ Solyester Component \#2: Test Date 1-30-02: 15"x 24" patch load: 9' Span } \\
\hline \multicolumn{8}{|c|}{52 kip failure due to web and flange separation } \\
\hline Load (kip) & $\# 1$ & $\# 2$ & $\# 3$ & $\# 4$ & $\# 5$ & $\# 6$ & $\# 8$ & $\# 10$ & $\# 11$ \\
\hline 0 & 0 & 0 & 0 & 0 & 0 & 0 & 0 & 0 & 0 \\
\hline 2 & 145 & 56 & 159 & 108 & 36 & 39 & 258 & 57 & 11 \\
\hline 4 & 290 & 107 & 322 & 207 & 73 & 74 & 480 & 78 & 15 \\
\hline 6 & 436 & 161 & 486 & 312 & 110 & 103 & 694 & 92 & 16 \\
\hline 8 & 588 & 218 & 648 & 417 & 146 & 132 & 914 & 107 & 15 \\
\hline 10 & 734 & 280 & 816 & 528 & 180 & 182 & 1148 & 138 & 16 \\
\hline 12 & 895 & 349 & 989 & 645 & 216 & 227 & 1411 & 173 & 14 \\
\hline 14 & 1045 & 425 & 1161 & 763 & 250 & 274 & 1653 & 205 & 13 \\
\hline 16 & 1202 & 506 & 1335 & 884 & 284 & 325 & 1904 & 237 & 12 \\
\hline 18 & 1362 & 592 & 1509 & 1007 & 318 & 379 & 2164 & 271 & 11 \\
\hline 20 & 1522 & 687 & 1684 & 1132 & 352 & 436 & 2420 & 308 & 8 \\
\hline 22 & 1685 & 786 & 1858 & 1253 & 384 & 486 & 2688 & 342 & 6 \\
\hline 24 & 1847 & 894 & 2037 & 1385 & 418 & 541 & 2954 & 377 & 3 \\
\hline 26 & 2020 & 1015 & 2225 & 1516 & 453 & 598 & 3236 & 413 & 2 \\
\hline 28 & 2177 & 1127 & 2401 & 1642 & 485 & 659 & 3501 & 452 & 5 \\
\hline 30 & 2344 & 1237 & 2572 & 1769 & 518 & 727 & 3782 & 489 & 8 \\
\hline 32 & 2512 & 1369 & 2758 & 1904 & 552 & 793 & 4075 & 525 & 13 \\
\hline 34 & 2675 & 1507 & 2945 & 2038 & 587 & 858 & 4363 & 555 & 19 \\
\hline 36 & 2847 & 1647 & 3130 & 2171 & 623 & 925 & 4680 & 587 & 24 \\
\hline 38 & 3009 & 1799 & 3314 & 2301 & 659 & 995 & 4986 & 616 & 33 \\
\hline 40 & 3182 & 1962 & 3502 & 2433 & 700 & 1063 & 5313 & 643 & 41 \\
\hline 42 & 3361 & 2123 & 3690 & 2564 & 742 & 1130 & 5657 & 668 & 49 \\
\hline 44 & 3526 & 2291 & 3872 & 2692 & 787 & 1202 & 5981 & 685 & 57 \\
\hline 46 & 3701 & 2465 & 4054 & 2814 & 832 & 1269 & 6328 & 702 & 67 \\
\hline 48 & 3866 & 2633 & 4233 & 2935 & 876 & 1337 & 6662 & 709 & 76 \\
\hline 50 & 4039 & 2816 & 4414 & 3044 & 927 & 1416 & 6997 & 711 & 86 \\
\hline 52 & 4214 & 3007 & 4593 & 3157 & 975 & 1491 & 7344 & 705 & 97 \\
\hline
\end{tabular}

Table C5-Polyester Component \#2

\begin{tabular}{|c|c|c|c|c|c|}
\hline \multicolumn{7}{|c|}{ Vinyl Ester Component \#1: Test Date 6-7-02: 10"x 20" patch load: 10' span } \\
Punching shear failure at 37 kips \\
\hline \multicolumn{7}{|c|}{ Strain values in micro-strains: Deflections in milli-inches } \\
\hline Load (k) & $\# 1$ & $\# 2$ & $\# 3$ & \#4 & DEF-1 \\
\hline 0 & 0 & 0 & 0 & 0 & 0 \\
\hline 2 & 191 & 20 & 631 & 1445 & 100 \\
\hline 5 & 470 & 71 & 761 & 1837 & 217 \\
\hline 10 & 937 & 204 & 888 & 2256 & 383 \\
\hline 15 & 1402 & 371 & 1021 & 2897 & 560 \\
\hline 20 & 1835 & 580 & 1189 & 3424 & 742 \\
\hline 25 & 2299 & 833 & 1354 & 3809 & 922 \\
\hline 30 & 2752 & 1119 & 1484 & 3711 & NA \\
\hline 35 & 3349 & 1345 & 1312 & 4431 & NA \\
\hline
\end{tabular}

Table C6-Vinyl Ester Component \#1 


\begin{tabular}{|c|c|c|c|c|c|}
\hline \multicolumn{6}{|c|}{$\begin{array}{l}\text { Vinyl Ester Component \#2: Test Date 6-4-02: } 15 " \times 24 " \text { patch load: } 10 \text { ' span } \\
\text { Failure of top flange buckling at } 67 \text { kips }\end{array}$} \\
\hline \multicolumn{6}{|c|}{ Strain values in micro-strains: Deflections in milli-inches } \\
\hline Load (k) & $\# 1$ & \#2 & \#3 & \#4 & DEF-1 \\
\hline 0 & 0 & 0 & 0 & 0 & 0 \\
\hline 2 & 179 & 66 & 585 & 1002 & 82 \\
\hline 5 & 440 & 159 & 982 & 1169 & 189 \\
\hline 10 & 867 & 326 & 1480 & 1153 & 357 \\
\hline 15 & 1300 & 545 & 1913 & 1067 & 517 \\
\hline 20 & 1708 & 778 & 2296 & 961 & 671 \\
\hline 25 & 2133 & 1049 & 2669 & 832 & 833 \\
\hline 30 & 2573 & 1361 & 3063 & 668 & 985 \\
\hline 35 & 3005 & 1694 & 3424 & 511 & NA \\
\hline 40 & 3452 & 2064 & 3781 & 362 & NA \\
\hline 45 & 3884 & 2458 & 4114 & 232 & NA \\
\hline 50 & 4330 & 2889 & 4411 & 222 & NA \\
\hline 55 & 4760 & 3360 & 4647 & 312 & NA \\
\hline 60 & 5219 & 3797 & 4678 & 666 & NA \\
\hline 65 & 5561 & 4208 & 4377 & 1297 & NA \\
\hline
\end{tabular}

Table C7-Vinyl Ester Component \#2 


\begin{tabular}{|c|c|c|c|c|c|c|c|c|c|}
\hline \multicolumn{10}{|c|}{ Rehabilitated Longitudinal Component: Test Date 2-1-02: 12"x 12" patch load } \\
\hline \multicolumn{10}{|c|}{ Strain values in micro-strains: Flange 1 loaded } \\
\hline $\begin{array}{l}\text { Load } \\
\text { (kip) }\end{array}$ & \#1 & \#5 & \#7 & \#8 & \#11 & $\# 12$ & \#20 & \#21 & \#22 \\
\hline 0 & 0 & 0 & 0 & 0 & 0 & 0 & 0 & 0 & 0 \\
\hline 1 & 73 & 33 & 82 & 27 & 33 & 75 & 66 & 218 & 37 \\
\hline 2 & 150 & 69 & 168 & 56 & 69 & 155 & 171 & 422 & 87 \\
\hline 3 & 227 & 105 & 255 & 86 & 106 & 236 & 262 & 609 & 139 \\
\hline 4 & 301 & 140 & 333 & 115 & 139 & 308 & 345 & 779 & 190 \\
\hline 5 & 376 & 180 & 424 & 145 & 178 & 393 & 456 & 942 & 242 \\
\hline 6 & 455 & 217 & 512 & 176 & 216 & 469 & 566 & 1096 & 292 \\
\hline 7 & 531 & 257 & 598 & 205 & 254 & 548 & 681 & 1246 & 343 \\
\hline 8 & 606 & 299 & 689 & 234 & 290 & 629 & 786 & 1384 & 394 \\
\hline 9 & 677 & 341 & 777 & 262 & 325 & 712 & 890 & 1513 & 445 \\
\hline 10 & 759 & 384 & 865 & 292 & 367 & 789 & 1004 & 1651 & 497 \\
\hline 11 & 835 & 430 & 959 & 318 & 403 & 872 & 1128 & 1766 & 552 \\
\hline 12 & 915 & 473 & 1047 & 350 & 446 & 949 & 1248 & 1884 & 606 \\
\hline 13 & 987 & 528 & 1141 & 369 & 479 & 1033 & 1348 & 1994 & 669 \\
\hline 14 & 1062 & 578 & 1241 & 390 & 516 & 1116 & 1464 & 2097 & 740 \\
\hline 15 & 1141 & 629 & 1340 & 413 & 554 & 1199 & 1582 & 2189 & 816 \\
\hline 16 & 1222 & 688 & 1440 & 427 & 596 & 1281 & 1709 & 2250 & 900 \\
\hline 17 & 1306 & 745 & 1554 & 434 & 639 & 1370 & 1845 & 2315 & 1004 \\
\hline 18 & 1387 & 802 & 1663 & 430 & 680 & 1457 & 1974 & 2345 & 1100 \\
\hline \multicolumn{10}{|c|}{ Test Date 2-1-02: 12"x 12" patch load: Flange 2 loaded } \\
\hline $\begin{array}{l}\text { Load } \\
\text { (kip) }\end{array}$ & $\# 1$ & \#5 & \#7 & \#8 & \#11 & \#12 & \#20 & \#21 & \#22 \\
\hline 0 & 0 & 0 & 0 & 0 & 0 & 0 & 0 & 0 & 0 \\
\hline 1 & 64 & 32 & 89 & 48 & 36 & 78 & 150 & 85 & 30 \\
\hline 2 & 142 & 52 & 169 & 83 & 77 & 149 & 310 & 164 & 63 \\
\hline 3 & 207 & 88 & 254 & 107 & 113 & 228 & 463 & 268 & 79 \\
\hline 4 & 267 & 122 & 344 & 146 & 150 & 312 & 620 & 362 & 102 \\
\hline 5 & 348 & 150 & 437 & 190 & 197 & 398 & 789 & 466 & 120 \\
\hline 6 & 428 & 180 & 526 & 232 & 244 & 484 & 956 & 565 & 179 \\
\hline 7 & 475 & 262 & 682 & 191 & 239 & 623 & 1063 & 727 & 245 \\
\hline 8 & 521 & 319 & 794 & 267 & 262 & 718 & 1210 & 849 & 296 \\
\hline 9 & 584 & 359 & 893 & 284 & 308 & 801 & 1362 & 944 & 417 \\
\hline 10 & 636 & 417 & 994 & 323 & 354 & 900 & 1504 & 1063 & 409 \\
\hline 11 & 738 & 406 & 1055 & 408 & 437 & 964 & 1694 & 1142 & 396 \\
\hline 12 & 799 & 464 & 1168 & 382 & 393 & 1125 & 1709 & 1341 & 449 \\
\hline 13 & 838 & 586 & 1317 & 442 & 461 & 1192 & 1904 & 1456 & 504 \\
\hline 14 & 871 & 582 & 1373 & 492 & 531 & 1265 & 2084 & 1550 & 556 \\
\hline 16 & 1113 & 588 & 1562 & 627 & 655 & 1420 & 2337 & 1722 & 640 \\
\hline
\end{tabular}

Table C8-Elastic Testing of Rehabilitated Longitudinal Component (12"x 12" Patch Load) 


\begin{tabular}{|c|c|c|c|c|c|c|c|c|c|}
\hline \multicolumn{10}{|c|}{ Rehabilitated Longitudinal Component: Test Date 2-1-02: 12"x 24" patch load } \\
\hline \multicolumn{10}{|c|}{ Strain values in micro-strains: Flange 1 loaded } \\
\hline $\begin{array}{l}\text { Load } \\
\text { (kip) }\end{array}$ & \#1 & \#5 & \#7 & \#8 & \#11 & \#12 & \#20 & \#21 & \#22 \\
\hline 0 & 0 & 0 & 0 & 0 & 0 & 0 & 0 & 0 & 0 \\
\hline 1 & 73 & 31 & 78 & 29 & 31 & 74 & 91 & 143 & 12 \\
\hline 2 & 154 & 65 & 162 & 50 & 66 & 153 & 192 & 287 & 35 \\
\hline 3 & 225 & 97 & 237 & 81 & 100 & 223 & 289 & 407 & 60 \\
\hline 4 & 297 & 133 & 319 & 106 & 129 & 299 & 388 & 520 & 88 \\
\hline 5 & 375 & 170 & 401 & 127 & 169 & 377 & 491 & 621 & 115 \\
\hline 6 & 444 & 207 & 481 & 137 & 198 & 449 & 583 & 704 & 144 \\
\hline 7 & 516 & 245 & 558 & 154 & 232 & 523 & 681 & 786 & 170 \\
\hline 8 & 597 & 281 & 634 & 174 & 269 & 595 & 785 & 856 & 194 \\
\hline 9 & 672 & 327 & 717 & 187 & 303 & 674 & 889 & 926 & 222 \\
\hline 10 & 745 & 363 & 791 & 204 & 335 & 747 & 984 & 986 & 246 \\
\hline 11 & 814 & 415 & 872 & 220 & 363 & 829 & 1083 & 1053 & 278 \\
\hline 12 & 888 & 459 & 958 & 225 & 393 & 904 & 1178 & 1106 & 300 \\
\hline 13 & 966 & 504 & 1037 & 236 & 431 & 979 & 1269 & 1157 & 322 \\
\hline 14 & 1042 & 553 & 1114 & 248 & 465 & 1055 & 1355 & 1207 & 345 \\
\hline 15 & 1122 & 606 & 1203 & 262 & 500 & 1136 & 1465 & 1258 & 368 \\
\hline 16 & 1202 & 657 & 1287 & 274 & 534 & 1216 & 1572 & 1306 & 390 \\
\hline 17 & 1279 & 712 & 1372 & 287 & 569 & 1295 & 1680 & 1353 & 412 \\
\hline 18 & 1357 & 768 & 1457 & 297 & 603 & 1376 & 1787 & 1397 & 434 \\
\hline 19 & 1438 & 827 & 1546 & 310 & 640 & 1458 & 1901 & 1438 & 456 \\
\hline 20 & 1515 & 884 & 1628 & 324 & 675 & 1536 & 2009 & 1473 & 475 \\
\hline \multicolumn{10}{|c|}{ Test Date 2-1-02: 12"x 24" patch load: Flange 2 loaded } \\
\hline $\begin{array}{l}\text { Load } \\
\text { (kip) }\end{array}$ & $\# 1$ & \#5 & \#7 & \#8 & \#11 & \#12 & \#20 & \#21 & \#22 \\
\hline 0 & 0 & 0 & 0 & 0 & 0 & 0 & 0 & 0 & 0 \\
\hline 2 & 131 & 36 & 153 & 70 & 92 & 130 & 196 & 183 & 229 \\
\hline 3 & 158 & 132 & 292 & 90 & 86 & 266 & 246 & 288 & 253 \\
\hline 4 & 261 & 216 & 484 & 46 & 40 & 416 & 264 & 453 & 408 \\
\hline 6 & 218 & 296 & 663 & 133 & 111 & 623 & 412 & 674 & 471 \\
\hline 8 & 456 & 282 & 771 & 282 & 272 & 667 & 654 & 788 & 592 \\
\hline 10 & 584 & 320 & 957 & 338 & 348 & 821 & 810 & 987 & 642 \\
\hline 12 & 688 & 385 & 1167 & 425 & 417 & 1005 & 975 & 1196 & 740 \\
\hline 14 & 858 & 435 & 1287 & 610 & 580 & 1133 & 1192 & 1342 & 860 \\
\hline 16 & 973 & 429 & 1477 & 675 & 687 & 1370 & 1342 & 1594 & 967 \\
\hline 18 & 1076 & 451 & 1681 & 779 & 776 & 1501 & 1483 & 1808 & 1084 \\
\hline 20 & 1166 & 581 & 1878 & 872 & 869 & 1675 & 1636 & 2021 & 1202 \\
\hline
\end{tabular}

Table C9-Elastic Testing of Rehabilitated Longitudinal Component (12"x 24" Patch Load) 


\begin{tabular}{|c|c|c|c|c|c|c|c|c|c|}
\hline \multicolumn{10}{|c|}{ Rehabilitated Longitudinal Component: Test Date 2-1-02: 6"x 24" patch load } \\
\hline \multicolumn{10}{|c|}{ Strain values in micro-strains: Flange 1 loaded } \\
\hline $\begin{array}{l}\text { Load } \\
\text { (kip) }\end{array}$ & \#1 & \#5 & \#7 & \#8 & $\# 11$ & \#12 & \#20 & \#21 & \#22 \\
\hline 0 & 0 & 0 & 0 & 0 & 0 & 0 & 0 & 0 & 0 \\
\hline 1 & 82 & 33 & 70 & 10 & 26 & 72 & 100 & 278 & 6 \\
\hline 2 & 143 & 68 & 133 & 7 & 41 & 133 & 192 & 430 & 6 \\
\hline 3 & 216 & 108 & 199 & 8 & 59 & 201 & 301 & 561 & 5 \\
\hline 4 & 292 & 145 & 261 & 6 & 81 & 267 & 385 & 671 & 2 \\
\hline 5 & 369 & 186 & 322 & 12 & 101 & 333 & 517 & 776 & 3 \\
\hline 6 & 436 & 236 & 397 & 5 & 117 & 407 & 611 & 880 & 6 \\
\hline 7 & 509 & 278 & 459 & 11 & 138 & 469 & 699 & 973 & 16 \\
\hline 8 & 587 & 323 & 527 & 16 & 161 & 534 & 817 & 1068 & 21 \\
\hline 9 & 654 & 369 & 583 & 21 & 179 & 592 & 881 & 1143 & 35 \\
\hline 10 & 741 & 422 & 651 & 31 & 204 & 660 & 1009 & 1234 & 55 \\
\hline 11 & 823 & 473 & 712 & 43 & 227 & 727 & 1117 & 1314 & 76 \\
\hline 12 & 900 & 525 & 771 & 58 & 251 & 782 & 1257 & 1384 & 100 \\
\hline 13 & 980 & 573 & 824 & 72 & 278 & 835 & 1328 & 1462 & 124 \\
\hline 14 & 1060 & 624 & 877 & 94 & 304 & 889 & 1450 & 1531 & 156 \\
\hline \multicolumn{10}{|c|}{ Test Date 2-1-02: 6"x 24 " patch load: Flange 2 loaded } \\
\hline $\begin{array}{l}\text { Load } \\
\text { (kip) }\end{array}$ & $\# 1$ & \#5 & \#7 & \#8 & $\# 11$ & $\# 12$ & \#20 & \#21 & \#22 \\
\hline 0 & 0 & 0 & 0 & 0 & 0 & 0 & 0 & 0 & 0 \\
\hline 1 & 61 & 5 & 85 & 33 & 48 & 79 & 57 & 85 & 88 \\
\hline 2 & 124 & 14 & 169 & 68 & 92 & 158 & 157 & 174 & 181 \\
\hline 3 & 182 & 24 & 247 & 102 & 132 & 232 & 263 & 259 & 268 \\
\hline 4 & 247 & 36 & 338 & 141 & 178 & 312 & 373 & 353 & 368 \\
\hline 5 & 311 & 48 & 434 & 181 & 224 & 393 & 469 & 447 & 473 \\
\hline 6 & 370 & 61 & 499 & 222 & 269 & 469 & 552 & 538 & 576 \\
\hline 7 & 434 & 75 & 586 & 265 & 317 & 551 & 629 & 635 & 687 \\
\hline 8 & 497 & 90 & 671 & 310 & 366 & 629 & 704 & 731 & 801 \\
\hline 9 & 560 & 105 & 762 & 357 & 416 & 712 & 778 & 833 & 924 \\
\hline 10 & 625 & 121 & 853 & 406 & 468 & 796 & 862 & 936 & 1055 \\
\hline 11 & 687 & 138 & 945 & 460 & 523 & 880 & 925 & 1041 & 1190 \\
\hline 12 & 746 & 155 & 1030 & 510 & 574 & 959 & 990 & 1141 & 1319 \\
\hline 13 & 804 & 173 & 1119 & 562 & 627 & 1040 & 1051 & 1242 & 1456 \\
\hline 14 & 862 & 191 & 1208 & 625 & 681 & 1121 & 1109 & 1336 & 1601 \\
\hline 15 & 920 & 211 & 1296 & 671 & 738 & 1203 & 1164 & 1451 & 1750 \\
\hline
\end{tabular}

Table C10-Elastic Testing of Rehabilitated Longitudinal Component (6"x 24" Patch Load) 


\begin{tabular}{|c|c|c|c|c|c|c|c|c|c|}
\hline \multicolumn{8}{|c|}{ Sehabilitated Longitudinal Component: Test Date 2-2-02: 10"x 20"patch load } \\
Flange 1 loaded: Failure at 27 kips due to local shear \\
\hline $\begin{array}{c}\text { Load } \\
\text { (kip) }\end{array}$ & $\# 1$ & $\# 5$ & $\# 7$ & $\# 8$ & $\# 11$ & $\# 12$ & $\# 20$ & $\# 21$ & $\# 22$ \\
\hline 0 & 0 & 0 & 0 & 0 & 0 & 0 & 0 & 0 & 0 \\
\hline 2 & 160 & 77 & 158 & 31 & 43 & 141 & 202 & 80 & 9 \\
\hline 4 & 319 & 158 & 313 & 57 & 92 & 282 & 410 & 139 & 19 \\
\hline 6 & 677 & 241 & 467 & 89 & 149 & 421 & 619 & 205 & 23 \\
\hline 8 & 630 & 325 & 618 & 127 & 209 & 559 & 826 & 261 & 25 \\
\hline 10 & 788 & 417 & 778 & 174 & 281 & 703 & 1049 & 312 & 26 \\
\hline 12 & 947 & 515 & 941 & 227 & 358 & 848 & 1275 & 355 & 28 \\
\hline 14 & 1102 & 615 & 1098 & 284 & 439 & 989 & 1499 & 388 & 30 \\
\hline 16 & 1258 & 717 & 1260 & 345 & 525 & 1130 & 1724 & 419 & 38 \\
\hline 18 & 1412 & 821 & 1421 & 408 & 615 & 1269 & 1952 & 445 & 41 \\
\hline 20 & 1569 & 942 & 1605 & 497 & 715 & 1409 & 2213 & 448 & 144 \\
\hline 22 & 1736 & 1071 & 1809 & 590 & 778 & 1556 & 2466 & 472 & 169 \\
\hline 24 & 1896 & 1194 & 2038 & 682 & 896 & 1698 & 2740 & 432 & 138 \\
\hline 26 & 2067 & 1334 & 2317 & 768 & 1034 & 1836 & 3049 & 415 & 712 \\
\hline
\end{tabular}

Table C11-Rehabilitated Longitudinal Component Failure Test

\begin{tabular}{|c|c|c|c|c|c|c|c|c|c|}
\hline \multicolumn{3}{|c|}{$\begin{array}{c}\text { Transverse testing with two layers of fabric } \\
\text { over the joints }\end{array}$} & \multicolumn{5}{c|}{ Transverse testing without fabric layers over } \\
the joints
\end{tabular}

Table C12-Transverse Testing 


\begin{tabular}{|c|c|c|c|c|c|c|c|c|c|c|c|c|c|}
\hline \multicolumn{14}{|c|}{ Polyester Deck Phase I: Test date 3-29-02 } \\
\hline \multicolumn{14}{|c|}{ Strain values in micro-strains: Deflections in milli-inches } \\
\hline Load $(k)$ & $\# 1$ & \#2 & \#3 & \#5 & \#6 & \#8 & $\# 11$ & $\# 12$ & $\# 13$ & $\# 14$ & $\# 15$ & $\# 16$ & \#18 \\
\hline 0 & 0 & 0 & 0 & 0 & 0 & 0 & 0 & 0 & 0 & 0 & 0 & 0 & 0 \\
\hline 2 & 87 & 67 & 68 & 3 & 43 & 41 & 8 & 14 & -27 & 66 & 532 & 1091 & 73 \\
\hline 3 & 132 & 105 & 107 & 7 & 66 & 62 & 13 & 23 & -18 & 106 & 675 & 1417 & 90 \\
\hline 5 & 221 & 170 & 182 & 12 & 120 & 105 & 23 & 40 & 25 & 174 & 724 & 1806 & 116 \\
\hline 10 & 417 & 309 & 342 & 31 & 223 & 203 & 50 & 89 & 120 & 334 & 706 & 2394 & 142 \\
\hline 15 & 607 & 428 & 504 & 47 & 334 & 298 & 81 & 141 & 190 & 498 & 712 & 2840 & 179 \\
\hline 20 & 820 & 550 & 680 & 70 & 445 & 405 & 108 & 201 & 259 & 692 & 762 & 3301 & 219 \\
\hline 25 & 1014 & 648 & 850 & 88 & 556 & 503 & 142 & 263 & 313 & 884 & 808 & 3670 & 270 \\
\hline Load (k) & $\# 19$ & $\# 20$ & \#22 & $\# 2$ & \#24 & \#28 & $\# 29$ & $\# 30$ & \#31 & \#32 & \#33 & \#34 & \\
\hline 0 & 0 & 0 & 0 & 0 & 0 & 0 & 0 & 0 & 0 & 0 & 0 & 0 & \\
\hline 2 & 57 & 34 & 8 & 3 & 14 & 7 & 3 & 13 & 9 & 2 & 3 & 9 & \\
\hline 3 & 89 & 49 & 14 & 8 & 20 & 11 & 5 & 19 & 14 & 4 & 3 & 12 & \\
\hline 5 & 158 & 81 & 24 & 28 & 34 & 17 & 9 & 33 & 22 & 6 & 4 & 19 & \\
\hline 10 & 283 & 157 & 50 & 43 & 69 & 35 & 17 & 68 & 45 & 9 & 9 & 38 & \\
\hline 15 & 433 & 236 & 77 & 64 & 104 & 50 & 25 & 106 & 70 & 12 & 13 & 57 & \\
\hline 20 & 569 & 325 & 104 & 89 & 140 & 70 & 34 & 144 & 94 & 14 & 18 & 77 & \\
\hline 25 & 721 & 417 & 130 & 117 & 177 & 85 & 41 & 186 & 119 & 16 & 22 & 97 & \\
\hline Load $(k)$ & DEF-1 & DEF-c & DEF & & DEF-6 & DEF-8 & DEF-9 & & & & & & \\
\hline 0 & 0 & 0 & 0 & & 0 & 0 & 0 & & & & & & \\
\hline 2 & 39 & 62 & 2 & & 13 & 55 & 63 & & & & & & \\
\hline 3 & 50 & 90 & 3 & & 20 & 80 & 96 & & & & & & \\
\hline 5 & 67 & 141 & 7 & & 34 & 129 & 154 & & & & & & \\
\hline 10 & 92 & 262 & 16 & & 68 & 254 & 295 & & & & & & \\
\hline 15 & 108 & 375 & 2 & & 103 & 388 & 430 & & & & & & \\
\hline 20 & 119 & 483 & 3 & & 139 & 513 & 560 & & & & & & \\
\hline 25 & 130 & 590 & 38 & & 174 & 634 & 697 & & & & & & \\
\hline
\end{tabular}

Table C13-Polyester Deck Phase I 


\begin{tabular}{|c|c|c|c|c|c|c|c|c|c|c|c|c|c|}
\hline \multicolumn{14}{|c|}{ Polyester Deck Phase II: Test date 4-23-02 } \\
\hline \multicolumn{14}{|c|}{ Strain values in micro-strains: Deflections in milli-inches } \\
\hline Load $(k)$ & $\# 1$ & \#2 & \#3 & $\# 4$ & $\# 5$ & \#6 & $\# 7$ & $\# \varepsilon$ & $\# 9$ & $\# 10$ & $\# 11$ & $\# 12$ & $\# 13$ \\
\hline 0 & 0 & 0 & 0 & 0 & 0 & 0 & 0 & 0 & 0 & 0 & 0 & 0 & 0 \\
\hline 2 & 6 & 15 & 32 & 9 & 4 & 29 & 76 & 15 & 21 & 5 & 7 & 3 & 65 \\
\hline 4 & 14 & 32 & 65 & 18 & 7 & 45 & 109 & 32 & 47 & 11 & 10 & 5 & 107 \\
\hline 6 & 19 & 49 & 97 & 25 & 9 & 59 & 144 & $\overline{44}$ & 70 & 16 & 19 & 9 & 145 \\
\hline 8 & 23 & 68 & 124 & 32 & 11 & 74 & 187 & 5 & 94 & 21 & 19 & 13 & 183 \\
\hline 10 & 20 & 85 & 151 & 36 & 13 & 82 & 222 & 60 & $\overline{113}$ & 24 & 23 & 19 & 231 \\
\hline 12 & 24 & 104 & 176 & 42 & 15 & 91 & 263 & $6 s$ & 134 & 28 & 22 & 25 & 269 \\
\hline 14 & 21 & 122 & 204 & 47 & 17 & 97 & 301 & $7 \varepsilon$ & 153 & 31 & 25 & 31 & 318 \\
\hline 16 & 24 & 142 & 230 & 52 & 18 & 105 & 349 & 85 & 174 & 35 & 24 & 37 & 355 \\
\hline 18 & 21 & 160 & 258 & 58 & 20 & 112 & 386 & 95 & 192 & 42 & 36 & 46 & 408 \\
\hline 20 & 25 & 179 & 284 & 64 & 22 & 119 & 428 & 11 & 212 & 42 & 40 & 53 & 444 \\
\hline 22 & 23 & 197 & 311 & 70 & 24 & 127 & 465 & 12 & 230 & 45 & 44 & 62 & 489 \\
\hline 24 & 25 & 217 & 336 & 75 & 25 & 136 & 511 & 13 & 251 & 48 & 45 & 69 & 523 \\
\hline 25 & 22 & 226 & 352 & 79 & 26 & 141 & 533 & 14 & 260 & 50 & 47 & 75 & 555 \\
\hline Load (k) & \#14 & \#15 & $\#$ & $\# 17$ & \#18 & $\# 19$ & "\#20 & "\#2 & $\# 23$ & \#24 & \#25 & \#26 & $\# 27$ \\
\hline 0 & 0 & 0 & 0 & 0 & 0 & 0 & 0 & 0 & 0 & 0 & 0 & 0 & 0 \\
\hline 2 & 17 & 20 & 212 & 206 & 96 & 6 & 6 & 2 & 0 & 4 & 22 & 23 & 5 \\
\hline 4 & 38 & 133 & 810 & 421 & 168 & 17 & 22 & 6 & 3 & 9 & 43 & 42 & 8 \\
\hline 6 & 57 & 141 & 1284 & 597 & 234 & 28 & 28 & 8 & 3 & 13 & 67 & 63 & 15 \\
\hline 8 & 69 & 117 & 1756 & 768 & 317 & 36 & 39 & 11 & 4 & 17 & 92 & 87 & 24 \\
\hline 10 & 84 & 81 & 2230 & 997 & 394 & 45 & 45 & 13 & 5 & 20 & 119 & 113 & 34 \\
\hline 12 & 97 & 41 & 2669 & 1265 & 476 & 53 & 57 & 14 & 5 & 23 & 145 & 130 & 44 \\
\hline 14 & 114 & 1 & 3083 & 1428 & 548 & 62 & 64 & 17 & 7 & 27 & \begin{tabular}{|l|}
172 \\
\end{tabular} & 165 & 55 \\
\hline 16 & 130 & -40 & 3482 & 1611 & 627 & 70 & 75 & 19 & 7 & 31 & 198 & 190 & 65 \\
\hline 18 & 153 & $\begin{array}{l}-81 \\
\end{array}$ & 3861 & 1827 & 691 & 80 & 82 & 22 & 8 & 35 & 224 & 216 & 76 \\
\hline 20 & 171 & -121 & 4230 & 2257 & 768 & 89 & 96 & 24 & 9 & 39 & 251 & 241 & 86 \\
\hline 22 & 195 & -160 & 4557 & 2598 & 824 & 100 & 103 & 27 & 9 & 42 & 277 & 267 & 97 \\
\hline 24 & 223 & $\begin{array}{l}-199 \\
\end{array}$ & 4882 & 2925 & 895 & 110 & 116 & 29 & 11 & 46 & 304 & 293 & $\overline{108}$ \\
\hline 25 & 247 & -221 & 5055 & 3048 & 924 & 116 & 118 & 30 & 11 & 48 & 317 & 306 & 112 \\
\hline Load (k) & \#29 & \#30 & \#31 & \#32 & \#33 & \#34 & $\overline{\mathrm{DE}}$ & & DEF-2 & DEF-3 & DEF-C & & $\overline{F-10}$ \\
\hline 0 & 0 & 0 & 0 & 0 & 0 & 0 & c & & 0 & 0 & 0 & & 0 \\
\hline 2 & 3 & 6 & 4 & 3 & 3 & 5 & 6 & & 9 & 6 & 1 & & 5 \\
\hline 4 & 4 & 11 & 9 & 5 & 7 & 8 & 1 & & 18 & 14 & 4 & & 21 \\
\hline 6 & 5 & 17 & 14 & 7 & 9 & 11 & 1 & & 26 & 22 & 7 & & 39 \\
\hline 8 & 6 & 21 & 17 & 7 & 14 & 12 & 1 & & 33 & 28 & 9 & & 62 \\
\hline 10 & 6 & 25 & 18 & 8 & 19 & 13 & 1 & & 39 & 34 & 12 & & 74 \\
\hline 12 & 7 & 29 & 20 & 7 & 25 & 14 & 2 & & 44 & 39 & 15 & & 90 \\
\hline 14 & 6 & 33 & 22 & 8 & 25 & 15 & 2 & & 49 & 43 & 17 & & 107 \\
\hline 16 & 6 & 37 & 24 & 7 & 23 & 16 & 2 & & 53 & 50 & 18 & & 21 \\
\hline 18 & 7 & 42 & 25 & 9 & 30 & 16 & 2 & & 59 & 54 & 20 & & 38 \\
\hline 20 & 6 & 46 & 25 & 9 & 23 & 17 & 2 & & 65 & 59 & 21 & & 155 \\
\hline 22 & 6 & 50 & 28 & 10 & 22 & 18 & 2 & & 70 & 64 & 25 & & 68 \\
\hline 24 & 6 & 54 & 31 & 11 & 15 & 17 & 2 & & 74 & 70 & 27 & & 80 \\
\hline 25 & 6 & 55 & 32 & 10 & 15 & 18 & 2 & & 76 & 72 & 27 & & 88 \\
\hline
\end{tabular}

Table C14-Polyester Deck Phase II 


\begin{tabular}{|c|c|c|c|c|c|c|c|c|c|c|}
\hline \multicolumn{11}{|c|}{ Polyester Deck Phase III: Test Date 4-24-02 } \\
\hline \multicolumn{11}{|c|}{ Strain values in micro-strains: Deflections in milli-inches } \\
\hline Load $(k)$ & $\# 1$ & \#2 & \#3 & \#4 & \#5 & \#7 & \#8 & \#9 & $\# 10$ & $\# 11$ \\
\hline 0 & 0 & 0 & 0 & 0 & 0 & 0 & 0 & 0 & 0 & 0 \\
\hline 2 & 13 & 3 & 2 & 26 & 3 & 31 & 9 & 1 & 25 & 1 \\
\hline 4 & 26 & 5 & 6 & 53 & 10 & 54 & 17 & 2 & 50 & 1 \\
\hline 6 & 38 & 6 & 9 & 78 & 16 & 69 & 24 & 4 & 75 & 1 \\
\hline 8 & 50 & 10 & 10 & 103 & 23 & 87 & 31 & 6 & 97 & 7 \\
\hline 10 & 67 & 12 & 11 & 124 & 28 & 103 & 33 & 5 & 122 & 23 \\
\hline 12 & 82 & 17 & 8 & 151 & 33 & 120 & 36 & 5 & 146 & 34 \\
\hline 14 & 101 & 18 & 7 & 173 & 38 & 135 & 38 & 4 & 169 & 44 \\
\hline 16 & 115 & 24 & 6 & 199 & 43 & 155 & 41 & 3 & 195 & 51 \\
\hline 18 & 135 & 25 & 6 & 224 & 47 & 169 & 43 & 3 & 218 & 60 \\
\hline 20 & 149 & 31 & 5 & 250 & 54 & 189 & 46 & 2 & 243 & 67 \\
\hline 22 & 168 & 32 & 4 & 271 & 57 & 203 & 49 & 2 & 266 & 75 \\
\hline 24 & 181 & 38 & 4 & 298 & 63 & 221 & 52 & 3 & 290 & 81 \\
\hline 26 & 200 & 39 & 5 & 321 & 68 & 236 & 55 & 3 & 315 & 90 \\
\hline 28 & 216 & 46 & 5 & 348 & 73 & 253 & 58 & 3 & 340 & 97 \\
\hline 30 & 233 & 47 & 3 & 372 & 84 & 267 & 62 & 2 & 364 & 107 \\
\hline 32 & 246 & 55 & 3 & 398 & 83 & 283 & 64 & 3 & 388 & 113 \\
\hline 34 & 269 & 55 & 3 & 422 & 89 & 300 & 67 & 3 & 415 & 124 \\
\hline 36 & 284 & 62 & 3 & 450 & 94 & 317 & 70 & 4 & 441 & 130 \\
\hline 38 & 302 & 64 & 4 & 473 & 99 & 329 & 73 & 4 & 467 & 141 \\
\hline 40 & 317 & 72 & 3 & 500 & 104 & 345 & 75 & 5 & 490 & 147 \\
\hline Load (k) & $\# \# 12$ & \#\#15 & $\# 16$ & "\#17 & $\# 18$ & "\#19 & \#20 & \#21 & \#22 & "\#23 \\
\hline 0 & 0 & 0 & 0 & 0 & 0 & 0 & 0 & 0 & 0 & 0 \\
\hline 2 & 6 & 18 & 23 & 26 & 9 & 2 & 20 & 28 & 7 & 3 \\
\hline 4 & 13 & 35 & 47 & 51 & 22 & 3 & 43 & 33 & 2 & 10 \\
\hline 6 & 19 & 52 & 68 & 76 & 31 & 4 & 60 & 39 & 2 & 14 \\
\hline 8 & 28 & 64 & 95 & 103 & 46 & 8 & 87 & 42 & 8 & 18 \\
\hline 10 & 35 & 95 & 118 & 129 & 59 & 13 & 106 & 46 & 13 & 22 \\
\hline 12 & 46 & 121 & 147 & 159 & 77 & 20 & 130 & 48 & 18 & 26 \\
\hline 14 & 56 & 141 & 167 & 186 & 89 & 24 & 146 & 52 & 17 & 30 \\
\hline 16 & 66 & 164 & 200 & 215 & 106 & 29 & 168 & 56 & 28 & 35 \\
\hline 18 & 77 & 186 & 227 & 244 & 120 & 35 & 185 & 58 & 32 & 40 \\
\hline 20 & 88 & 217 & 255 & 276 & 140 & 40 & 207 & 62 & 38 & 45 \\
\hline 22 & 97 & 232 & 284 & 307 & 148 & 45 & 226 & 63 & 42 & 51 \\
\hline 24 & 111 & 255 & 316 & 339 & 170 & 51 & 248 & 68 & 49 & 55 \\
\hline 26 & 122 & 277 & 345 & 372 & 179 & 56 & 267 & 68 & 54 & 61 \\
\hline 28 & 134 & 304 & 377 & 407 & 196 & 62 & 290 & 70 & 61 & 66 \\
\hline 30 & 147 & 323 & 408 & 441 & 208 & 67 & 308 & 70 & 67 & 71 \\
\hline 32 & 159 & 346 & 442 & 474 & 227 & 74 & 333 & 72 & 74 & 76 \\
\hline 34 & 169 & 369 & 474 & 510 & 238 & 80 & 354 & 72 & 79 & 82 \\
\hline 36 & 185 & 392 & 507 & 546 & 256 & 85 & 378 & 75 & 85 & 87 \\
\hline 38 & 195 & 415 & 540 & 582 & 267 & 91 & 398 & 75 & 90 & 92 \\
\hline 40 & 210 & 438 & 575 & 620 & 284 & 97 & 423 & 77 & 96 & 97 \\
\hline
\end{tabular}




\begin{tabular}{|c|c|c|c|c|c|c|c|c|c|c|}
\hline \multicolumn{10}{|c|}{ Polyester Deck Phase III: Test Date 4-24-02 } \\
\hline \multicolumn{10}{|c|}{ Strain values in micro-strains: Deflections in milli-inches } \\
\hline Load (k) & $\# 24$ & $\# 25$ & $\# 26$ & $\# 27$ & $\# 29$ & $\# 30$ & $\# 31$ & $\# 32$ & $\# 33$ & $\# 34$ \\
\hline 0 & 0 & 0 & 0 & 0 & 0 & 0 & 0 & 0 & 0 & 0 \\
\hline 2 & 11 & 19 & 21 & 1 & 1 & 14 & 7 & 1 & 0 & 3 \\
\hline 4 & 20 & 35 & 37 & 3 & 1 & 27 & 14 & 2 & 0 & 5 \\
\hline 6 & 31 & 51 & 51 & 8 & 3 & 40 & 19 & 2 & 0 & 5 \\
\hline 8 & 40 & 68 & 69 & 15 & 6 & 50 & 24 & 2 & 1 & 6 \\
\hline 10 & 50 & 88 & 87 & 22 & 10 & 59 & 28 & 1 & 2 & 5 \\
\hline 12 & 60 & 105 & 107 & 28 & 14 & 66 & 32 & 1 & 3 & 6 \\
\hline 14 & 69 & 126 & 127 & 37 & 18 & 75 & 36 & 2 & 4 & 6 \\
\hline 16 & 78 & 145 & 146 & 46 & 21 & 85 & 41 & 2 & 5 & 7 \\
\hline 18 & 89 & 163 & 163 & 53 & 23 & 93 & 45 & 4 & 6 & 8 \\
\hline 20 & 98 & 182 & 183 & 61 & 28 & 103 & 49 & 5 & 6 & 9 \\
\hline 22 & 108 & 201 & 201 & 69 & 33 & 111 & 54 & 6 & 8 & 10 \\
\hline 24 & 118 & 219 & 221 & 76 & 37 & 121 & 57 & 8 & 9 & 11 \\
\hline 26 & 130 & 239 & 239 & 85 & 41 & 129 & 62 & 10 & 9 & 13 \\
\hline 28 & 138 & 257 & 258 & 93 & 45 & 140 & 66 & 12 & 11 & 14 \\
\hline 30 & 149 & 276 & 277 & 106 & 50 & 149 & 71 & 13 & 12 & 16 \\
\hline 32 & 159 & 295 & 296 & 111 & 54 & 158 & 75 & 15 & 13 & 18 \\
\hline 34 & 170 & 315 & 315 & 120 & 58 & 167 & 79 & 16 & 14 & 20 \\
\hline 36 & 178 & 334 & 333 & 128 & 63 & 177 & 84 & 19 & 15 & 22 \\
\hline 38 & 188 & 352 & 351 & 137 & 67 & 185 & 88 & 21 & 17 & 23 \\
\hline 40 & 198 & 371 & 370 & 145 & 72 & 196 & 93 & 22 & 18 & 25 \\
\hline \hline
\end{tabular}

\begin{tabular}{|c|c|c|c|c|c|c|}
\hline \hline Load (k) & DEF-1 & DEF-2 & DEF-3 & DEF-4 & DEF-5 & DEF-7 \\
\hline 0 & 0 & 0 & 0 & 0 & 0 & 0 \\
\hline 2 & 5 & 7 & 11 & 3 & 12 & 26 \\
\hline 4 & 10 & 14 & 23 & 5 & 24 & 56 \\
\hline 6 & 15 & 21 & 38 & 9 & 37 & 81 \\
\hline 8 & 18 & 27 & 50 & 12 & 48 & 99 \\
\hline 10 & 21 & 32 & 59 & 15 & 60 & 127 \\
\hline 12 & 24 & 36 & 70 & 18 & 71 & 149 \\
\hline 14 & 30 & 41 & 77 & 20 & 79 & 166 \\
\hline 16 & 33 & 45 & 90 & 22 & 89 & 183 \\
\hline 18 & 34 & 48 & 99 & 25 & 89 & 201 \\
\hline 20 & 37 & 51 & 108 & 28 & 107 & 219 \\
\hline 22 & 39 & 56 & 116 & 29 & 116 & 234 \\
\hline 24 & 43 & 59 & 128 & 32 & 125 & 251 \\
\hline 26 & 45 & 63 & 136 & 34 & 134 & 268 \\
\hline 28 & 48 & 66 & 149 & 35 & 142 & 284 \\
\hline 30 & 50 & 69 & 158 & 38 & 153 & 301 \\
\hline 32 & 52 & 72 & 166 & 40 & 162 & 316 \\
\hline 34 & 55 & 76 & 176 & 42 & 170 & 332 \\
\hline 36 & 57 & 80 & 185 & 43 & 178 & 348 \\
\hline 38 & 59 & 83 & 194 & 44 & 186 & 363 \\
\hline 40 & 61 & 87 & 203 & 46 & 195 & 379 \\
\hline
\end{tabular}

Table C15-Polyester Deck Phase III 


\begin{tabular}{|c|c|c|c|c|c|c|c|c|c|c|c|c|}
\hline \multicolumn{13}{|c|}{ Vinyl Ester Deck Phase III: Test Date 5-25-02 } \\
\hline \multicolumn{13}{|c|}{ Strain values in micro-strains: Deflections in milli-inches } \\
\hline Load (k) & $\# 1$ & \#2 & $\# 3$ & \#4 & $\# 5$ & $\# 6$ & $\# 7$ & \#8 & \#9 & $\# 10$ & $\# 11$ & $\# 12$ \\
\hline 0 & 0 & 0 & 0 & 0 & 0 & 0 & 0 & 0 & 0 & 0 & 0 & 0 \\
\hline 2 & 6 & 12 & 14 & 5 & 8 & 31 & 10 & 20 & 9 & 13 & 26 & 333 \\
\hline 4 & 14 & 26 & 30 & 11 & 17 & 58 & 18 & 40 & 16 & 32 & 47 & 466 \\
\hline 6 & 22 & 42 & 48 & 15 & 28 & 91 & 27 & 62 & 24 & 39 & 70 & 529 \\
\hline 8 & 30 & 56 & 61 & 20 & 39 & 119 & 34 & 81 & 30 & 49 & 92 & 568 \\
\hline 10 & 39 & 71 & 77 & 27 & 46 & 150 & 42 & 103 & 37 & 58 & 119 & 590 \\
\hline 12 & 47 & 84 & 91 & 34 & 58 & 178 & 49 & 121 & 44 & 65 & 144 & 602 \\
\hline 14 & 55 & 99 & 106 & 41 & 67 & 207 & 56 & 143 & 50 & 74 & 174 & 609 \\
\hline 16 & 64 & 114 & 120 & 47 & 80 & 237 & 64 & 163 & 57 & 81 & 200 & 616 \\
\hline 18 & 72 & 127 & 135 & 53 & 91 & 266 & 72 & 184 & 64 & 90 & 227 & 619 \\
\hline 20 & 80 & 141 & 149 & 60 & 102 & 297 & 81 & 206 & 71 & 98 & 250 & 623 \\
\hline 22 & 88 & 155 & 165 & 66 & 113 & 329 & 90 & 228 & 77 & 106 & 268 & 628 \\
\hline 24 & 97 & 172 & 180 & 72 & 125 & 358 & 97 & 250 & 84 & 116 & 288 & 630 \\
\hline 26 & 104 & 189 & 195 & 79 & 136 & 383 & 104 & 268 & 95 & 125 & 312 & 643 \\
\hline 28 & 110 & 212 & 213 & 85 & 146 & 414 & 139 & 289 & 117 & 134 & 334 & 648 \\
\hline 30 & 116 & 229 & 227 & 92 & 155 & 443 & 147 & 308 & 124 & 144 & 354 & 654 \\
\hline 32 & 124 & 248 & 243 & 99 & 164 & 471 & 154 & 327 & 130 & 153 & 378 & 659 \\
\hline 34 & 131 & 266 & 249 & 105 & 176 & 498 & 163 & 348 & 137 & 158 & 399 & 668 \\
\hline 36 & 139 & 286 & 276 & $\overline{110}$ & 185 & 527 & 173 & 368 & 144 & 164 & 423 & 673 \\
\hline 38 & 146 & 304 & 292 & $\overline{116}$ & 198 & 555 & 181 & 387 & 151 & 168 & 446 & 678 \\
\hline 40 & 152 & 322 & 307 & 120 & 205 & 582 & 189 & 407 & 158 & 172 & 471 & 687 \\
\hline Load (k) & $\# 13$ & $\# 1$ & & $\# 15$ & DEF-1 & DEF-2 & $\mathrm{DEl}$ & & DEF-4 & DEF-5 & & EF-6 \\
\hline 0 & 0 & 0 & & 0 & 0 & 0 & 0 & & 0 & 0 & & 0 \\
\hline 2 & 665 & 46 & & 129 & 6 & 4 & 1 & & 9 & 2 & & 21 \\
\hline 4 & 954 & $\overline{60}$ & & 222 & 16 & 9 & 1 & & 18 & 5 & & 51 \\
\hline 6 & 1120 & 65 & & 314 & 23 & 14 & 2 & & 28 & 8 & & 78 \\
\hline 8 & 1250 & 70 & & 416 & 29 & 20 & $\overline{3}$ & & 37 & 12 & & 104 \\
\hline 10 & 1349 & 71 & & 513 & 34 & 23 & 4 & & 47 & 15 & & 126 \\
\hline 12 & 1439 & 71 & & 614 & 38 & 29 & 5 & & 56 & 20 & & 147 \\
\hline 14 & 1533 & 70 & & 722 & 42 & 36 & 7 & & 66 & 23 & & 173 \\
\hline 16 & 1621 & 69 & & 820 & 45 & 42 & 8 & & 75 & 27 & & 192 \\
\hline 18 & 1728 & 72 & & 935 & 49 & 48 & 9 & & 84 & 31 & & 214 \\
\hline 20 & 1836 & 76 & & 1046 & 52 & 52 & 10 & & 94 & 32 & & 230 \\
\hline 22 & 1931 & 80 & & 1147 & 54 & 57 & 11 & & 105 & 34 & & 245 \\
\hline 24 & 2046 & 87 & & 1258 & 57 & 61 & 12 & & 115 & 38 & & 269 \\
\hline 26 & 2173 & 95 & & 1381 & 59 & 68 & $\overline{13}$ & & 123 & 42 & & 280 \\
\hline 28 & 2294 & 10 & & 1496 & 62 & 75 & 14 & & 131 & 45 & & 308 \\
\hline 30 & 2406 & 110 & & 1600 & 64 & 81 & 15 & & 141 & 48 & & 319 \\
\hline 32 & 2542 & 12 & & 1729 & 66 & 86 & 16 & & 150 & 52 & & 347 \\
\hline 34 & 2649 & 12 & & 1833 & 69 & 91 & 17 & & 160 & 55 & & 358 \\
\hline 36 & 2766 & 13 & & 1946 & 71 & 95 & 18 & & 169 & 57 & & 375 \\
\hline 38 & 2873 & 14 & & 2053 & 73 & 99 & 19 & & 178 & 59 & & 392 \\
\hline 40 & 2986 & 15 & & 2168 & 75 & 103 & 20 & & 188 & 62 & & 403 \\
\hline
\end{tabular}

Table C16-Vinyl Ester Deck Phase III 


\begin{tabular}{|c|c|c|c|c|c|c|c|c|c|c|}
\hline \multicolumn{10}{|c|}{ In-Plane Shear: Test Date 9-6-02 } \\
\hline \multicolumn{10}{|c|}{ Strain values in micro-strains: Deflections in milli-inches } \\
\hline Load (Ib) & $\# 1$ & $\# 2$ & $\# 3$ & $\# 4$ & $\# 5$ & $\# 6$ & $\# 7$ & $\# 8$ & $\# 9$ & $\# 10$ \\
\hline 0 & 0 & 0 & 0 & 0 & 0 & 0 & 0 & 0 & 0 & 0 \\
\hline 500 & -70 & 50 & 12 & 10 & 7 & 1 & 1 & 1 & 1 & 46 \\
\hline 1000 & 27 & 131 & 22 & 18 & 10 & 0 & 4 & 0 & 5 & 84 \\
\hline 1500 & 107 & 184 & 29 & 23 & 8 & 1 & 7 & 3 & 9 & 137 \\
\hline 2000 & 159 & 211 & 34 & 28 & 7 & 1 & 8 & 2 & 14 & 165 \\
\hline 2500 & 237 & 277 & 43 & 36 & 8 & 2 & 10 & 3 & 18 & 201 \\
\hline 3000 & 293 & 306 & 49 & 40 & 15 & 0 & 14 & 4 & 27 & 246 \\
\hline 3500 & 383 & 357 & 60 & 49 & 22 & 2 & 17 & 5 & 33 & 279 \\
\hline 4000 & 469 & 421 & 67 & 56 & 28 & 0 & 21 & 4 & 44 & 337 \\
\hline 4500 & 548 & 467 & 74 & 63 & 27 & 2 & 26 & 4 & 55 & 396 \\
\hline 5000 & 609 & 527 & 81 & 69 & 27 & 1 & 30 & 3 & 65 & 435 \\
\hline Load (Ib) & $\# 11$ & $\# 12$ & DEF-1 & DEF-2 & DEF-3 & DEF-4 & DEF-5 & DEF-6 \\
\hline 0 & 0 & 0 & 0 & 0 & 0 & 0 & & 0 & 0 \\
\hline 500 & 8 & 3 & 3 & 3 & 2 & 1 & 1 & 0 \\
\hline 1000 & 12 & 2 & 11 & 10 & 5 & 2 & & 1 & 7 \\
\hline 1500 & 16 & 2 & 21 & 16 & 12 & 6 & 1 & 18 \\
\hline 2000 & 23 & 3 & 42 & 31 & 27 & 14 & 2 & 39 \\
\hline 2500 & 27 & 2 & 60 & 46 & 40 & 22 & 4 & 56 \\
\hline 3000 & 32 & 2 & 83 & 65 & 55 & 33 & 9 & 76 \\
\hline 3500 & 36 & 2 & 105 & 81 & 68 & 42 & 12 & 99 \\
\hline 4000 & 41 & 2 & 133 & 105 & 91 & 51 & 16 & 127 \\
\hline 4500 & 45 & 3 & 158 & 125 & 109 & 65 & 20 & 153 \\
\hline 5000 & 50 & 3 & 172 & 140 & 118 & 72 & 26 & 172 \\
\hline
\end{tabular}

Table C17-In-Plane Shear 